\title{
The spatial restructuring of resource regulation. The gold mining enclave of Zaruma and Portovelo, Ecuador, 1860-1980
}

\author{
by \\ Andrea Carrión \\ A thesis submitted to the Faculty of Graduate and Postdoctoral Affairs \\ in partial fulfillment of the requirements for the degree of \\ Doctor of Philosophy \\ in \\ Geography with Specialization in Political Economy \\ Carleton University \\ Ottawa, Ontario \\ (C) 2016 \\ Andrea Carrión
}




\begin{abstract}
This dissertation explores the production of space and the spatial restructuring of resource regulation in the gold mining enclave of Portovelo and Zaruma, Ecuador, between 1860 and 1980. I use the theoretical tools of critical human geography, regulation theory, and political economy to analyze the spatiality of regulation over time in a dialectical manner. Methodologically, I develop an extended case study with explicit attention to scale as produced through material practices and their associated discourses and power relations. I argue that transnational mining companies, in responding to the international demand for raw materials, do not indiscriminately "penetrate" but, rather, negotiate the conditions for their deployment. Hence, there is an ongoing restructuring and rescaling of regulations that is a product of mediation between extractive capitalism and state formation in Ecuador.
\end{abstract}

Key words: Spatial restructuring; resource regulation; mining enclave; company town; historical geography; local/global; Ecuador. 
A Gilbert, Daniela y Martín, el amor de mí vída 


\section{Acknowledgements}

This dissertation owes much to the curiosity, the lessons learned, and the challenges I faced while working as a public official, human rights advocate, researcher, teacher, and student. First, I would like to thank my co-supervisors, Jill Wigle and Derek Smith, who provided insightful feedback on my ideas, allocated invaluable time in revising and editing thesis drafts, and coached me towards fulfilling the doctoral process. The questions and detailed commentaries of Dominique Marshall made me appreciate her thoroughness and the value of historical analysis. Emilie Cameron broadened the horizons of my research through helpful leads to bibliographic references. Throughout the examination processes, Anthony Bebbington strained my contribution to knowledge in a way that was meaningful to me. Cristina Rojas and Laura Macdonald fostered a stimulating community of scholars committed to Latin America studies. Nathalie Pressburger, Donna Coghill, Cheryl Murphy, and Erin Johnston offered invaluable guidance to navigating administrative issues and accommodating my requests at Carleton University.

There are many people whose writings opened up new perspectives or provided outstanding insights. I would like to acknowledge my intellectual debt to the Ecuadorianists who helped me appreciate the rigour of doing historical, ethnographic, and multi-scalar research. My dissertation was first inspired by the methodological approach and captivating analysis of Steve Striffler. His book, In the Shadows of State and Capital. The United Fruit Company, Popular Struggle 
and Agrarian Restructuring in Ecuador, 1900-1995, was a basic reading throughout the research and writing process. Marc Becker's generosity helped me to move beyond my comfort zone and to find new documentary sources during the research process. Martha Romero provided invaluable advice on municipal politics and everyday life in the mining district. While the public officials, historians, archivists, and chroniclers who assisted me are too numerous to mention, Lorena Carrión deserves special acknowledgement for making available Zaruma's municipal archives.

My dissertation would have been much longer in the making were it not for the pressure to resume work and meet the obligations of the doctoral scholarship. While carrying out my graduate studies, I received a grant from the Secretaría Nacional de Educación Superior, Ciencia y Tecnología (SENESCYT, National Secretariat of Higher Education, Science, and Technology) and the institutional sponsorship of the Instituto de Altos Estudios Nacionales (IAEN, National Institute for Higher Studies). At the Centro Nacional de Estrategia para el Derecho al Territorio (CENEDET, National Strategic Center for Right to Territory of IAEN), conversations with Lisset Coba, Thomas Purcell, and David Harvey served as a catalyst for ideas at a time when I was compiling the first draft of the dissertation. Mary Ellen Fieweger's careful copy-editing made the manuscript more readable and accurate. Some sections were presented at international conferences, and an earlier version of section 7.2 appeared in the 
Extractive Industries and Society Journal. Many thanks for the comments made by conference participants and anonymous referees.

At a personal level, there are some people who made a difference throughout my doctoral studies: Paola Ortiz, Matthew Hawkins, Alejandro Hernández, Daniel Tubb, Ana Cuesta, José Bustamante, Pablo Heidrich, Cornelio Delgado, Grace Jaramillo, Katty Mora, and Hilda Sisalema provided ongoing companionship and thought-provoking conversations as we shared homewarming meals while coping with the Canadian weather. Ryan KatzRosene, Gary Martin, and Luc Struckman introduced me to graduate student life in the Department of Geography. Analía Minteguiaga gave me the opportunity to display my ongoing commitment with academia in Ecuador. Thanks to Adrián López and María Elena Acosta for backing me at work during the revision process. Katiuska King, Nury Bermudez, and Doris Sanchez stimulated lively dialogues in the final stages of the doctorate. Ulises Unda and Roy Siguenza ignited enthusiasm after the invitation to participate at the artistic residence in Portovelo and Zaruma. John Tweedy and Beret Strong opened their memories and personal archives for me, thanks again to both. I am particularly grateful to the Jaramillo family for making me feel at home during my stay at Zaruma. My yoga and meditation instructors helped release emotions and survive the rhythm of academia. None of these friends and colleagues bears any responsibility for the shortcomings of the present manuscript. 
My family has supported me in multiple ways as I obsessed about parenting, working, and fitting into academia. My father, Diego Carrión, and my mother, Henriette Hurtado, have always manifested confidence in my projects. My siblings, Carolina and Manuel, have been examples for me, displaying the courage to follow their dreams. My in-laws, Mónica Fierro and Gilberto González, dealt with all the paperwork required while living abroad and were understanding when studies forced me to skip family gatherings. Gilbert, Daniela, and Martín, my reasons for living, are complicit in this process through our conversations, their patience after my sleepless nights, and their energy while traveling the world. They have my enormous respect and bottomless affection. 


\section{Table of Contents}

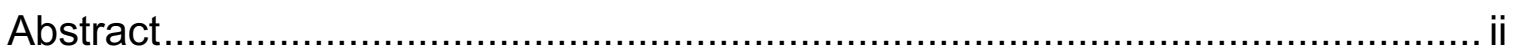

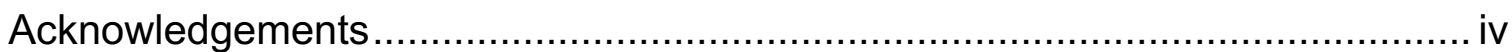

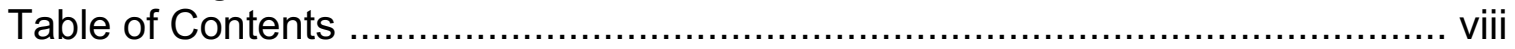

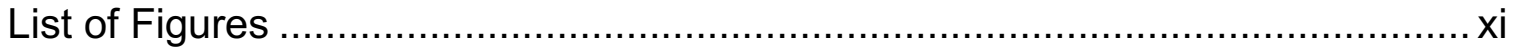

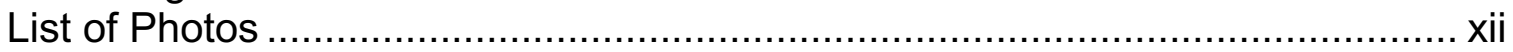

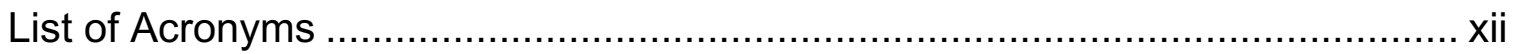

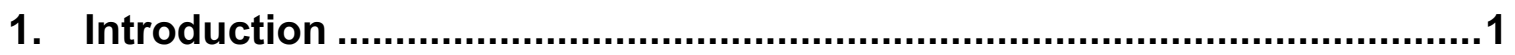

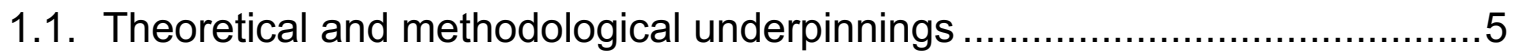

1.2. The Zaruma and Portovelo gold mining district ...................................14

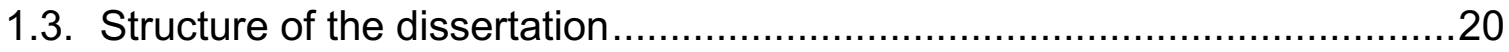

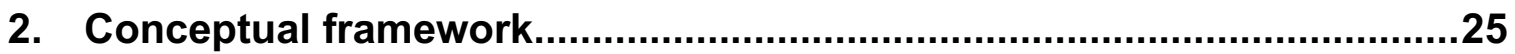

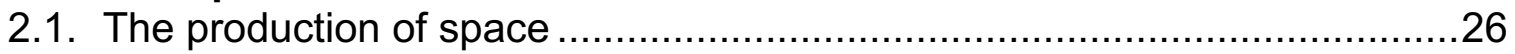

2.2. The political economy of the gold mining enclave ..................................33

2.3. The spatial restructuring of resource regulation ........................................

2.3.1. Institutional forms in the production of space..............................42

2.3.2. Agency in the spatial restructuring of regulation ............................44

2.3.3. A multi-scalar understanding of regulatory processes .....................46

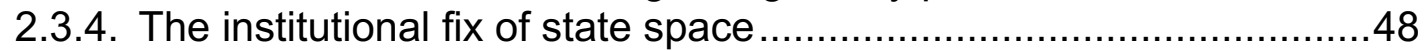

2.3.5. The mobility and mutation of regulations .....................................51

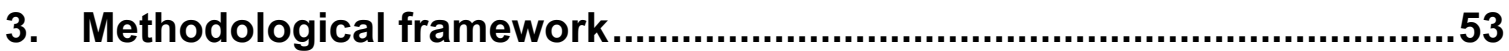

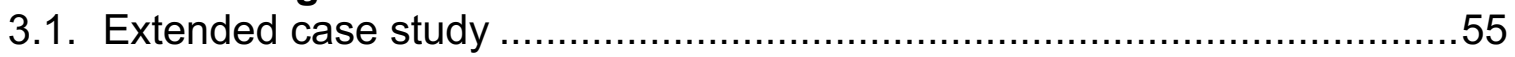

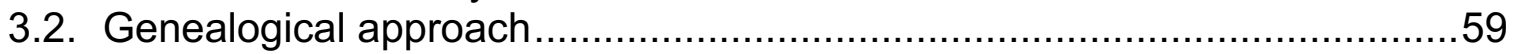

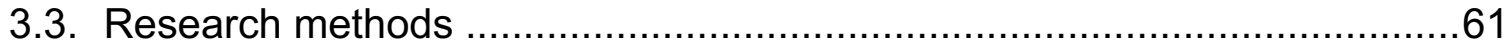

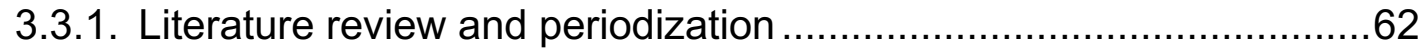

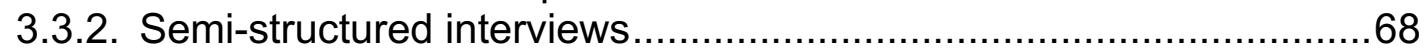

3.3.3. Archival research and historical sources ...................................... 70

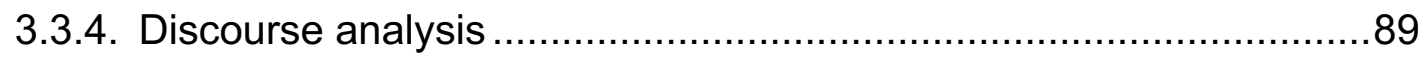

4. The expansion of corporate mining: Enabling conditions beyond

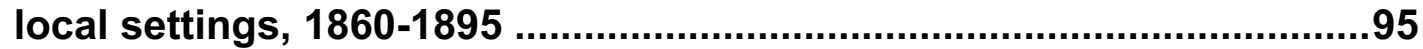

4.1. Industrialization, the gold standard, and corporate restructuring of

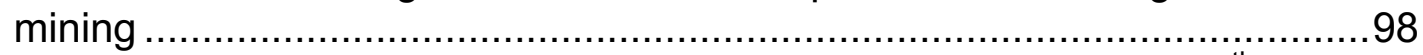

4.2. The mobility, replication and mutation of mining laws in the late-19

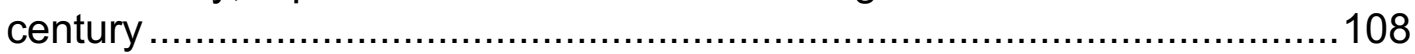

4.3. Zaruma: From colonial villa to corporate enclave ….............................121

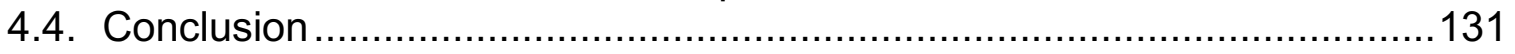




\section{The birth and evolution of the mining enclave: A changing}

landscape for resource regulation, 1895-1950 ................................133

5.1. Appropriation and extraction of natural resources ................................135

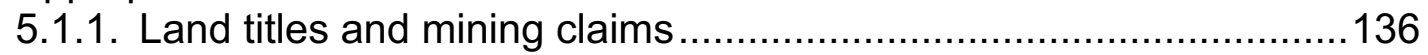

5.1.2. The spread of mining technology .............................................. 143

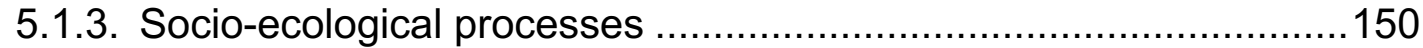

5.2. Socio-spatial engineering and urban differentiation ..............................153

5.2.1. The modern sanitary project of the Portovelo camp ......................155

5.2.2. The beautification project of the city of Zaruma ............................166

5.3. Overcoming (and working with) relative isolation .................................177

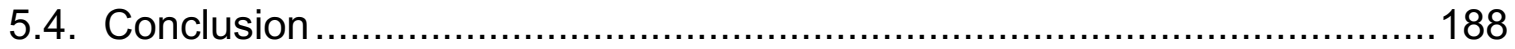

6. The social relations of production: Contradictions in the production of space, 1895-1950 .....................................................191

6.1. The proletarianization of the work force ...........................................194

6.1.1. Mestizaje as a condition of production.......................................194

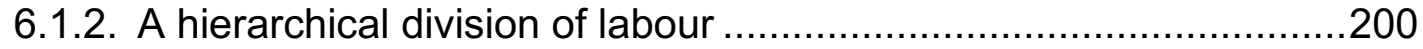

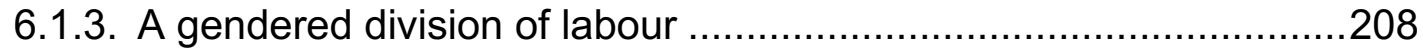

6.2. The Portovelo labour movement ..................................................214

6.2.1. Class consciousness and collective struggles ............................217

6.2.2. Velasquismo, communism and the heroic deed of the Portovelo labour movement ......................................................223

6.2.3. Legal regulation of wage-labour relations ...................................234

6.3. Benevolence, paternalism, and social control ....................................242

6.3.1. The political economy of subsidized food and controlled

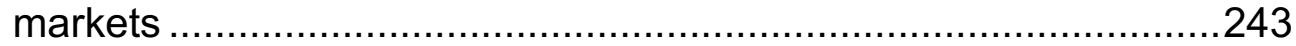

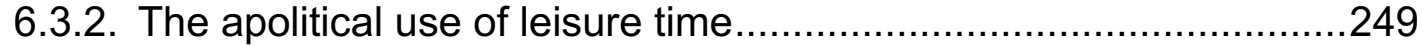

6.3.3. Patronage in the building of urban infrastructure .........................260

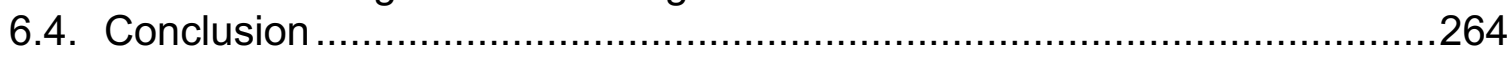

7. The public domain of mineral resources: The restructuring and rescaling of national regulations, 1925-1950 .....................................267

7.1. The "inalienable and imprescriptible" public domain of mineral

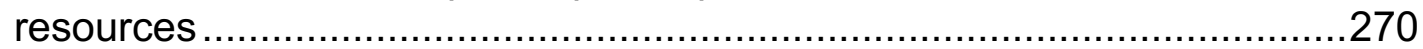

7.1.1. The public domain of mineral resources ..................................275

7.1.2. Centralizing features of the Mining Law of $1937 \ldots \ldots \ldots \ldots \ldots \ldots \ldots \ldots \ldots . . .286$

7.1.3. Economic nationalism and the upscaling of resource

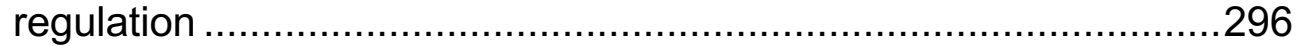

7.2. Portovelo: From foreign enclave to municipal workers association ...........309

7.2.1. Municipal incomes and the restructuring of local governance ........310

7.2.2. Technological challenges, labour laws, corporate restructuring, and the decrease in mine productivity ........................................318

7.2.3. De-industrialization and the downscaling of the employment crisis

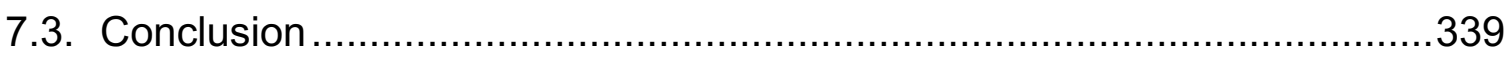


8. The municipalization of the mining camp: The search for a new institutional fix, 1950-1980 ...............................................................342

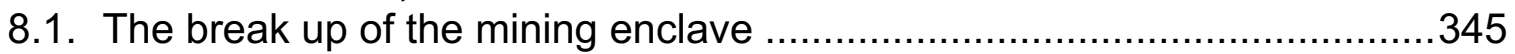

8.1.1. Creative distribution of and dispute over corporate assets .............347

8.1.2. The persistence of mining as a subsistence enterprise ..................354

8.2. The politics of space and resource regulation ......................................369

8.2.1. Differential articulation with the development state.......................371

8.2.2. Self-determination and the search for a new institutional fix...........379

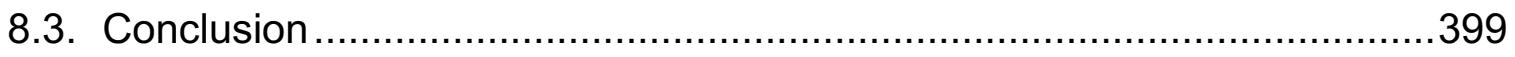

9. Conclusion: The spatial restructuring of resource regulation ............402

9.1. Main arguments and contributions to Ecuadorian historiography ..............405

9.2. The production of space in the mining enclave ..................................411

9.3. The spatial restructuring of resource regulation ...................................415

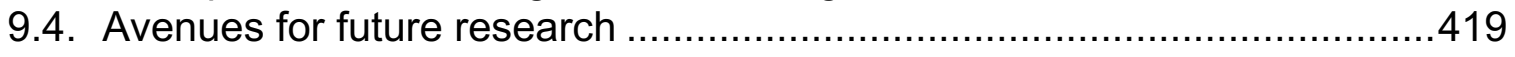

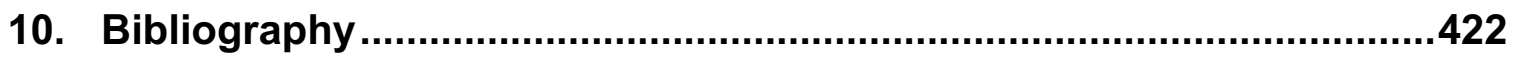

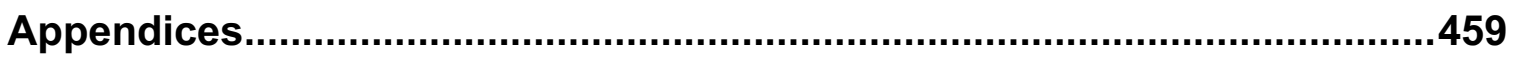

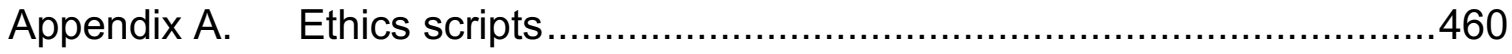

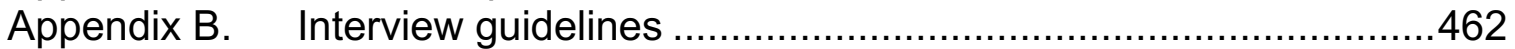

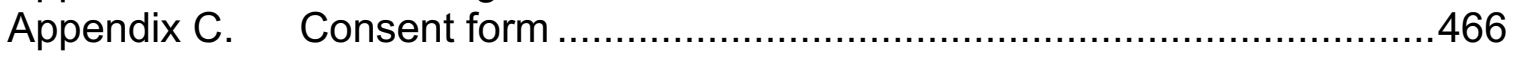

Appendix D. Presidents of Ecuador 1830-1980 …..................................468 


\section{List of Figures}

Figure 1.1. Map of main cities and major highways near the Zaruma and Portovelo mining district ..........................................................16

Figure 3.1. Number of documents by type and archival repositories..............73

Figure 3.2. Files of the Municipal Archive of Zaruma ...................................78

Figure 4.1. World production of gold, in tons, 1800-1975 .........................103

Figure 4.2. Detail of the Geological Map of Ecuador, 1892 _.......................122

Figure 4.3. Evolution of Ecuador's provinces, 1824-2007 ..........................127

Figure 5.1. "Plan Showing Surface Geology and Principal Underground Workings on the Various Vein Systems," 1932 ..........................141

Figure 5.2. Cross-section of the Portovelo Mine Works, 1932 ....................144

Figure 6.1. Detail of the Portovelo powerhouse, 1929 ..............................262

Figure 8.1. Chart of CIMA's administrative structure, circa $1960 \ldots \ldots \ldots \ldots \ldots . . . .352$

Figure 8.2. Tonnes of gold from Ecuador sold on international markets, 1913-1976

Figure 8.3. Dollar value of CIMA's metallic and non-metallic production, 1951-1976

Figure 8.4. CIMA's profits and losses in thousands of U.S. dollars, 1951-1976

Figure 8.5. Total provincial gross value of the primary sector by product and type of landscape. Province of El Oro, 1974 ........................376

Figure 8.6. Coat of arms of the county of Zaruma .....................................380

Figure 8.7. Establishment of rural parishes in Ecuador, 1900-2000 ..............397 


\section{List of Photos}

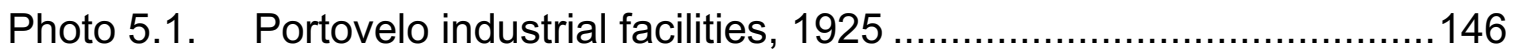

Photo 5.2. Locomotives used to increase productivity, $1941 \ldots \ldots \ldots \ldots \ldots \ldots \ldots \ldots . . . . . . . . . . .148$

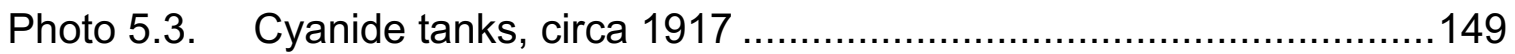

Photo 5.4. Wood necessary for the mining industry …............................152

Photo 5.5. Panoramic view of the southern access to Portovelo, circa 1940

Photo 5.6. American party at the Newberry Social Club.............................162

Photo 5.7. The Curipamba Hospital was the most modern in southern Ecuador

Photo 5.8. Streets of Zaruma in the early $19^{\text {th }}$ century ..............................167

Photo 5.9. Zaruma's urban landscape after the Construction and Beautification Ordinance, 1947

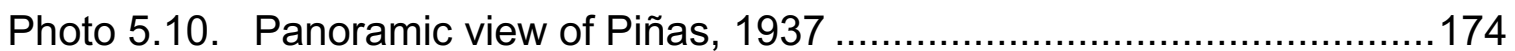

Photo 5.11. Mule train with cable on the stairs route ...................................180

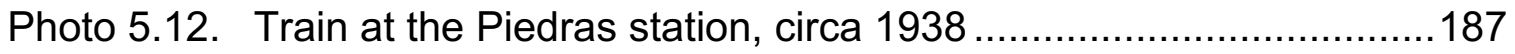

Photo 6.1. SADCO's General Manager observed by a group of indigenous people 196

Photo 6.2. Human power used to haul heavy equipment ..........................202

Photo 6.3. American engineers developed geological surveys ....................205

Photo 6.4. Florence Dahl on the trail upon her arrival to the Portovelo camp to work as a nurse in the Curipamba Hospital, 1917 ..........210

Photo 6.5. Angela Ortega and Rosa Vivar, who served as housemaids and nannies for the Tweedy family

Photo 6.6. The body of a worker, victim of a mining accident......................216

Photo 6.7. Reception of President-elect José María Velasco Ibarra, 1934 
Photo 6.8. The workers' commission prior the strike of 1935

Photo 6.9. Labour shift ends and workers leave the American Shaft, circa 1940

Photo 6.10. Second visit of President José María Velasco Ibarra to

Zaruma after the Glorious Revolution, July 29, 1944

Photo 6.11. A massive soup kitchen provided meals to the workforce 244

Photo 6.12. Zaruma's Sunday fair in the new marketplace, 1937 247

Photo 6.13. Good Friday Procession in the Portovelo camp ........................250

Photo 6.14. Baseball team with women at the sportsfield ............................252

Photo 6.15. Gymnastics at the Gabriela Mistral School for Girls, 1941 ..........258

Photo 7.1. Second visit of President Galo Plaza Lasso to Zaruma, 1951 .....337

Photo 8.1. General Guillermo Rodríguez Lara in Portovelo, 1972 .................363

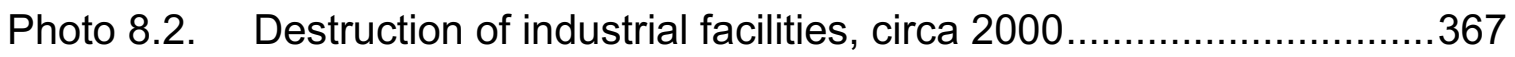

Photo 8.3. Zaruma's Children Battalion during the war with Peru, 1941 .......382

Photo 8.4. Street rally of the Socialist Party during the presidential campaign, Zaruma, 1960

Photo 8.5. Women holding a poster in defense of Portovelo's interests, 1968 


\section{List of Acronyms}

$\begin{array}{ll}\text { ABANE } & \begin{array}{l}\text { Archivo-Biblioteca de la Asamblea Nacional del Ecuador } \\ \text { (Archive and Library of the National Assembly of Ecuador) }\end{array} \\ \text { AH-MC } & \begin{array}{l}\text { Archivo Histórico, Ministerio de Cultura } \\ \text { (Historical Archive of the Ministry of Culture) }\end{array} \\ \text { AHM/Z } & \begin{array}{l}\text { Archivo Histórico Municipal de Zaruma } \\ \text { (Historic Municiapl Archive of Zaruma) }\end{array} \\ \text { AI-MPS } & \begin{array}{l}\text { Archivos Intermedios, Ministerio de Previsión Social } \\ \text { (Intermediate Archives, Ministry of Social Security) }\end{array} \\ \text { ANE } & \begin{array}{l}\text { Archivo Nacional del Ecuador } \\ \text { (National Archive of Ecuador) }\end{array} \\ \text { BEAEP } & \begin{array}{l}\text { Biblioteca Ecuatoriana Aurelio Espinosa Pólit } \\ \text { (Aurelio Espinosa Pólit Ecuadorian Library) }\end{array} \\ \text { BM/P } & \begin{array}{l}\text { Biblioteca Municipal de Portovelo } \\ \text { (Municipal Library of Portovelo) }\end{array} \\ \text { CAMINE } & \begin{array}{l}\text { Compañía Anónima Minera Industrial Nacional Ecuatoriana } \\ \text { (Ecuadorian National Industrial Mining Company, Inc.) }\end{array} \\ \text { CEDOC } & \begin{array}{l}\text { Corporación de Accionistas Propietarios } \\ \text { (Shareholders Corporation) }\end{array} \\ \text { CPDIZ } & \begin{array}{l}\text { Central Ecuatoriana de Organizaciones Clasistas } \\ \text { (Ecuadorian Central Committee of Working Class }\end{array} \\ \text { Organizations) } \\ \text { CIMAS }\end{array}$




\begin{tabular}{|c|c|}
\hline DGGM & $\begin{array}{l}\text { Dirección General de Geología y Minas } \\
\text { (General Office of Geology and Mines) }\end{array}$ \\
\hline eSILEC & $\begin{array}{l}\text { Sistema Integrado de la Legislación Ecuatoriana } \\
\text { (Integrated System of Ecuadorian Legislation) }\end{array}$ \\
\hline ETSA & Elizabeth Tweedy Sykes Archive \\
\hline GDP & Gross Domestic Product \\
\hline IESS & $\begin{array}{l}\text { Instituto Ecuatoriano de Seguridad Social } \\
\text { (Social Security Institute of Ecuador) }\end{array}$ \\
\hline INEMIN & $\begin{array}{l}\text { Instituto Ecuatoriano de Minería } \\
\text { (Mining Institute of Ecuador) }\end{array}$ \\
\hline JUNAPLA & $\begin{array}{l}\text { Junta Nacional de Planificación y Coordinación Económica } \\
\text { (National Planning and Economic Coordination Council) }\end{array}$ \\
\hline LME & London Metal Exchange \\
\hline MMC & Minutes of the Municipal Council \\
\hline MREMH & $\begin{array}{l}\text { Ministerio de Relaciones Exteriores y Movilidad Humana } \\
\text { (Ministry of Foreign Relations and Human Mobility) }\end{array}$ \\
\hline NYMEX/COMEX & New York Commodity Exchange/Commodity Exchange \\
\hline PCE & $\begin{array}{l}\text { Partido Comunista del Ecuador } \\
\text { (Comunist Party of Ecuador) }\end{array}$ \\
\hline PSC & $\begin{array}{l}\text { Partido Social Cristiano } \\
\text { (Social Christian Party) }\end{array}$ \\
\hline PSE & $\begin{array}{l}\text { Partido Socialista del Ecuador } \\
\text { (Socialist Party of Ecuador) }\end{array}$ \\
\hline SADCO & South American Development Company \\
\hline UTAP & $\begin{array}{l}\text { Unión de Trabajadores Accionistas de Portovelo } \\
\text { (Portovelo Worker Shareholders Union) }\end{array}$ \\
\hline
\end{tabular}




\section{Introduction}

In June 2011, I arrived in the valley of Intag, Ecuador, to conduct some scoping fieldwork for my doctoral studies and to visit my sister. Intag is the site of an internationally recognized conflict over a mining project in Ecuador. Interprovincial transportation - decent but tacky and slow - brought me to a tempo very different than my everyday routine involving academic studies in Canada. Life was not easy in the countryside. The threat of mining - backed by large investments and political power - had, in the course of nearly twenty years of resistance, polarized the community. Resources for local development projects had become scarce. The people were tired of interviews, workshops, and consultations related to the mining conflict: they were sceptical of their utility, the flight of knowledge, and the distorting of information by public authorities. Distrust and anger sometimes turned into fear and exhaustion. The experts and scholars had arrived and departed, they asked questions, created expectations, and left 
without explanation, and seldom returned to share their analysis with the community. ${ }^{1}$

As a planning official in Ecuador's national government between 2007 and 2010, I had faced the request of defining the locations of new mining districts. My professional background and my personal experience meant that I was unable to treat this issue as simply a technocratic exercise. It was my concern that largescale mining projects, proposed in the context of a national development strategy, would turn out to be a resource curse. I decided to resign and to begin a doctoral program. My initial interests in graduate studies focused on territorial planning and the spatial management of mining districts. During my visit to Ecuador in June 2011, however, I was confronted with the popular resistance to developmental extractivism and my sister's insistence that I should not work at a distance without a direct commitment to local communities. The political economy of extractive industries is such that it was not a matter of shaping its existence but rather confronting its nature.

Going back to my home country from Canada also raised my awareness of the gaps in and benefits of theoretical analysis, and how research questions

1 I will not expand on this over-studied case of grassroots' resistance against proposed mining projects. More information is available at: Bebbington et al. 2008; Buchanan 2013; Davidov 2014; Dooley-Feldman 2007; D’Amico 2012; Kuecker 2007; López 2012; Martinez-Alier 2001; Rogge 2008; Vallejo 2010; Varela 2011. The regional newspaper is also available at: Periódico Intag, accessed May, 2015, http://www.intagnewspaper.org 
may have different relevance in one location than another. During my exploratory fieldtrip, I had been doing interviews, attending seminars, and gathering information to narrow down my research proposal. I was able to read Latin American authors reflecting on the relation between territory and extractive industries, and to retrieve "non-academic" bibliographic materials. In a context where academia (and what is said to be scientific knowledge) has not yet achieved the high social status it enjoys in the North, Latin American debates and discussions accept multiple sources as legitimate for the production of knowledge.

At that stage, my doctoral studies had already broadened my insights and led me to embrace some post-structuralist accounts and methodologies in my research, but they also seemed insufficient for explaining the structural relations of production in the mining sector. On the other hand, structuralism risks leading to a reification of economics and reduction of the class struggle to a contradiction necessary for the continued existence of capitalism. This tendency suggests the inevitability of accumulation. However, as I argue in this thesis, structure and agency are not antagonists but rather co-protagonists in the emergence of particular modes of regulation. It is my view that institutions at different scales as well as place-based struggles mediate and transform the accumulation regime. I contend that structuralist theory and post-structuralist methodology complement one another, leading to a better understanding of the spatial restructuring of resource regulation. 
I had planned to visit several mining sites throughout the summer of 2011. Zaruma was not my first choice for the doctoral investigation, but it is a unique site as the only historical mining enclave of the country. I arrived at noon after a twelve-hour trip; the municipal office was closed and would not open for another two hours. The town was still ruled by the shifts of the American company that had operated the Portovelo mines until the mid-twentieth century. Despite my physical fatigue, I felt comfortable waiting in the central plaza of the colonial villa. A rally approached with demonstrators holding signs demanding peace and justice, requiring that a crime against an artisanal miner not go unpunished. In the distance, I could see the construction of a new mining camp; people said that a Chinese or Canadian company was building it, but no one knew (or wanted to tell me) for sure. ${ }^{2}$ How could I understand mining enclaves without understanding their historical present?

During my stay there, I stumbled across the municipal archives of Zaruma in my quest for materials that could inform the background section of my proposal. The documents were beautifully kept, and I felt passionate about the archival sources that included manuscripts, photographs, and newspapers. The stories of the mining camp echoed my interests in the long-term impacts and

2 This is not an isolated phenomenon. Throughout Latin America, the growth of Canadian and Chinese investment in the mineral sector has brought changes to resource landscapes and has generated widespread opposition (Bebbington et al. 2008; MMSD-IIED 2002; North, Clark, and Patroni 2006; Svampa 2010). 
spatiality of extractive industries. Although I was not fully aware of it at the time, historical geography would turn out to be a space of serendipity for deep reflection throughout my doctoral studies, making an important contribution towards reasserting the explicit connection between critical geography and regulation theory. The dialogues, criticisms, and encounters during this initial fieldwork deserve credit for defining the theoretical and methodological approach used in this dissertation as well as the choice of analyzing the case of the Portovelo and Zaruma mining enclave in the longue-durée.

\subsection{Theoretical and methodological underpinnings}

The international mining boom of the last two decades has attracted scholarly analysis with the assumption that commodity markets "propelled mineral exploration and development into areas remote from centers of urbanization, where formal state control is relatively weak; in regions which have not experienced intensive colonization; and where significant indigenous or tribal populations remain" (Bridge 2004, 247). This statement - which assumes the reality of Marx's idyllic moments of primitive accumulation - needs to be nuanced in at least three ways. First, it overestimates the omnipotence of international markets and neglects the historical configuration of regulatory processes that condition the expansion of extractive industries at the national level. Second, it does not take into account the dense hierarchy of urban centers and transport networks, the extension of urbanization throughout Latin America, and the importance of local governments in mediating the production of space. Finally, it 
concentrates progressive political action and academic research in areas where indigenous populations or marginalized social groups can build networks, sometimes dismissing areas where peasant and urban communities continue to co-exist with mining.

In a desire to expand this analysis, I examine the production of space and the spatial restructuring of resource regulation over the long term by asking how global forces of capitalist accumulation produce particular locations for the appropriation of gold-bearing grounds required to supply the capitalist economy. A second related question I pose is how local modes of regulation develop responses to assimilate, negotiate, or resist place-making projects associated with the global expansion of capitalism. The analysis of the spatial restructuring of regulation is not simply a matter of describing a process of "glocalization" - the way global forces tailor their needs to satisfy local regulations and preferences but, rather, of analyzing the ways in which capitalist globalization is reframed and modified through multi-scalar relations of power. ${ }^{3}$ The phenomenon I examine is not simply an automatic response to the needs of capitalism but part of a conflict-

3 According to Swyngedouw (2004), "glocalization" refers to two main processes: the reconfiguration of institutional arrangements, displacing the national level as the privileged scale of social regulation, and the ways in which economic activities and inter-firm networks become localized or regionalized to activate networks and flows that facilitate transnational operations. 
laden process in which localities have some agency in determining the structuration of global forces and actors. On this basis, transnational mining companies, in responding to the international demand for raw materials do not indiscriminately "penetrate" but, rather, negotiate the conditions for their deployment.

Scholars have devoted extensive research to demonstrating the agency of workers, indigenous populations, and peasants who resist extractive industries or negotiate a share of the revenues in conflict with imperialist capitalism. ${ }^{4}$ Other studies pertaining to extractive industries privilege the standpoint of the national government or emphasize the array of voluntary codes, standards, and alternative accountability mechanisms related to corporate social responsibility. ${ }^{5}$

4 Echave (2009) provides an example of how local communities in mining regions achieved national recognition in Peru. Mining activities and socio-environmental conflicts have received the attention of human rights organizations such as Mining Watch, Mining Injustice Solidarity Network, Amnesty International, and the Observatorio de Conflictos Mineros de América Latina. In addition, multilateral organizations, such as the UN International Rapporteur on the Rights of Indigenous Peoples, follow some cases in indigenous territories, for example, the Marlin Mine in Guatemala (Anaya 2011). Over past years, the mining industry has developed norms for ethical behaviour consistent with sustainable development and the welfare of society, and strategies to "facilitate more meaningful industry engagement with indigenous peoples" (Render 2005).

5 Literature on the role of national governments in the regulation of the mining industry privileges the analysis of normative frameworks, redistribution of revenues, and environmental policies (Campodónico 2008; Chaparro 2002; Moreno and Chaparro 2009). Studies on corporate social responsibility look at the relations among society, state, and mining as well as the practices of multinational companies (Boon 2011; Chaparro and Salgado 2005; Haslam 2004; Fox et.al. 2002; Sagebien et al. 2008). Therefore, public policies emphasize the need for developing the leadership and management capacities of local authorities, promoting participatory planning, improving fiscal accountability, encouraging public-private partnerships, and endorsing corporate social responsibility. Corruption and patronage are usually listed as the main obstacles to resource governance. 
The active engagement of the local government is usually seen as a pre-requisite for mitigating socio-environmental conflicts, fostering local economic development, and improving the resilience of mining regions. ${ }^{6}$ Existing approaches neglect the role of multi-scale relations in mediating these tensions. Certainly, the spatiality of the relations among mining industries, modes of regulation, and institutional forms has not been studied to the same extent by researchers in Latin America.

While our understanding of the issue is limited, it is evident that institutional arrangements play much more complex roles in the transformation of place-based social, political, and economic relations related to extractive industries, and that they represent a potential challenge to capitalist relations in a broader sense. This suggests a number of questions: Who produces the mining enclave? How is such a space produced? What type of space and place results? The expansion of capitalism and the settlement of extractive industries is an ongoing process of negotiation that results in the social production of space, a feature that is revealed only by looking at longer periods of time. In this dissertation, I argue that exploring this avenue is relevant as it provides

6 By way of example, Ruiz (2003) provides a descriptive account of the roles and responsibilities of authorities in mining locations but his analysis focuses on designing policies for capacity building rather than providing an analytical framework. 
additional insight into how global forces are grounded and transformed by local processes.

I am particularly interested in the politics and spatial dimensions of resource regulation as an iterative and multi-scalar process between global capitalism and the socio-political situation at the local level. I ask two more specific questions: How do institutional forms come into being and/or act to produce particular places as mining enclaves? How does the spatial restructuring of resource regulation transform the accumulation regime at different scales? To answer these questions, I explore the production of space and the spatiality of resource regulation in the gold mining enclave of Zaruma-Portovelo over the long term, from 1860 to 1980.

In this dissertation I demonstrate that the production of a mining enclave as a particular kind of place is much more than the physical transformation of the landscape, the instalment of a mining camp, or the extraction of mineral grounds. Instead, it is mainly the transformation of the social relations of production at different scales. Analyzing the evolution of institutional forms necessary for the regulation of the mining industry contributes to a more nuanced understanding of the tensions between extractive capitalism and state formation in Ecuador. My research focuses on three main intertwined spatial aspects of resource regulation: the production of space in the mining enclave, the evolution of mining codes, and the spatiality of state practices. 
In this study, I apply the theoretical tools of critical human geography, regulation theory, and political economy to analyze the spatiality of resource regulation in a dialectical manner. The "production of space" is an important concept because it provides a framework for studying these industrial landscapes. Lefebvre (1991) argues that every society and mode of production produces a particular spatiality, dialectically articulated by material practices, representations of space, and representational spaces. Therefore, the production of space is a situated practice, and the history of particular locations denotes the endurance and transformation of social values, kinds of knowledge and ways of knowing, and practices in their interaction across scales. In this respect, I am particularly interested in the political economy of gold mining enclaves as places where primitive accumulation acquires materiality; they are the stage on which conflictive and contradictory processes associated with the appropriation of surplus value take place.

Mining enclaves are place-making sites through which capitalist accumulation creates the conditions for the appropriation of both nature and labour. The identification, extraction, and management of mineral deposits for the provisioning of industrial societies responds to a particular cultural process and its concomitant politics of value, through which nature is transformed into resources, commodities, and conditions of production (Bakker and Bridge 2006; Castree and Braun 2001; Harvey 1996; Smith 2008). The political economy of resource extraction in large scale foreign-owned industrial camps creates enclosures of private rule, through a combination of physical, legal, technological, 
exchange, and fiscal measures that produce distancing from the domestic economy and society (Furtado 1976; Thorp 1998). In this respect, the mining enclave, although geographically isolated or situated in a relatively remote location, is central to capitalism.

In seeking to understand the production of space in mining enclaves, I turn to some key geographical insights developed through the regulation theory. On a historical and institutional basis, this approach postulates a tight relation between regimes of capitalist accumulation and social modes of regulation (Aglietta 1976; Boyer and Saillard 2002; Jessop 1996; Lipietz 1987). However, each accumulation regime, as the dominant technical and social division of labour that substantiate production and consumption patterns over a long period, is subject to contradictions and crises. Therefore, the social regulation of economic processes leads to an ensemble of rules, norms, social networks, organizational mechanisms, and institutions that sustain the mode of production, minimize crises, and transform productive relations. Insofar as regulation involves intentional social practices and political struggle, it is also dynamic and prone to internal contradictions. Neither capitalism nor regulations are monolithic entities; there is an ongoing restructuring of the everyday politics and social processes that sustain accumulation, varying across time and space. Hence, the mode of regulation assumes radically different forms across history and geography within each configuration of capitalist accumulation. 
Understanding the production of space in the mining enclave and the spatiality of resource regulation requires: 1) an historical perspective from which to explore and explain continuities and transformations in state formation and resource regulation, 2) an ethnographic approach in order to examine specific actors and practices beyond abstract categories of capitalist accumulation, and 3) a geographic lens that transcends place-bound descriptions to capture the assemblages of institutional or structural forms that come together and operate in particular locations. Application of the methodology described leads to what has been called an "extended case study" or a "global ethnography" (Burawoy 1998, 2000; Gille and ÓRiain 2002).

Rather than relying on general assumptions about imperialism, resourcebased state formation, and accumulation by dispossession, I analyze the geographic and genealogical aspects of the modes of regulation accompanying these phenomena. These perspectives reject a linear description of institutional roles and responsibilities in favour of a more complex and scale-sensitive understanding of the imbrications between the social production of space and local modes of economic regulation. A genealogical approach has the potential to reveal the continuities and transformations of the spatiality of resource regulation, denaturalizing assumptions about material practices, legal entitlements, and actors across scales while providing insights essential to understanding the crises in the accumulation regime and the multi-scalar processes of regulation. This suggests looking at the juxtapositions, disjunctions, and contradictions among different sources of power, where multiple power relations are expressed 
through struggles and confrontations to enforce or resist exploitation and domination at various scales (Jessop 2007). Underpinning my work is a commitment to the production of a theoretically informed case study that sheds light on the interconnections between global forces and local processes that transform places where capitalist accumulation is planned or underway in Ecuador.

In the course of my investigation, I used four principal methods: literature review and periodization, semi-structured interviews, archival research, and discourse analysis. As part of my research process, I conducted a literature review used for producing a multi-scalar chronology and a periodization relevant to the regulation of the mining enclave of Portovelo. To complement written materials, I conducted 28 interviews with public officials, researchers, community leaders, and residents of Zaruma and Portovelo. The primary sources assembled throughout the archival research cover the period from 1822, when the municipality of Zaruma came into existence, to the 1990s, when the mining enclave was finally dismantled. Finally, the discourse analysis centered on laws as a means of connecting sources of power at different scales: legal texts are used as a way to explore how trans-local and extra-local relations are actually produced in local settings. 


\subsection{The Zaruma and Portovelo gold mining district}

Zaruma represents the one of the few mining colonial villas in Ecuador while Portovelo is the only gold mining enclave ever developed in the country, with large-scale operations between 1896 and 1950. The story of these twin towns reveals the challenges of places with abundant mineral resources central to the expansion of global capitalism - but which face relative isolation from metropolitan areas and political decision-making centers. The proximity between Zaruma and Portovelo contributes to exploring the connections between enclaves and small urban centers, and the differential mechanisms used to deal with the booms and busts of the mining industry. This particular case lends itself to an analysis of long-term processes in the production of space in industrial landscapes, including the construction of the single-industry town and the institutional mechanisms necessary for its operation across different scales and times. Moreover, a long-range study reconnects the seemingly different administrative processes of state formation in order to understand how they operate in locations central to a staples economy.

Zaruma and Portovelo are located in the subtropical foothills of southwestern Ecuador, between the coastal plain and the Andes. Zaruma is situated at 1,200 meters above sea level (masl), on a plateau of the western cordillera; Portovelo lies on the banks of the Amarillo River, at an altitude of 600 masl, within the Puyango-Túmbez river basin that flows into the Pacific Ocean. The area, with its rolling hills and steep ravines, remains relatively isolated from 
large urban settlements. The mining district is 100 kilometers south of Guayaquil, Ecuador's main commercial and port city. Residents of Machala, Cuenca, and Loja also engage in trade and services in the country's southern region, which borders with Peru. The production of cacao, bananas, shrimp, and tropical fruits has been the most important economic activity in the coastal region of El Oro Province, while at higher altitudes cattle and coffee are produced. In the mountains, a dense network of tunnels and quarries are the setting of the vein system that extends throughout the municipalities of Zaruma, Portovelo, and Minas Nuevas in the province of El Oro and continues into San Gerardo and Ponce Enríquez in the province of Azuay. 
Figure 1.1. Map of main cities and major highways near the Zaruma and Portovelo mining district

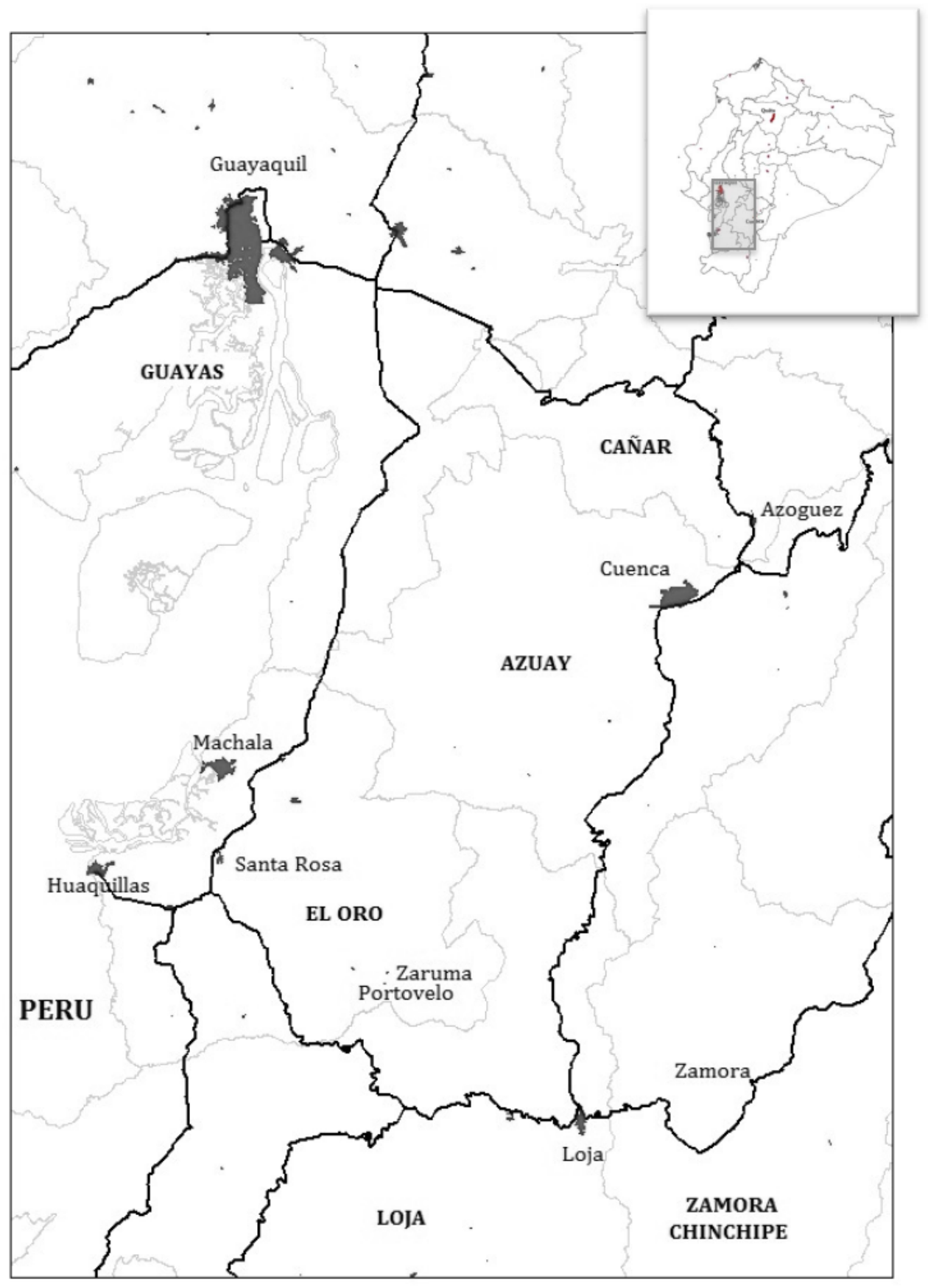

Note: The mining district is relatively isolated from major highways (dark gray lines) and urban centers (dark gray areas). Provincial boundaries represented (light gray lines) correspond to current administrative jurisdictions. 
Goossens (1972) asserts that Ecuador was one of the more important gold producing countries before World War II, when the Portovelo mines were in full-scale operation. In 2005 the district delivered more than $60 \%$ of the country's annual gold production, with a total historic output exceeding 4.5 million ounces of gold and some 250 tons of silver (Van Thournout et al. 1996; Vikentyev et al. 2005). The geology of the district was first described in the late- $19^{\text {th }}$ century (Wolf 1879). The mineralized system covers an area of more than 150 square kilometers. The ore is found over an extensive plane that runs diagonally northsouth for almost 15 kilometers within a parallel vein system, with a maximum width of four kilometers. The gold is located in quartz-sulphide veins, which crosscut andesitic rocks associated with tertiary continental arc magmatism. The gold quartz is distributed in steeply deepening veins, averaging about two meters wide. Four major gold veins, named Abundancia, Portovelo, Sarigüela, and La Colorada, cross the area, with an unusually large vertical range of 1,400 meters.

The Zaruma and Portovelo district is the longest running hard-rock gold camp in South America. It has been a precious metal extractive site since the Inca Empire, the Spanish colonization and the Republican era. ${ }^{7}$ Alonso de Mercadillo founded the Villa of San Antonio del Cerro Rico de Zaruma in 1549,

7 For a detailed analysis and alternative periodization of colonial mining in the Andes and Zaruma, see: Anda 1960; Caivallet 1988; Lane 2004; and Sempat 1982. 
while exploitation records appear in the Cajas Reales of Quito from 1557.

Between 1575 and 1625, the region became a focal point of regional production, invigorating trade circuits within the Andean region (Anda 1960; Sempat 1982). This process created a local elite that was structured around the cabildo (local government council) and the recruitment of forced labour from distant locations. The decline in mining production (1630-1763) was driven by a shortage of indigenous workers, lack of adequate technology for deep extraction, physical isolation, and inadequate institutional support (Lane 2004). A second cycle of colonial exploitation was encouraged by the use of quicksilver for ore recovery, a more flexible taxation system, and the labour of miners and their families. During the Bourbon Reforms of the $18^{\text {th }}$ century, attempts were made to revive the mines, through the Tribunal de Minería in Mexico, by encouraging fiscal concessions and raising the level of trade, but independence wars hampered this process (Barbier 1977; Sempat 1982). However, the reforms also centralized government and taxation, creating conditions for the emergence of a local hierarchy topped by the white landed oligarchy and the Catholic Church along with a group of lawyers, police, merchants, teachers, and clerks based in the urban center, which partially reduced the effects of the economic crisis (Rueda and Romero 2002).

Ecuadorian historians have described six mining cycles based on the dominant mode of production during the Republican period. Until 1860, the local landed elite controlled the mines with scarce investment in new discoveries or technological upgrading. Between 1860 and 1895, the Zaruma area saw an 
increase in independent miners and the association of national entrepreneurs with foreign investors. From 1896 to 1950, SADCO, a subsidiary of the Vanderbilt group of the United States, established the Portovelo mining enclave. The governmental regulation of the mining industry shifted throughout this period. This topic will be the matter of subsequent analysis, but it is worth noting here that the national regulation of natural resources was sometimes interchangeable with infrastructure, mining royalties, state sovereignty or local development. Important labour struggles helped to redistribute the profits of the mining enclave in 1919, when workers confronted the company managers; in 1935, when the union and the bargaining commission led a strike; and in 1947, when the union forced the signing of a collective agreement.

The withdrawal of the American investors in 1950 launched a new cycle, leading to the municipalization of the mining industry. Between 1951 and 1978, the Compañía Industrial Minera Asociada (CIMA, Associated Industrial Mining Company) managed the mines as a local partnership between the miners' cooperative and the municipality of Zaruma. The de-industrialization of the mining town happened steadily. In fact, memories of this period speak to a chronological continuity of the mining enclave throughout SADCO and CIMA's administration. The industry came under government control in 1980 after several bailouts. Since then, neoliberal policies have helped in the dismantling of the industrial infrastructure and led to the spread of artisanal mining in southern Ecuador. 
To understand the conditions and regulatory practices that enabled the creation, operation, and closing of the mining enclave, my research covers the longue-durée between 1860 and 1980, with particular attention to moments of crisis and transformation. The extended timeframe and multiscale approach enhances traditional historiography by incorporating a critical analysis of the local, national, and international processes that influence the development of large-scale mining.

\subsection{Structure of the dissertation}

In the pages that follow, I examine the spatial dimensions of resource regulation by studying the Zaruma and Portovelo mining enclave. I have structured the dissertation as a series of chapters that can be read as separate units. Each chapter includes two dialectical approaches: the first refers to the processes constituting the production of space; the second speaks to moments of crisis by visualizing contradictions and qualitative changes in the mode of regulation. The manuscript is divided into nine chapters.

The introduction presents the theoretical and methodological foundations that guide my research and an overview of the history of mining in the study area. I call for an analysis of the spatial restructuring of resource regulation using a scale-sensitive, ethnographic, and genealogical approach in order to highlight the differential involvement of multiple actors and everyday processes shaping the production of space of the mining enclave. 
In chapter two, I examine the conceptual framework in greater depth. The chapter builds on Lefebvre's work on the production of space and moves towards understanding a particular kind of place within capitalist economies: the gold mining enclave. To understand the historical and multi-scale relations between the regimes of capitalist accumulation and the social modes of economic regulation, I work with theoretical insights derived from regulation theory.

Chapter three provides key methodological insights to undertaking extended case studies intended to connect global forces and local processes using a genealogical approach. Throughout this chapter, I argue for a placebased analysis on how global forces become grounded and transformed through local processes. In this chapter, readers will find a detailed description of the research methods, and the challenges faced and the decisions taken in the organization and analysis of primary and secondary sources.

In chapter four, I explain the restructuring of the monetary regime and the forms of competition of the mining industry at the international and national levels, and how such processes enabled corporate capital to arrive in Zaruma. Between 1860 and 1895, international demand for base metals and the quest for gold to supply metropolitan markets required the opening of national spaces to foreign investment. The appropriation of mineral resources by capitalist economies included not only the expansion of the mining sector through market mechanisms and technological innovation, but also a flow of information, expertise, and regulations. The emergence of liberal democracies and the 
institutionalization of the state apparatus internally transformed center-periphery relations by limiting municipal autonomy and strengthening the presence of state representatives throughout the country. However, the "penetration" of foreign investors was never straightforward insofar as foreign-owned mining companies had to negotiate the conditions for their operation in Ecuador.

Chapters five analyzes the restructuring of the geographical landscape at regional and urban levels. The period between 1895 and 1950 encompasses the creation of the Portovelo camp, the physical integration of the mining district and the proletarization of labour, which propelled economic growth, and the consolidation of a new urban hierarchy. Life within the camp was regulated through a combination of spatial engineering and modern methods of discipline and social control.

In chapter six I uncover the restructuring of social relations of production at the level of the enclave, and how such a process is influenced by - but also influences - national regulations. In the actual development of the mining district, the company had to deal with the existing socio-spatial structures and emergent social powers, which transformed the dynamics, productivity, and outcomes of the overall industrial venture. Both chapters highlight the partial reach of the liberal state that allowed foreign capital to benefit from local resources and create a porous enclosure of private rule.

Chapter seven presents a multi-scale approach highlighting the up-scaling and down-scaling of the regulations conditioning the circulation of capital in the 
mining sector, with a special focus on the contractual agreements and norms enacted between 1925 and 1950. In Ecuador, nationalist laws for the mining sector were place-specific, constructed vis-à-vis the interaction among the state, foreign investors, and groups involved in socio-spatial struggles. In this chapter, I demonstrate how the institutional system, administrative practices, and the historical juncture restricted the application of the progressive principles of the period while allowing corporate actors to continue extracting mineral resources with minimal redistribution of profits to the national economy.

Chapter eight provides an examination of the territorial restructuring of state space in its interaction with the mining enclave. This approach requires understanding how the state shapes the creative breakdown of the mining enclave, the continuous transformation of internal borders and the rescaling of resource regulation. To delay de-industrialization, the government municipalized the mining industry. The association between the municipality and the workers gave way to complex competition between alternative projects: the continued existence of the mining camp as an enclosure of self-rule versus the diversification of the economy to sustain local livelihoods. The chapter covers the period between 1950 and 1980, when both populist and bureaucraticauthoritarian regimes favoured the creation of a new administrative territoriality to facilitate resource-based accumulation. The institutional solution provided a temporary means of subsistence for the work force, delayed mine-closure, and created new patron-client relations. This process displaced social externalities to 
local shareholders without the technical, financial, and entrepreneurial capacities to sustain the mining industry.

Chapter nine revisits the research questions and discusses the imbrication between the production and the regulation of space in mining enclaves. The concluding reflections highlight the theoretical and methodological contributions of the investigation and connect historical studies with current processes for regulating the mining industry in Ecuador. Finally, it reveals avenues that were not fully addressed and constitute opportunities for future research. 


\section{Conceptual framework}

The present work is situated within the field of critical human geography. Arising in the 1970s in response to positivism and empiricism, Marxist-inspired critical scholarship explores the historical geography of capitalism and develops research based on a dialectic-materialist method of inquiry (Harvey 2001, 1985). Critical geographic studies have evolved to question uneven geographical development, unmask socio-spatial relations of power, and embrace theoretically informed social activism aimed at spatial justice. Within this broader framework, three theoretical contributions constitute the main corpus of this dissertation: the production of space, the political economy of resource extraction, and the spatial restructuring of resource regulation. It is beyond the scope of this dissertation to provide an exhaustive account and a comprehensive discussion of each body of thought. Rather, I focus on the spatial dimensions necessary to understand how capitalist accumulation produces certain locations for the extraction of surplus value, and how local modes of regulation develop responses to assimilate, negotiate, or resist place-making projects for resource extraction. 


\subsection{The production of space}

[Social] space is a [social] product... the space thus produced also serves as a tool of thought and of action; that in addition to being a means of production is also a means of control, and hence of domination, of power; yet that, as such, escapes in part from those who would make use of it.

(Lefebvre 1991, 26)

Writing in the late 1970s, the French Marxist philosopher Henri Lefebvre developed a conceptual framework to explain that every society — and every mode of production - produces a space of its own. ${ }^{8}$ From this perspective, social relations shape spatial structures and vice-versa. For Lefebvre, the production of space and place are both conceived in terms of embodied practices and processes of production that are simultaneously material and discursive. To unravel the social production of space, Lefebvre developed a triad explaining how material and non-material dimensions of social spatiality are dialectically articulated.

The material practices are the concrete and everyday experiences of space, which encompass the production, and reproduction, of particular locations and socio-spatial formations (Lefebvre 1991, 33). Space is appropriated, used, and transformed through practices that modify the physical landscape. The representations of space refer to conceptualized, conceived, and designed 
spaces that impose "order" to sustain relations of production through abstract codes and knowledge. The mental space represented by planners, scientists, and social engineers is commonly expressed through maps, urban design, institutional rules, and symbols. The spaces of representation relate to the subjective and symbolic appreciation of space, which leads to signifying associations, whereby imagination seeks to change, and appropriate, space through non-verbal symbols and signs. The trialectic relation amongst lived, conceived, and perceived space substantiates and transforms the spatial structures that underlie any given society. Therefore, spatiality is a social product that is simultaneously the medium and the outcome of social actions and relationships. The idea that space is socially produced is embraced as a foundation of critical human geography, generating a wealth of debate and criticism in exploring the historical geography of capitalism (Harvey 1989; Soja 1989; Smith 2008; Unwin 2000).

With the above in mind, I emphasize that space is much more than the physical landscape of the company town; it embraces nationalist claims over mineral resources, the urban policies that shape the enclave, and the supra-

8 For a discussion of Lefebvre's ideas and influence see: Elden 2004; Goonewardena et al. 2008; Kipfer, Saberi, and Wieditz 2013; Merrifield 2006; and Shields 1999. 
national institutions that oversee and guarantee foreign direct investment in the mining sector. This means that diverse institutional forms come into being and/or act to produce particular places such as the mining enclave. Space is not restricted to place, although particular places shape how extractive industries are perceived at different levels while creating a dynamic tension between the upscaling and the down-scaling of resource regulation.

Lefebvre also argues that if social space is produced, then we are dealing with the history of space. Any shift in the mode of production entails the production of a new space, even though the inscription of human actions onto space occurs only very slowly. Therefore, any attempt to drastically modify the conditions for the production of space could be understood as a place-making project. For Lefebvre, the history of space has its place between anthropology and political economy, and provides an understanding of not only the genesis of any given location, but also the "interconnections, distortions, displacements, mutual interactions, and their links with the spatial practice of the particular society or mode of production under consideration" (Lefebvre 1991, 42). Space and place are produced through time, layered within webs of broader social and economic relations.

In a more intriguing manner, Lefebvre states that "[i]f there is such a thing as the history of space, if space may indeed be said to be specified on the basis of historical periods, societies, modes of production, and relations of production, then there is such a thing as a space characteristic of capitalism" (ibid., 126). At 
this stage his answer is somewhat deceptive, as he goes on to describe the form and aesthetics of architectural volumes. Later, he broadens the perspective to add that "the history of space corresponds to the accumulation of capital, beginning with its primitive stage and ending with the world market under the reign of abstraction" (ibid., 129). Within capitalism, the history of space is linked to the spread of abstract social relations, namely, exchange value in its monetary expression, first through gold and silver, and then through capital. The abstraction of exchange value includes the production of particular spatial forms in the shape of relational markets and commodity chains coordinated through communication networks and hierarchically organized centers.

In this regard, my goal in this dissertation is to demonstrate how the social regulation of the resource-based economy produces particular kinds of spaces at the international, national, and local levels. I am not interested in globalization as an abstract space of financial flows, nor am I addressing planetary urbanization as the full expression of capitalist accumulation. The approach that informs this dissertation requires grounding the theoretical analysis in concrete locations. Hence, I am displacing the focus to the resource regions, the hinterlands of extractive capitalism, and the places where gold was extracted to back social value in order to see how those places change as the international monetary regime changes.

We may then ask, what is the distinctive spatial form of capitalist accumulation when the monetary expression of social value is represented by 
gold and how has such a spatial form changed with changes in the social value of gold over time? Answering this question involves adopting a multi-scale approach sensitive to the institutional forms where gold is understood as a commodity necessary for the circulation of capital, including international monetary regimes, the adoption of the gold standard, the dismantling of this financial regime, and the secular increase in the importance of finance capital. Within such a framework, I am interested in understanding the particular places where gold is produced to supply the capitalist economy, and in the kinds of institutional forms involved in the regulation of this particular kind of place. In doing so, I analyze how extractive capitalism gets grounded and shaped through flows of people, ideas, and things that establish connections among multiple sites.

Before proceeding, I offer the following key insight from critical geography, crucial to my analysis. The primary determinant in the production of space is the appropriation of space. Within Marxist theory, the enclosure of space as private property makes possible the appropriation and control of nature, labour, rents, and surplus value. Space is made operational through its fragmentation by administrative subdivision and by the retail sale of space (Lefebvre 1991). The fragmentation of space into parcels of private property, bought and traded on the market, is a means of reorganizing social, economic, and political power. To this end, it is important to understand the evolution of property regimes insofar as the appropriation of space and the subsequent measurement, division, and 
distribution of land make possible the productive work that occurs afterwards. Such a process includes the domination of space, through legal or extra-legal means, by individuals and groups to exercise control over space, as well as the contradictions and resistance resulting from this process (Harvey 1989, 222).

Working from a different theoretical perspective, Schmitt $(2006,327)$ also points to land appropriation as the constitutive act which produces a primary criterion for any further social relations, economies, and legal orders. Land is a condition and an output in the process of production. Therefore, the control of space is intimately connected to the obligatory reorganization of the people who live on the land in question, a process that involves violence or the threat of violence. In extractive regions, this is particularly important insofar as property rights - enforced by custom or law - regulate relations of production by distributing the power to control valuable resources. Therefore, the formation of a political body embodies the existence of "a political power controlling and exploiting the resources of the market or the growth of the productive forces in order to maintain and further its rule" (Lefebvre 1991, 112).

Lefebvre $(1991,281)$ emphasises that each new form of political power introduces its own partitioning of space and an administrative classification of the discourses about space. The production of space is granted by the state's intervention whereby the ordering of nature and society works for the reproduction of capital and the centralization of power. From such a perspective, the state is involved in the mobilization of diverse forms of technical knowledge, 
along with political and institutional capacities, so as to produce, manipulate, manage, and regulate the geographies of production and social reproduction.

The theoretical framework developed by Lefebvre helps in understanding the spatiality of the mining enclave and the spatial restructuring of resource regulation from different standpoints. First, it directs our attention to the production of space in the gold mining enclave as a place-making project whereby the built environment is an expression of spatial practices pertinent to a particular mode of production and regime of accumulation at different levels of governance. The construction and transformation of the mining enclave and the investments required to connect the extractive region with metropolitan markets are necessary preconditions for capitalist expansion. Such a process is filled with contradiction and struggle insofar as the socio-spatial engineering of the industrial landscape is a competitive arena for divergent economic practices, social values, and political powers. Second, as Lefebvre's framework indicates, the mining enclave, as a social space, contains and transforms the relations of production and the "order" that those relations impose. ${ }^{9}$ Therefore, the production of the mining enclave encompasses a particular ideology, knowledge, and discursive praxis that present capitalism and modernity as a desirable and

9 While I recognize the importance of the family and kinship as a basic unit in production, social reproduction, and consumption, my research is focused more on the social relations of production than on the more specific conditions of biological reproduction. 
attainable way of life. Specifically, I use Lefebvre's work to excavate how the spatiality of the enclave transcends the geographical location to include social regulations needed for the reproduction of the mode of production at different scales.

\subsection{The political economy of the gold mining enclave}

The discovery of gold and silver in America, the extirpation, enslavement, and entombment in mines of the indigenous population of that continent, the beginnings of the conquest and plunder of India, and the conversion of Africa into a preserve for the commercial hunting of blackskins, are all things which characterize the dawn of the era of capitalist production. These idyllic proceedings are the chief moments of primitive accumulation.

(Marx [1867] 1982, 915)

Political economy helps reveal the relationship between economic and political processes from both liberal and critical world-views. Marxist political economy offers an analysis of capitalist relations that transform nature through labour, creating class relations that lead to primitive accumulation. The division of labour and the production of nature presuppose an ongoing geographical differentiation and an uneven distribution of resources for the appropriation of surplus value (Harvey 1996; Smith 2008). From this perspective, the accumulation, concentration, centralization, and circulation of capital tend to 
reproduce and reinforce geographical inequality. ${ }^{10}$ The possibilities for development are constrained insofar as spatial forms are linked to spatial productivity, reinforcing the specificity, specialization, hierarchies, and differentiation of particular places (Massey 1995; Santos, M. 2000, 1977).

Latin America is marked by a history of colonial conquest and the extraction of precious metals. The exploitation of labour, the appropriation of natural resources, the transfer of surplus, and the creation of social institutions resulted in prosperity for the colonial metropolis and genocide for indigenous populations (Galeano 1997; Quijano 2007). The incorporation into and dependence on colonial metropolitan markets were made possible through political and institutional systems enabling export-oriented agriculture, the extraction of mineral resources, and the maintenance of reservoirs of untapped resources. The decline of Spanish rule, the expansion of European capitalism, the introduction of the liberal state, and the emergence of national elites allowed for some redefinition of political and economic control over the productive structure. The expansion of European powers, notably Britain and France, and the rise of the United States as an imperial power, created new forms of

10 Marxism, structuralism, and dependency theory emphasize how the international division of labour, the concentration of the economy on primary products for supplying metropolitan markets, the unequal terms of exchange and the structural socioeconomic relations for the extraction of surplus value create core-periphery dynamics (Bielschowsky 2009; Di Filipo 2009; Osorio 2003; Romo 2007). 
colonialism that reinforced export-led growth (Bulmer-Thomas 2002). In some cases, the landed oligarchy and the urban bourgeoisie failed to maintain full control over activities requiring technological advancement, marketing systems, and large inputs of capital. This process resulted in an export-oriented model whose maximum expression is the economic enclave, around which domestic policies are articulated to reinforce the structures of political domination and economic exploitation (Cardoso and Faletto 1971, 48).

At this stage, I would like to emphasize that accumulation strategies require access to specific resources. Given the social value and the material qualities of gold, its production cannot be predicted based solely on a quantitative projection of the availability of gold-bearing ore reserves. There are several other factors influencing the process: the state of mining technology, material costs of gold production, net revenue as expressed by the commodity price, regulations which constrain circulation and consumption of gold reserves (pertinent up to the early 1970s), and property regimes which grant access to gold-bearing ores. The search for gold has led to two spatial expressions: the gold rush and the gold mining enclave. Gold rushes have been documented in California, the Klondike, Australia, and South Africa (Bernstein 2004; Blainey 1970; Morse 2003; Peck 1993; Smith 1987). My research is an attempt to understand the institutional forms that come into being to produce the particular spatial form of the gold mining enclave. 
The concept of economic enclave stresses the particularities of locations where a single corporate agent controls the domestic relations of production of export-oriented commodities. Cardoso and Faletto (1971) distinguish between enclaves controlled by foreign capital and those that are domestically controlled by export sectors. Foreign controlled enclaves develop due to the inability of national productive sectors to react and compete in international markets, or as the result of imperialist expansion of central economies. In those cases, capitalist expansion is performed independently of the initiative of local groups, which become subordinated to the staples economy.

Plantation and mining enclaves came into being as a result of the demand for industrial raw materials and the penetration by industrial capitalism (Cardoso and Faletto 1971; Hayter 2000). The difference between the aforementioned sectors lies in the intensity of the conditions of production in terms of land, labour, and capital. The plantation enclave represents an extensive regime of accumulation that occupies large land areas with relatively low investments but high inflows of labour. The mining enclave is primarily an intensive regime of accumulation, which develops industrial facilities with a hierarchical specialization of labour, differentiated wage regimes, and high concentration of technological and financial capital.

The mining enclave is a social space - an enclosure of private rule where particular modes of production and social relations are enforced to ensure the outflow of surplus value. The "single industry town" or "company town" was 
the model preferred by corporate mining interests in locations such as the hardrock gold district of Portovelo due to economies of scale, massive fixed costs, processing efficiencies, access to financial markets, and risk-coping capacities (Hayter 2000). The company town is commonly defined as an urban settlement in which at least 75 percent of the working population serves a single industry and supporting institutional services (Lucas [1971] 2008, 14). Socio-spatial engineering, residential segregation, and corporate ownership or control over urban infrastructure, social services, and leisure activities serve to control and discipline the work force (Dinius and Vergara 2011, 7). Commonly, company towns are geographically isolated despite their close linkages with the centers of political decision-making; this arrangement contributes to the maintenance of institutional arrangements that guarantee the monopolization of resources, enable foreign direct investment, and facilitate outward flows of surplus value.

Critical geographic studies illustrate how centralized and authoritarian regimes, coercion, corruption, and violence facilitate resource extraction (Bilion 2007; Downey, Bonds, and Clark 2010). Extractive industries redirect the ruling classes towards the pursuit of political and administrative functions and create a bureaucracy maintained through taxes collected from the enclave sector (Cardoso and Faletto 1971, 52). The politically motivated expansions of the public sector distort the allocation of productive factors that regressively distribute national income and concentrate wealth (Acosta 2009; Robinson, Torvikb, and Verdierc 2006; Sachs and Warner 1997). 
In such a context, resource regions become "spaces of nationalism" controlled by the state acting through local political entities and rent-seeking groups, as an emanation of material and symbolic authority of the national community (Watts, 2003). The national elites linked to the staples economy act as intermediaries to enforce internal order and make available the workforce necessary for economic exploitation. But, "there is no sense of the national fantasy at the local level where political confrontation, violence, and identity politics shape the landscape of an 'unimaginable' national community” (ibid., 26). Yet, decentralization proponents commonly approach local resource regulation from a perspective that tends to naturalize the capacities and supportive role of local government (Andersson and Ostrom 2008; Ruiz 2003). However, social movements and local powers, including municipalities, sometimes confront extractive capitalism and authoritarian governance by promoting political participation and democratization of society (Bebbington 2007; Echave 2009; Svampa 2010; Touraine 1978).

Taking the above research into consideration, my analysis of gold mining enclaves seeks to avoid at least two fallacies: the assumptions that location is determined solely by firstly, the physical availability of gold-bearing mineral deposits, and secondly, by foreign hegemonic domination. Primitive accumulation is by no means an "idyllic" feature of the colonial past limited to the "new" world or authoritarian regimes. The existence of mineral deposits drives location-based decisions, but the timing and characteristics of such enterprises are selective, based on factors external to the industry itself, including the socio- 
political struggle and the regulatory framework for extractivism (Bridge 2004b, 2009). As mentioned above, states and local populations are not passive entities with which transnational enterprises do as they wish. Even during the period of export liberalism, Latin American governments and communities took measures to regulate foreign capitalists, as I explain in greater detail in chapter seven.

\subsection{The spatial restructuring of resource regulation}

The proposal for a spatial and multi-scalar analysis of institutional and place-based responses to the political economy of the mining sector originates in the body of literature known as the regulation school. The "regulation school" rejects the concepts of general market equilibrium, individualist reductionism, and structuralist invariance. This approach is a critique of orthodox economics and neo-classical theory inspired by insights provided by economic geography, dependency theory, political science, and historical sociology. This approach has an interdisciplinary origin and vocation with multiple specializations and diversification since it was first developed in France and Germany (Boyer 1990; Boyer and Saillard 2002; Jessop 1996; Jessop and Sum 2006). Regulation theory - as developed by the French school and subsequent Anglophone literature - focused primarily on the dynamic nature of capitalism as a particular regime of accumulation and its relation with the state.

Capitalism requires institutional mechanisms to reproduce or transform social and economic orders for the purpose of guaranteeing the dominant regime 
of accumulation. Moreover, the persistence of capitalism, despite its successive crises, depends on economic and extra-economic frameworks that sustain accumulation at different locations. The regulation approach developed in the tradition of political economy postulates a tight relation between the regimes of capitalist accumulation and the social modes of economic regulation. ${ }^{11}$ According to Lipietz $(1987,32)$, a regime of accumulation refers "to a systematic and longterm allocation of the product [social labour] in such a way as to ensure a certain adequation between transformations of conditions of production and transformations of conditions of consumption." In the case of a mining enclave, the industrial camp is much more than a production system insofar as it is "articulated with other modes of production within a national economic and social formation, and between the social and economic formation under consideration and its 'outside world"' (ibid., 14). I use this work to argue that any study of the resource region should include an understanding of the tension between the international forces of capitalist accumulation and the processes of stateformation at the national level.

11 This approach has been criticized for not being a general theory but rather a series of "intermediate concepts" used to observe empirical phenomena and describe cycles of economic development, namely the rise and decline of Fordism as the dominant regime of accumulation in North America and Europe (Jenson 1992; Jessop 1997; Mavroudeas 1999; Tickell and Peck 1992). While this remains true, the theory has seldom been used to understand the modes of regulation in Latin America where neo-structuralism and neoinstitutionalism has gained pre-eminence in the academic analysis of economic cycles and political processes (Bresser-Pereira 2011; Grugel and Riggirozzi 2012; Kaltwasser 2011; Leiva 2008; Love 2005). 
Lipietz goes further to assert that the regime of accumulation is not a disembodied entity but, rather, requires "institutional forms, procedures and habits, which either coerce or persuade private agents to conform to its schemas" (Ibid., 33). A mode of regulation arises as a means to "normalize" the behaviour of economic agents who act in isolation or with limited rationality in order to ensure the regime of accumulation. Such a process comprises an ensemble of rules, norms, social networks, organizational forms, conventions, practices, discourses, and institutions used to uphold accumulation, minimize crisis, transform productive relations, and "normalize" the structural relations of production and consumption. However, economic actors interact on the basis of situated rationales (Orléan 1994, in Boyer 2002, 14). The intrinsic contradictions of capitalist accumulation result in the uneven evolution of institutional forms, insofar as "not every mode of regulation can regulate every regime of accumulation and that a single mode can take the shape of different combinations of partial forms of regulation" (Lipietz 1987, 15). The institutional adaptation to the imperatives of economic growth and forms of political legitimacy does not happen automatically, leading to the historical and geographical variability of capitalist accumulation.

Contrary to neoclassic economic theorists who claim that crisis is an anomaly of economic growth that tends toward general equilibrium, regulation theory postulates that crisis is the expression of the internal contradictions of the accumulation regime. Harvey $(2007,432)$ goes further to recover Marx's argument to highlight crises as "violent fusions of disconnected factors operating 
independently of one another yet correlated." Crises are the result of overaccumulation, inadequate financial credit, inappropriate currency devaluation, and legitimization of hierarchical structures. The structural contradictions of capitalism are solved through a time-space displacement of crisis, that is, by transfer to other territories or by postponement (Harvey 1990).

In this dissertation, I examine how external forces of capitalist accumulation opt for particular places and how local modes of regulation develop responses to assimilate, negotiate, or resist place-making projects. Departing from the regulation approach, in the following section I explore some geographical insights as a means to understanding the spatial restructuring of resource regulation.

\subsubsection{Institutional forms in the production of space}

The French school of regulation identifies five "institutional or structural forms" that are fundamental social relations at the base of any regime of accumulation and mode of regulation in any given society and at any moment in history. The five forms of social relations that define the connection between economic units and surplus appropriation are: the wage-labour relation, the monetary system, forms of competition, the international regime, and the form of the state (Boyer 1990; Boyer and Saillard 2002). Institutional forms act as an intermediary to stabilize the economic system and arise "from conflicts between social groups arbitrated by political and legal processes" (Boyer 2002, 17). 
However, what seems absent from these debates are the institutional forms that influence the production of space and the appropriation of land. Thus, researchers who study regulation have analyzed the interaction between capitalist production and nature, in proposals such as Lipietz's $(1987,2002)$ "economy of the environment", Becker and Raza's (1999) "ecological constraint", or, from a different theoretical standpoint, Smith's (2008) "production of second nature". ${ }^{12}$ These insights move away from geographic determinism or the causal analysis of the environmental effects of capitalism, to explore the social conditions that transform land, nature, and space according to the productive forces at play in the bargaining between capitalist accumulation and social reproduction at different scales. ${ }^{13}$ According to Becker and Raza (1999), the "sixth structural form regulates access to, and utilization of, the material world both for productive and reproductive activities." I make use of this concept to analyze the long-term spatial restructuring of resource regulation in order to understand the specific conditions by which institutional forms, such as the

12 The global ecological crisis has led to a series of regulations, some based on the precautionary principle, involving market mechanisms and governmental norms, intended to alter relations of production and consumption. Concern with the institutional features needed for the production of space and nature have involved the integrated analysis of property regimes and urban areas (i.e., Harvey 1988; Jager 2003; Topalov 1988). In addition, studies departing from political economy bring into question the naturalness of ecological processes in their articulation with political decisionmaking (i.e., Blaikie 1985; Peet and Watts 2004). These features are apparently still considered separate disciplines related to urban theory and political ecology. 
property regime, come into being and perform in the production of space in the mining enclave.

\subsubsection{Agency in the spatial restructuring of regulation}

The feminist critique of regulation theory brought into the debate the relation between structure and agency. In this regard, Jenson $(1991,194)$ calls for "concrete investigations of historically developed sets of practices and meanings which provide the actual mechanisms of regulation." The evolution of the economic order and the role of the state - as the institutionalized political power that helps internalize the costs and the conflicting demands of capitalist accumulation - proceeds apace with the construction of a mode of regulation in which different actors struggle for control of the state, that is, over the state's ability to grant power over the accumulation of capital and the reproduction of social relations (Jessop 2008). From this perspective, governance is far from being a single cohesive and unitary process. The scope and reach of the mode of regulation is continually evolving vis-à-vis socio-political struggles and economic processes, which become especially apparent when examining these political geographies over a longer time period.

Contrary to previous assumptions based on the invisible hand of the market or state sovereignty, current studies problematize the assemblages and multi-scale orders of institutional organization, political authority, and relative autonomy (Brenner 2004; Harvey 2005; Jessop 2002; Lefebvre 2009; Peck and Tickell 2002; Sassen 2008; Swyngedouw 2004). Different rationalities, 
government programs, and political practices coexist and compete, producing transformations and continuities both in the state's material practices and in the institutional framework that sustains them. The uneven development of institutional mechanisms results in disparate capacities through diverse policy areas and geographical reach whereby the government has developed a distinctive set of resources and powers at different scales and in different sectors (Jessop 2008; Skocpol 1985). ${ }^{14}$ Yet, institutions have a path-dependent involvement with various social powers, respond to situated rationales, and achieve relative autonomy, as routine practices also become a means of social reproduction and regularization (Jessop 2007; Foucault 2010). The particular forms of the state are a temporal balance of forces within specific conjunctures and structural limitations.

The contingency of power and state formation is related to the conduct of the agents, their organization, resources, strategies, tactics, and relations with other agents (Jessop 2008, 29). Hence, the analysis of regulatory mechanisms and the politics of space transcend the territorial structure of the state (Brenner 2004; Cox 1998, 1990; Lefebvre 1976, 1991) whilst particular places, such as

14 Historical sociology deepens the analysis by arguing that the state is not a "thing" but a social process (Abrams 1988; Campbell 1998; Corrigan and Sayer 1985; Joseph and Nugent 1994). Authors such as Anna (1996) and Quintero and Silva (1991) suggest that the state be analyzed by looking at the historical processes involving regionalism, power sharing, regional economic disparities, ethnic differences, and institutional forms of power. 
mining enclaves, are active agents in the production of the national and the global as particular scales of resource regulation. Building from these insights, my aim is not to develop a general theory but, rather, to analyze the actors, the practices, the institutions, and the evolution of the mode of regulation in the mining sector in Ecuador from a historical perspective.

\subsubsection{A multi-scalar understanding of regulatory processes}

The mode of regulation is a concept involving certain assumptions about the role of the state. According to Jessop (2008), the state is commonly described as an apparatus whose primary role is to define and enforce collectively binding decisions within a territory over which it holds sovereign power in the name of the "common interest" or the "general will." Thus, the state is normalized as the entity of social regulation, political organization, and political intervention within a given jurisdiction (Dalby 1991; Driver 1991; Jessop 1997, 2002; Streeck 2011). From this perspective, national territory is a geographical area under government jurisdiction. Territorial configurations are usually understood as sets of interacting and nested hierarchies of discrete, enclosed jurisdictional spaces ranging from the parish to municipal and provincial jurisdictions up to the national or the global realm, which are administered and controlled through spatially bounded forms of power.

From a geographical perspective, the most innovative research inspired by the regulation approach moved beyond state-led forms of governance to address the unevenness of regulation, the multi-scalar processes of regulation, 
or the rescaling of statehood. Territory under state jurisdiction is not a fixed asset or a static background structure for economic accumulation (Agnew 1994; Jessop 2008). Insofar as any institutional form is internally differentiated into discrete and hierarchically organized spatial units, we can refer to the geography of regulation and the problem of its scalar organization (Brenner 2004). The core of regulatory forms can indeed refer to the ensemble of bureaucratic institutions controlled at the national level, but there is also a collection of auxiliary entities that achieve some degree of autonomy and continue to be animators and mediators of political-economic restructuring through different forms of statehood (Brenner 2004; Jessop 2008). Scales denote the production, reconfiguration, and contestation of some aspect of socio-spatial organization within a relatively bounded geographical arena (Brenner 2001). Scale — as an actively produced spatial configuration - mediates between cooperation and competition, homogenization and differentiation, succession and coexistence, and the empowerment and disempowerment of specific actors (Swyngedouw 2004, 34). The nuances of such a process become evident in chapter eight, where I discuss the municipalization of the mining enclave.

Bridge and McManus $(2000,14)$ highlight that "interest in the spatiality of regulation, together with the recognition that heterogeneous regulatory modes can exist within national economic spaces, has underpinned more recent efforts to understand processes of socioeconomic restructuring at the subnational and local scale using regulationist concepts." The intersection and juxtaposition of different regimes of accumulation drive temporary assemblages of actors, legal 
frameworks, and discourses that dispute socio-spatial regulation. ${ }^{15}$ In such circumstances, different sets of powers, interests, networks, and practices interplay, leading to social reproduction at the local level. I argue that this feature allows for the analysis of local resource regulation not just as a subsidiary activity of global demand for raw materials and national modes of regulation, but as a process of transformation and rupture that is necessary to enable the continued existence of local economic accumulation.

\subsubsection{The institutional fix of state space}

Lefebvre (2009) analyses the complex and changing relationship that binds space and the state. He suggests that the state takes control of the whole society, in that it produces a space to mould, regulate, and organize social and economic relations within and beyond its territorial borders. Such a process includes the creation of an institutional architecture along with an ensemble of mechanisms that allow the exercise of specific forms of socio-spatial power. The space thus created is simultaneously homogeneous and fractured. The state regularizes social life through normalizing policies that promote the equalization of difference (ibid., 108). However, as I argue in this dissertation, the functionality of state control is fractured and fragmented by market mechanisms and everyday

15 DeLanda (2006) and Deleuze and Guatari (1987) define the concept of assemblage within the social sciences. In addition, work by Sassen (2008) provides a detailed explanation of institutional arrangements and territorial articulations at various scales. 
practices. State action cannot impose abstract coherence or spatial cohesion on the diverse moments of capitalist accumulation, ranging from the production to the circulation of surplus value (ibid., 244).

The idea of "state space," developed by Lefebvre (1976, 2009), helps to explain the production of social space within national territory and the spatiality of state strategies for dealing with capitalism. In capitalist economies, interventions by the governmental apparatus must be conceived spatially as attempts to organize and regulate social space to serve its own economic and political ends. The state has a changing role in promoting, financing, and subsidizing the regime of accumulation through the construction of infrastructure and the provision of social services that influence locational geographies. In addition, the state extends its power and control over social and economic relations, inasmuch as it manipulates space to create relatively stable territorial grids of social regulation (Brenner, 2004).

According to this perspective, both space and territory are simultaneously produced through the state. The space so produced is political, homogenizing, and hierarchical, but also fragmented insofar as it responds to localized relations of production and social regulation. Goodwin and Painter $(1996,645)$ argue that:

... the differentiated spaces of regulation within a nation arise not only as a result of localized conditions of production and consumption, and local constellations of social forces and cultural practices but also because local agencies are often the very medium through which regulatory practices are interpreted and ultimately delivered. 
Administrative jurisdictions are a specific kind of spatial and institutional fix which operate as a system of social regulation. ${ }^{16}$ These spatial forms are the result of the areas of influence of different agents who are not limited by administrative attributes, but stimulated by organizational arrangements within a mode of production. Some spatial forms and scales are established, differentiated, and stabilized as temporary units of socio-spatial organization, activity, conflict, struggle, discourse, and imagination. In particular, local governments could be defined as a force of production insofar as they are defined "as coordinators of services in the field; as a reconciler of community opinion; as a consumer pressure group; as an agent responding to rising demand; and finally as a counterweight to incipient syndicalism" (Sharpe 1970, 174). I use this framework to argue that local governments (parishes, municipalities, provinces) are an expression of how the mode of regulation is constituted, coordinated, and produced, but also resisted, leading to a restructuring of capitalist accumulation.

The notion of "scalar fix" was developed for exploring the tension between the fixity and the circulation of capital (Harvey 1981, 2001, 2005). Brenner $(1998,462)$ examines the notion of a "scalar fix" for understanding the "configurations of territorial organization within, upon, and through which each round of capital circulation is successively territorialized, deterritorialized, and reterritorialized." Empirical studies tend to focus on the role of cities, metropolitan areas, national states, and international arrangements in the reconfiguration of socio-spatial relations after Fordism was applied in Western economies. 


\subsubsection{The mobility and mutation of regulations}

The reconfiguration of institutional frameworks and regulatory practices among and across scales has been studied more frequently in the context of neoliberal regimes, as an ongoing questioning of the spatial boundedness of the nation-state (Agnew 1994; Keil and Mahon 2009; Peck and Tickell 2002; Sassen 2010). Such a process encompasses understanding the diffusion and restructuring of regulatory practices (Levi-Faur 2005; Meseguer and Gilardi 2009), the mobility and mutation of policy (Peck and Theodore 2010), the standardization and dissemination of knowledge (Mahon and McBride 2009), and the concrete actors, associations, and technological mediators in the passage of laws (Latour 2010, 1986). I demonstrate that these processes are not exclusive to neoliberalism and that understanding them requires a historical and ethnographic interpretation of institutional forms to uncover socio-spatial relations in the transmission and restructuring of the social modes of regulation.

I conclude this chapter by briefly highlighting the methodological implications that the theoretical framework poses for my research. First, I analyze the tension between the production of a global space for the circulation of capital and the place-making projects necessary to uphold capitalist accumulation. In this regard, I am particularly interested in the role of mining enclaves as constituent forces of long-term industrialization as they reflect the changing imperatives of colonialism, Fordism, and flexible accumulation insofar as resource regions speak to the expansion of the capitalist economy worldwide. However, following Lipietz $(1987,14)$, I recognize that the regulation of the 
mining sector is "articulated with other modes of production within a national economic and social formation." Such an approach calls into question the coherence and consistency of resource regulation at different scales and requires an analysis of struggles and practices in the production of space within socio-political contexts.

Second, the theoretical framework selected leads to attentiveness to the institutional forms that enable and transform capitalist accumulation. I focus on the initiatives, norms, and networks which sustain the productive process and normalize social life within the mining enclave, namely, the material practices in the production of space and place, the evolution of mining codes, and the spatiality of the state apparatus. In doing so, I move away from a functionalist account of legal responsibilities and look instead at the processes and nuances in the spatial restructuring of resource regulation at different scales.

Finally, I explore moments of crisis as an opportunity to identify the contradictions of capitalist accumulation. In times of crisis, existing institutional forms do not guarantee the reproduction of the regime of accumulation nor does the emergence of new forms of structural regulation guarantee the coherence or the success of the accumulation regime. My approach moves away from economic determinism and facilitates a dialectical understanding, which is informed by and attributes value to the concrete socio-spatial struggles that have already transformed capitalist accumulation. 


\section{Methodological framework}

In my dissertation, I develop an extended case study to analyze: 1) how global forces of capitalist accumulation settle in particular locations for the appropriation of gold-bearing grounds required to supply the capitalist economy; and 2) how local modes of regulation develop responses to assimilate, negotiate, or resist place-making projects. I then ask how institutional forms come into being and/or act to produce particular places as mining enclaves, and how the spatial restructuring of resource regulation transforms the accumulation regime at different scales.

To answer these questions I explore the production of space and the spatiality of resource regulation in the gold mining enclave of Zaruma and Portovelo over the long term, from 1860 to 1980 . My methodological premise is that the production of space is a situated practice. Hence, the mode of regulation assumes radically different historical and geographical forms within each configuration of capitalist accumulation. On this basis, transnational mining companies, if they respond to the international demand for raw materials and require national alliances to ensure surplus outflows, do not indiscriminately "penetrate" but, rather, negotiate the conditions for their deployment. To explore this hypothesis, my research is focused on three intertwined spatial aspects of 
resource regulation: the production of space at the mining enclave, the evolution of mining codes, and the spatiality of state practices.

Rather than relying on general assumptions about modes of regulation, resource-based state formation, and the local politics of capitalist accumulation, I attend to the more genealogical and geographic aspects of this question. This suggests looking at resource regulation as an expression of juxtapositions, disjunctions, and contradictions among different sources of power, where multiple power relations are expressed through struggles and confrontations to enforce or resist exploitation and domination at various scales (Jessop 2007). An ethnographic approach facilitates understanding local modes of regulation, since it provides the tools for exploring the entanglements of power relations of capitalist accumulation (Bridge and McManus 2000; Li 2007; Watts 2003). Underpinning my work is a commitment to the production of a theoretically informed case study that sheds light on the interconnections between global forces and local processes that transform places for capitalist accumulation.

In this chapter I present the methodological approach and research methods applied in my doctoral investigation. I begin with an explanation of ethnographic and genealogical perspectives, which reject a linear description of institutional roles and responsibilities in favour of a more complex and scalesensitive understanding of the imbrications between the social production of space and local modes of economic regulation. The remainder of the chapter focuses on the methods, sources, issues, and challenges faced during different 
stages of research. The reflexive combination of theory, methods, and sources has been critical in defining the methodological insights that guide this research.

\subsection{Extended case study}

In my research I applied an "extended case study" methodology whereby "place becomes a launching pad outward into networks, backward into history and ultimately into the politics of place itself" (Gille and ÓRiain 2002, 287). The extended case study methodology comes from sociology, through work spearheaded by Michael Burawoy. The methodology facilitates an explicit attention to scale as produced through material practices and their associated discourses and power relations (Hart 2009). The extended case study involves implicit criticism of positivist science and offers, instead, a research paradigm around the micro-macro tensions of global capitalist accumulation (Burawoy 1998; Gille and ÓRiain 2002).

My research is situated within a trend of analysis designed to understand how global forces of capitalist accumulation settle within particular locations and how local modes of regulation develop responses to assimilate, negotiate, or resist place-making projects associated with the global expansion of capitalism. ${ }^{17}$

17 Burawoy (2000) signals that studies within this framework tend to cluster around three main criteria: global forces, global connections, and global imaginations. 
However, as Gille and ÓRiain $(2002,279)$ assert, place-based and ethnographic research faces a basic constraint, because the "actors and places being studied are caught up in a place-making project constituted well beyond their influence that can hardly be shaped by them - although they may develop complex forms of adaptation, avoidance, and survival." In this case, national and local actors serve the advancement of global capitalism, which requires national mediators to transmit interests and values. Locality can only resist or adapt. This tension produces discourses, imaginaries, and accounts that mystify capitalist accumulation and external domination.

From a historical perspective, Comaroff and Comaroff $(1992,32-33)$ point out that "[e]ven macro-historical processes — the building of states, the making of revolutions, the extension of global capitalism - have their feet on the ground." For these authors, ethnography is a mode of observation that avoids explicit narratives and generally accepted models of historicity of non-Western societies to explore how the concrete processes and meaningful practices of people at different levels shape economic and political super-structures. Global forces — such as colonialism, capitalism, modernity, and neoliberalism — are themselves the product of contingent social processes that get grounded and shaped through flows of peoples, ideas, and things that establish connections among multiple sites. Following this thinking stem, I maintain that structure and agency, and the local and the global, should be understood not as antagonists but rather as interconnected for a thorough analysis of the historical and spatial restructuring of resource regulation. 
Rather than "doing" ethnography, I adopt an ethnographic lens to the historical and spatial restructuring of resource regulation. This perspective acknowledges that the analysis being presented is not a "correct" representation of people and processes, but one that is informed from my point of view as researcher. In applying the extended case study, I seek to extend observations over time and place, from local processes to external forces, while also extending theoretical references, and including multi-sited archival research (Burawoy 2000, 25-28). My observations are centered on a concrete place - the Portovelo mining enclave - to explore the institutional forms, the multi-scalar forces, and the actors at work in the production of space. This attempt goes beyond contextualized locality studies of industrial restructuring. ${ }^{18}$ This methodology allows for delving beneath abstract concepts, such as the "regime of accumulation" or the "mode of regulation," to examine the mediating institutional forms and the specific instances involved in the restructuring of regulation.

Extended case studies that adopt historical, geographic and ethnographic approaches - with different levels of immersion and use of archival material involve the interplay of different values and knowledges. Reality is never fully captured by the observer, as perceptions and practices differ across time, space,

18 Locality studies have been questioned for inducing to a "spatial trap" that focuses on descriptive and empirical studies over a more theoretical analysis, see the discussion between Smith (1987) and Massey (1991). 
and culture. In practical terms, all research is guided by prior knowledge, and extended case studies demand a critical lens in order to avoid moulding the world we study "so that it conforms to the framework through which we observe it" (Burawoy 2000, 28). Moreover, the researcher gets to tell the story, which distorts the mutuality of the exchange. Therefore, I also adopt an ethnographic approach to archival research and use oral history to complement the analysis (see section 3.3). Herein, I recognize the subjectivity of all academic work and emphasize that this study is my personal interpretation of the subject at hand which, I hope, will contribute to the production of knowledge in this field.

A corollary to the above is the recognition that archives in and of themselves deserve an ethnographic approach. Public and personal repositories are not only a source of information but also sites in the production of knowledge (Derrida 1995; Gracy 2004; Stoler 2002). Archives are not an aseptic collection of historical facts or a source of objective historical evidence but the institutional validation of social memory. On the one hand, the archival materials determine the language we can use to describe them, whether to reassert "scientific" history, to recover subaltern voices, or to disrupt standard historical interpretations. On the other, the theoretical background, the experience, and the personal condition of the researcher (in terms of race, gender, and origin) condition the "findings" (Burton 2003; Smith 1995). The selective use of particular repositories and archival materials denotes a political project and leads to rethinking the parameters by which each of us writes history. There is an 
embodiedness and a reflexivity in archival research, which I make explicit in further sections.

Exploring the social production of space not only uncovers the impact of global forces on local settings, but is also a means of understanding how local processes are constitutive of socio-spatial, political, and economic relations at a global scale. Thus, the deployment of critical conceptions of spatiality allows for analyses that go beyond binary concepts embedded in the abstraction of global capitalism or the empiricism of locality studies (Cox 2005; Massey 1991; Sayer 1991; Smith N. 1987). The extended case study goes beyond locality studies to enable a non-positivist understanding of the case at hand by paying attention to how the places, jurisdictions, and scales involved are constituted and connected in relation to one another through power-laden practices, along with slippages, contradictions, and possibilities for alliances (Hart 2001, 21). In this case, my aim is to disturb the apparent unity of the mining enclave, make evident the juxtaposition of partial forms of regulation, and explain how spatial regulation emerges out of concrete struggles across scales.

\subsection{Genealogical approach}

Foucault $(2010,156-157)$ argues that state and society have no unitary existence but, rather, express a juxtaposition, liaison, coordination, and hierarchy of different, specific local and regional powers. He suggests that "by deinstitutionalizing and de-functionalizing relations of power we can grasp their 
genealogy, i.e. the way in which they are formed, connected up with each other, develop, multiply, and are transformed on the basis of something other than themselves" (Foucault 2007, 119). This view leads to "free[ing] relations of power from the institution in order to analyze them from the point of view of technologies; to distinguish them also from the function, so as to take them within a strategic analysis; and to detach them from the privilege of the object, so as to resituate them within the perspective of the constitution of fields, domains, and objects of knowledge" (ibid., 118). Understanding the dynamic processes by which places are constitutive of, and transformed by, global forces demands accounting for the history of the locality and of extra-local social relations that lead to the emergence of particular regulations.

The application of what Foucault calls a genealogy implies moving away from the linear account of regulatory frameworks towards a "coupling of scholarly erudition and local memories, which allows us to constitute a historical knowledge of struggles and to make use of that knowledge in contemporary tactics" (Foucault 2003, 8). This requires detaching analysis from scholar objectivity to embrace multiple sources as legitimate for understanding the mechanisms at work in the formation of institutional frameworks. By focusing attention on details emerging from meticulously and patiently documented historical narratives, genealogical accounts help reveal the discontinuous processes, inconsistencies, false appraisals, and uncertainties which come together to produce a particular phenomenon (Foucault 1984). This insight calls for a critical approach to analyzing the ensemble of institutions involved in the 
codification of social relations, in order to uncover the internal contradictions, struggles, and tensions in the mode of regulation. Power and knowledge are expressed, reified, and transformed through institutional forms. Yet, the very nature of the institutional forms under examination needs to be questioned.

In this dissertation, I make use of a genealogical approach to reveal the continuities and transformations in the spatiality of resource regulation, thereby denaturalizing assumptions about institutional forms and legal entitlements. My goal, then, is not to trace the institutional relationship between resource extraction and resource regulation back to its colonial origins and legal responsibilities but, rather, to look at critical episodes that reveal power relations that transform the concepts, procedures, and discourses aimed at the regulation of extractive industries. It is worth noting that I am not working to historicize mining laws in Ecuador but, rather, to try to understand the emergence and endurance of multiscalar relations of power that could illuminate possibilities for change and resistance in the regulation of the mining industry in the present.

\subsection{Research methods}

This section includes a critical discussion of the research methods and the primary sources that inform the dissertation. The fieldwork for the doctoral investigation included a scoping visit to Zaruma and Portovelo in June 2011; intensive fieldwork in Ecuador from June to August 2012; a one-day visit to the Ecuadorian Consulate in New York in June 2013; a four-day trip to Boulder, 
Colorado, in May 2014; and a second round of archival research in Ecuador between October 2014 and January 2015, to identify and collect materials necessary to fill gaps in the overall analysis. In June 2015, I participated in an artistic residence organized by graduate students and professors of Western University. This activity gave me the opportunity to see the history of Portovelo and Zaruma from a new perspective and figure out novel ways of engaging with my own academic work. I also consulted online databases and processed digital materials between September 2012 and January 2015. During the investigation, I employed four principal methods: literature review and periodization, semistructured interviews, archival research, and discourse analysis.

\subsubsection{Literature review and periodization}

The first challenge was deciding how to approach and periodize this longterm study. Whereas the existence of the mining enclave might lead to a selfevident choice of the period of study - SADCO worked the mines between 1896 and 1950 - modes of regulation and socio-spatial articulations extended over a longer period. A critical approach to periodization supposes that periods do not exist in and of themselves. Furthermore, "the history of space may be expected to periodize the development of the productive process in a way that does not correspond exactly to widely accepted periodizations" (Lefebvre 1991, 53). The duration and roles of external forces and local processes engaged in the production of space cannot always be precisely defined. I have chosen the periodization used in these pages in order to provide an analytical lens for 
understanding the continuities and transformation of spatial forms in terms of internal and external factors at both an empirical and a theoretical level.

In doing so, I followed Clarke (1992), who notes that periodization is an attempt to find a middle way between empiricism, which stresses historical contingency, and reductionism, which stresses dogmatic fundamentalism. Within political economy and regulation theory, the tendency is to link dominant regimes of accumulation to changing forms of statehood and class struggle. This attempt tends to reduce the activity of the state to an expression of needs functional to accumulation and ignores the internal contradictions within the state as well as the multi-scalar process in the regulation of capitalist accumulation. Furthermore, regulation theory highlights the role of crisis and rupture in visualizing contradictions and qualitative change in institutional frameworks. Therefore, periodization entails the question of whether to isolate the times of crisis and transition or to integrate them within a broader explanation of the dominant mode of accumulation and social regulation.

Any periodization presupposes regularities within a particular historical epoch and a theoretical approach that risks the economic and political over determination. However, capitalism and state-formation do not occur in a homogeneous and progressive fashion across space and through time. The complexity and juxtaposition of socio-spatial relations and modes of production produce myriad contradictions in modes of regulation at different scales. This being the case, a critical approach to social regulation should lead to questioning 
the chronological nature of historical time. To avoid producing a narrative of the fatalistic determinism of extractive capitalism, I argue for the need for an ethnographic lens which explores historical tendencies and geographical contexts involved in the regulation of the mining enclave. With such a perspective, the analysis moves away from a linear interpretation of "stages" or "phases" of capitalist development to explore the disjunctive and multi-scalar interpretation of historical events. Thus, I adhere to the notion that multiple temporalities and spatialities coexist in any given moment and place (Koselleck 2002; Massey 2005; Munn 1992).

The periodization of the gold mining enclave is nothing more than an academic exercise or an account of a local phenomenon without significance in a wider context if it is not linked to a broader reflection about the history of capitalism and state-formation in Ecuador. In this regard, the theoretical framework provides for analysis of theories of capitalist development in the world and the specific spaces where capitalism acquires materiality. I argue that periodizing the restructuring of local resource regulation in places such as Portovelo and Zaruma goes beyond understanding a particular mode of production and relates, instead, to the dynamic - and sometimes contradictory - coupling between the regime of accumulation and the creation of partial modes of regulation at different scales. The production of space encompasses the creation, transformation, and enforcement of regulatory practices, which are selective in their temporal and spatial manifestations. As a result of my 
methodological approach, I was able to redefine, to some extent, the overall periodization of resource regulation in Ecuador.

As a first step, I compiled a multi-scalar chronology relevant to the case of Zaruma and Portovelo. Local historians had already identified key moments in the socio-spatial transformation of the mining enclave (Andrade 1911, 1923; Anda 1960; Cortázar and Lavanda 2008; Mora 2008; Murillo 2000, 2003; Rueda and Romero 2002; Rodríguez 1992a; Sáenz de Tejada [1892] 1975). In addition, regional accounts include information on the transformation of power relations in the southern Andes (Fauroux 1983, 1984; Palomeque 1994; Jaramillo Alvarado 1955). Interviews also helped me to identify key events, influence peddling, and policy responses used to address social demands and economic pressures. I used written memories that describe the early origins of the mining enclave to contextualize everyday life in that space (Kellogg 1933ca.; Schraps n.d.; Williams n.d.).

A chronology was also needed to identify national regulatory frameworks, namely, constitutional and legal reforms, which modified entitlements and responsibilities for resource governance. I was unable to develop this thread of analysis with existing studies alone as they tend to privilege the colonial period (Sempat 1980, 1982), geological characteristics (UNDP 1969; Paladines 2005; 
Wolf [1892] 1975), the socio-environmental problems associated with artisanal mining (Sandoval 2002; Tarras-Wahlberg 2002), or the recent development of the mining sector in contemporary Ecuador (Acosta 2009; Anderson 2004). ${ }^{19}$ Hence, the main sources for my analysis have been, primarily, legal and government documents: legislative debates retrieved from ABANE and the online legal database eSilec.

In my chronology, I analyzed international processes in the transformation of regimes of accumulation, including industrial geographies of the mining sector (Bluestone and Harrison 1982; Bridge 2009; Dinius and Vergara 2011; Hayter 2000; Humphreys 2010; Lucas 2008; Schmitz 1986) and the restructuring of capitalist modes of regulation (Brenner 2004; Harvey 2005; Peck and Tickell 2002; Swyngedouw 2004). Finally, works by Bordo (1993), Eichengreen and Flandreau (1997), and Morse (2003) were particularly relevant in understanding the changing value of gold at the international level.

In addition, I explored efforts to periodize modes of production, political regimes, and socio-spatial transformations in Ecuador throughout the $20^{\text {th }}$ century (Acosta 1995; Ayala Mora 1995; Cueva 1981; Deler 2007; Hurtado 1980; Quintero and Silva 1991; Maiguashca 1994; Moreano 1976; Ramón and Torres

19 The references provided in this paragraph reflect overall debates; they do not constitute a comprehensive bibliography. I provide a more detailed account of some of the problems associated with resource governance in the pages that follow. 
2004; Velasco 1981). From a political economy perspective, Ecuador has been characterized as a staples economy and regional state. Indeed, the national economy has been articulated around the production of cacao (1860-1920), bananas (1948-1965), and oil (1972-present). Regionalism continues to be a political phenomenon that cannot be reduced to conflict between or among local economic interests. What is more, power struggles occur at different times in different places, which suggests that regional and national socio-economic and political dynamics might not coincide at all times and in all places (Maiguashca $1992,180) \cdot{ }^{20}$

In light of the above, I developed four analytical periods, all related to the spatial regulation of the gold mining enclave: enabling conditions beyond local settings (1860-1895); socio-spatial production of the mining enclave (1895-1950); national restructuring of resource regulation (1925-1950); and decentralization of social externalities and the subsequent creation of administrative jurisdictions (1950-1980). The chapters are organized according to these themes and

20 The conservative government of President García Moreno (1861-1865; 1869-1875), the liberal regimes of Eloy Alfaro (1895-1901; 1906-1911), the structural policies of Isidro Ayora (1926-1931), the populist administrations of Velasco Ibarra (1934-1935; 1944-1947; 19521956 ; 1960-1961; 1968-1972), and the military administration of General Guillermo Rodríguez Lara (1972-1976) radically transformed the institutional apparatus and political articulations between state and society. Although less prominent for Ecuadorian historiography, the administrations of José María Plácido Caamaño (1883-1888), Luis Cordero Crespo (1892-1895), Federico Páez (1935-1937), and General Alberto Enríquez Gallo (1937-1938) were particularly significant for the mining sector as they introduced or reformed mining codes in a way that was critical for the development of this industry. See Appendix D. 
historical junctures, which makes the rescaling of resource regulation and a restructuring of state apparatus more evident. But this account does not pretend to be a single linear narrative. Rather, I focus on both continuities and change. On one hand, the production of space is path dependent; on the other, the spatial restructuring of resource regulation overlaps and interplays with multiple processes occurring at different scales.

\subsubsection{Semi-structured interviews}

Oral sources complement written materials. Whereas the latter have been produced primarily by the ruling classes, the former help "reveal unknown events or unknown aspects of known events" so as to "cast new light on unexplored areas of the daily life of the nonhegemonic classes" (Portelli 1991, 50). I conducted 28 interviews with public officials, researchers, community leaders, and residents of Zaruma and Portovelo. I selected key informants on the basis of their professional expertise or personal experience. I gained access to informants through public officials and my research networks in Ecuador. Informants, in turn, suggested further contacts.

During interviews I explained the project objectives and methods and asked for oral consent prior to recording; I promised all interviewees would remain confidential. At times, compliance with anonymity — in keeping with the procedure of Carleton's Ethics Board - meant that I cannot credit sources for their contributions to the research project. With one exception, I conducted all interviews in Spanish. 
According to Portelli $(1991,54)$, the information provided by oral sources depends, in large part, on the questions the interviewer asks, the dialogue that takes place, and the relationship developed by both parties to the interview. Interviews conducted in the context of oral history are often suspect: their authenticity and validity as historical evidence are sometimes questioned (Burton $2003,24)$. In-depth interviews frequently raise criticism related to researcher bias, subjectivity, liability, and generalizations from findings based on statements by a few individuals (Hoggart, Lees, and Davies 2002, 202). Nonetheless, the interviews also help fill gaps in knowledge, identify differing opinions, and reflect the orientation of the research project.

In-depth interviews were designed to deepen the "investigation of empirical linkages among local settings of everyday life, organizations and translocal processes of administration and governance" (DeVault and McCoy 2006). I used a semi-structured protocol, which included variable topics and questions evolving out of the initial questionnaire. This allowed interviewees to explain in detail their opinions, to make connections, and to introduce other ideas (see Appendix C). In addition, informal conversations with multiple actors helped to redefine the scope and reach of the overall investigation. Through interviews I, as researcher, was able to "derive a more nuanced understanding of the meanings of social acts, as well as a greater appreciation of interacting and contextualized rationalities that impact on behaviour" (Hoggart, Lees, and Davies 2002, 202). 
The interviews introduced a certain level of flexibility in comprehending the production of space and the spatiality of resource regulation. I used interviews primarily to reconstruct narratives, perceptions, and understandings linked to resource governance and everyday life in the mining enclave for the period between 1950 and 1980, when CIMA was running the mines, as this is the historical period for which witnesses who are still alive are able to share their memories. The interviews I conducted for that timeframe reveal changes in the spatiality of the mining enclave and the transformation of regulatory practices, particularly how workers' struggles and institutional policies transformed and shaped the politics of space. Overall, interviewees remember SADCO's period as a time of regional progress despite labour exploitation. However, when it comes to CIMA, the narratives include many silences and side comments about corruption and the absence of a socially progressive initiative. The oral accounts helped refine the overall periodization, provided leads for further archival research, and challenged me to explore the meaning and subjectivity of social relations that influenced local politics but remain unmentioned in official texts.

\subsubsection{Archival research and historical sources}

Archival research is the key method in my analysis; without archival sources, the spatial exploration of resource regulation restructuring over the long term would be impossible. Genealogical studies depend on the vast accumulation of historical sources in order to question hegemonic narratives and examine contradictory evidence, explore emergent processes, and question the 
heterogeneity of what was imagined consistent with itself (Foucault 1984, 82). In the course of my extended case study, I did not confine my archival research to a single location but, instead, visited multiple sites and consulted multiple sources to get perspectives from diverse actors and scales.

Institutional archives, personal records, and online databases are not innocent collections of disparate materials. The selection, classification, hierarchy, and display of historical documents reveal a cumulative institutionalization that gives the greatest authority to those who possess, organize, and allow access to their contents (Derrida 1995; Stoler 2002, 91). In addition, the selection and analysis of historical material creates a representation of the past through the eyes of the present, through what is available to the researcher, and what the researcher prioritizes as a relevant account of the past, making the material used a selection of a selection. Therefore, archival research is a mediated process whereby power structures, dominant narratives, archival techniques, and casual references shape access to historical material.

The archival research was iterative and incremental, thrilling but timeconsuming. The research process was influenced by my own expectations, experiences, skills, and lack of formal training as a historian. There are very few digital repositories or computerized catalogues in Ecuador, and the archives I used did not include registers organized according to topic, so that when I had access to historical material, I often had no clue as to where to begin. Thus, patience and determination were fundamental to making connections and 
gathering details. At times, a casual encounter with historical documents and photos led to the compulsive and unstructured accumulation of evidence to support the active role of the locale in the transformation of resource governance.

The breadth, subtleties, and complexity of archival material led me to reconsider my methodological approach. While in the initial proposal I emphasized identification of municipal discourses and practices in the regulation of the mining industry, I have since shifted that emphasis to a multiscalar analysis of the spatiality of resource regulation, without by any means omitting the role of the municipality. In my research strategy I came to focus on moments of crisis and transformation, which represent keys to analyzing "the variation in the objects, subjects, purposes, and technologies used for governing, the selection of some technologies and practices over others, and the retention of some of these to the extent they are integrated into state or class strategies" (Jessop 2008, 151).

The materials I have assembled cover the period from 1822, when the municipality of Zaruma came into existence, to the 1990s, when the mining enclave was finally dismantled. The historical material comes from various repositories, as I will explain below, and includes 8,227 folios and 517 historical photos in digital format; 57 documents with historical relevance: 145 laws, 
decrees, deeds, and normative debates; ${ }^{21} 352$ articles published in local, national, and foreign newspapers and journals; plus other materials, such as maps, diplomas, videos, and music (see figure 3.1).

Figure 3.1. Number of documents by type and archival repositories

\begin{tabular}{|c|c|c|c|c|c|c|}
\hline Archive & Folios & Documents & Regulations & Photos & $\begin{array}{l}\text { News } \\
\text { Articles }\end{array}$ & Other \\
\hline $\mathrm{AHM} / \mathrm{Z}$ & 6133 & 6 & 2 & 63 & 299 & \\
\hline BM/P & 320 & & & & & 15 \\
\hline ETSA & 799 & 12 & & 281 & 6 & 6 \\
\hline eSILEC & & & 118 & & & \\
\hline ANE & 309 & & & & & \\
\hline Al-MPS & 412 & & & & & \\
\hline BEAEP & 130 & 8 & & & & \\
\hline CIGMA & 5 & 12 & & & & \\
\hline MREMH & 20 & 5 & & & & 11 \\
\hline $\begin{array}{l}\text { Ecuadorian } \\
\text { Consulate in NY }\end{array}$ & 70 & & 3 & & & \\
\hline AH-MC & 3 & 6 & & 48 & & 2 \\
\hline ABANE & & & 22 & & & \\
\hline Romero Witt & & & & 58 & & \\
\hline Rodríguez & & & & 46 & & 10 \\
\hline Cortázar Crespo & & & & 20 & & \\
\hline Other repositories & 26 & 3 & & 1 & 47 & 8 \\
\hline TOTAL & 8227 & 57 & 145 & 517 & 352 & 52 \\
\hline
\end{tabular}

21 The "folios" refer to municipal ordinances, minutes, debates, communications, and other handwritten documents I retrieved, mainly at AHM/Z, ETSA and AI-MPS. 
Analyzing thousands of documentary sources from different times, scales, and repositories is an enormous challenge. Initially, I attempted using qualitative research software for data reduction (Cope 2010, 283). However, the processing proved to be much more complicated than expected. To a large degree, I learned by trial and error. While technological aids were helpful in handling materials, organizing documents into files classified by source, period, descriptive topic, and conceptual category, the amount of work required to digitalize, process, transcribe, and code each text or photo was beyond the requirements of this dissertation. Nonetheless, thanks to that effort I was able to evaluate and reorganize my field research, in terms of both descriptive processes and critical reflections, based on questions regarding the "naturalness" and relevance of the initial categories. My supervisors' suggestions regarding a more selective use of archival sources and the structure of the dissertation helped me focus efforts on what was needed for a more rigourous analysis. Subsequently, I patiently read documentary material to identify information relevant to my argument.

As a result of this research experience, I now approach archives with a deep respect for the documentary sources they may contain and the systematic effort required to analyze the information. Looking back at my files and work with archives, I can identify moments of exhaustion that have been captured in poorly centred or blurry photos. The shadows and textures of the table in the background bring back episodes of the working process, when a tropical storm dimmed the light or when I had to move books to the open corridor as there was no space for me to work in the municipal office. The sound of the rain, the sight 
of the midday sun, and the colourful sunsets made me wonder how people experienced everyday events while writing or typing those documents. Today I understand the importance of having a journal to keep track of ideas that emerge while going through documentary material for the first time; those ideas can guide analysis and such a journal would also help in subsequently deciphering issues in the coding process after leaving the archive. I also appreciate the importance of having more than one camera, an extra memory card, and an extra battery, especially while working at times or locations when power outages were common. ${ }^{22}$ I also learned the importance of using gloves and a mask, carrying hand cream, and seeing a doctor to deal with dust mites.

Archival repositories have, in themselves, a story to tell, even through their absences. There are no formal corporate archives for SADCO or CIMA.

Theoretically, the central government kept the materials when the concession reverted to the state in 1980; those documents were not available during my

22 At different stages I used the following cameras: Sony (DSC-W120), Sony (DSC-HX10V), Nikon (D5000), and in few cases the iPhone camera in situations in which by chance (and unprepared) I came upon documentary materials relevant to my study. Most photos were shot in black and white in JPG format. Using the larger camera does not mean getting better photos of documentary materials: it is heavy to handle, casts a bigger shadow, and the autofocus takes a few seconds longer. Taken together, these minor details make working unpleasant. The processing stage included sorting, naming, and coding the photos. In the case of full text documents, I reduced the size of images (without sacrificing readability) to merge them into PDF files. Later I learned - from the visual artists participating in the artistic residence in Portovelo - that good quality pictures of photographic material require laying the picture under a non-glowing glass, illuminating the area with diffuse light, and using a $50 \mathrm{~mm}$ prime lens, placing the camera on a tripod, with ISO 100, and shootoing with a remote trigger. Shooting in RAW captures data that is otherwise compressed if using a JPG format. 
investigation. The industrial facilities were razed during the late-1990s and the American head shaft, symbol of the mining enclave, was dismantled in 2001. The repositories described here were those of greatest significance throughout the doctoral investigation; references to other locations containing corporate and contextual documents are indicated throughout the dissertation.

\section{The municipal archives of Zaruma and Portovelo}

Most of the documents used in this doctoral investigation are from the Archivo Histórico Municipal de Zaruma (AHM/Z, Historic Municipal Archive of Zaruma). The collection includes board minutes, ordinances, annual budgets, annual reports, official correspondence, publicity brochures, photographs, and local newspapers. Archival fieldwork consisted of a systematic review of all minutes referring to mining, debates pertaining to the annual budget, and references to the most relevant events during the period under study. Documents available at the time of my investigation covered the years from 1822 to 1992.

The history of the archive reveals moments in the formation of the municipal government and the transformation of the local public agenda to legitimize local powers. The documents were collected, numbered, and bound in 1945, when the municipality of Zaruma experienced a period of prosperity and institutional consolidation due to extraordinary income from mining royalties. In 
that year, Juan F. Ordóñez, municipal secretary between 1940 and 1959 and again in 1966, took the initiative to compile the minutes of the Municipal Council of Zaruma. ${ }^{23}$ The municipal minutes, handwritten in blue or black ink on lined paper, recorded political discussions, regulatory debates, and budgetary decisions from the creation of Zaruma in 1822 as one of the first administrative jurisdictions established after independence from Spain. In 1947, a palaeographer visited the archives and provided advice on their maintenance. Thereafter the bound volumes were kept at the office of the municipal secretariat. In Ecuador there are few institutions with this wealth of historical documentation, as the norm requires that most public files be kept for only five to ten years. The volumes are well maintained, though some have traces of insect and moisture damage. The specific subjects and overall organization of board minutes vary from one administration to another. Most significantly, the municipal budgets are recorded only up to the early-1950s; subsequent records do not include appendices specifying how funds were allocated. The proceedings have few annotations or revisions; some include spelling and grammar corrections, and others have notes on visits by previous researchers and the specific topics they were interested in.

23 In 1933, while serving as senior clerk to the municipality of Zaruma, he arranged the minutes, organized the volumes from 1824 to 1931 , and filed them in a new cabinet. See: AHM/Z. MMC, T.13, unbound folio with a typed note signed by Juan F. Ordóñez R. 


\section{Figure 3.2. Files of the Municipal Archive of Zaruma}
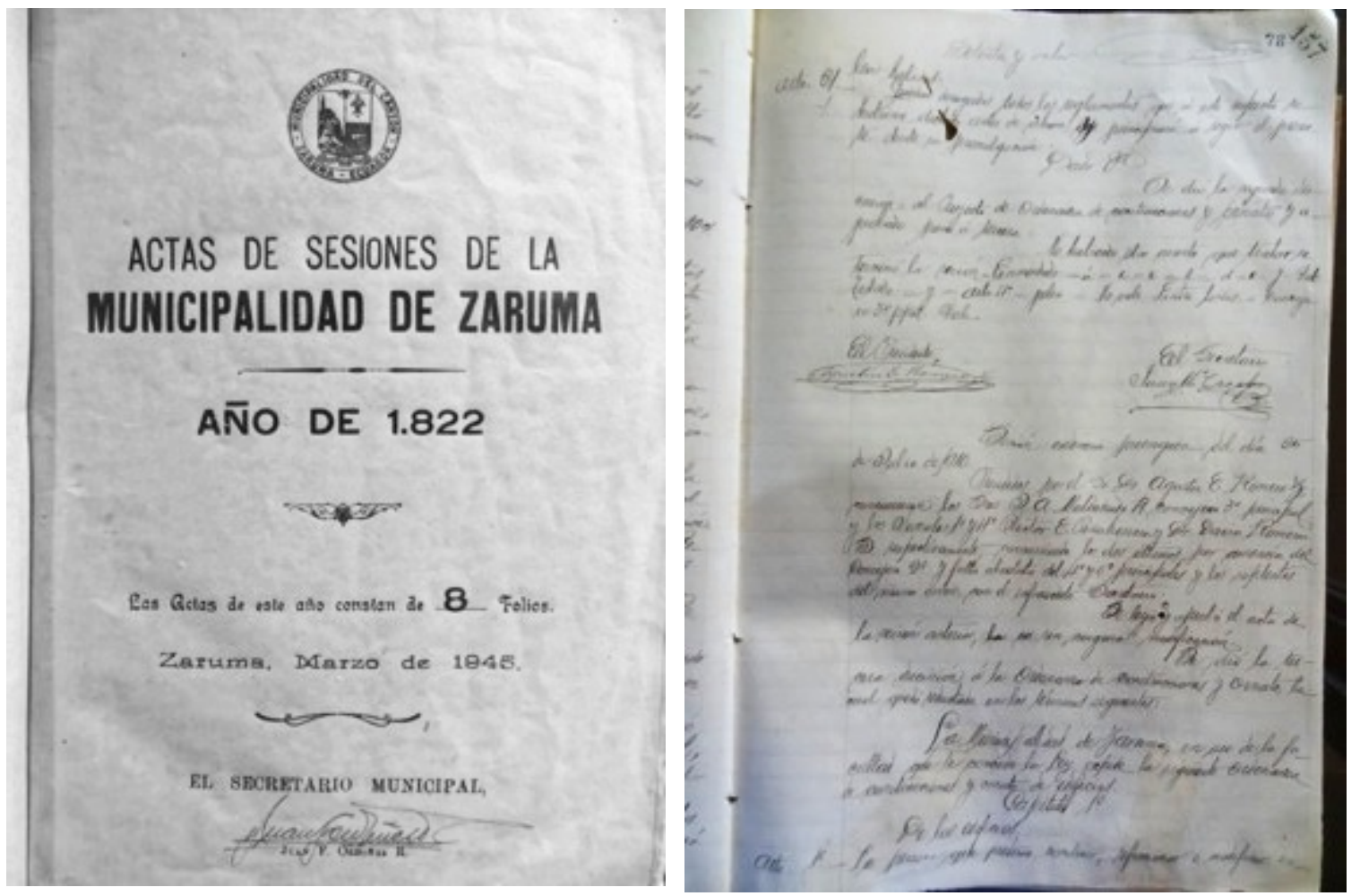

Note: To the left, the first page of the first bound volume of municipal board minutes. The text reads: "Minutes of meetings of the municipality of Zaruma. Year of 1822. The minutes of this year consist of 8 folios. Zaruma, March 1945. The Municipal Secretary. Juan F. Ordóñez R." To the right, an example of the handwritten minutes, this one referring to the council resolution approving the Construction and Beautification Ordinance that will have a deep impact on the urban landscape (see section 5.2). A snapshot of this page is also included in Rueda and Romero (2002). At the time of my research, ten years after that publication, termites had perforated the volume and there were bits of scotch tape on many pages.

Source: AMH/Z. Minutes of the Municipal Council (hereafter MMC), T.13, July 23, 1910, 78.

In 1980, Zaruma's Municipal Council approved the resolution passed at the First Meeting of Municipal Secretaries, held in Cuenca, recommending that "the minutes of meetings be modernized and typed in duplicate, eliminating the 
former manuscript system." ${ }^{24}$ This decision was taken during the consolidation of the Ecuadorian Association of Municipalities and the modernization of public administration, coinciding with the return to democracy in 1979 .

In 2000 , a consultant group hired by the municipality of Zaruma undertook studies to nominate the city as a UNESCO cultural heritage site. The process included production of a history of the township. A group of local historians found colonial and early republican documents pertaining to administration and trials in the Archivo de la Curia Arquidiocesana de Cuenca (Archive of the Archdiocesan Curia of Cuenca). Efforts by Ruth Boas, former municipal councillor, and Lorena Carrión, head of the Heritage Office that sponsored the initial studies, helped raise money to acquire and preserve the material. The municipality purchased copies of these documents and trained two public officials in the preservation of historical documents. This is when the documentary collection was formally named the Archivo Histórico Municipal de Zaruma Juan Ordóñez (Juan Ordóñez Historical Archive of the Municipality of Zaruma), in honour of the municipal secretary who, in 1945, began the process.

Thereafter, the Heritage Office recovered materials scattered throughout the municipality in storage rooms, warehouses, and cabinets, and negotiated the

24 AHM/Z. MMC, T.80, February 20, 1980; front page, typed, signed, and stamped by Jorge A. Reyes Samaniego, Municipal Secretary. 
donation of private files to the municipal archive. This repository includes newspapers in which articles on local politics point to the disjuncture between the dominant rhetoric and accounts by leftist movements. The physical collection includes five albums with photos, pamphlets, and greeting cards. There are also binders with communications sent and received, although I consulted only a few of these. In addition, there are unclassified digital materials, including photos, videos, planning documents, and an inventory of heritage buildings.

In 2011, a few months prior my arrival to Zaruma, the National Heritage Institute fumigated the board minutes as part of a national policy implemented by the current government that seeks to identify and preserve material of historical value. In 2013 , the municipality moved the repository to a refurbished location in the Casa del Herrero, and the National Ministry of Culture and Heritage financed a project to digitize some of the material. Access to the historical archive is open to the public on request; to date, few researchers have used the material.

Overall, the very shape and content of the municipal archive reveals the history of projects, the practices and constraints of public administration, and the restructuring of state space in the course of a century. The content of board minutes indicates changes in topics relevant to local politics, the channels of national influence, and the problematization of national regulations. The archive is also telling for its silences and omissions, much of it due to an administrative and hierarchical structure controlled by local elites. The regulation of the mining industry included conflicts which are not always recorded in official documents. In 
such instances, newspapers and the claims of labour organizations kept in other archives provide competing political discourses and criticisms, which I found particularly relevant in identifying moments of crisis, conflict, and change.

The Biblioteca Municipal de Portovelo (BM/P, Municipal Library of Portovelo) has four volumes of minutes of the general meetings of the Unión de Trabajadores Accionistas de Portovelo (UTAP, Portovelo Workers' Shareholders Union), which co-managed the mines between 1951 and 1977. The volumes are the only public record left by the labour organization, corresponding to the years $1951,1955,1960$, and 1966-1969. The spine of the first volume includes the inscriptions "Journal" and "SADCO", Corlies, Macy and Co. Incorporated, New York, a reminiscence of the assets of the American company. The communications are numbered, indicating familiarity with administrative techniques and union practices for regular meetings. The content of these volumes fills some of the silences in the municipal minutes, with information on organizational challenges, internal divisions, and the party politics of shareholders.

The municipality of Portovelo, created in 1980, does not have a formal archival repository. The Municipal Secretariat has binders with board minutes and other materials related to local administration. While I was doing fieldwork, municipal offices were abuzz with rumours of corruption and patronage. The reigning distrust towards investigators resulted in restricted access to official 
documents. This situation limited access to only one binder, with municipal documentation from 1981 to 1983.

\section{The private collection of SADCO's General Manager}

Andrew Mellick Tweedy, general manager of SADCO, collected memorabilia, photographs, $16 \mathrm{~mm}$ black and white film, and personal documents, including frequent letters written to his wife, Florence, while he lived in Portovelo and travelled around Ecuador between 1917 and 1943. The Tweedy family also kept memoirs and photos from other Americans with whom they established friendships during their time at the Portovelo camp. Elizabeth Tweedy Sykes, daughter of A.M. Tweedy, preserved and transcribed much of this material after her parents passed away. Around 2000 , another family member, a professional photographer, scanned the original photos, which are mainly snapshots measuring $2 \times 3$ inches. To date, most of the original documents and photos remain in the care of Elizabeth's son, at the Knickerbocker Ranch in San Antonio, Texas.

John Tweedy, Elizabeth's nephew, found the "trove of materials" in 1999. After scattering the ashes of his father, John B. Tweedy, on the Texas ranch, the family gathered to look at the "amazing, beautiful, black and white photos" and 
the old films of his grandfather during his time in Ecuador in the $1930 \mathrm{~s} .{ }^{25}$ This sparked John's interest in his personal roots at a time when he was questioning his legal career; he subsequently decided to venture into film production. John, his wife Beret Strong, and their two children spent a summer in Portovelo and Zaruma, interviewing miners, shooting footage, and gathering material to produce a documentary originally named Mines of our Fathers and later released as Streams of Gold (Tweedy and Strong, 2004). As a result of these investigations, John Tweedy keeps three boxes with photocopies, $3 \frac{1}{2}$-inch floppy disks with digital files, reel logs, newspaper clippings, obituaries, photos, books, and booklets used to produce the film. I gained access to the material after a two-year-long correspondence involving a query for an English copy of the film, a series of questions about the materials on which the documentary is based, doubts about whether the family records were extensive enough to make the trip worthwhile, and, finally, discussion of a mutually agreeable date for a visit.

In the case of this powerful family as in that of many others, private memories served as evidence of political history (Smith B. 1995). Through affectionate words and detailed gossip, the letters denote not only the everyday life of the camp but also the politics that underscored the relationships among SADCO, the American Embassy, the legislature, the national government, and

\footnotetext{
25 John Tweedy, interview, May 27, 2014.
} 
local authorities. Those accounts were particularly relevant to understanding the managers' perspective on contractual renegotiations as well as his dealings with a central government in which executive and legislative branches were involved in a series of crises and divisions.

\section{Legal databases and debates on norms}

The Sistema Integrado de la Legislación Ecuatoriana (eSilec, Integrated System of Ecuadorian Legislation) was the main repository of documents I used to analyze regulatory frameworks and contracts. The eSilec database includes digital versions of the Registro Oficial, the official gazette - established during the Liberal Revolution of 1895 - in which laws, decrees, and other regulatory decisions at the national level are published. The Archivo-Biblioteca de la Asamblea Nacional del Ecuador (ABANE, Archive-Library of the National Assembly of Ecuador) contains a collection of constitutional and legislative debates. These documents were particularly relevant for analyzing the Constitution of 1929 and the restructuring of resource governance in the late 1940s. In the absence of corporate documentation, the laws, legal debates, and other documents published in the official gazette prove important sources for analyzing discursive moments and reconstructing the political history of the economic enclave. The Internet Archive includes the mining laws of the late- $19^{\text {th }}$ century and reports issued by the International Bureau of the American Republics. I did not have direct access to the U.S. archives, but Marc Becker at Truman State University shared some archival documents with me for which I remain very thankful. 


\section{Official repositories and supplementary sources}

There are materials useful for understanding the Portovelo mining enclave in the following repositories. In the Archivo Nacional del Ecuador (ANE) there are documents which aid in contextualizing mining investments, administrative practices, and labour disputes in the southern region; these are found in the "Minas," "Gobierno," and "Ministerio del Interior" sections. Documents related to labour disputes, union organization, and collective bargaining in 1919, 1935, and 1947 can be found in the Archivos Intermedios del Ministerio de Previsión Social (Al-MPS). Small collections of corporate documentary evidence are kept in the Biblioteca Ecuatoriana Aurelio Espinosa Pólit (BEAEP), the Centro de Información Geológica, Minera y Ambiental (CIGMA), and the Archivo Histórico del Ministerio de Cultura (AH-MC). The Ministerio de Relaciones Exteriores y Movilidad Humana (MREMH, Ministry of Foreign Affairs and Human Mobility) has a series of communications from the Ecuadorian Embassy in the United States and the annual reports of the Minister of Foreign Affairs; these documents include references to foreign investors in the country. The Ministry also holds a collection of historical maps. The Ecuadorian Consulate in New York has two volumes of notarized documents from the early $20^{\text {th }}$ century, including documents indicating the responsibilities delegated to SADCO's resident managers.

Murillo $(2000,78)$ recalls that in 1991 , in the ruins of the church built in 1924 , he found a concrete urn containing a lead capsule with 16 sheets of paper with the names of employees, workers, and students, plus a historical account of mining operations until 1924. Presumably people from Zaruma and Portovelo 
have more corporate papers and personal memoirs to which I did not have access while doing fieldwork, although they could well be uncovered by future researchers. ${ }^{26}$

The Quimbalate Mineralogical Museum, established by Magner Turner in Portovelo, contains a variety of mineral samples, mining artefacts, and miningrelated documents, including payrolls, health booklets, work tokens, and Patterson currency. The Quimbalate Museum is a private effort to recover, purchase, and preserve in one place materials that provide evidence of Portovelo's industrial past. Notably, Turner has a map of the potable water project for Zaruma drawn by SADCO engineers in June 1925, and the graphic details of the power house, produced by Charles B. Hawley \& Co. Inc. Consulting Engineers, Washington D.C., and traced from blue prints in February 1929.

Finally, published works and digital repositories, available through the Carleton University's MacOdrum Library and the interlibrary loan system, were very important to my research. Online databases allowed me to explore how

26 At a later stage of my research, in 2015 , I encountered the Cortázar Crespo and the Romero Witt private collections. The latter was in the process of being classified, digitized, and analyzed by the historian Martha Romero. I was also able to see the images and industrial plans kept by Alex Rodríguez, grandson of Enrique Rodríguez, a former employee of SADCO and a local photographer based in Portovelo who shot pictures from the 1950s until the 1990s. 
specific events were reported in the international media, namely, The New York Times, the Mining Journal, and the Spirit of the Age. I also consulted literature at the Simon Bolivar Andean University (UASB), the Latin American Faculty of Social Sciences (FLACSO), and the online repository FLACSO-Andes.

\section{A note on the system of references for photographs}

Working with historical photos from different repositories was a compelling process. I don't know how to frame an image, and photography is not one of my passions. Sometimes observation questions opened new avenues of reflection about social relations in the camp: Who took the photo and for what purposes (photo 5.8)? What can be inferred about social relations within the photograph (photo 6.2)? Why is there a black man at the end of the procession and who is he (photo 6.13)? None of these women is wearing a wedding ring; who are they (photo 6.14)? What were the ecological imprints of the mining industry (photo 5.4)? Looking at the pictures helped me to formulate analytical questions different than those inspired by documentary sources. In doing so, I encountered a wealth of literature that explores the life of static images and the significance of the "corporate eye" (Brown E. H. 2008; Poole 1997; Rose G. 2000; Shedden et al. 1983).

During my interview with John B. Tweedy, he mentioned that his grandfather and other members of the company had cameras and probably had a darkroom for processing the negatives. According to Tweedy, the images circulated among the American and high-ranking Ecuadorian employees, 
although some photos had been withheld from the public eye insofar they revealed lustful behaviour (see photo 5.6). The pictures themselves give no clear indications of the photographers' identities. Prints from personal archives either physical or digital — are rarely dated, although I could sometimes guess based on historical data, the stage of construction or the ages of children. The digital photos of the Tweedy archive had been classified with a coding system based on numbers I could not decipher. However, the historical photos of the $\mathrm{AHM} / \mathrm{Z}$ repository were placed in municipal albums, clearly labelled, organized by year and event, and many included the signature or the stamp of the photographer on the back. The photos preserved in those albums depict civic events, public works, and customs. In the first case, the photos provide a glimpse of affective memories or a corporate view; in the second case, they reveal the authoritative production of visual knowledge.

The politics of memory, preservation, conservation, and distribution of visual images has proved significant in the declaration of Portovelo and Zaruma as national heritage sites and the acceptance of Zaruma's candidacy as a UNESCO cultural heritage site in 1998. In 2005, Mariana Cortázar published one of the first illustrated reports of the history of Portovelo based on the photos compiled by her father, Héctor Rubén Cortázar Coronel (Cortázar 2005). The publication is not accidental. The images that brought John Tweedy to Ecuador began to circulate in 2001. At that time, people were sad about the destruction of the "Pique Americano"; at the same time, there was renewed interest in mining due to foreign investments in the sector in Ecuador. A decade later, the National 
Council for Culture sponsored research and a publication entitled "Imágenes de Zaruma" (Images from Zaruma) explaining the origins of professional photography and depicting the work of two photographers: Ramón Jijón and León Jiménez Ramírez (Cevallos 2011).

I have selected a limited number of photographs to illustrate or contextualize my analysis. Most photos included come from the ETSA and the $\mathrm{AHM} / \mathrm{Z}$ repositories, but they are cross-referenced when available in more than one repository or publication. The system of references for figures does not follow a chronological order but are numbered in sequence by chapter. When available, I have included the name of the photographer, the approximate date, the location, and the title of the photo. These materials merit additional analysis, a potential topic for future researchers.

\subsubsection{Discourse analysis}

The production and regulation of space includes the production of a discourse in/about/of space (Lefebvre 1991, 132). Space is not produced separately from language in a dialectical signifying process. Discourses allow a practical intervention in space insofar as they express power relations and the appropriation capacities of the different actors. Discourses help to modify power relations and condition experiences that reframe the capacities of different actors to appropriate space and profits (Lefebvre 1991, 56-65). In this regard, discourses are modes of social regulation that shape the processes of capitalist accumulation. 
The analysis of discourses includes at least two major trends relevant to my study. One strand, the critical political economy approach, conceives discourses as instruments of hegemony that help impose, conceal, and legitimize the interests of dominant groups (Van Dijk, 1996). Hence, the discourses of the governmental apparatus reproduce dominance, create alliances, and enact forms of power insofar as they represent dominant economic practices and vested interests. From this perspective, discourses are "ways of combining and integrating language, actions, interactions, ways of thinking, believing, valuing, and using various symbols, tools, and objects to enact a particular sort of socially recognizable identity" (Gee 2007, 21). This understanding of discourse requires close semantic scrutiny to narrative structures and helps discern discourse coalitions, but takes for granted the identity of particular actors and institutions.

A second strand, developed by Foucault (2003), analyzes discourses as a process through which the identities of social and economic agents are constructed. From a post-structuralist perspective, analysis of discourse proceeds by recognizing the existence of manifest and latent messages among texts that require de-essentializing the institution that produced the discourse for the purpose of exploring its fields of power and contestation. From a genealogical perspective, discourse analysis implies looking at historical texts to make more apparent the problems and decisions that shape its strategies (Kellner 1989, 128). This approach leads to questions about how certain concepts and discursive practices are used, normalized, and resisted in an ongoing construction of power. 
Fairclough $(1992,2003)$ provides a framework that helps bridge these two trends of discourse analysis. For this author, texts are conventions of complex, diverse, overlapping, and sometimes contradictory meanings that should be analyzed in the context in which they are produced, distributed, and consumed. Textual analysis is the most descriptive stage that encompasses vocabulary, grammar, cohesion, and text structure. Such an approach also includes the discursive practices, such as political moments, debates, and linkages in which policy statements are made. Therefore, analysis of discourse requires the understanding of social practices within the broad ideological context in which meaning takes shape. Moreover, "most discourses bear upon hegemonic struggle in particular institutions [and places]... rather than at the level of national politics" (Fairclough 1992, 88). Political and normative discourses get distributed across "different institutional domains, each of which has its own patterns of consumption, and its own routines for reproducing and transforming texts" (ibid., 79). As a mode of social regulation, institutional discourses are situated practices. Hence, the discursive regulation of the mining sector involves actors, acquires meanings, and refers to material expressions that differ according to the organizational framework and the levels of governance under exploration.

In studying resource regulation, I analyzed regulatory texts and policy documents produced at different levels: union records, municipal minutes, legislative proceedings, national laws, and international statements. These sources are privileged sites for determining the ways in which discourses are produced, recorded, and implemented. I approach discourse analysis as a critical 
interpretative approach that emphasizes the genealogy of regulation. From this perspective, it is possible to treat laws as a means of connection among sources of power at different scales: legal texts are a way to explore how trans-local and extra-local relations are actually produced in local settings. My inquiry begins with an analysis of the relations into which specific laws and their discourses enter in order to investigate the social activities the laws in question generate in particular relational contexts (Smith 1999, 2001). Namely, discourses help to position global forces and local processes within a scalar relation.

Analyzing discourses among multiple scales requires understanding the networks, connectivity, and interactions across spatial scales that condition the flow of representations and narratives (Fairclough 2006). Thus, re-scaling involves the re-contextualization of discourses but also involves tensions linked to assumptions about social reality from one scale to another. Therefore, multiscalar discourse analysis must take into account dominant discourses, the hybridity of discourses at each scale, and the representation of spatio-temporal relations used in contradicting and legitimizing social practices (ibid., 96). This becomes apparent in chapter seven, when the state appeals to the concept of public domain of mineral resources as central to the redistribution of national wealth, while the American entrepreneurs appeal to hemispheric policies and regional progress to create alliances and mobilize popular support in favour of the mining enclave. 
I included this approach after I came across a reference to Chile's mining code of 1874 (see section 4.2). My concern with the multi-scalar understanding of legal texts grew while reading a publication entitled Mines and Mining Laws of Latin America, published by the Bureau of American Republics in 1892. This document includes a compendium of mining regulations in 20 countries: Argentine, Bolivia, Brazil, British Colonies, Chile, Colombia, Costa Rica, Cuba, Dutch Guiana, Ecuador, Guatemala, Honduras, Mexico, Nicaragua, Paraguay, Peru, Salvador, Santo Domingo, Uruguay, and Venezuela. The publication is descriptive in character, with a brief reference to mineral resources and a summary of mining regulations in force. The timing of the publication is suggestive; it was released during the period when Great Britain and the United States were competing to gain control over industrial mineral resources, particularly gold (see section 5.1). More interesting to me was finding that the new mining regulations combined property regimes relative to the Spanish tradition of stake claiming and Californian practices after the gold rush. Sufficient evidence does not exist to maintain that the United States was directly involved in promoting the dissemination of Chile's new mining law, but the appearance of that code, which would later influence most regulatory frameworks in the region, does coincide with the spread of Guggenheim investment in the copper industry in Chile.

This case proved to me the importance of deciphering the context in which laws emerge, researching networks of power, grasping the meaning of words from the past, and understanding the protocols under which laws come into 
existence. However, this approach creates additional challenges for a long-term analysis, so as to understand what laws make happen and how they are used in everyday life to coordinate social activities (Widerberg 2004). In the end, I prioritized analysis of three discursive moments linked with particular regulations governing extractive industries: the advancement of liberal ideas as expressed in the Mining Code of 1892 (section 4.2), the partial deployment of economic nationalism after the Constitution of 1929 was approved (section 6.1), and the legal regulation of wage labour and occupational diseases as enacted in the Labour Code of 1938 (section 6.2). 


\section{The expansion of corporate mining: Enabling conditions beyond local settings, 1860-1895}

Zaruma will someday play a big role in the mining industry; but considering the current situation, it is difficult to predict when such hopes will come true. Entrepreneurship, sufficient capital, and intelligent engineers: here are three prerequisites for mining to take flight and benefit the country. Others may judge if these requirements are found in Zaruma and throughout the province of Loja, or if they must come from outside.

(Wolf 1879,53 , emphasis in the original)

Theodor Wolf, German geographer, geologist, naturalist, and Jesuit, arrived in Ecuador in 1870 as professor at the Escuela Politécnica Nacional (EPN, National Polytechnic School). Promoting science was a comprehensive strategy of the conservative, modernizing, and centralizing administrations of President Gabriel García Moreno (1861-1865, 1869-1875). Wolf arrived in Zaruma in 1876, a time when Ecuador was characterized by internal contradictions, financial crisis, and weak institutional capabilities. Political upheaval and regional disputes fractured the country. Sharp rivalry existed among the departments of Quito, Guayaquil, and Cuenca. Until the early-20 ${ }^{\text {th }}$ century, elites concentrated exclusively on the development of their particular regions, displaying little or no interest in a common national project. Ecuador's existence as a sovereign territorial space evolved with the application of cartographic tools and geographic knowledge within the context of positivism; 
thus geopolitical legitimacy, federalist demands, and access to land-based resources were key elements in a process of state formation (Radcliffe 2001).

As State Geologist, Wolf embarked on a general survey of Ecuador, with particular attention to the provinces of Azuay and Loja. The silver mines near Cuenca, placer gold mining along the eastern ridge of the Andes, and the Zaruma gold mines appeared to be encouraging options for bolstering the economy in southern Ecuador (Chacón 2001; Palomeque 1994). At the time of his survey, mining was little more than a subsistence activity practiced by local entrepreneurs, the Zaruma mines were abandoned, and the region was devoid of economic investment (Wolf 1879). In this context, Wolf suggested the need for foreign investment and technical knowledge to undertake geological prospecting and develop the mineral sector. Zaruma seemed to hold the promise of better times.

In the late- $19^{\text {th }}$ century, growing industrial development and the establishment of the gold standard brought a new wave of investments in mining activities to Latin America. British and North American corporations controlled the mining boom, discovering new deposits, extracting industrial metals, controlling foreign commerce, and introducing new technologies for extracting and processing precious minerals (Humphreys 2010). However, the expansion of the mining sector in Ecuador required more than entrepreneurship, capital, and engineering expertise, as Wolf had suggested. The development of the modern mining sector was at the crossroads between the expansion of industrial 
capitalism and the formation of a state apparatus with the institutional capacity to sponsor scientific surveys, supply productive infrastructure, guarantee mineral concessions, and create conditions for foreign investment.

In this chapter, I analyze how the global expansion of financial capitalism based on the gold standard included not only the technological and corporate restructuring of the mining industry, but also the inflow of expertise and the dissemination and transformation of regulatory frameworks in nations such as Ecuador. I explore in detail the transformation of the property regime, used to enable access to natural resources and to favour foreign investment in the mining sector. I argue that the expansion of the American expressions of Fordism and liberalism - the dominant regime of accumulation and mode of regulation at the global level — was facilitated through institutional forms created in response to national economic interests. In doing so, I provide an account of the international processes, meaningful practices, and events shaping the emergence of particular laws and modes of regulation that will later influence the production of space in the mining enclave. I demonstrate how the creation of El Oro Province, as a separate administrative space, was the result of the alliance between foreign mining entrepreneurs and regional powers interested in increasing investment profits and policy-making autonomy. I conclude the chapter by stating that exploratory investment by speculative mining entrepreneurs and the adoption of a new institutional framework laid the groundwork for the arrival of large-scale operations that transformed Zaruma from a colonial village into a corporate enclave. 


\subsection{Industrialization, the gold standard, and corporate restructuring of mining}

In the early $19^{\text {th }}$ century, changes in the world economy stimulated and diversified the demand for both industrial and precious metals (Lynch 2002; Schmitz 1979). Industrialization in Europe and North America expanded the demand for base metals such as tin, copper, and lead. ${ }^{27}$ On the one hand, colonial powers developed commercial networks with their protectorates to provide for their industries. On the other, the United States, as the emergent hemispheric power, extended its reach in its quest for copper, silver, and gold. Humphreys (2010, 3-4) states that Great Britain and the United States "dictated the terms on which resources were developed and traded, backing this up with latent or actual force, so as to ensure that the needed commodities were able to flow back to the home nations and that the assets of investors were protected." This process perpetuated colonial-style relationships of economic dependency under a new hegemonic power, creating new center-periphery dynamics.

In Latin America, the expansion of the mining industry took place simultaneously with incipient processes of state formation. Political emancipation from Spain highlights the internal fragmentation of Latin America in conditions

27 Local resources in Great Britain, Belgium, Germany, and France were unable to meet demand in terms of grade and/or supply. The United States, with its large land mass and rich domestic resources, became the leading producer and consumer of base metals (David and Wright 1997; Spence 2000). 
where mining had lost its capacity for maintaining internal cohesion and led to differential linkages within the international division of labour (Sempat 1980). The extraction of gold and silver under conditions existing during the period of primitive accumulation and colonial articulation was no longer an option by the early $19^{\text {th }}$ century. Mining was in decline as sufficient labour was no longer available, the pits were flooded, and the lack of investment in technology made the activity unprofitable (Bulmer-Thomas 2003; Brown K. 2012; Sempat 1980).

The lack of an economic base, political differences after the independence wars, and the dismantling of the colonial administrative apparatus produced territorial disintegration leading to the formation of separate countries in the Latin American region. Until the 1850s, the central Andean countries - Bolivia, Peru, and Ecuador - experienced economic recessions and rampant political instability, until articulation with the international economy was restored through the export of silver, guano, and cacao, respectively. In Ecuador, competition among local centers of power was not conducive to the creation of a stable regime of accumulation and a cohesive mode of regulation.

These new republics had few resources for rehabilitating the mining industry as a state-led venture or for financing infrastructure needed for the development of mineral deposits. Throughout the region, foreign speculators tied to powerful economic groups, such as the Guggenheim family, worked to rehabilitate the mines in Mexico, Peru, Bolivia, and Chile (Marcosson 1949; Otto and Cordes 2002, 1-32; Waszkis 1993). This wave of extractive activity was 
organized on the basis of isolated enclaves to satisfy the demand for copper, tin, and oil required by countries in the later stages of the industrial revolution (Clark and North 2006). These mining operations, influenced by the existing pattern of colonial holdings, were more technologically sophisticated and capital-intensive, with relatively few workers and few redistributive effects in national economies, since the profits were repatriated by foreign investors to their home countries and shareholders (ibid., 3). The subsequent mining boom represented a very modest share of the Gross Domestic Product (GDP), serving, instead, to enrich the governing elite and reinforce unequal terms of exchange (Cardoso and Faletto 1971; Prebisch 1986; Thorp 1998). ${ }^{28}$

28 This statement has to be analyzed case by case. In some countries, mines were owned and ruled locally. For example, Chile became a major mining player due to nitrate exports and rich copper deposits, which provided up to $40 \%$ of the world's production by 1852 (Brown $2012,105)$. Chilean nationals controlled the mining industry and other extractive enterprises and foreign investment never constituted more than 4 percent of the gross domestic product after 1865, although Great Britain controlled its commerce (Taylor 2006, 64). That was not the case for Mexico, where the federal government supported U.S. investment in important mining and ranching concessions. In this case, revenues were used to maintain internal political stability and economic growth (Solbrig 2006, 344). 
The global space of financial capitalism was under construction. During the period under study, governments, merchants, and businessmen conducted exploratory surveys, transformed regulatory frameworks, and implemented a new commercial regime that attracted investment and guaranteed the flow of revenue to metropolitan centers. The commercial sector established the commodity exchange market to control mineral trade internationally, to reduce contractual uncertainties within a competitive context, and to raise capital to fund large projects. $^{29}$

The rapidly expanding international economy depended on a strong currency, fixed exchange rates, and monetary reserves to sustain trade and commodity-based transactions. Polanyi ([1944] 2001) asserts that such a strategy made trade flows less sensitive to price fluctuations insofar as it created greater predictability in international transactions and reduced gold outflows. Great Britain, the leading imperial power, adopted the gold standard in 1816 and several countries around the globe followed this policy measure in subsequent years (Bordo and Schwartz 2009; Eichengreen and Flandreau 1997). Paper money was thus backed by gold. Governments needed gold reserves to

29 The London Metal Exchange (LME) was established in 1877 to assure the supply of minerals from Chile to Great Britain. The LME is a multi-commodity exchange that sets the standards for forward-dealing contracts, including the size of the contract, the quality, and the method of payment on a specified date (Gibson-Jarvie 1983, 31-35). LME was not very much concerned with gold markets and the New York Commodity Exchange (NYMEX/COMEX) only took precedence after New Deal policies were implemented in 1933. 
guarantee the purchasing power of their currency and to assure the convertibility

of their national credit and paper money in international markets. ${ }^{30}$ Gold regulated economic life: doing business and making money required gold. Hence, gold was not something beyond the social realm.

Morse (2003) explains that the economic value of gold and the adoption of the gold standard were not without critics. In the United States, the dispute between gold standard advocates and promoters of "soft" and silver-backed money was at the core of political campaigns and arguments for dealing with the financial crisis of the mid- $19^{\text {th }}$ century. The "gold-bugs" argued that gold had intrinsic qualities for sustaining the monetary regime, but could also promote moral values, such as honesty, along with progress, stability, and materialism. The "silverites" denied the natural value of gold and claimed that money was a social creation, the expression of economic interests. The gold standard was adopted following the election of William McKinley as the $25^{\text {th }}$ President of the United States in 1891. Accordingly, the volume of world production increased dramatically as gold became more valuable despite its relatively stable price on official markets. ${ }^{31}$

30 For a discussion of how physical stocks of ore deposits become a valuable resource, see Bakker and Bridge (2006) and Castree and Braun (2001).

31 In the United States the price of gold remained relatively stable for a long period: US\$19.75/oz in 1792, US\$20.67/oz in 1834, and US\$35/oz in 1934. 
Figure 4.1. World production of gold, in tons, 1800-1975

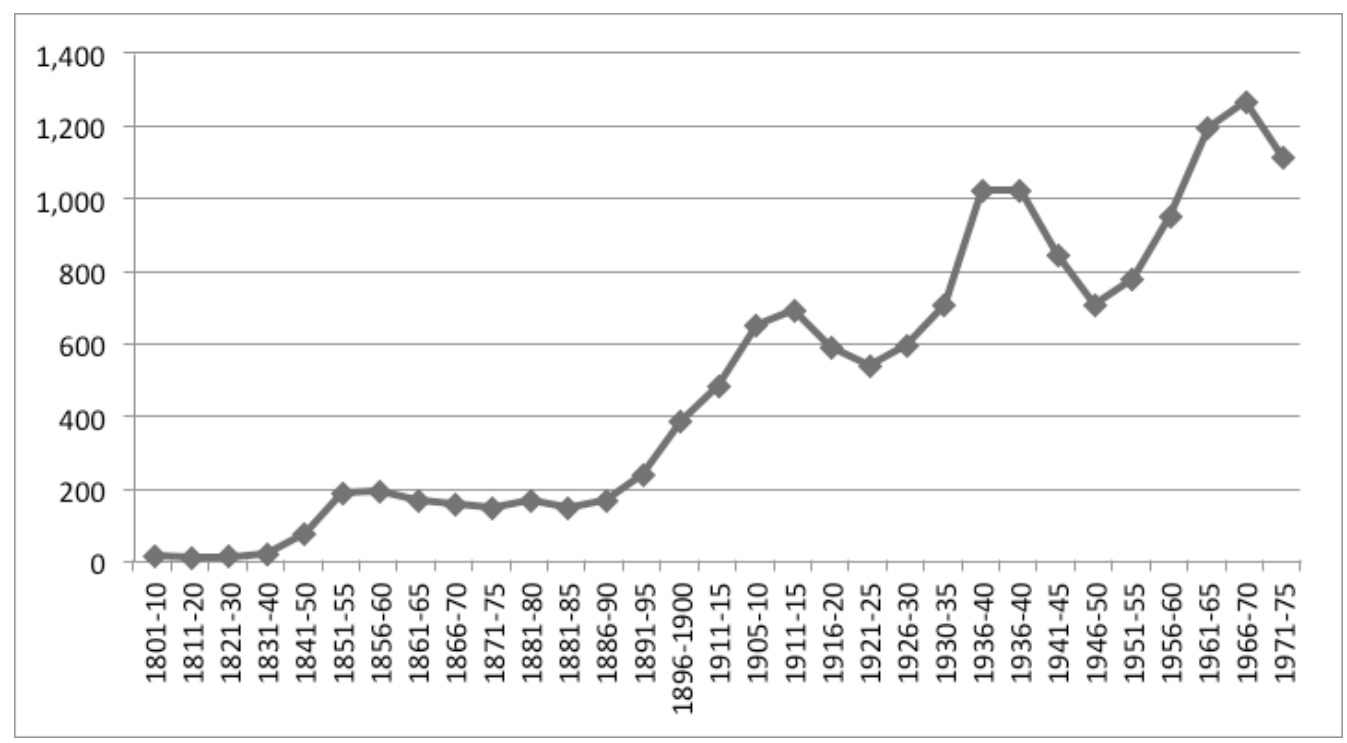

Note: The $\mathrm{X}$-axis is distorted when the varying lengths of some of the periods, due to available records, are taken into account. Observe the steep increase in world production in the early $20^{\text {th }}$ century and the decline during the Great Depression and the Cold War.

Based on: Schmitz 1979.

The gold standard represents an institutional tool that coordinated the spaces for the circulation of capital and created particular places for its production. This process cannot be predicted solely based on a quantitative projection of the availability of gold-bearing ore reserves. There are at least three other factors that came into play: the state of mining technology, the material costs of gold production, and net revenue as expressed by the commodity price (Hirsch 1968). In addition, regulations limited the circulation and consumption of gold until the early-1970s. The rise of the purchasing power of gold, the emergence of centralized monetary reserves, the abandonment of bimetallism, and relative price stability generated incentives for the exploitation of gold deposits world-wide (Bordo and Schwartz 2009; Morse 2003). The discovery of 
gold-bearing grounds in the United States, Canada, Australia, South Africa, Southern Rhodesia, Russia, and Mexico led to two major phases of growth in gold mining, beginning in 1848 and again in 1890 (Eichengreen and McLean 1994; Schmitz 1979) (see figure 4.1). These countries supplied international markets until the $20^{\text {th }}$ century, although marked variations occurred after the introduction of New Deal policies, the collapse of the gold standard, large increases in South African output, and the industrial use of gold (Bordo 1993; Hirsch 1968).

Such considerations speak to the argument that the value of resources is not inherent in the materials themselves or in stocks of a physical nature, but is conferred by a given society (Bridge 2009). We may then ask what the distinctive spatial form of capitalism is when the monetary expression of social value is represented by gold reserves, and how this spatial form has changed as the social value of gold has changed. In this respect, I am more concerned with the places where gold is produced than the spaces where gold is the particular commodity necessary for the circulation of capital, moving in trade circuits or stored in the vaults of central banks or exchanged on metropolitan markets.

The discovery of gold fields is sometimes portrayed as an accident, a matter of luck, or a random effort linked to private entrepreneurship, as 
maintained by Mumford ([1934] 2010, 66-74).$^{32}$ On the contrary, Blainey (1970), together with Harvey and Press (1990), suggest that mining ventures resulted from the spread of human activities into regions of recent settlement under depressed macroeconomic conditions. In these cases, unemployment and low interest rates encouraged speculative projects and this accelerated mineral discoveries. Moreover, state-led initiatives propelled the discovery of mineral fields and the arrival of large numbers of people to places with scant infrastructure and few public services, transforming the regional landscape and social relations of production.

Some aspects of this analysis are helpful in understanding mining development in Zaruma throughout the mid- $19^{\text {th }}$ century. Mines worked in that area during the colonial period proved to be profitable once again after new geological surveys were undertaken and technological innovations introduced, and the regional elites based in Cuenca were willing to make speculative investments to increase their return rates in light of the overaccumulation of capital linked to the expansion of palmetto straw-hat manufacturing in the region (for more details, see section 4.3).

32 Gold rush episodes occurred in remote areas such as California and Alaska (United States), New South Wales and Victoria (Australia), the Yukon (Canada), and Witwatersrand (South Africa), to mention some of the more prominent discoveries. The feverish migration of workers, merchants, and fortune hunters is seen as a journey in search of personal wealth (Morse 2003). 
Technology clearly plays a role in the way social relations materialize, thus shaping the regulatory framework and affecting the evolution of any given landscape. Technical-scientific research applied to mining and metallurgy resulted in inventions and innovations, such as the cyanide process, hydropower drainage, the mining dredge, and mechanical grinding. Advances in mining technology were followed by investment in new forms of energy to replace wind, water, and animal power (Brown 2012, 108). The transformation included steam engines and electricity to run pumps, fans, grinders, mills, and air compressors. Electricity had a modernizing effect as it was used to light underground works, power carts, run elevators, and move men and materials inside and outside the mine shafts. At the same time, the introduction of rail transport made it possible to move heavy loads and machinery at reduced costs. In addition, new mining technology facilitated the extraction of low-grade deposits, reducing the number of local workers needed and increasing the overall profitability of the mines.

The technicization of mining led to the professionalization and international mobility of a pool of engineers, geologists, and managers (Brianta 2000; Harvey and Press 1989). The development of ore deposits required engineering capacities to solve complex technical problems. The industry implemented hierarchical organizational practices to oversee mechanized extraction and processing. British, French, and American mining companies employed formally trained engineers to work overseas, insofar as they were capable of developing scientific prospecting, operating machinery, providing legal and financial advice, spreading modernizing ideas, enforcing work organization 
practices, and strategizing risk management tactics (Harvey and Press 1989; Hovis and Mouat 1996; Ochs 1992; Phimister and Mouat 2003). Reformers of modernizing states also recruited foreign scientists to assist with technical education and the professionalization of a technical bureaucracy in the mining sector. Theodor Wolf was one such expert — with his studies in geology, mineralogy, and zoology at the University of Bonn - he was able to spread practical knowledge and develop geological surveys (Pérez Pimentel 1975).

The industrialization of mining required a restructuring of the business based on multinational corporations able to undertake exploration risks and invest capital overseas. ${ }^{33}$ Corporate mergers and networks gave rise to largescale operations to consolidate mining, smelting, and refining concerns (Schmitz 1986). Mining enterprises integrated horizontally into adjacent claims to benefit from economies of scale, and vertically with subsidiary sectors, such as water, transportation, timber, and manufacturing. The flow of capital, technology, and goods took place within firms, which gained control of finance and commodity markets to pursue profit maximization independent of national policies (Deverell 1975; Sunkel 1972). The new organizational structures allowed for the rapid expansion of the mineral industry during the 1890s. This process was

33 For example, by 1929 the leading United States copper firms in the region had capital assets of $\$ 1.5$ billion, while three American corporations controlled some 48 per cent of the world's refining and smelting capacity, United Metals Selling Co. Group, American Smelting and Refining Co. (ASARCO), and Phelps Dodge (Schmitz 1986). 
accompanied by regulatory reforms based on post-colonial and imperialist relations of production, as will be explained for the case of Ecuador in the following section.

\subsection{The mobility, replication and mutation of mining laws in the late $-19^{\text {th }}$ century}

The mining laws that govern us are diminutive and the Spanish ordinances are typical of the era in which they occurred, in my opinion, it would be desirable to adopt the Code of Chile... . Since our Civil Code is taken from the Chilean and the mining code of which I speak is in perfect accordance with Chilean civil law, I believe that there is no need to search for another foreign code to form our own.

(Rafael Arízaga, Civil and Military Chief of El Oro Province, to the Ecuadorian Minister of Government, September 1883.

In: Rodríguez 2002, 253)

The international expansion of the mining sector faced the dilemma of complying with colonial legislation within a liberal context. Transnational corporate capital required norms to back up investment that would facilitate the monopolization of natural resources, provide ground rules for the operation of the mining industry, and ensure the outflow of revenues to the home country. Ecuador's 1886 Mining Code exemplifies how the coloniality of law was transformed and adapted according to new institutional frameworks that facilitated capitalist accumulation, attracted foreign investment to the extractive industries, and boosted liberalism, both economically and ideologically. The purpose of this section is to demonstrate how mining claims and private property are institutional forms contingent upon the historical and political context within 
which a national mode of regulation takes shape, and how they are also influenced by the mobility of regulatory frameworks.

In the $19^{\text {th }}$ century, Ecuador's regulatory framework reflected an unstable socio-political compromise. ${ }^{34}$ The confrontation between regional elites, territorial wars with Peru and Colombia, hemispheric policies, party politics, and social unrest generated ongoing disputes pertaining to legal and political systems. Between 1830 and 1897, the country was governed according to the frameworks established by eleven constitutions, six of them reflecting the wishes of the Conservative Party, with the remainder reflecting those of the Liberal Party (Vásquez and Saltos 2007, 150).

In the new republics, criticism of the multiplicity of laws and, above all, their shortcomings and contradictions with the new economic and political framework, raised the need for a coherent and comprehensive code regulating social and economic relations. Venezuelan writer Andrés Bello drafted a scholarly work that reasserts the importance of the rule of law and of distinguishing between truth and superstition, legend, and practices (Guzmán 1982, 2000; Jaksic 2001). The Bello Code was widely disseminated, adopted,

34 This phenomenon was not exclusive to Ecuador but has been reported as common to political institutions across Latin America in the years immediately following independence (Drake 2012; Gargarella 2010). In Ecuador, domestic legislation developed into what has been called "pluri-constitutionalism," the successive modification of the supreme law that rules the national society and the institutional apparatus (Paz y Miño 2007). 
and adapted to prevailing conditions in countries of Spanish and Portuguese colonial origin. ${ }^{35}$

Spatial mobility and an unquestioning adoption of policy frameworks are clearly expressed in Ecuador's Civil Code. In 1857, Ecuador's Supreme Court, stated that it "stands not on pride or vanity, and believes there is no discredit whatsoever in taking the good that is already done,"36 and abandoned its own Civil Code draft and embraced the proposal drafted by Andrés Bello for Chile. ${ }^{37}$ This code became crucial to subsequent mining legislation insofar as it established the basis of the property regime, in the transition from colonial to republican laws.

Mining is intimately connected with the heritage of Spanish colonialism and civil law (Vergara Blanco 2006, 1992). The exploitation of mineral

35 Bravo Lira (2010) describes the spread of the Civil Code developed by Andrés Bello, approved by the Chilean Congress in 1855. The text was adopted in full in Colombia (1857, 1876, 1887), Ecuador (1861), El Salvador (1859), Panama (1860), Honduras (1880), Nicaragua (1871), while Venezuela (1863). Argentina (1869), Uruguay (1869), Paraguay (1876), and Brazil $(1860,1865)$ produced their own norms, highly influenced by the Bello Code. The Chilean Code partially affected the drafting of civil laws in México $(1871,1884)$, Guatemala (1877), and Costa Rica (1888). The work influenced regulations in Portugal, Spain, Cuba, Puerto Rico, Angola, Mozambique, the Phillipines, Portuguese Guinea, Cape Verde, Sao Tome, Goa, Macao, and Timor.

36 "Oficio de la Corte Suprema al Ministro de Estado en el Despacho del Interior," Quito, February 21, 1857, in: Bravo Lira 2010, 97. 
concessions was guaranteed by the political and administrative organization of the Spanish Crown. This produced a "patrimonial" link between sovereign and subterranean resources; the mines were an originating good which generated royalties for the colonial political apparatus. Vergara Blanco (2006) insists that republican legislation not only continued this tradition, but also included language that emphasized state ownership of mines. The liberalization of the economy and the relinquishing of underground resources to foreign investors accompanied this process.

Towards the end of the $19^{\text {th }}$ century, Ecuador's mining legislation consisted of a collection of laws, sometimes inconsistent, comprising the Spanish Mining Ordinances of 1753 and the post-independence mining regulations established by Simón Bolívar in 1829. Following the pattern of the Bello Civil

37 In 1929, Simón Bolívar issued the Reglamento de Minas to promote the industry in Gran Colombia, which included the present-day countries of Venezuela, Panama, Colombia, and Ecuador. In 1830, the newly established Republic of Ecuador issued the Ley de Fomento de la Minería. These two pieces of legislation stipulated tax exemptions, preferential prices for mining supplies, tariff exemptions on machinery and tools, and indirect subsidies insofar as municipalities were required to finance roads in mining districts (Wolf [1892] 1975). 
Code, the legislature adopted, verbatim, the Chilean Mining Code of $1874 .^{38}$ The Ecuadorian Mining Code of 1886 aimed at broadening the participation of foreign and national investors in the prospecting, discovery, claiming, and operation of mines, as well as providing security for mineral concessionaires. ${ }^{39}$

With the passage of the Mining Code, a transformation of the institutional forms for the appropriation of land came into effect. Ecuador developed a res nullius regime whereby mines became private property granted to the first discoverer and applicant. ${ }^{40}$ According to this system, legitimate property is that which incorporates the application of productive work; mine holdings were given to individual legal subjects in perpetuity as long as owners could demonstrate the active development of mineral deposits. Only in the event of abandonment of mining works did the holdings return to the state. Moreover, the state subsumed other ecological processes and land uses to mine productivity.

In Latin America, normative reforms for the mining sector were passed in a rush: Chile (1874, 1888), Nicaragua (1876), Bolivia (1880), Honduras (1880, 1887), Guatemala (1881), México (1884, 1892), Argentina (1886), Ecuador (1886, 1897), Colombia (1887), Peru (1887, 1890), and Venezuela (1891). In 1872, the United States passed the Mining Law entitled "An Act to Promote the Development of Mining Resources of the United States." For a comparative analysis of mining laws in the late- $19^{\text {th }}$ century, see: Bureau of the American Republics 1892b; Morris 2008; and Walmesley 1894.

39 Some of the main features of the mining code include: perpetual ownership of mining rights, procedures for registration of mineral discoveries, demarcation of the mining claim, surface easements to facilitate mining activities, and the creation of an administrative apparatus to oversee the mining sector.

40 The res nullius introduced a property regime proper to common law and British imperialism. For an explanation of different doctrinal systems pertaining to property regimes applicable to mine holdings, see: Campbell 1956; Ossa Bulnes 1999; and Vergara Blanco 1992. 
As noted above, mines were granted to the first discoverer and applicant, and any person or legal entity permitted to own property in Ecuador was allowed to claim a mineral deposit. The ban on foreign ownership of mineral rights, imposed by the Spanish Ordinances, and introduced into the colonial mining code of 1783 , was lifted. The right of free entry meant that acquiring a new mining claim was a matter of finding an ore body, announcing an interest in mining, and posting a public notice to prevent conflicts. The right to search in unenclosed and uncultivated land was open to anyone, including foreign investors. ${ }^{41}$ On farmland, the prospector had to get permission from the owner or the government mining authority and, if applicable, pay compensation for damages. The minimal presence of the state in the mining sector was, in fact, produced by state regulations.

The production of space and the appropriation of surplus value included securing the conditions for extraction through the identification and demarcation of natural resources. Whether for placer ground or hard-rock quartz, the procedure to secure a claim was the same. The discoverer and applicant had to

41 The appropriation of land was not exclusive to the mining sector. The expansion of export agriculture on coastal plains and the construction of the railway system across Ecuador required land and labour. The Vacant Land Law of 1865 - and further reforms in 1875 and 1896 - allowed the expropriation of uncultivated properties and the transfer of public lands to private owners upon productive use. Between 1884 and 1909, the state transferred almost 115,000 hectares to private owners and was compensated in the amount of 69,289 sucres for said land sales (Ramón and Torres 2004, 82). 
uncover a reef within ninety days and dig a pit so that public officials could measure and determine the size and direction of the claim. Each new claim had to be declared to the mining judge and a public notice had to be issued through the local newspaper or posted on the courthouse door a total of three times, at ten-day intervals. Those who believed they had a prior right to a claim had to present a counterclaim within ninety days or forfeit their claim. The claims were granted in perpetuity - whether or not the claim holder paid royalties - and the Civil Code applied as for any other real estate in Ecuador.

Harvey $(2014,55)$ notes that private ownership is a primary requirement for the expansion of capitalism, and depends on the existence of state authorities and legal systems encoding, defining, and enforcing the contractual obligations of individual legal subjects. In this sense, the above-mentioned provisions had an important role in opening up spaces for the operation of export-oriented industries and the appropriation of natural resources in the name of economic progress (Chacón 2001; Ramón and Torres 2004).

Another example of the durability, transformation, and dissemination of mining regulations involves technical procedures used in the demarcation of mining claims. This process included the colonial practice of surface-area demarcation and the California principle of longitudinal measurement (Walmesley 1894). Since colonial times, miners had to stake a claim with posts or piles to make underground rights visible on the surface. The visibility of such a process 
involved not only a technical question of land use, but also the enforcement of a social order, which included the threat of violence (Blomley 2003).

The principle of longitudinal measurement was new to South America; it was not included in the Mining Ordinances of New Spain but, rather, comes from California mining practice (Hansen and Porter 2012). The miners acquired exclusive rights to all mineralized grounds and could follow a lode "on its dip," a concept introduced in the Mining Law of the United States in $1872 .{ }^{42}$ In Ecuador, the "dip" was determined using the metric system to measure the length of the claim within the limits mapped from the outcrop apex along the vein course, independent of the lode width and spurs. ${ }^{43}$ This principle allowed miners to follow the depth of the ledge but did not imply a substitution of the Spanish system of allotment or surface demarcation. Miners were not allowed to trespass the downward course beyond the lateral borders of the surface claim. According to the code, mining claims could be bought and sold like any other private property, under the provisions of the Civil Code.

42 For a discussion of variations in the mining laws of New Spain, see Rockwell (1851). For a discussion of the different principles pertaining to the Mexican and California mining systems, see Walmesley $(1894,162)$. Examples of the application and implications of following a vein "on its dip" can be explored in: Colby 1917; Smith D.A. 1987; and Smith G.H. 1998.

43 The Mining Law of Ecuador, passed in 1892, increased the size of the mining claim and added provisions favourable to foreign investors. Rregular claims could measure up to $600 \mathrm{~m}$ of horizontal longitude by $200 \mathrm{~m}$ of latitude. The mass, or irregular lodes, could be claimed in a square holding of $200 \mathrm{~m}$ per side. The placer mine claims could have up to $50,000 \mathrm{~m}^{2}$ in the shape and size requested by the applicant. 
At this stage, I return to the quote introducing this section to expand on the agency behind institutional mechanisms in the mining sector. The governor of El Oro province, Rafael Arízaga, was the leading person in the transformation of mining regulations. He was also a shareholder in the Great Zaruma Gold Mining Company along with other members of Cuenca's elite, such as Luis Malo, Manuel Vega, and Roberto Crespo Toral (Palomeque 1994; Wolf [1892] 1975, 687). This group of mining entrepreneurs and speculators captured political power in the newly established province of El Oro and developed linkages with the national government to assert control over the mining sector. The provincial governor, as representative of the central government, became the mining authority and judge in mining-related matters.

In the late- $19^{\text {th }}$ century, political legitimacy and economic development required intermediaries for the organization of labour and social control throughout Ecuador (Maiguascha 1994, 367). The process included the appointment of authorities at different administrative scales - the parish, the county, and the province - as an extension of state control over the national territory. ${ }^{44}$ In addition, a group of engineers, inspectors, and other experts hired by the state were empowered to oversee the requests for and mapping of mining

44 The jefe politico (chief justice of the peace) had a prominent role as the representative of the national government at the county level; he was directly responsible for overseeing matters related to labour practices, workplace accidents, and mine inspections. 
claims and to provide advice during litigation processes - although their presence would be minimal until the mid- $20^{\text {th }}$ century. The code did not provide for representation of miners in the political arena, as had been the case with the Miners Tribunal in colonial times. Instead, Article 22 prohibited the acquisition of mines or participation in mining profits by public officials and engineers. However, the prohibition had a loophole: the provision did not apply to mines acquired by a public official or an engineer before their administrative appointment or as a result of a bequest. As a result, Rafael Arízaga and his partners maintained control over the mining sector while pursuing their political careers as ministers, deputies, senators, governors, or municipal councillors.

The Mining Code of 1886 was short-lived as its application was thought to be problematic and liberals issued further reforms after they gained control of the national government. In 1887 , an amendment stated that mining claims were open to nationals and foreigners, and royalties were reintroduced as a precondition to holding a mining claim. ${ }^{45}$ In addition, Congress passed reforms according to which "the state owns all deposits of gold, silver, copper, mercury, tin, precious stones, petroleum, coal, and other fossil substances, notwithstanding the domain of corporations or individuals to the land surface below which they are located," and the state could grant individuals the right to

45 Decreto Legislativo № 1, August 15, 1887; Decreto Legislativo № 84, August 8, 1892. 
prospect, excavate, work, and process minerals and "dispose of [mines] as

owners" ${ }^{46}$ Such a principle represented a triumph for progressive regimes. The state was recognized as the legitimate owner of all mineral deposits and could therefore grant concessions through a royalty-based system.

The new regulations benefited large mine owners. The maximum area that could be claimed increased from three to twenty holdings over the same vein, provided that the land in question was vacant and the tract contiguous. Mining claims were granted in perpetuity, whether the mines were worked or not. ${ }^{47}$ Under the amended mining law, mining property and mine output enjoyed immunity from any national or municipal dues and taxes for twenty-five years. No customs were to be charged for importing machinery, tools, utensils, and explosives during the same period.

The amendment ended the colonial principle of pueble de minas (effective mining works) as the criterion for granting mining claims and the despueble de

46 Mining Code of 1892, article 1. This amendment introduces oil as a mineral, probably responding to early investment and prospection carried out in Ancon in the province of Guayas. The first law related to hydrocarbons was passed in 1937. See: Decreto Supremo $N^{\circ}$ 70, in: Registro Oficial, N 560, August 9, 1937.

47 In 1900, a presidential amendment issued by Eloy Alfaro ended perpetual proprietorship, limiting leases to a 50-year period, but the following year President Leonidas Plaza revoked that decree. See: Ley 3, in: Registro Oficial, № 1247, October 23, 1900; Decreto Legislativo (unnumbered), in: Registro Oficial, $\mathrm{N}^{\circ}$ 6, October 3, 1901. 
minas (abandonment of mines) as the condition for revoking holdings. ${ }^{48}$ Those miners holding a fraction of a pertenencia minera (mining property) had to pay for at least one claim. However, owners working several contiguous holdings had to pay for a maximum of fifteen claims, regardless of the extension of their holdings. The annual patent was established at eight sucres per mining claim, whether the mine was worked or not. After 1892, the sole reason for revoking a mining claim was the failure to pay the annual royalty.

The case of mining regulations suggests the need for looking into nondominant economic sectors and secondary legislation for a deeper understanding of how the spread of industrial capitalism, as the dominant regime of accumulation, required institutional forms adapted to the national mode of regulation. In addition, the convergence of two property regimes for mining claims denotes difficulties in transforming institutional forms insofar as colonial tradition persists despite the advent of capitalism and liberal states.

The evolution and content of mining legislation denote various systems. On the one hand, the mining code legitimized the requirements of liberalism and

48 Until the late- $19^{\text {th }}$ century, tenure was not linked to the payment of any permits, dues, taxes, customs, patents, or royalties but, rather, to the continued occupancy and working of the mine by a minimum of four operators. The mine-owner had to begin activities within one year after the concession had been granted and could suspend activity for a maximum of two years upon payment of a local contribution determined by the municipal government every three years (arts. 53, 59). For a comparative analysis of legal changes in the mining sector, see the case of mining laws in Chile (Vergara Blanco 1992). 
industrial capitalism, whereby private property and class relations sustain primitive accumulation. On the other hand, economic regulations were linked to the institutional apparatus as a means to legitimize political power. Throughout the process, the coloniality of law subsumed local communities and alternative land uses to mining as the dominant mode of production. Hence, these regulations "both connect, and establish relations between, distant ... sites in complex webs of experimentation" (Peck and Theodore 2012, 22).

From a theoretical perspective, this case contributes to debates on the mobility, replication, and mutation of regulatory frameworks in order to understand the institutional and political embedding of extractive capitalism (Peck and Theodore 2010, 2012). In Ecuador, the mining regulation adopted in the late$19^{\text {th }}$ century would remain relatively stable for over forty years, until Marxist ideas challenged the status quo resulting in class awareness, social organization, and mobilization. At the regional level, regulatory change of similar intensity and reach would occur only a century later, when fourteen countries reformed their mining legislation in the 1990s (Chaparro 2002). In that decade, neoliberal reforms promoted the deregulation of the mining industry to attract foreign investment, stressed competitive advantages, streamlined informality in the mining sector, and adapted mining practices to new environmental concerns. 


\subsection{Zaruma: From colonial villa to corporate enclave}

The transition from a depressed colonial setting to a corporate enclave began slowly and was rife with uncertainty. Investment in the mining sector shows a regional trend, with speculators and entrepreneurs seeking to increase monetary returns from excess capital in Cuenca. Nonetheless, local investors and municipal governments had insufficient resources or lacked access to the technology needed to undertake mineral prospecting and, as a result, mining initiatives faltered. By 1895, the adoption of the gold standard, the transformation of mining into a technologically sophisticated and capital-intensive sector, the production of geological knowledge, and legal reforms implemented in Ecuador paved the way for the arrival of American investors who transformed Zaruma into a corporate enclave. 


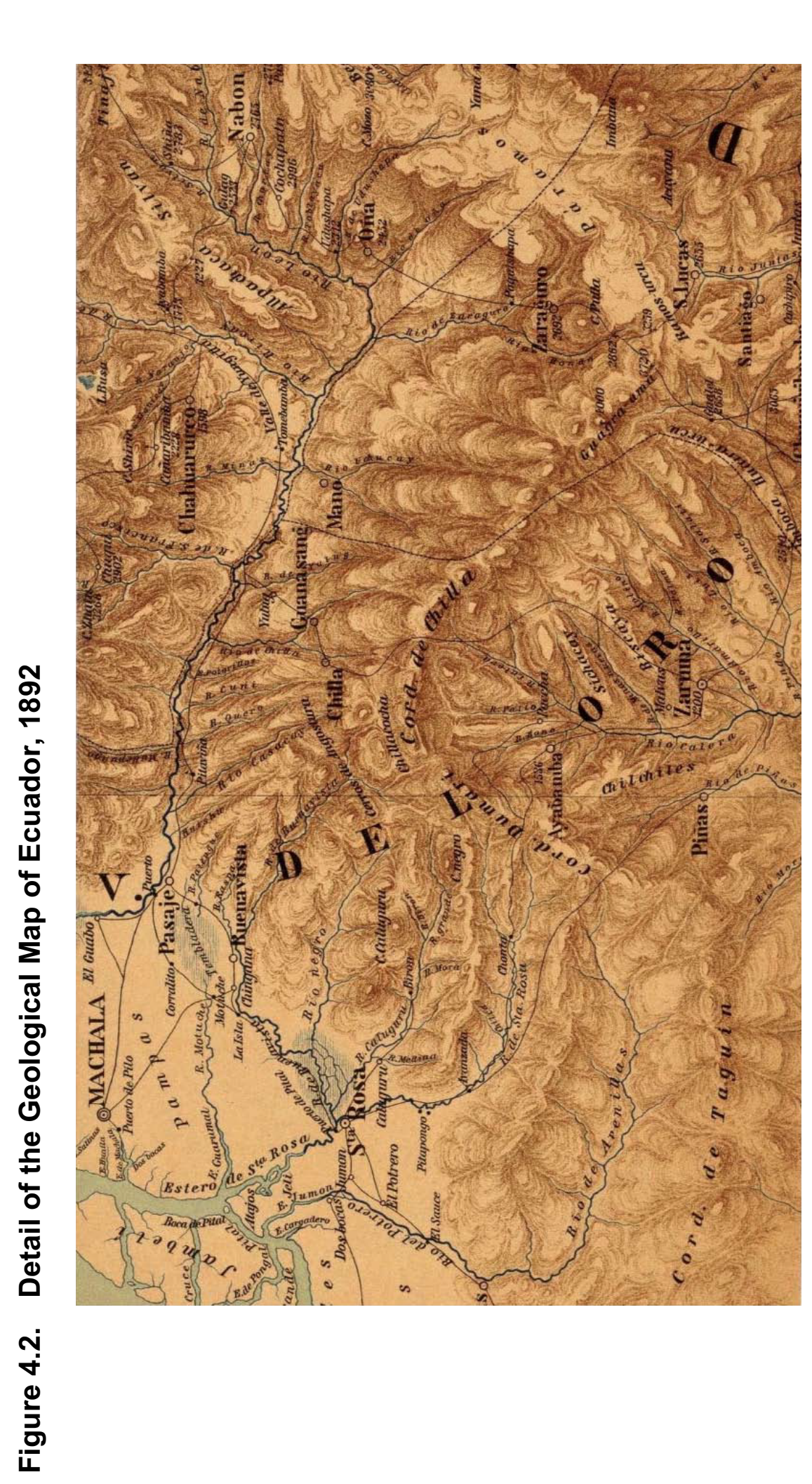

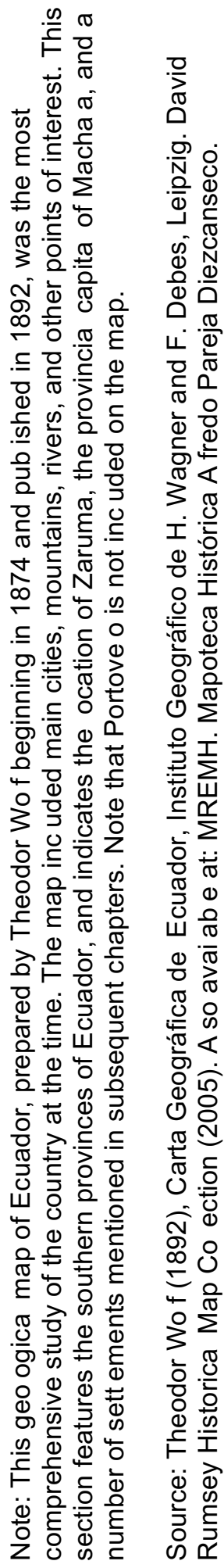

N 
The revival of the mining sector was never straightforward in Ecuador. After independence, the mines were abandoned due to the depletion of readily accessible deposits, the destruction of production units, the lack of labour, internal conflicts, and technological difficulties presented by mining at great depths (Lane 2004; Sempat 1980). The state was "weak" and local elites had little experience with technology for mineral exploitation. Palomeque (1994) explains how mining investments linked to expanding monetary returns were fuelled by the regional surplus of capital. Mining first developed in Azuay with the reactivation of the Pilzhum and Gualleturo mines, the gold placers of Collay, and ore discoveries in Gualaceo and Chordeleg. Cuenca experienced a boom associated with the recovery of the manufacturing sector, cascarilla exports, and the incipient straw hat industry. Profits from these activities boosted mining investments in Zaruma.

Regional elites and local businessmen expanded their range of action to acquire mining concessions in Zaruma (Palomeque 1994, 98). Manuel Federico Muñoz Serrano partnered with Chilean mining engineers and regional businessmen to apply for mining concessions. Years later, in 1880, Muñoz Serrano sold the claims to international investors and formed the Great Zaruma Gold Mining enterprise with an initial capital investment of $£ 250,000$. The transaction included the colonial mines of Sesmo, Portovelo, Jorupe, Bomba de Vizcaya, Bomba de Pacchapamba, Toscón Blanco, and Curipamba (Sánchez Tejada in Wolf [1892] 1975, 687). The connection with foreign investors is no coincidence. This period witnessed the gradual establishment of British 
companies and the formation of alliances between the local bourgeoisie and the commercial oligarchy. ${ }^{49}$

The mine manager of the newly settled "British company", Raymond Peiger, was driven by modernizing and liberal ideas related to market economy expansion and the promotion of democracy. ${ }^{50}$ Peiger authorized allocating the initial investment towards opening a road from Zaruma to Santa Rosa and for bringing industrial machinery into the mining district. However, the road was not finished and the equipment remained idle at the port of Santa Rosa, resulting in high administrative costs. The manager was criticized for his spendthrift administration and his involvement in internal political conflicts, and blamed for the company's eventual bankruptcy. As this example suggests, problems arising from geographical isolation, technological demands, and politics remained a constant feature and challenge up to the first half of the $20^{\text {th }}$ century.

In 1886, Ecuador signed the Treaty of Friendship, Commerce, and Navigation with the United Kingdom and, in 1897, exporters, importers, and several banks signed a Gentleman's Agreement to stabilize the exchange rate for demand drafts. The Ancon Limited Oil Company of Ecuador began oil exploration in the Santa Elena Peninsula, the Ecuadorian Corporation Ltd. of Quito was set to generate and distribute electricity in the capital city, and the Ecuador Land Company Ltd. received land allotments in Esmeraldas as foreign debt payments.

50 Peiger, a Hungarian earl and an early investor, moved to Ecuador in 1871, ten years before the British Company arrived in Zaruma. He had come to the country at the request of President Antonio Flores and served as a civil engineer and geologist to the Ecuadorian government. He subsequently lived in the United States and Europe where he was inspired by democratic governments and the industrial society. As mine manager, he joined the Restauración (Restoration) social movement, together with colonels Dolcey Patiño, César Guedes, Guillermo Ortega, and Ángel Polibio Chávez, and formed a volunteer militia to fight the dictatorship of Ignacio de Veintimilla (León Mera 1932; Sáenz de Tejada [1892] 1975). 
The mining entrepreneurs based in Zaruma supported political initiatives to distance the mining district from regional powers in Cuenca. ${ }^{51}$ They had a longstanding desire to break administrative ties with the province of Loja in order to gain political autonomy and be annexed to the province of Guayas, or to form a new province together with Santa Rosa and Machala. ${ }^{52}$ Local authorities, miners, and tradesmen associated with the municipal council of Zaruma welcomed the Ejército de Restauración (Restoration Army). The army, commanded by General Francisco Javier Salazar, opposed the dictatorship of Ignacio de Veintemilla (Jaramillo Alvarado 1955; Murillo 2000). The political and economic powers of the southern provinces, including those based in the municipality of Zaruma, joined the military, demanding changes in the territorial division of the state. On November 29, 1882, residents of Zaruma, together with Santa Rosa and Machala, counties in the Province of Guayas, established a new province called El Oro, in honour of its gold deposits (Romero 2011).

The local elites had strong federalist tendencies and the economic boom reinforced these aspirations. The increase of export agriculture, linked to cacao on the coastal plains, quinine in the southern Andes, mining in Zaruma, and

51 Capitalist expansion was proceeding from Cuenca while political control was based in Loja. 52 Records show that these attempts go back to 1845 , when the country was experiencing unemployment and agricultural disinvestment. A proposal to create the province of Jambelí was presented at the National Convention meeting in Ambato in 1877 (Romero 2011, 6); it was not approved. 
tobacco in the Amazon basin, resulted in changes to regional political powers. Differential linkages with international markets led to production diversification, urbanization, and the expansion of communication and transportation systems as well as financial markets. In addition, opposition politicians, such as José Rafael Arízaga, also fanned aspirations to create a new province to favour the economic interests of mining companies and the political interests of the Restauradores.

Administrative jurisdictions were modified in response to economic interests, administrative needs, and socio-political pressures. The Constitutional Assembly of 1884 ratified the creation of the provinces of El Oro, Cañar, Carchi, and Bolivar, along with five new municipalities (counties) and thirty-two rural parishes. Nonetheless, regional political pressure led the Constitutional Assembly to move the capital of El Oro Province to Machala, a dynamic center of the cacao boom with significant commercial interests and strong ties with Guayaquil. José María Plácido Caamaño, Ecuador's president from 1883 to1888, would later note that such jurisdictional decisions were arbitrary insofar as [internal] boundaries were not clearly defined and were simply based on the distance of certain areas from the administrative center of a territorial jurisdiction. ${ }^{53}$

53 AH-MREMH. Communication from J.M.P. Caamaño, Gobernador de la Provincia de Guayas, April 28, 1894 in: "Informe del Ministro de lo Interior y Relaciones Exteriores de la República al Congreso Ordinario de 1894," Quito, Imprenta del Gobierno, 206. 
Figure 4.3. Evolution of Ecuador's provinces, 1824-2007

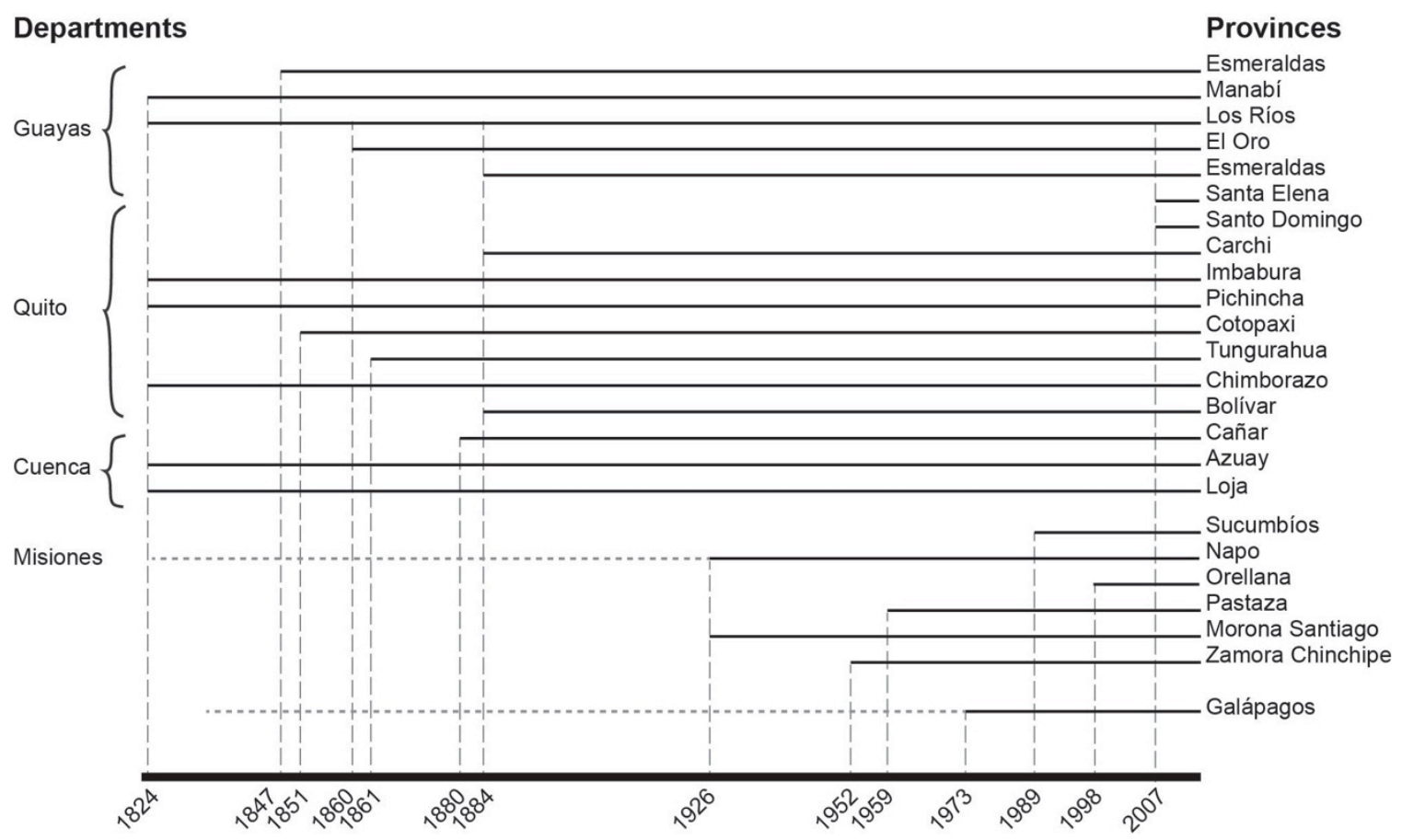

Note: The departments were abolished in 1861, leading to a structure of administrative organization based on provinces. The creation of new provinces is directly articulated with cycles of economic expansion and the modification of power relations between regional elites.

Based on: Gondard 2005; updated.

The new provincial authorities lobbied for mining laws favourable to the mining boom. José Rafael Arízaga, sworn in as civil and military chief of the province, requested that new regulations be created. The Mining Code was passed in 1886, as described above. Additionally, the government issued a decree naming a juez de minas (mine judge) in Zaruma, to facilitate and oversee business, stating that "due to the distance from the capital of the province it can 
not communicate easily with the respective Governor. ${ }^{54}$ Thereafter, the mine judge was appointed by the national government, reported to the provincial governor based in Machala, and had the same rights as a county mayor. This arrangement provided greater administrative flexibility for granting mining claims, thus circumventing the cacao businessmen of the lowlands.

The development of gold fields was facilitated by concrete evidence of mineralization and the institutional support of the state granting mining concessions. As suggested by Blainey (1970), the opening of mineral fields was sensitive to economic conditions in regions where governments and entrepreneurs were willing to undertake risks. The alluvial and shallow deposits were developed rapidly, requiring little investment. Ancient, poor, or abandoned mineralized districts were also developed as mines became profitable because of rising demand and more advanced technology. However, knowledge of the existence of gold-bearing ores and silver deposits was not sufficient to develop the mining fields; early discoveries proved unrewarding and the time lag between exploration and development required risk management strategies.

National and foreign entrepreneurs flocked to Zaruma. Companies formed at this time include the Compañía de Minas de Oro de la Quebrada (1886), with Chilean capital, whereas French capital financed the Compañía Minera Nacional

54 “Convención Nacional,” Decreto Legislativo, April 9, 1884. 
Fénix in the area of Minas Nuevas (1887) and the Compañía de Exploración de Minas de Oro de Pacay-Urcu (1890). The British company continued to be the main operator in the area, devoting efforts to exploration and requesting mining concessions. The discovery of the Portovelo vein and investment in a twentypiston stamp mill — with a daily twenty- to thirty-ton crushing capacity — paid off and the first shipment of gold was sent to London in 1886 (Sáenz de Tejada [1892] 1975).

Despite some setbacks, speculative mining investments opened the mineral fields and stimulated production in the agriculture and livestock sectors. The local economic boom created jobs, increased revenues and tax collection, and activated the market. Agricultural products and goods coming from rural parishes were traded in Zaruma at a busy market each Sunday where sugar cane-based items and rice and coffee were among the principle products on offer (Municipio de Zaruma 2002, 74).

Nevertheless, the limited availability of operational capital, inappropriate quartz processing methodology, and administrative mismanagement generated debts that led to the bankruptcy of several mining companies. The Portovelo shaft collapsed in 1886, destroying the pump and other equipment. In 1889, mine dewatering, clearing operations, and the discovery of a new vein, the 
Abundancia, led to renewed ore extraction and processing, and profits were sent to the company's home country (Sáenz de Tejada [1892] 1975). ${ }^{55}$ The work force shortage, lower grade ores, changes in the administration, and the lack of new geological surveys brought mill activity to an end. The Zaruma Gold Mining Company Limited abandoned the project. ${ }^{56}$ In addition, the results of exploration by British and French companies on other mining properties were disappointing.

By 1894, the Provincial Governor complained to the national government:

The British company, which owns mines in Zaruma on a substantial land tract, calls itself the owner of the land, so that the village of Zaruma has no further domain beyond land occupied by the population's houses, especially in the area facing north. This situation seriously affects town residents, because they have no land for crops, pastures, and gathering firewood; in addition, the Mining Law entitles miners to the surface lands needed for production; it seems essential that the next legislature issue a provision to avert this evil, so that needed land is returned to that population for the purposes indicated. ${ }^{57}$

Clearly, Zaruma was no longer the abandoned village that Theodor Wolf had visited twenty years earlier during his government-sponsored exploring

55 Zaruma Gold Mining Company extracted 400 to 500 ounces per month. According to 1890 reports, 4,671 ounces of gold were exported, valued at $£ 12,325$. At that time, the company was studying ways to increase stamping power for ore grinding. See: Diplomatic and Consular Reports. Annual Series, Issues $781-835$ by Great Britain Foreign Office, 1890 Annual Series, Report Nos. 805 and 832.

56 Apparently, the discovery of the Transvaal gold mine in South Africa and a series of accidents ended investor interest in the Portovelo mine (Andrade 1923).

57 AH-MREMH. Communication from Antonio Jurado, Governor of El Oro Province, April 13, 1894 in: "Informe del Ministro de lo Interior y Relaciones Exteriores de la República al Congreso Ordinario de 1894," Quito, Imprenta del Gobierno, 190. 
expedition. In fact, entrepreneurship, capital, and engineers had arrived in the mining district, transforming social relations and producing a space for the circulation of capital. Yet, such a process was not free of contradictions. Stagnation in the mining industry demonstrated the consequences of economic dependency and land appropriation under the new mining laws and the property regime.

\subsection{Conclusion}

The international demand for base metals and the quest for gold to supply metropolitan markets stimulated a non-linear process for creating the knowledge and institutions required for the appropriation of land-based resources and the opening of national spaces to foreign investment. In Ecuador, the expansion of the mining sector occurred gradually during the administrations of García Moreno (1861-1875) and progressive administrations (1875-1895). Hence, this period includes the production of geological information and the reform of colonial mining regulations. The presence of Chilean, British, and French foreign investors staking mining claims reflects the international dispute over mineral resources while the settlement of American investments reflects the transformation of hemispheric hegemony. In addition, the institutionalization of the state apparatus internally transformed center-periphery relations by limiting municipal autonomy and strengthening the presence of state representatives throughout the nation's territory. Moreover, the cacao boom — which began in 1860 and lasted until 1920 - provided resources for the expansion of transport 
infrastructure, such as the railway system, as well as the spread of wage labour on the coastal plains and the articulation of an incipient domestic market. However, Ecuador continued to be a fragmented state with limited connectivity and serious differences among regional elites who exercised economic, social, and political power and whose ideologies were at odds. In this context, the "penetration" of foreign investors was never straightforward and foreign-owned mining companies failed to consolidate operations at profitable rates during this time period.

The international context, while important, should not be overstated as the leitmotif in the (re)discovery of ore deposits in Zaruma. The demand for gold to back the monetary regime provides a framework for understanding how this particular mineral was positioned as a key resource for industrial capitalism at the global scale. The construction of gold as a resource to be appropriated by capitalist economies included not only the international expansion of the mining sector through market mechanisms and technological innovation, but also the flow of information, expert knowledge, and regulations. However, the concrete processes and material conditions that enabled exploration and further exploitation have to be examined at the national scale. Domestic responses to international events included the selective diffusion of policy choices. Replication and changes in mining regulations served not only to accommodate capitalist interests but also to sustain oligarchic regionalism. 


\section{The birth and evolution of the mining enclave: A changing landscape for resource regulation, 1895-1950}

The money of the New York multi-millionaires will, if possible, make a bonanza out of an industrial enterprise that the easy-going Spaniards gave up in despair three hundred years ago; that speculative Britons tried to revive with insufficient capital and ignominiously failed. It is to dig gold out of the wild, mountainous regions of Ecuador.

(“Gold digging for gold," Spirit of the Age, 1896)

In 1896, James Burnett Lowell, representing the South American

Development Company (SADCO), based in West Virginia, United States, bought the assets of a failed British Mining Company operating in the gold district of Zaruma. Burnett Lowell was a member of a strong "combination of millionaires," pragmatic men with the technical wherewithal to go into the mining business in the Andes. ${ }^{58}$ The American engineering mission issued a favourable report for the Zaruma gold fields and, shortly after, they secured the mining claims,

58 According to the same newpaper article from which the epigraph that begins this chapter is taken, the founding members included: William A. Kissam, President and nephew of William Henry Vanderbilt; Hamilton McKown Twombly; a nephew of John G. Heckser, a rich iron manufacturer in Philadelphia; W. E. Newberry, scientist and geologist on the faculty at Columbia College; and James Burnett Lowell, grandson of the poet James Russell Lowell See: "Gold digging for gold," Spirit of the Age [Woodstock, VT], October 10, 1896, Vol. LIII, No 10, 1, from The Library of Congress, Chronicling America: Historic American Newspapers Site, accessed July 3, 2013, http://chroniclingamerica.loc.gov/lccn/sn84023296/issues/1896/ 
established the mining camp of Portovelo, and began exploration. The entrepreneurial spirit, sufficient capital, and trained engineers - considered by Theodor Wolf as essential conditions for mining in Zaruma - were finally arriving from abroad. However, mining in the Andes was never an easy task, as suggested by the newspaper Spirit of the Age, and foreign investors had to establish a series of material conditions and neo-colonial practices to dig gold out of what the newspaper described as the "wild, mountainous regions of Ecuador."

The birth and evolution of the Portovelo enclave can be understood through the lens of what Henri Lefebvre calls the production of space (see section 2.1). Company towns represent place-making projects, the deliberate effort to modify the physical and social landscape for a productive end. They symbolize the power of industrial capitalism to exploit natural resources through social and spatial engineering in order to establish the material conditions required to sustain production and retain the work force in relatively isolated areas (Dinius and Vergara 2011, 2). An additional factor — and a major topic of my dissertation - involves the institutional forms that influence gold production, including regulations that govern access to gold-bearing grounds, governmental policies needed to build productive infrastructure, and everyday practices associated with the social reproduction of the labour force, including wages and basic social services.

In this chapter, I analyze the ways in which the industrial enterprise appealed to, and worked with, multiple levels of government and regulatory 
requirements to secure mining claims and build the infrastructure necessary to enable the extraction of gold. Here I explore the transformation of the physical landscape through the appropriation of land and the establishment of the material conditions necessary for the extraction of natural resources; the socio-spatial differentiation between the Portovelo camp and the city of Zaruma; and efforts to connect the mining district to international markets.

\subsection{Appropriation and extraction of natural resources}

The appropriation of land-based resources is central to the political economy of extractive industries. Any attempt to extract mineral resources requires "the monopoly by certain persons over definite portions of the globe, as exclusive spheres of their private will to the exclusion of all others" (Marx [1867] 1999 , 424). From a different standpoint, Schmitt $(2006,46)$ argues that landappropriation is the constitutive act which produces a primary criterion for any further social relations, economies and legal orders. The subsequent measurement, division and distribution of usable soils allow the productive work that occurs afterwards (Schmitt 2006, 327). In the case of the mining enclave, the process involves the violent and/or legal transfer of land ownership, as well as technology for the extraction of ore and the control of ecological processes in extensive areas beyond enclosure of private rule. 


\subsubsection{Land titles and mining claims}

In Ecuador, two gold-bearing areas were a matter of foreign interest during the late $19^{\text {th }}$ century: the hard-rock lode district of Zaruma in the province of El Oro and the placer fields of the Santiago River in the province of Esmeraldas. ${ }^{59}$ In 1895, an American engineering mission hired by the Vanderbilt group arrived in the country to conduct geological surveys and take samples of mineralized grounds. The local manager of the Zaruma Gold Mining Company, Joaquín González, captures the fears foreign businessmen inspired:

...the New York Banking Union, directed by engineers Van Slooten and Conger, intend to take possession of the entire mineral deposit and, to that effect, I believe they have here a commissioner to auction the mines .... New York confirmed promising results .... What the engineers thought best was that of the British Company, especially the Portobelo mine and its establishment .... Great care must therefore be taken with the Yankees. If you have any interest in these mine properties, send orders posthaste to save them. ${ }^{60}$

59 In 1892 the Bureau of the American Republics published the Handbook of Ecuador. This document highlights the abundance of mineral resources and the presence of American enterprises exploiting the gold-bearing gravel in Cachavi, Uimbi, and Playa de Oro in the province of Esmeraldas, and British investments in Zaruma and Portovelo. The report also notes the influence of and the continuous monitoring by American diplomatic missions in Ecuador. The information on gold discoveries was available to a wider public through newspapers; see, for example, "Gold mining in Ecuador," The Herald, (Los Angeles [Calif.]) 1893-1900, June 18, 1896, 4, from the Library of Congress, Chronicling America: Historic American Newspapers Site, accessed July 3, 2013, http://chroniclingamerica.loc.gov/lccn/sn85042461/1896-06-18/ed-1/seq-4/

60 Communication from Joaquín González to A.P.M. Rivolta, British Company official in charge of liquidation, March 30, 1896 in: Andrade 1923, 134. 
The mines had been inactive since 1894 and the Zaruma Gold Mining Company had not paid municipal taxes. Under the provisions of the 1892 Mining Code and the Civil Code described in the previous chapter, the government auctioned off the assets seized. ${ }^{61}$ It was a good deal for the foreign investors, who bought the property for half the original price (Rodríguez 1992, 238).

The efficient, fast-track nature of the auction of Zaruma Gold Mining Co. assets was unusual. Between February and August of 1896, plaintiffs fulfilled all requirements, including the embargo, pricing, appeal, and re-valuation of all holdings (Andrade 1923; Rodríguez 1992). The process involved legal disputes. ${ }^{62}$ Manuel Muñoz Barrios filed a lawsuit alleging "flawed titles" insofar that norms governing the notification process had been violated. ${ }^{63}$ Andrade $(1923,140)$ recounts that the presence of Dr. Peralta, Muñoz Barrios' lawyer and

61 The Vacant Land Act of 1865 - and reforms in 1875 and 1896 - also permitted the sale of uncultivated properties and the transfer of public land to private owners who would put it to productive use. Between 1884 and 1909, the state transferred over 115,000 hectares to private owners (Ramón and Torres 2004, 82).

62 Federico Muñoz Serrano, who held shares in the British company, issued a third-party request for the Portovelo surface estate and the Muluncay River waters, but soon withdrew his petition (Rodríguez 1992, 234). Plaintiff Darquea Luque requested the revaluation of the properties, but then withdrew his request and asked that bids for half of the appraised price be admitted and reserved the right of petition for all properties that had been seized for which a value had not been assigned (ibid., 236). After experts had priced the assets, on August 27, 1986, a judge scheduled the auction for August 31.

63 According to the 1892 Mining Law, judges had to publish a notice in a local newspaper five times prior to the date of the auction, which was to be scheduled for 40 to 50 days after the first announcement. Proceeds were to be used to recover public debts and tendering costs; the concessionaire received any remaining funds. Burnett Lowell paid in cash, the money was deposited with the local court and then transferred to British Company creditors, represented by Darquea Luque (Rodríguez 1992, 238). 
a renowned liberal politician, led to precautionary action. Newberry, SADCO's first manager, asked a local attorney to settle the dispute. Property rights were legalized through a public deed ratifying the transaction; an indication of how foreign investors were able to acquire land rights despite initial opposition from local entrepreneurs. There are no records of other complaints presuming corruption or patronage. Dubious procedures of land acquisition by foreign investors are barely registered or analyzed in the Ecuadorian historiography of the $19^{\text {th }}$ century, a signal of power relations in the archival materials and the narration of historical accounts. ${ }^{64}$

Over the next decades, SADCO acquired over $40 \mathrm{~km}^{2}$ in the Zaruma mining district and worked three main vein structures (see figure 5.1 ): ${ }^{65}$ the Curipamba system included the Fortuna, Centenario, Barbasco, Curipamba, and Oeste Curipamba mines; the Abundancia system included the Elena, Portovelo, Abundancia, Veintiseis, and Soroche mines; and the Northwest system included the Nudo, Cantabria, Tamayo, Este Tamayo, Matalanga, and Jorupe mines. In addition, work took place in isolated veins in Tablón, southeast of the

64 Ecuador was willing to surrender vacant land as payment for international debt. The EspinelMocatta agreement of 1854 and the Ycaza-Pritchett contract of 1857 ceded uncultivated lands in the Oriente and areas of Esmeraldas, Los Ríos, and Guayas provinces to pay loans from the English to finance the independence wars (Albornoz 2001; Flores 1890; Quintero and Silva 1991, 169-170). Those accounts refer to international negotiations and general procedures but do not speak to the local politics of land grabbing.

65 The following information is included in the document entitled "Concesión de la South American Development Company," CIGMA, GMMEO1423, 1944ca. 
concession; Tres Reyes, to the east; Sesmo, located north of Zaruma; Calderón and Palacios, west of Sesmo; Salvadora and Gobernadora, northeast of Sesmo; and Vizcaya, west of Gobernadora. The concession included both hard rock and placer claims, at altitudes of between 490 and 3,000 meters above sea level along the Amarillo, Pindo, San Luis, Ambocas, Grande, and Calera Rivers. SADCO also acquired rural properties, in Tablón Grande and Bella Vista, suitable for agriculture and ranching, where items such as meat and milk were produced for subsequent sale at the company store. The Zaruma-Portovelo gold district was exceptionally large, with continuous veins extending for $15 \mathrm{~km}$ from north to south, $4 \mathrm{~km}$ east to west, and with depths of up to $1.6 \mathrm{~km}$. The average content of gold in these veins was 10 to 12 grams per ton; the ore was also made up of, on average, $10 \%$ zinc, $4.5 \%$ lead, and $4.5 \%$ copper. The richest area was located near the Amarillo River, five kilometers south of Zaruma, where the South American Mining Company built a whole new industrial complex.

The American investors had to coexist with other small mine-holders. ${ }^{66}$ The matter of multiple companies operating in the area requires further study as

66 Muñoz Barrios and associates retained eight mines in the parishes of Ayapamba and Paccha as well as the San Fernando and Nuevo Portovelo mines near SADCO's camp; the Fenix Group operated the Zancudo mines; and the Anglo-French Company, represented by Chambost, continued working in the area of Malvas, Muluncay, and Minas Nuevas. Andrade (1923) made this observation, which is also included in: BEAEP. "Breve exposición de los trabajos hechos por la South American Development Company en el Ecuador," 1923ca., 3. According to this document, the company invested over one million U.S. dollars prior to 1910 with no significant returns. 
it could call into question the idea of an enclave insofar as the whole district was never fully controlled by a single corporation, despite SADCO's rule over the Portovelo camp and its pre-eminence in determining labour and trade relations in the area. Moreover, the property regime and the mining claim system required active negotiation with local powers to enforce regulations favourable to the corporate appropriation of natural resources. By way of example, the exploitation of the Abundancia vein system, one of the richest, was stopped due to adjacent claims owned by Chambost to the north of SADCO's property. 


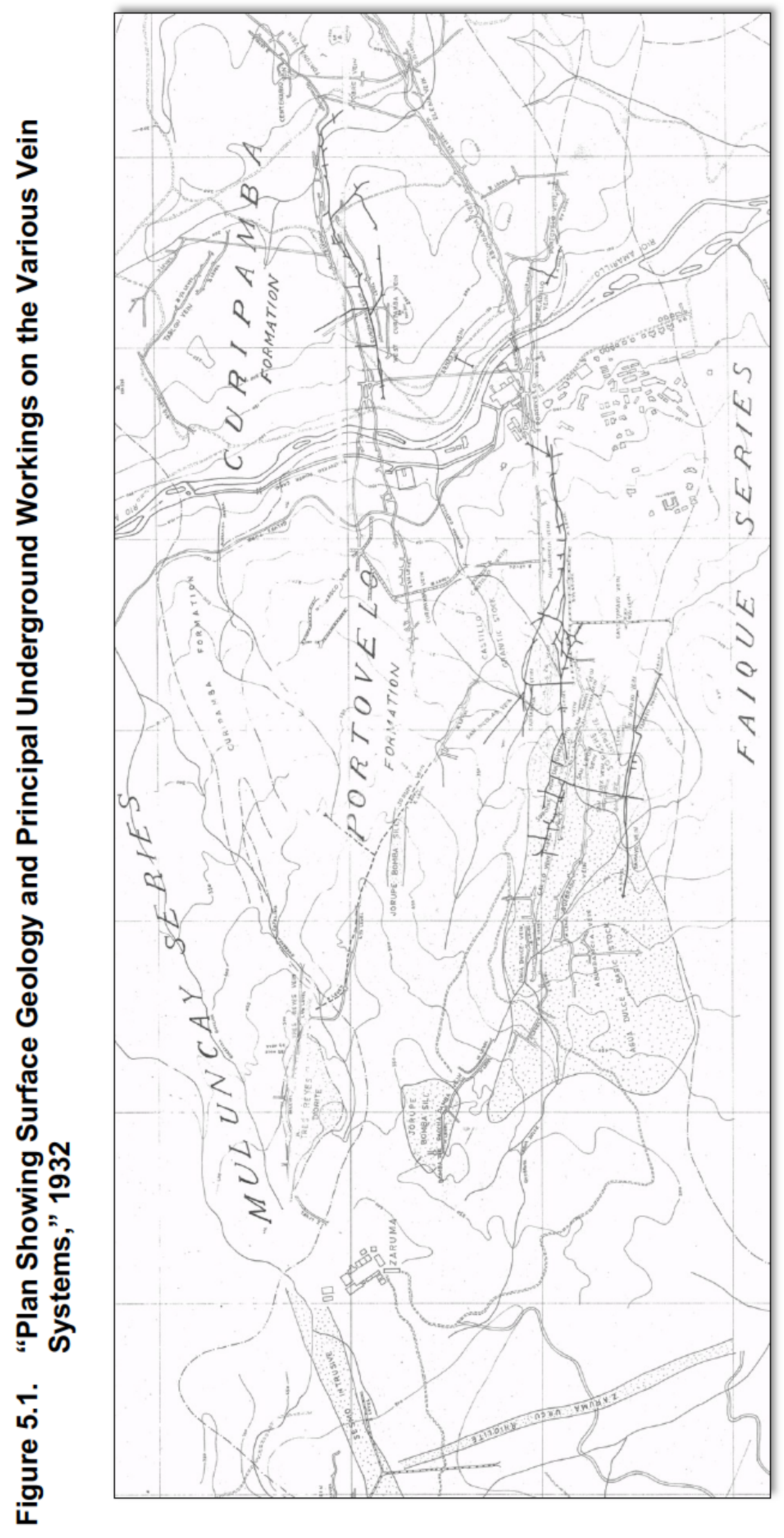

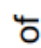

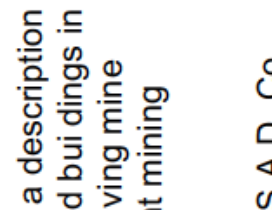

क 다월

인

융뭉

중

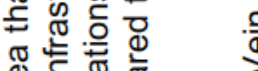

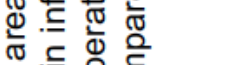

띤

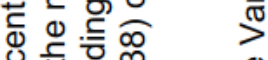

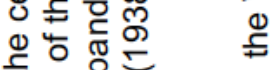

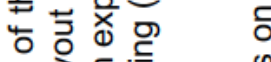

능 交.

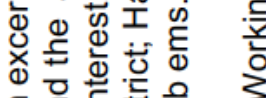

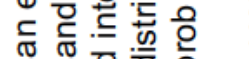

에 的边

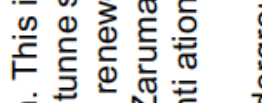

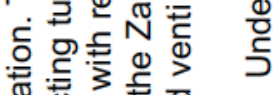

.

ऐ 융 항요

๓⿴囗十心

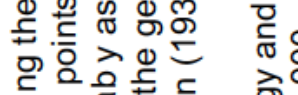

은

은

응

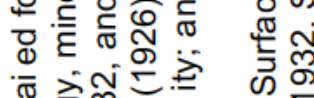

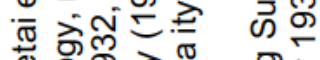

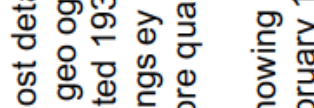

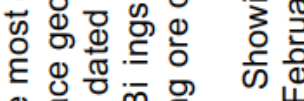

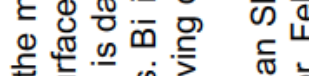

.ొ

๙

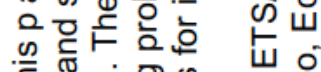

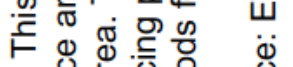

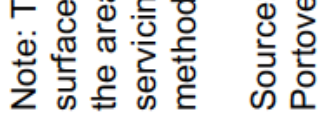


SADCO had to establish alliances and a junior partner - the Calera Exploration Company - to expand operations in this location. ${ }^{67}$ The American businessmen also established the Cotopaxi Exploration Company for exploration and prospecting in the Provinces of Cotopaxi and Pichincha. ${ }^{68}$ Presumably, both junior companies helped SADCO to divert and reduce political confrontation and exploration risks, and to evade taxes through the application of "creative" accounting mechanisms. The junior companies were a new institutional mechanism within a broader corporate strategy, specializing in the early stages of mining activity, when the risks were greatest and there was potential resistance, a feature explored by Dougherty (2011) for recent mining operations.

67 The Compañía Exploradora de Minas de Oro Pacay Urcu abandoned the claims and the state revoked the properties with expedititious procedures (Cortázar and Lavanda 2008, 74; Murillo 2000, 99). Subsequently, the mines were reassigned to Fernando Maulme. This contract was at odds with provisions in the Mining Law. As an example, the concessionaire was granted 211 holdings in the area of Minas Nuevas and Muluncay, despite the 20 holdings per claim limit. Apparently, Maulme was a front for the Americans; in 1944 he transferred all claims to the Calera Exploration Company, a junior partner of SADCO. See: "Autorización para que el Ministro de Minas otorgue una concesión a favor del Sr. Fernando Maulme." Decreto Supremo № 5; Registro Oficial, August 5, 1938, 189-192. "Contrato Adicional con el Sr. Francisco Maulme que establece prórroga de la concesión minera." Decreto Ejecutivo № 282; Registro Oficial № 293-294, November 23 and 24, 1938, 1454. "Traspaso de la concesión Minas Nuevas a la Calera Exploration Company." Decreto Ejecutivo No 50; Registro Oficial № 102, November 2, 1938, 52. In 1937, during the administration of Federico Páez, the Cotopaxi Exploration Co. acquired concessions in Pujilí, current Province of Cotopaxi. The exploration and exploitation contract granted 120 holdings for a 30-year period, including the Mercedes, Maria Luisa, Guillermina, Julia Martha, Tajaló, Elsita, Juanita, and Elena mines, as well as any others the concessionaire claimed during the five following years within a $10 \mathrm{~km}$ radius from the Mercedes mine. In 1946, the government granted an additional temporary contract to undertake exploration in 75,000 hectares, in the provinces of Cotopaxi and Pichincha. 


\subsubsection{The spread of mining technology}

The production of space involved a complex relation between the mining camp and the underground operations. In this case, technical knowledge was required for resource extraction and technologies shaped everyday routines. The Portovelo mines were little known and represented a challenge because of their complex geology; the engineering expertise and capital-intensive investments were fundamental for augmenting productivity (Haring 1938). SADCO worked at a loss for the first two decades while establishing the conditions for extraction.

The company constructed industrial facilities while reinforcing underground structures. The surface of the industrial complex included a sawmill, a chemical laboratory, a carpentry shop, an industrial blacksmith and automotive workshop, the foundry crushers, a cyanide plant, a compressor, the cellars, and a warehouse. The company established offices for general administration, coordination of subterranean mine works, and geological surveys. The camp also included offices for accounting, transportation, radio-communications, store administration, and internal policing matters. Underground, the company had to rebuild works, as supporting wood was rotten, tunnels were clogged, and "all was a pile of rubble" (SADCO 1929, 3). 
Figure 5.2. Cross-section of the Portovelo Mine Works, 1932

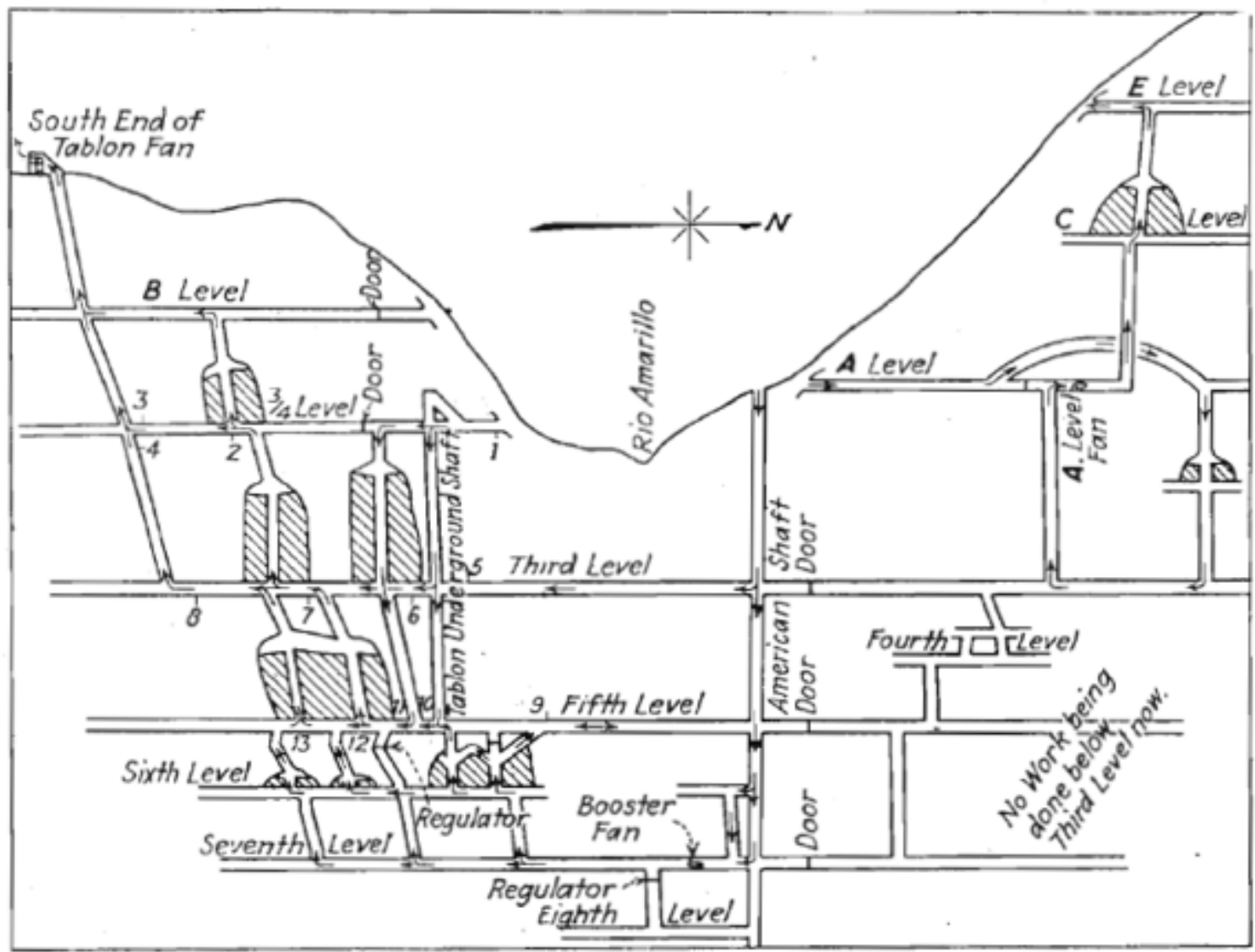

Note: Access to the mines was furnished by adits at various elevations and by two vertical shafts. The American Shaft had two compartments, one for hoisting men, ore, and waste and the other serving as a space for a ladder and air, water, and electric lines. The Tablón Shaft was a secondary winze used for servicing the mines.

Source: Harmon 1932, 4.

A problem common to mining was supplying the power needed to move workers, machinery, air, water, and ore. ${ }^{69}$ In 1912, the Portovelo Channel

The difficulty of moving equipment through the rugged terrain produced delays in the construction stage and restricted the exploration and exploitation of mineral soil, a matter explained in greater detail in section 5.3. 
(1.5 km) was finished, supplying a basic water network, and by 1916 , the Galvez Channel $(5.27 \mathrm{~km})$, with a hydroelectric installation to power the metallurgical plant and provide electricity to Portovelo and Zaruma, was up and running. Also by 1916, a vertical tunnel 390 meters deep connected thirteen levels of underground galleries for ore extraction.

The construction of the vertical shaft was a complex civil engineering project that facilitated the exploration of underground lodes and rich mineral veins. The Pique Americano (American shaft headframe) was fully lined with concrete, equipped with a steel headframe thirty meters high, and connected to a winding tower structure called El Castillo (the castle) (see photo 5.1). The elevator provided the means for men and materials to enter and exit the mine, as well as allowing light and air to enter the tunnel. There are no direct records of mineral production in Portovelo during the first decades of the $20^{\text {th }}$ century, but international gold records for Ecuador register an increase from 0.6 tonnes in 1913, to 0.8 tonnes in 1916 and to 1.3 tonnes in 1917 (Schmitz 1979, 82). These gains are probably linked to productivity associated with this particular technology, as there were no other significant investments in Ecuador's mining sector before this time. 


\section{Photo 5.1. Portovelo industrial facilities, 1925}

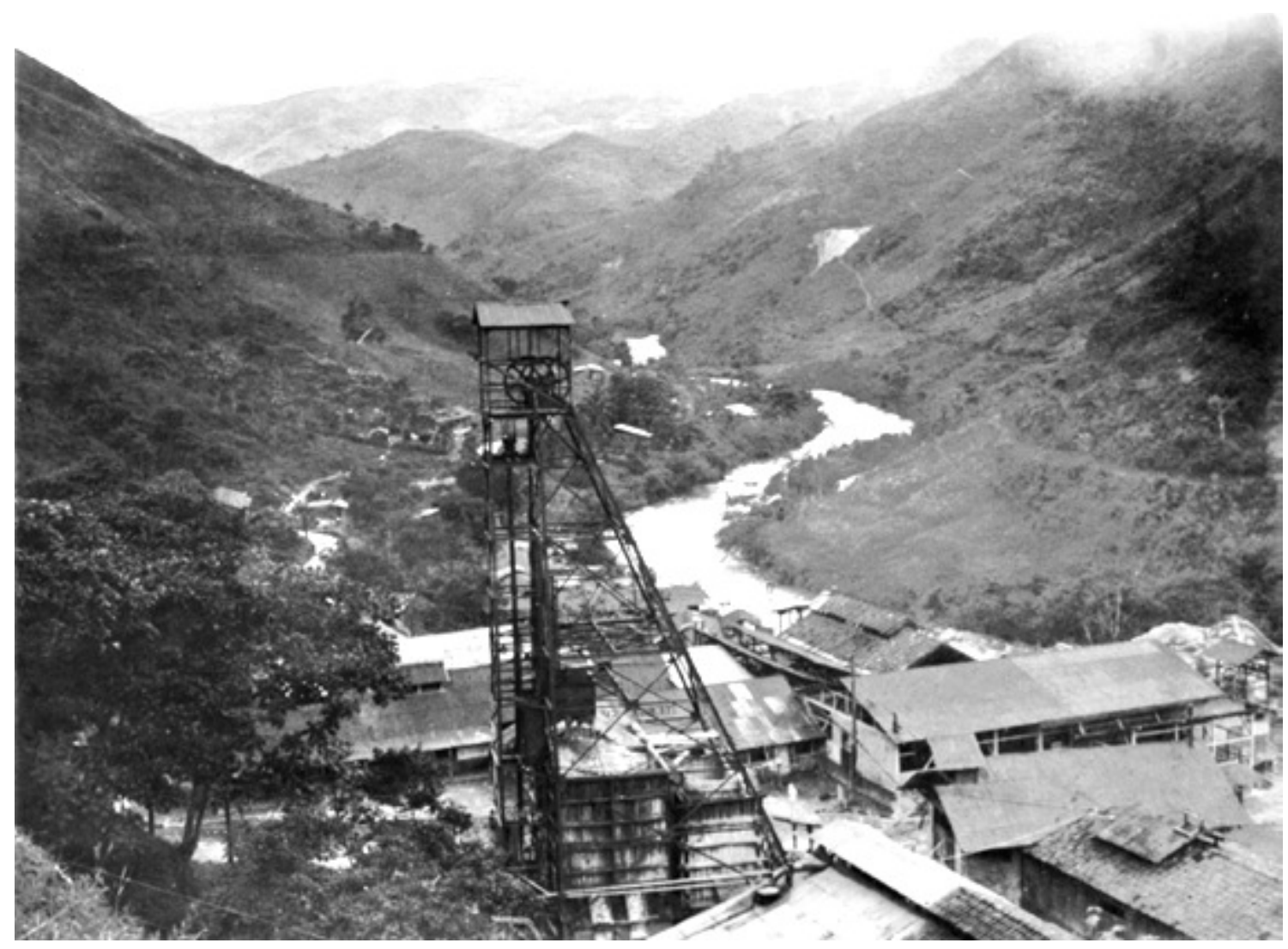

Note: The steel headframe - known as El Castillo - became the symbol of the Portovelo camp. The hoist was an Allis-Chalmers, single drum, connected to a 225 horse-power motor that moved the steel wire and the mine cage on the order of 120 meters per minute (Haring 1938, 10). Here it is surrounded by the industrial facilities near the Amarillo River and upstream the Barrio de los Cutos is visible.

Source: “El Castillo,” Cevallos 2011, 57. Photographer: Ramón Jijón, 1925.

The company carried out geological surveys and studied underground structures, identifying quartz mineralization. The mine was "developing remarkably with very rich ore in unexpected tonnage. ${ }^{\prime 70}$ Mining engineers 
developed detailed diagrams to determine the direction of steeply dipping faulted vein bodies distributed in irregular and dispersed bedded deposits, and to improve the performance of underground extraction through the filling stopes mining method. ${ }^{71}$ This method was somehow unique to the Zaruma mines, applicable to moderately wide deposits of solid and firm ore, allowing connections between levels by means of rises in the footwall through which waste material was introduced into the stopes (Crane 1910, 78-80). The mine subsequently reached a depth of 200 masl, 900 m below the uppermost workings. The method allowed for the placement of levels at a considerable distance one from another but was difficult to work on. The process caused the mixing of waste with the gold-bearing ore, and only rich material was hauled to the American shaft or the Newberry tunnel to be processed on the surface. In the latter, the company introduced locomotives to increase efficiency in transporting ore.

71 This method is relatively unusual but similar to that applied in the gold mines of Butte, Montana, US. For a description of the mining procedures and specific technical requirements see: Brady and Brown 2004; Crane 1910; Haring 1938; and Harmon 1932. 
Photo 5.2. Locomotives used to increase productivity, 1941

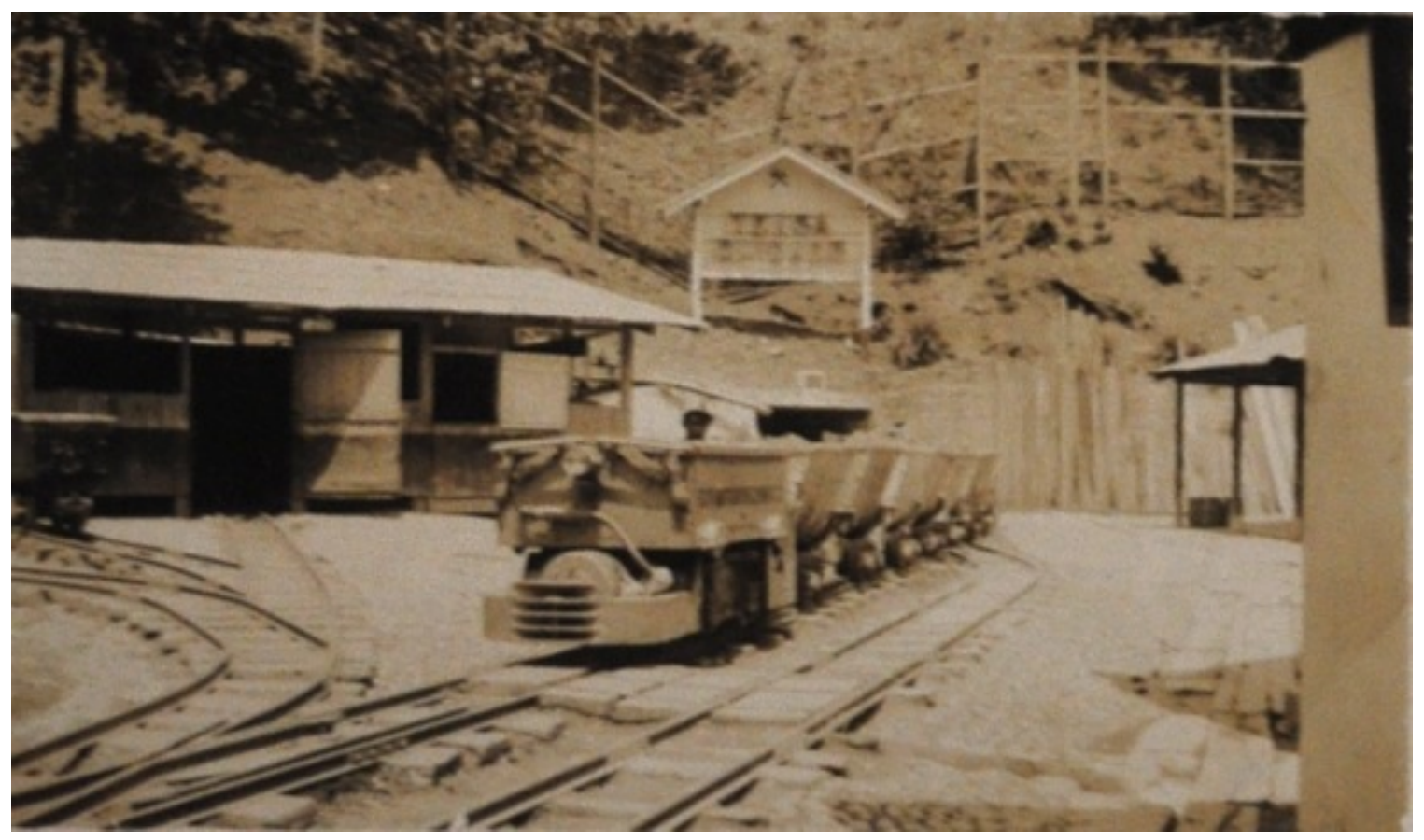

Note: The original communication reads: "To the discerning eye this picture shows mine efficiency in every detail. The yard is paved, mine timbers stand on end near the tunnel, the charging house is conveniently located, and the safety-first board is neatly painted and properly placed just above the tunnel entrance. Everything is clean. The scene is in the tropics, close to the equator, at the Portovelo mine of the South American Development Company in Ecuador." The complex operating requirements of the Portovelo mine were used for promotional purposes within the mining industry, as in this photo of Mancha's electric locomotive at the Portovelo site, used in promotional sales letters.

Source: ETSA. Communication from C.C. Austin, General Manager, Mancha Storage Battery Locomotive, Division of Goodman Manufacturing Company, to Mr. Robert W. Hughes, Mine Superintendent, Miami, March 17, 1941.

The company also operated a relatively sophisticated treatment plant to recover gold and silver. SADCO first introduced mercury amalgamation to directly recover gold and silver, and a flotation method to produce a concentrate, which was sold to smelters to retrieve the lead and copper. The company decided to change the processing method after ore volumes increased with the 
vertical shaft and a gold bullion robbery took place. In 1919, the company introduced a significant innovation: the cyanide agitation decanting system.

\section{Photo 5.3. Cyanide tanks, circa 1917}

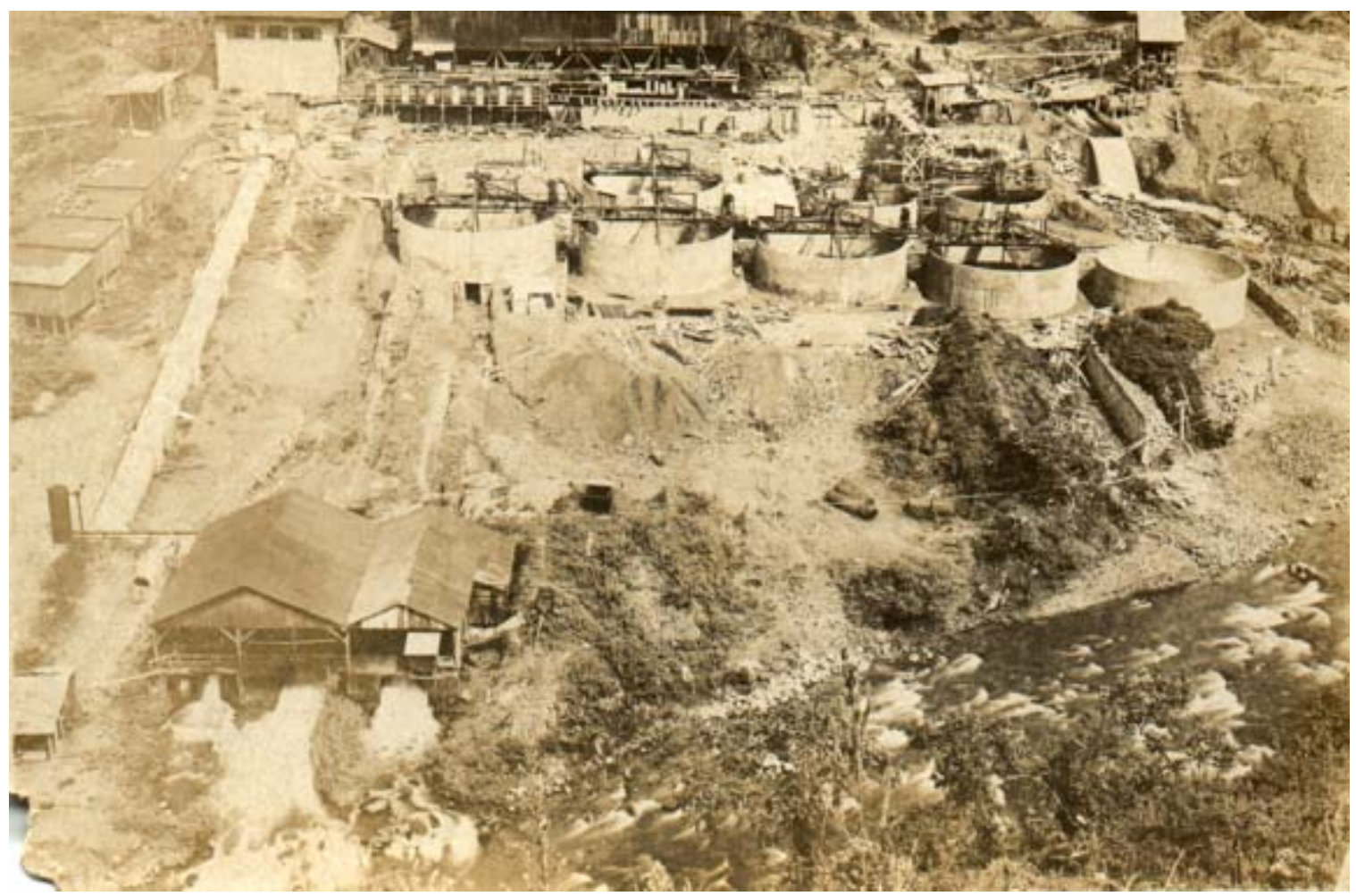

Note: Construction of cyanide tanks. Note discharge water pouring directly into the river. Wood gutters transported tailings to create a level plot - located on the left side of this photo - that would later become the much celebrated soccer field.

Source: ETSA, 1917ca.

The beneficiation process is complex and describing the full technique is beyond the scope of this dissertation (Haring 1938). However, it is important to recognize that this gold recovery technology had a significant bearing on the efficiency of plant operations and represents a hallmark in industrial mining. In 1938,510 tons of ore were milled daily (ibid., 27). The gold-bearing solution was carefully collected, treated, and stored in a vault and the overflow disposed of, 
with some loss of minerals, in the primary slimes. The tailings were then transported through wood gutters to the banks of the Amarillo River or used to level ravines that were then conditioned to build sports fields, streets, restrooms, and laundries. These dumps of low-grade mineral grounds impregnated with toxic reagents polluted the rivers, but they also became the reserves that later helped to resolve the Portovelo crisis of the 1960s.

We can assume that mercury, cyanide, and other toxic ore-related elements — including arsenic, cadmium, copper, lead, and zinc — were present from the onset of SADCO's operations in Ecuador (Appleton et al. 2001; Espinosa 1986a, 1986b; Tarras-Wahlberg 2002). However, not until the 1980s would environmental issues become a concern due to recognition of the health risks associated with artisanal mining activities and water contamination. Regulation of cyanide leakages would not come into effect until the late- $20^{\text {th }}$ century, when the state introduced norms for environmental protection and remediation (Moreno and Chaparro 2009).

\subsubsection{Socio-ecological processes}

In the mining sector, the politics of ownership and control of natural resources relates not only to subterranean mineralized deposits or the localized investments, but also to ecological processes in a more extensive hinterland. The mining laws of 1892 and 1937 separated surface estates and subordinated them to mining activities. Land resources were subject to servidumbres (easements) for mining activities; mining claim owners had the right to appropriate adjacent 
resources for extraction. The mountains and forests found on neighbouring land, whether vacant or private, could be used for providing timber, firewood, and charcoal, upon compensation to the mining claim owner. Writing in the late 1940s, Reinaldo Espinosa was the first to undertake ecological studies in the Zaruma county. ${ }^{72} \mathrm{He}$ noted the clearing of valuable forests to serve industrial needs; this, combined with slash and burn farming practices, resulted in soil erosion and reduced water sources (Espinosa 1990).

Mining operations required tremendous quantities of lumber to line and support tunnels and as fuel for the smelting process and housing construction; this item accounted for 10 to $12 \%$ of production costs. In 1938 , some 2,000 loggers provided SADCO with timber, firewood, charcoal, and mules to transport goods (Paredes [1938] 1970, 97). The company bought timber locally, posting prices for poles of different sizes; prices increased with the distance that the lumber was transported. Haring (1938) complains about the poor quality of the short-fibered timber but Paredes ([1938] 1970) notes the despotism of company

72 Reinaldo Espinosa received a scholarship to study at the Juan Montalvo High School in Quito and then another scholarship to study Mathematics and Natural Sciences in Germany. He served as Director of the Botanical Garden of Loja and Minister of Education, founded the Boy Scouts in Zaruma, and was a translator for Radio Berlin (Cevallos 2011, 24; Municipal Museum of Zaruma). In 1947, the Council of Zaruma requested a study of soils, wildlife, and alternative agricultural production as an economic alternative in view of the possible departure of the mining company. 
employees who sorted logs, rejecting those that had been damaged during transportation along winding roads. SADCO never reforested.

\section{Photo 5.4. Wood necessary for the mining industry}

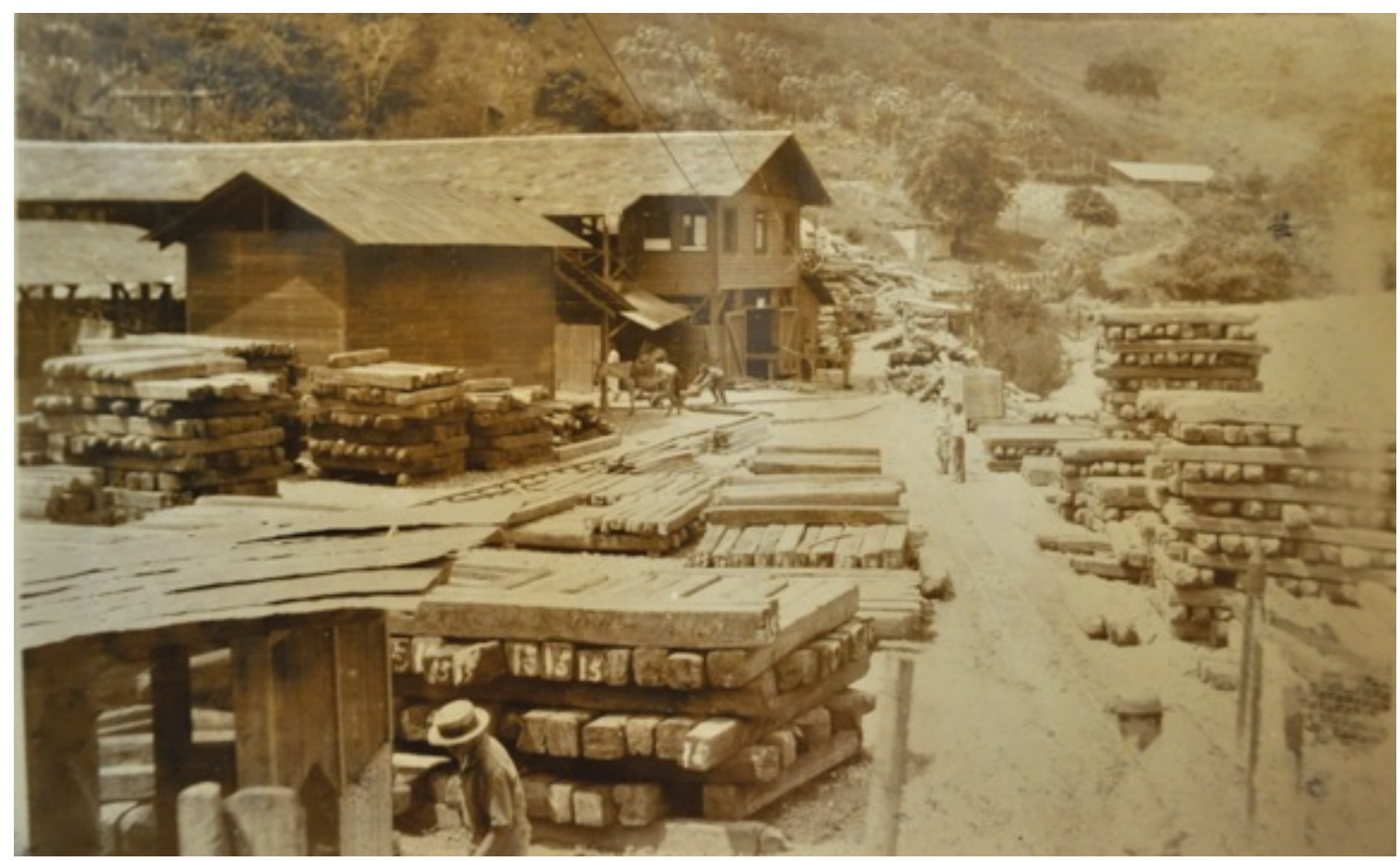

Note: Mining involved intensive wood consumption. By mid-century, deforestation for industrial needs and the absence of reforestation projects caused desertification and erosion.

Source: ETSA

Locally, material flows were transformed into municipal revenues by virtue of institutional arrangements. By way of example, appropriation of forests increased the transport of timber across Zaruma. As mentioned above, timber was a key input. However, the heavy loads transported often disrupted urban life 
and damaged infrastructure. Disruption to daily life is reflected in a municipal

ordinance "forbidding any type of timber dragging through the town's streets and bridges located over rivers." ${ }^{13}$ The mining company could not work without these raw materials and the mine manager therefore questioned the municipal ordinance.$^{74}$ Consequently, the municipality modified the ordinance due to the "practical difficulties and disadvantages" that compliance would entail. ${ }^{75}$ Thereafter, pack animal traffic and timber dragging were subject to fees. The taxation of timber-dragging was ratified a year later and remained a core body of local legislation, providing the single highest source for municipal revenues until the mid- $20^{\text {th }}$ century.

\subsection{Socio-spatial engineering and urban differentiation}

The Company has established in Portovelo, which was a miserable hamlet where a few families wracked by malaria led a pitiful existence, a model mining camp where 700 workers and their families, paid well and on time, enjoy the benefits of living and working in a hygienic, prosperous, and civilized town. It has changed Zaruma from a town of infamous repute into a hardworking, orderly city, an industrial and commercial center, in which hundreds of thousands of sucres are exchanged annually. ${ }^{76}$

AHM/Z. MMC, T.10, January 27, 1897.

AHM/Z. Communications. Received, February and March, 1897.

AHM/Z. MMC, T.10, April 29, 1897.

BEAEP. Letter from A.M. Tweedy to the Ministro de lo Interior y Obras Públicas, Documentos relativos a los contratos..., n.d. 1923ca., 28. This and all other translations from Spanish sources are mine. 
The spatial engineering of Portovelo, like other company towns, was deliberately designed in the hope of delineating social relations that would facilitate continuous and profitable mining operations (Herod 2011). The production of urban space was a means of regulating social life within and beyond the camp. The Americans wanted a healthy and docile working class infused with work habits such as discipline, efficiency, and punctuality, and moral values such as respect for authority and honesty (Murillo 2000, 142-145). The inhabitants of Portovelo associated the socio-spatial segregation and the "hygienism" of the campground with prosperity. These features reinforced the distinctive character of the enclave and helped to differentiate it from surrounding hamlets. In the colonial city of Zaruma, on the other hand, the home of conservative elites with very clear notions of the boundaries separating their territory from that of the workers and other inhabitants of Portovelo, urban beautification became a priority.

Kingman (2002) analyzes hygiene and beautification as practices linked to urbanization, industrialization, and modernism and their spread to Andean cities in the late- $19^{\text {th }}$ century. In Europe, hygiene was imposed as a disciplinary sociomedical intervention aimed at organizing the social and physical setting upon positivist principles. Kingman (2002) states that the sanitary ideal of modern capitalism was never fully implemented in Ecuador's Andean cities insofar as racial and ethnic differentiation prevailed over class relations. He emphasizes that public authorities used beautification as a means of shaping perceptions, conditioning tastes, and reasserting social relations. The ornamentation of 
houses and public spaces was a form of social engineering that created separate, exclusive, and prosperous white neighbourhoods that were off-limits to the indigenous and poor mestizo work force. Beautification helped reassert the value of real estate while perpetuating servitude relations and corporate social organization. The case of Portovelo and Zaruma brings into debate this approach. The arrival of foreign capital, wage labour, and internal migration transformed the landscape, giving rise to the co-existence of two distinct placemaking projects: while the modern sanitary model was implemented in the Portovelo camp, beautification was the priority in the city of Zaruma.

\subsubsection{The modern sanitary project of the Portovelo camp}

To house the work force, the American company built a settlement south

of the industrial site that represented a significant, modern sanitary project. ${ }^{77}$ By 1911, the "flourishing population" had a restaurant, marketplace and butcher shop; public baths and schools for both sexes; and lovely houses for company employees and sanitary houses for regular workers (Andrade 1911, 20-21). The residential area featured American-style dwellings, all painted green and white, distributed in a way that reinforced labour hierarchies and social status within the camp. The town had no clear grid pattern and the church was not the center of

77 The following descriptions come from various sources, primarily: Andrade 1911, 1923; Cortázar and Lavanda 2008; López Saa 1937; Haring 1938; Murillo 2000; Paredes [1938] 1970; and Rueda and Romero 2002. 
social life, as in other colonial villages. Portovelo was a new settlement in rugged topography composed of a migrant population who organized everyday life around the rhythms of their jobs and, as a result, professional or class identities were often more important than those associated with the land. Daily movement tended to take place around the Pique Americano, the town's most prominent building. The elevator was the entry point into the mine for men and materials. Under conditions of industrial labour, the concentration of the work force facilitated the delivery of housing and other services, the scheduling of work shifts, and policing.

The mining boom led to demographic growth and new residential sociospatial forms. By 1922, the county had some 25,000 inhabitants, with the city of Zaruma accounting for 2,668 and the company town of Portovelo about 1,300, including "70 Yanquis with their wives and children" (Andrade 1923, 101). Population growth was estimated at 647 persons per year, with significant migration from the neighbouring counties of Calvas, Macará, Paltas, and Loja, as well as from the province of Azuay (ibid., 15). The nearby neighbourhoods of Castillo, Limoncito, and El Faique also experienced significant growth. By 1937 Portovelo's population had doubled to 3,074, with an additional 2,700 persons living outside the camp (Paredes [1938] 1970, 14).

Place-making was an exclusionary process. The functionalist design separated housing spaces from those for work and leisure activities. There were three main, segregated socio-residential areas: the campamento americano 
(American camp), houses for Ecuadorian managers and white-collar employees, and housing for mineworkers. ${ }^{78}$

The Americans lived with their families in bungalows located on the higher slopes, overlooking the industrial site, close to the general office, the church, the hospital, and the social club. This area was not open to Ecuadorians and signs prohibited trespassing. The general manager had the largest house at the top of the hill, known locally as the Casa Blanca (white house). American officials lived in single-family detached cement houses featuring basic amenities and private gardens. Unmarried foreign engineers shared a common dwelling on a nearby hill, close to the Newberry Club.

78 By 1937 there were 148 company houses with a total of 956 rooms; $50.4 \%$ of families lived in one- or two-room dwellings (Paredes [1938] 1970, 30). 


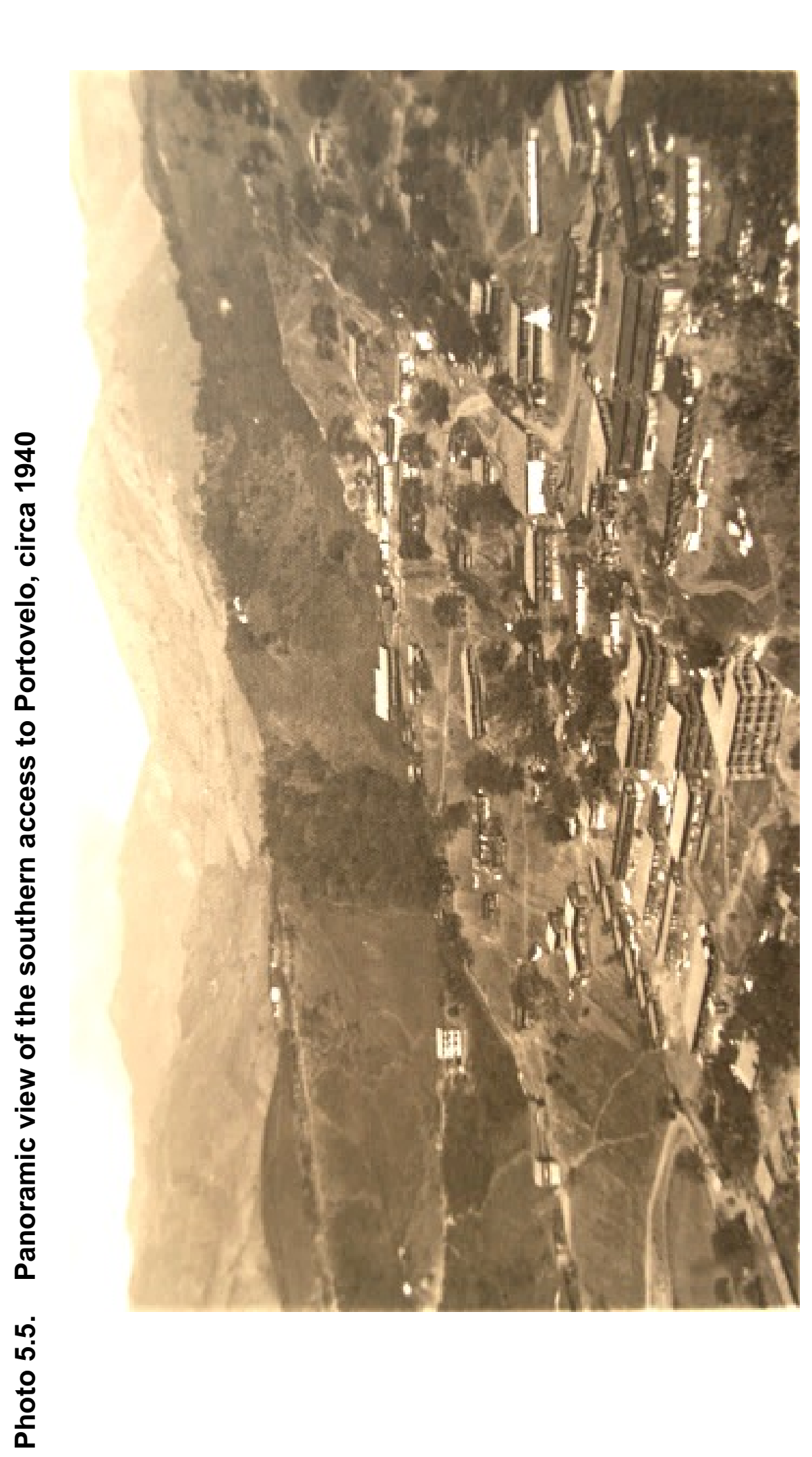

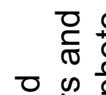

के

雨

ก

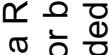

눈

œ $\frac{0}{0} .0$

की ष्ट

?드.

잉 을

웡

든

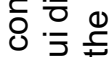

융ㅇㅇㅇ

잉 \&

क융

3.1 is

Ф $\vec{\varepsilon} \stackrel{\Phi}{\rightleftarrows}$

ö

गे

잉

4 需

응 3

ब) बे है

등

专通

के

$\stackrel{\oplus}{\rightleftarrows} . \stackrel{0}{\frac{0}{2}}$

त⿱一兀)

ฮั

की

ठु

$\pi$ \%

든

这

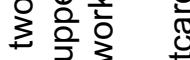

ब 仓

ब․ㅛ \&

㐫.

ह ते

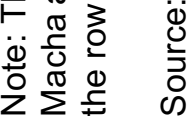


Ecuadorian employees had wooden single-family houses or duplexes and some workers' families lived in row houses along cobbled streets. ${ }^{79}$ These buildings had walls of wood planks placed horizontally rather than vertically as dictated by traditional construction methods. Americans introduced zinc roofs, a feature new to the area. Most of the male workers were unmarried and lived in a large common dormitory. After 1935, single male workers lived in multi-storey buildings in which each room opened onto a corridor and was shared by two or three workers.

When the housing shortage was at its peak, overcrowding was partially relieved by the construction of shanties along roads climbing the dusty slopes surrounding the mining camp (Paredes [1938] 1970). These eventually became informal settlements and dwellings where mine workers and service people lived. The shanty towns contrasted with the highly engineered landscape of the mining camp and reflected a practical solution to the housing shortage, but also speak to popular strategies of resistance to the discipline imposed within the camp.

There were numerous neighbourhoods beyond the industrial enclave. The Barrio Machala consisted of a group of ramshackle houses and canteens where workers, traders, craftsmen, muleteers, and prostitutes lived permanently or

79 For example, the single-family houses located in El Carretero neighbourhood had one 2.7×3.0 meter room or two 2.2×2.6 meter rooms, plus a kitchen (Paredes [1938] 1970, 32). 
rented rooms by the day. Farther away, the Osorio sector became a small hamlet of workers and merchants. Near the cemetery, north of the industrial site, close to the river and isolated from the rest of the camp, there was a small settlement of indigenous Saraguro people, the Barrio de los Cutos (Cortázar 2005, 131). The neighborhood was "an enclave where [the Saraguro] transplanted and maintained their culture, without integrating or influencing others" (Murillo 2000, 116).

The stable nuclear family household was not central to the relations of production but a privilege of the few, unlike other company towns where management encouraged workers to settle with their families as a way to increase labour productivity (Garcés Feliú and Vergara 2011; Striffler 2002). The entire work force was male and about $29 \%$ of the overall population consisted of single men living in shared housing (Paredes [1938] 1970, 15, 51). In 1937, there were 905 bachelors and 716 workers living in 356 households, with an average of 6.3 persons per family (ibid., 13-18).

In an effort to maintain order, the company separated families from single workers. According to Murillo $(2000,85)$, loneliness turned workers into violent, greedy individuals, eager for sexual satisfaction; the author claims that an atmosphere of anarchy and lust raged in Portovelo. A male culture featuring 
gambling, alcohol, violence, and prostitution caused problems in the camp, prompting the company to move those activities to the Barrio Machala, ${ }^{80} \mathrm{a}$ common strategy implemented in other mining towns (Brown 2012, 134).

After a workers' strike in 1936, the sale of liquor was banned within five kilometers of the camp: "Portovelo workers have to go to Zaruma now to get drunk" (López Saa 1937, 36). This trend resulted in an increase in the volume of alcohol sales in Zaruma, officially recorded at 11,412 liters more than in 1935, and an increase in gambling, which led to the "evaporation of surplus personal earnings" (ibid., 37). All dances, carnivals, and social gatherings were temporarily banned in the camp to preserve discipline and prevent the waste of earnings (Murillo 2000, 117).

80 The study of the biological, economic, and social conditions in the Portovelo Mining Camp, by Dr. A. López Saa (1937), is one of the first accounts of an institutional concern for the hygiene of the mining enclave. The report includes a section on alcohol, stating that the Barrio Machala had 27 cantinas. 


\section{Photo 5.6. American party at the Newberry Social Club}

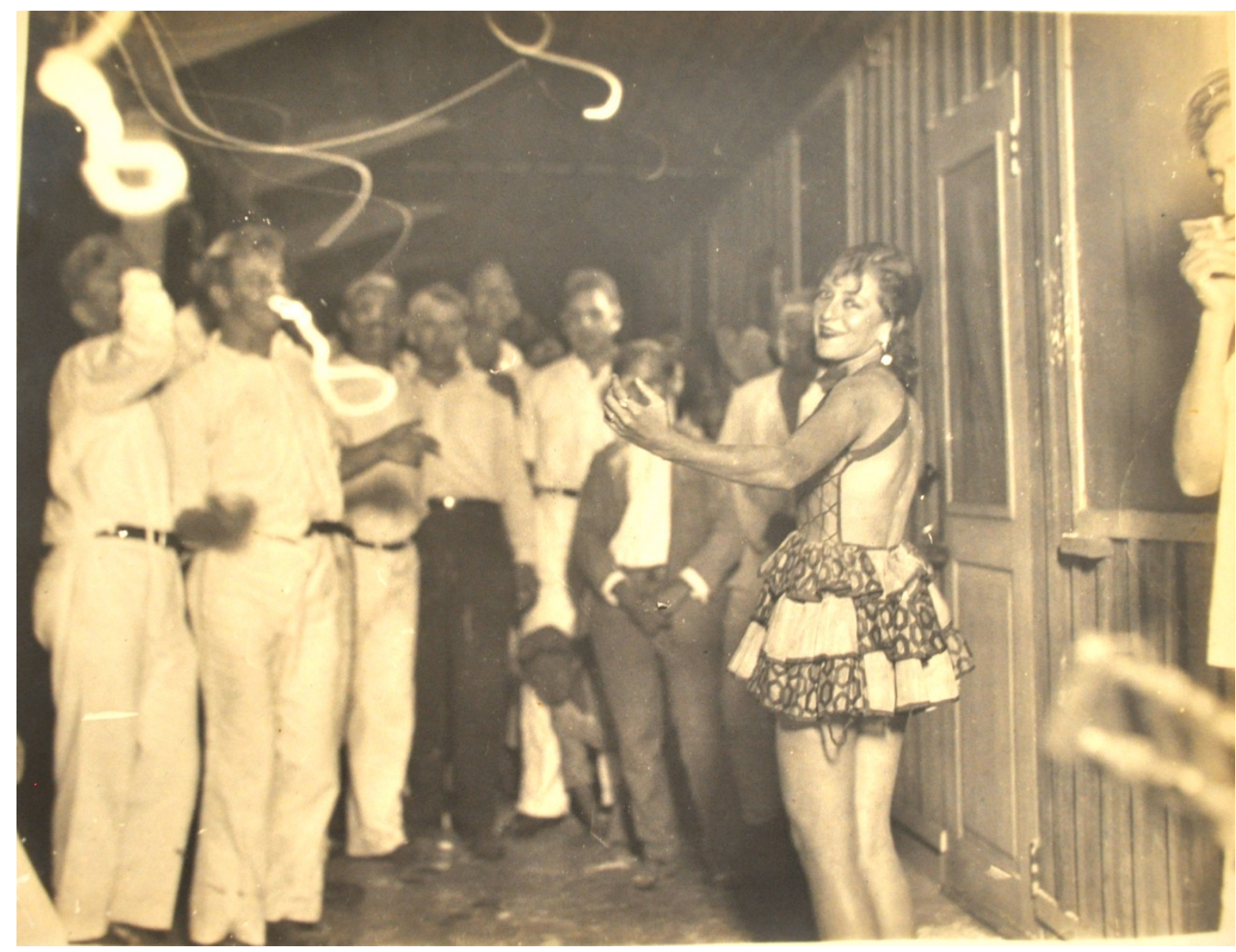

Note: This image - excluded from public circulation - reveals a party at the Newberry Social Club that seems to contradict the stereotype of work and order imposed by foreign entrepreneurs on the operation of the mining camp. Gambling, alcohol and prostitution were not exclusive to Barrio Machala or the popular sectors of the Portovelo camp but also involved American employees.

Source: ETSA. Bought from eBay by John B. Tweedy.

Socio-spatial segregation was achieved in subtle ways so as to reinforce the difference between the upper classes and the populace, and to reassert the hierarchies within the mode of production. In church, the front, padded pews were reserved for foreign residents whose names were indicated on the pews. Foreigners were welcomed at the Fonda Americana, a restaurant with linen and amenities that served vegetables and fruits grown in El Jardín (the garden), a 
private orchard that supplied American families only. Ecuadorians had access to the Fonda Nacional, a massive soup kitchen that provided meals at a subsidized price. There were even two cemeteries, one in Barrio Machala for nationals and another in the neighbourhood El Faique where foreigners were buried.

The company saw hygiene and the provision of social services as key elements to productivity. André Roosevelt, who visited in 1939, observed that the Americans had begun "a bitter battle between the hardships attendant upon sanitary conditions and disease on the one side, and sanitation on the other" (Roosevelt 1939, 2). Portovelo was once an unhealthy tropical site, plagued by marsh fever, yellow fever, hookworm disease, and malaria. In 1917, the Company contracted Dr. Michael E. Connor, who had worked on abating mosquito-borne diseases during the building of the Panama Canal, to undertake health studies, make recommendations, and build a hospital (Andrade 1923, 139-140). The spread of tropical diseases was controlled through bush clearings, and water and sewer lines helped diminish mosquito-breeding sites. Garbage was collected daily. Most of the population had potable water and dwellings were connected to sewage lines. There were also public toilets equipped with septic tanks or pipes that emptied into the river. Ricardo Paredes qualifies these services, noting that the untreated water was full of impurities, the toilets were dirty, the drains uncovered, and that these conditions were inevitable sources of infectious and parasitic diseases (Paredes [1938] 1970, 33). 


\section{Photo 5.7. The Curipamba Hospital was the most modern in southern Ecuador}

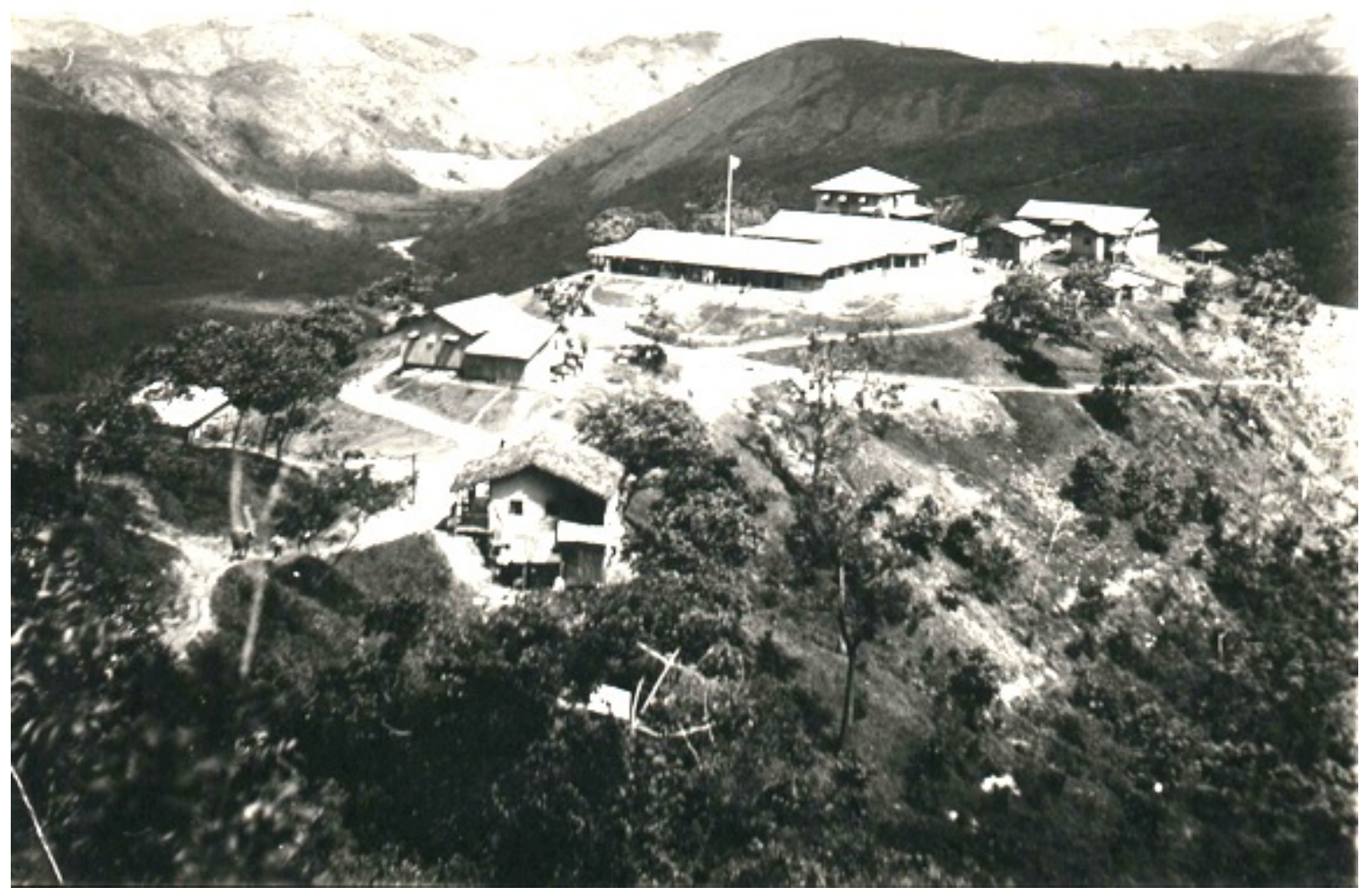

Note: Portovelo was once an unhealthy tropical site, plagued by marsh fever, yellow fever, hookworm disease, and malaria. The spread of tropical diseases was controlled through clearing vegetation and installing pipelines for water and sewage that helped diminish mosquito-breeding sites. The Curipamba Hospital was the most modern in southern Ecuador and provided free services for the work force.

Source: ETSA.

Sanitary measures were implemented to promote the well-being of the population, but diseases arising from mining activities undermined these efforts. Morbidity and mortality in the area was mostly due to influenza, malaria, dysentery, syphilis, tuberculosis, leprosy, chronic intoxication, anemia, sexually transmitted diseases, and mining work related accidents. Toxic gases, mineralized dust, and poor ventilation in the mines produced lung diseases. The Curipamba Hospital was said to be one of the best in southern Ecuador and 
provided free health services for the work force, but sick and elderly workers did not receive full wages or were fired without compensation. ${ }^{81}$ In other words, health concerns were focused on labour health, not the overall wellbeing of the people.

Vergara (2005) describes the ways in which the medical community approached and debated illnesses common to mineworkers in the 1930s, providing insights into the emergence of the concept and regulation of occupational diseases. In Ecuador, the rise of socialist ideas, the expansion of state regulation, and the process of unionization in the gold industry shaped this process. Physicians such as A. López Saa, of the Social Security Institute, and Ricardo Paredes and Cesar Descalzi, both of whom had political ties with the Communist and the Socialist Parties of Ecuador, conducted health inspections in the camp (Descalzi 1951; López Saa 1937; Paredes [1938] 1970). Medical attention for occupational diseases and industrial accidents, and extended health coverage to family members were major workers' demands in 1935 (Paredes [1938] 1970, 214-221). These were elements in negotiations with national authorities that would ultimately lead to the inclusion of specific regulations in the

81 However, the local population, with no equivalent service, had to pay for health care. In Zaruma, the municipal government financed a public hospital, opened in 1920, and the Liga Ecuatoriana Antituberculosis set up a clinic in 1949 (Rueda and Romero 2002). 
Labour Code of $1938 .{ }^{82}$ But ultimately, the modernizing sanitary project of the Portovelo camp fell short of meeting the needs of workers in an industry that, by its very nature, requires that members of the labour force work in a toxic environment and expose themselves to extraordinary risks.

\subsubsection{The beautification project of the city of Zaruma}

Understanding the difference between the Portovelo "camp" and the "city" of Zaruma is central to understanding local identities and attempts to regulate the mining industry. Local processes of accumulation became possible when increases in earnings introduced transformations in the lifestyle of the population articulated with the mining enclave. The company town provided only limited opportunities for improving living conditions but Zaruma was close enough for a daily commute. Zaruma continued being the political, religious, and agricultural center, able to capture local surplus and reinvestment in urban infrastructure. The production of space in the city of Zaruma included the enactment of urban policies and the building of public works aimed at shaping perceptions and reasserting social stratification.

82 The Labour Code of 1938, art. 303, typifies occupational diseases specific to mining activities, including silicosis, tuberculosis, and middle ear sclerosis. It also identifies risk factors in mining activities related to elements such as ammonia, mercury, cyanide acid, hydrogen carbides, and compressed and confined air. 


\section{Photo 5.8. Streets of Zaruma in the early $19^{\text {th }}$ century}

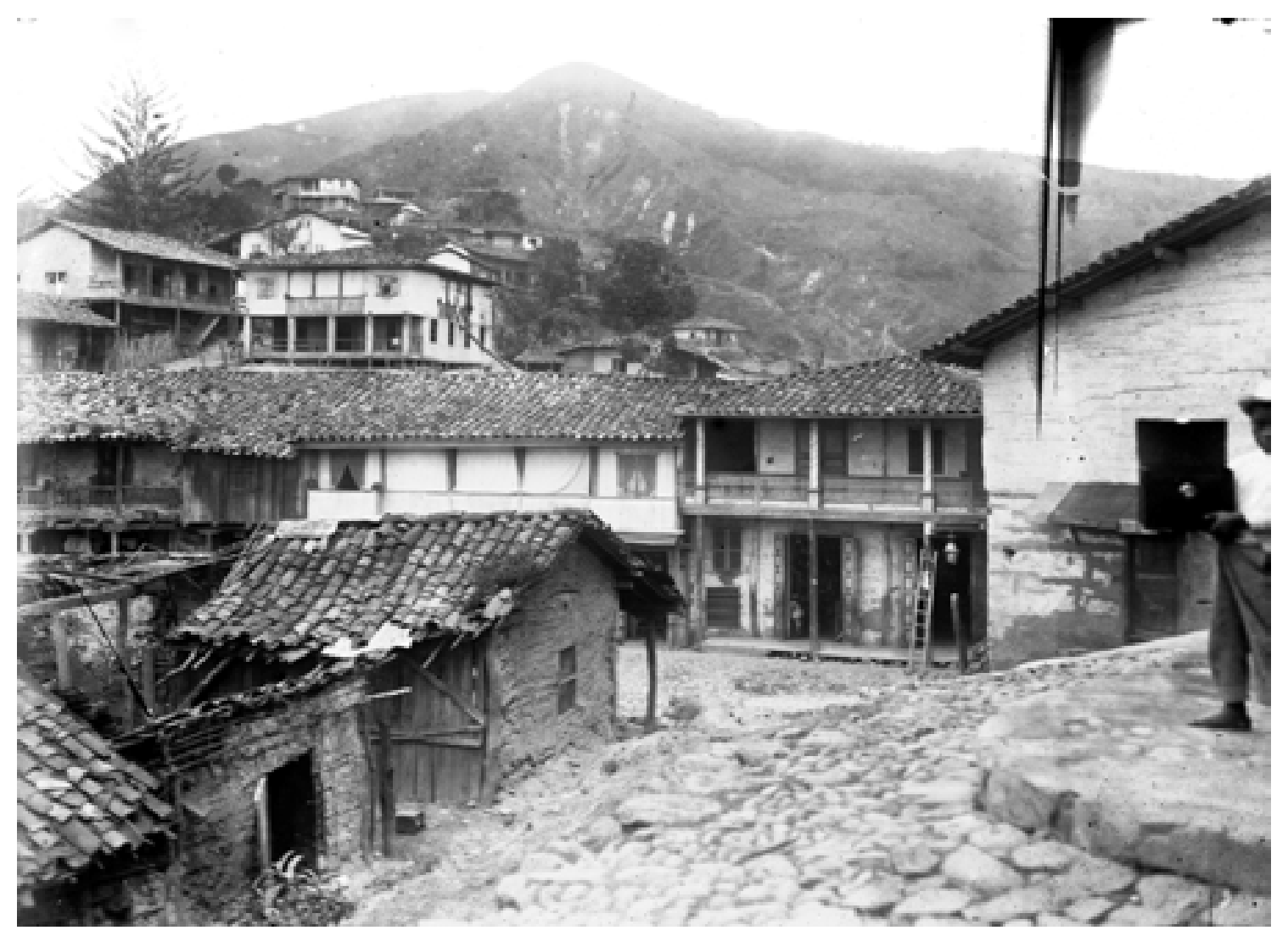

Note: Bolívar Street, seen from the entrance to the main church. In the background, the Barrio San Francisco and Mount El Calvario. Few of the houses in this photo are still standing as most of the colonial buildings were in ruins by the beginning of the $20^{\text {th }}$ century. Zaruma was one of the first towns in Ecuador to have public lighting and kerosene lanterns, both introduced in 1895.

Source: Cevallos 2011, 39. Photographer: Ramón Jijón, 1908.

Zaruma was a colonial villa nestled in the Andean landscape of southern

Ecuador, home to mining entrepreneurs, professionals, and a strong white landed elite which controlled the native population. The city was the focal point in the flow of products and people moving from rural areas in the highlands to the coast. Zaruma's professionals, merchants, and artisans worked in administrative offices, schools, markets, and churches that serviced the whole region. By 1911, Zaruma had about 2,000 inhabitants, two churches, three drugstores, a 
slaughterhouse, 20 shops, a municipal building, schools for both sexes, a telegraph office, four doctors, seven lawyers, a hostel, two taverns, three shoe shops, two tailor shops, two hairdressers, six pianos, a band of 20 musicians and good public lighting (Andrade 1911, 28).

The city developed significantly during the first years of the mining boom. Before 1900, the urban area covered 2.43 hectares, expanding to 11.69 hectares by 1935 (Municipio de Zaruma 2002, 123). The center maintained its colonial pattern, but new neighbourhoods grew in an unplanned fashion, adapted to the rugged terrain descending to Portovelo. Zaruma's municipal authorities chose beautification as the basic concept underlying the urbanization process, the promotion of capital accumulation, and the rationale for social stratification. Such a process denotes the diffusion and adaptation of urban policies.

In 1910, the Municipal Council of Zaruma issued a construction and beautification ordinance emulating that of the national capital. In the early $20^{\text {th }}$ century, Quito had launched a modernization and sanitation process to commemorate the independence centennial and public works, particularly electricity, potable water, and sanitation, became associated with progress and urbanization (Carrión et al. 1997). Urban initiatives undertaken in the capital were replicated to one extent or another in cities and towns throughout the country. The process was possible thanks to the Constitution of 1906 and the subsequent Municipal Regime Act of 1912, which granted municipalities jurisdiction over the urban process. 
The urban ordinance was applied to distribute dwellings so as to produce a harmonious urban landscape that would retain its charm over the decades. According to the law, individuals could build, refurbish, or modify their houses at will, on the condition that the results not be "capricious" but, rather, consistent with existing architecture. ${ }^{83}$ In fact, the colonial buildings were in ruins and the ordinance promoted a new urban landscape (see photos 5.8 and 5.9). The ordinance regulated construction requirements, including maximum height (two stories), alignment to the street, dimensions of entryways and balconies, characteristics of patios and eaves, and overall land use. The beautification project included a requirement for cleaning and painting façades, repairing damaged tables and curtains, regulating signs, and fencing vacant land nearprinciple streets. The construction of hovels with thatched roofs was forbidden, and industries that posed a danger to the health of residents had to be relocated on the outskirts of the city. Individual decisions were moulded through a beautification policy.

The municipal regulation was a means of producing a material reality linked to the mode of production. Lefebvre $(1991,76)$ highlights that within urban settings, "suplus production [is] put to an aesthetically satisfying use." The

83 Home owners had to submit construction plans signed by an architect or registered carpenter to the City Council where authorities inspected and approved the design and granted construction licenses. See: AHM/Z. MMC, T.13, July 23, 1910, 78-81. 
buildings constructed during the gold boom gave way to a particular type of architecture, with carefully crafted woodwork and a tiled roof (Viteri et al. 1974, 85-91). The distinguishing characteristics include lathed balconies, ornamental fretwork, and polished orthogonal boards to hide structural columns. This style is a mixture of the coastal housing patterns developed during the cacao boom, with fine timber and materials characteristic of the highlands. Zaruma's influence on housing design eventually spread to Piñas, Pasaje, Santa Rosa, and Machala. The city's distinctive character would lead to its recognition as part of the country's national heritage in 1990 (Municipio de Zaruma 2002). 


\section{Photo 5.9. Zaruma's urban landscape after the Construction and}

Beautification Ordinance, 1947

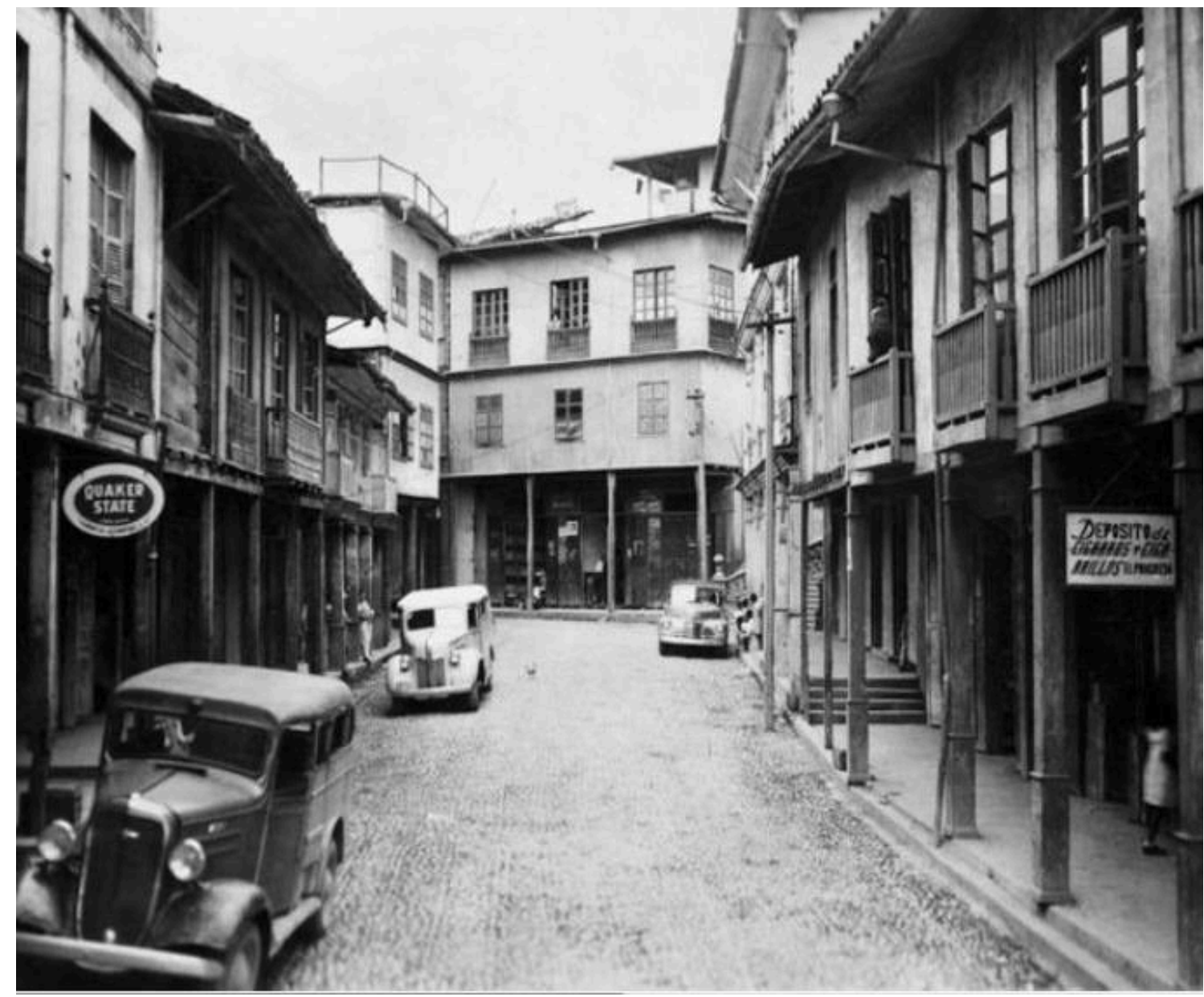

Note: Bolívar Street. Note the cobbled streets, portals, and balconies as defined in the Construction and Beautification Ordinance of 1910.

Source: AHM/Z. "Calle Bolívar," Album Municipal, T.II., 1945-1950; Cevallos 2011, 86. Photographer: León Jiménez Ramírez, 1947.

The municipality of Zaruma improved urban infrastructure in different ways. The Council allocated resources to build facilities such as public restrooms and laundries, a market, and a new municipal building. The municipality paved 
the streets with quarry stone in $1915 .{ }^{84}$ The new church, the center of urban life, was inaugurated with a clock tower and a siren in 1922 (Rodríguez 1992b). At the same time, the old central square was transformed into a park with landscaping design, palm trees, and a central fountain. Zaruma was one of the first towns in Ecuador to install electricity and streetlights in 1921, and the first potable water system was finished in 1929. In the following decade, the municipality constructed new public buildings - the public hospital, the new municipal hall, public laundry areas, and a new market (Rueda and Romero 2002). In the 1940s, extraordinary revenues linked to mining royalties enabled the construction of a new potable water system along with the Guillermo Maldonado Municipal School, the Municipal Market, the Trébol Sports Circle, the MAESJI Theatre, the school of the Francis de Sales religious order, and the Ecuadorian Anti-tuberculosis League's hospital.

As in Spanish colonial villas, the production of space included a hierarchical organization of space in a progression outwards from the central plaza (Lefebvre 1991, 151). Clearly, the beautification ordinance, the public works, and the sanitary measures benefited the accumulation of urban elites and reinforced socio-residential segregation. Housing became an indicator of power and social prestige, reflecting individual preferences and whims. The most

\footnotetext{
84 AHM/Z. MMC, 1915, Various records.
} 
prestigious residences were located near the central square. The houses located in this area were extensively decorated with cornices, balconies, decorative woodwork, and pillars. Property ownership in the urban center was restricted to social and economic elites. Workers were relegated to neighbourhoods such as Castillo, Limoncito, El Faique, La Libertad, and Barrio Obrero.

The practical and material transformation of Zaruma's urban landscape cannot be separated from the circulation of surplus value in a wider hinterland. The regional economic dynamism, the opening of new roads, and urban improvements became associated with progress and development, attracting population at a time of economic crisis at the national level. By 1934, the county had 44,690 inhabitants, with Zaruma, Portovelo, and Malvas accounting for 32,192 of the total (Madero 1934, 101). In 1935, the town of Portovelo and the hamlets of Soroche, Faique, and Castillo had 3,074 inhabitants (Paredes [1938] $1970,14)$. There are no clear accounts of the number of mine workers, national staff, and service people living in the city of Zaruma. However, some lawyers, engineers, doctors, and miners working in the camp lived there and employees frequented the taverns, stores, and services located in Zaruma. We can also assume the existence of a floating population linked to trades and crafts. 
Photo 5.10. Panoramic view of Piñas, 1937

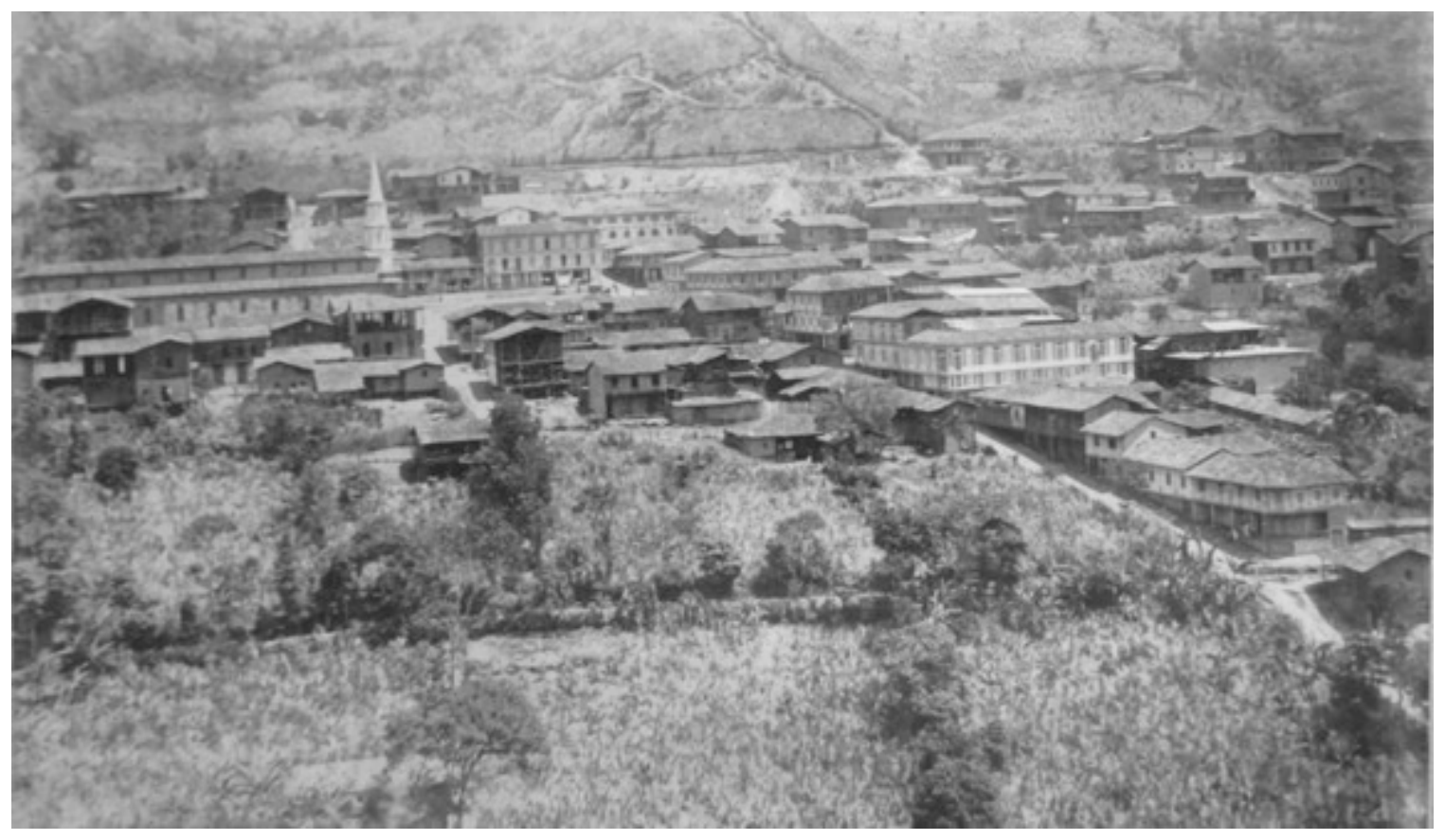

Note: Piñas developed into a wealthy township and trading post supplying the mining district. The urban landscape resembles the architectural typology of Zaruma rather than the industrial design of the Portovelo camp.

Source: AHM/Z. "Vista General de Piñas - 1937," Album Municipal, T.I., 1931-1944.

The expansion of capitalism in the region included services related with the mining industry. Villages along the route connecting the mining district to the seaport developed into trading posts. For example, by 1935 the town of Piñas had 7,318 inhabitants, more than the population of Zaruma. Growth was linked to agriculture to supply the Portovelo camp, the construction of the railway system to the mining district, and the early development of banana plantations in El Oro 
Province ${ }^{85}$ Higher wages made possible the consumption of industrialized goods and the consolidation of a commercial and financial bourgeoisie in Zaruma, Piñas, Machala, and Guayaquil. Piñas developed a wealthy elite whose members worked for almost 50 years, in one way or another, to turn their territory into a county, that is, to declare their independence from Zaruma. Francisco Carrión, a successful merchant, was one of those involved in lobbying national authorities to declare the parish an autonomous jurisdiction, but Zaruma's municipal authorities resisted this effort as the taxes collected in that prosperous parish funded public works. This tension between capitalist accumulation and territorial autonomy would become a recurring issue for decades, as will be explained below.

To sum up, at this stage there was no such a thing as a national state space capable of regulating the production of the urban landscape in the remote mining district. Both capitalists and territorial powers, influenced by extra-local urban rationalities and practices, had the partial autonomy to define urban policies. The company congratulated itself for having built a hygienic and prosperous camp. Portovelo was characterized by socio-spatial segregation imposed by a foreign authority, based upon sanitation, and productivity. Internal

85 Piñas produced sugar, alcohol, coffee, nuts, corn, rice, peanuts, manioc, banana, carrots, pork, lard, and eggs, most likely supplying the mining camp and exporting surplus to national markets and Peru (Madero 1934, 116). 
differentiation revolved around a mobile foreign work force unwilling to accumulate surplus value within the local urban landscape who, consequently, settled in surrounding neighbourhoods. Meanwhile, some workers and wealthy national employees settled in Zaruma where living conditions were better. As discussed, local elites used beautification and sanitation policies to reassert local power in Zaruma.

The ornamentation of houses and public spaces was a means of accumulation that helped consolidate the urban core while reinforcing distinctions between the prosperous local population, on the one hand, and the general populace and the Americans themselves, on the other. Zaruma did experience modernization, but the aim of the municipal policies remained racial differentiation, decency, and privileged access to the urban center. In Portovelo, on the other hand, the modest, picturesque houses of the American camp were destroyed over time; no one was interested in or, in the case of the workers, had the financial means to, invest in the mining camp, a subject I return to below. As a result, today Zaruma is recognized as a national heritage site and a source of national pride while Portovelo is just another ordinary, unsung town of little interest to national authorities. 


\subsection{Overcoming (and working with) relative isolation}

For Harvey $(1989,2005)$, the time-space relation and the "friction of distance" constitute a key element of capitalist accumulation insofar as it imposes transaction costs on any system of production. The inaccessibility of any given location from centers of capitalist accumulation is both a barrier to and a defense against such accumulation. Investment in transport infrastructure is a necessary precondition for exchange, production, and consumption processes, and is also required to liberate other forms of capital and labour (Harvey 2005, 75). In the mining enclave, these elements not only refer to investment and innovations in transport and communication necessary to connect the extractive region with the seaport and the metropolitan markets so as to ensure the flow of goods, labour, and capital, but also involve narratives of isolation, abandonment and political practices to gain access to the centers of political power at the national level. The spaces thus produced can be understood as functional to a hegemonic class or a mode of production whereby political-economic processes have a prior determining role in relationship to society.

However, the apparent annihilation of space is accompanied by a proliferation of places and connections that transform and "ground" extractive capitalism in national political processes. Rather than naturalizing the existence of transportation systems to sustain extractive capitalism, I shed light on the genealogy of such transportation infrastructure, highlighting the discontinuity, the uncertainty, and the constant negotiation required for its completion and 
functioning. In fact, the first attempts to regulate the mining industry involved requiring it to pay for such infrastructure.

Zaruma was isolated from the rest of the country. The rugged topography and lack of means of communication made this area a "hidden treasure" (Jaramillo Alvarado 1955, 415). Santa Rosa, the nearest coastal port, was 80 kilometers from Zaruma and three-days travel on horseback along steep slopes. Loja and Cuenca, cities in the interior, were connected to the outside world by narrow, unpaved roads subject to landslides, while villages and hamlets relied on mule-paths; maintenance in all cases was difficult. SADCO's arrival led to placebased arrangements for the re-investment of gains and royalties in roads and other infrastructure to support mineral production. ${ }^{86}$

To "make a bonanza out of an industrial enterprise", as stated by the newspaper The Spirit of the Age, the American mining entrepreneurs required people, supplies, machinery, and infrastructure. The extractive industry depended on external resources and markets to retain its work force, sustain the local consumer population, and ensure surplus outflows. Haring $(1932,4)$ reports that "transportation of materials and supplies to the mine was one of the most

86 In 1899, royalties were established at 10 sucres per unexploited holding and 50 sucres per holding under active exploitation. Those revenues were earmarked for the opening and maintenance of roads connecting the mining fields to the nearest coastal port. See: Decreto Legislativo n.n., in: Registro Oficial, № 969, October 10, 1899. 
difficult problems which had to be faced and solved before the mine could be regarded as economic."

The transportation of industrial materials was a monumental undertaking. Equipment was transferred at Guayaquil to riverboats sailing to Puerto Bolívar. Machinery parts were loaded by men and transported by mules along narrow paths often following mountain ridges that topped the steep walls descending into deep ravines. On arriving at their destination, the machines were assembled by company employees. As many as 2,000 mule-loads of freight moved over the mountains per year into the area. Schraps (n.d., 33) recalls that in 1916 "the muletrains were always under the care of arrieros or muleteers who ran on foot ahead or behind the mules shouting at them and beating them with clubs when necessary." For long stretches, the path was marked by a series of deep muddy depressions and the overloaded mules had to cross from one side of the trail to other in search of a point to cross. The ruta de las escaleras (stairs route), considered the most dangerous stretch, was the site of frequent accidents (Aguilar, 1990). 


\section{Photo 5.11. Mule train with cable on the stairs route}

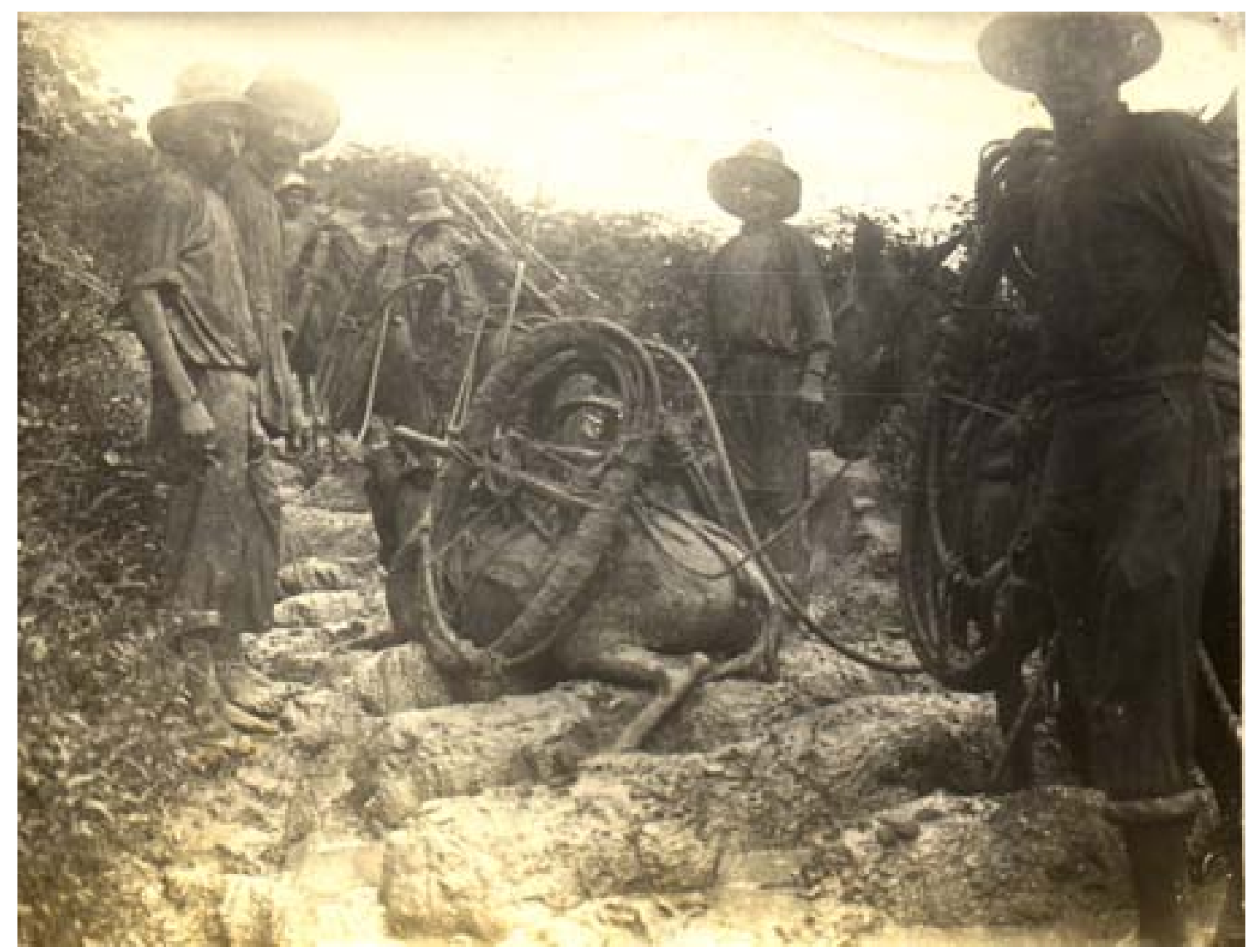

Note: Mules were used to carry machinery from the coastlands along narrow, uneven trails. A string of 12 mules carried the steel cable for the American Shaft. Since the cable could not be cut and each mule could not carry more than 200 pounds, the cable was rolled into smaller coils that remained connected and connected the mules to one another, as can be seen in this photo. Ox carts were used for timber dragging and heavy loads through less challenging terrain.

Source: ETSA.

A variety of interest groups agreed on the need for an all-season route connecting the mining camp with international markets. At the national level, the railway was one of the few issues on which liberals and conservatives, that is, the coastal export agricultural sector and the landed elites of the highlands, respectively, were able to agree. The Guayaquil-Quito route, inaugurated in 1908, was the "redemptive work" that, it was hoped, would bring Ecuador out of 
obscurantism (Clark 1998, 43). This process accentuated the peripheral condition of towns that remained isolated from this infrastructure and from the main urban centers (Deler 2007). Regionally, the landed elites from Cuenca and Loja competed for resources for infrastructure that would reduce distance and connect them to capital flows. Locally, municipal authorities focused much attention on road and railway projects; land was designated for the project, ${ }^{87}$ as were lumber and funds for the construction of the bridges over the Calera, Amarillo, and Luis Rivers (Rueda and Romero 2002).

The mining companies had to provide the infrastructure necessary for the sustained extraction of resources to capitalize on their investment. The Zaruma Gold Mining Company was the first to promote the construction of paths able to support heavy loads. ${ }^{88}$ This company undertook studies for a railway and began the construction of a road between Santa Rosa and Piñas (Andrade 1923, 114). Later, the Central South American Company, incorporated in the United States and apparently linked to SADCO, presented a proposal for a railroad linking

87 ANE. Communication from Francisco Darquea, Governor of El Oro, to Ministro de lo Interior y Municipalidades, Machala, April 5, 1904; this document includes the resolution of the Municipal Board, February 19, 1904. Serie Min. Interior, El Oro, C.16, Expediente Abril.

88 In April 1883, the Provisional Government in Quito reached an agreement with Muñoz Barrios to build a road from Santa Rosa to Zaruma. A year later, in May 1884, via Decreto Legislativo funding was provided for the road connecting Loja to Zaruma (Jaramillo Alvarado 1955, 416). 
Puerto Bolivar, Zaruma, and Loja. ${ }^{89}$ In turn, Chambost, owner of the Muluncay

Mines, presented another proposal, which was more favourable to the national

government. ${ }^{90}$ None of these initiatives was implemented. Foreign entrepreneurs

had few resources and little institutional support for the construction of expensive infrastructure.

Residents of Ecuador's southern provinces had for centuries lobbied for a road to the coast. The archives are replete with statements that emphasize the provinces' isolation from national and international markets. ${ }^{91}$ The road would serve multiple purposes: it was a means to promote development, to connect with modernity, to attract foreign investments, and to ensure the flow of political power and mineral resources. The provincial government created the Junta de

89 George Mumford (1900) suggested a concession agreement for ninety-nine years and demanded the exclusive right of way. The proposal included the right to build coastal harbours, stores, and warehouses, and to operate a steamship line between Puerto Bolívar and other domestic and foreign ports. The allocation or expropriation of land and bridges was deemed the responsibility of the national or municipal governments, at no cost to the Company. The proposal also included a request for exemptions from taxes and tariffs on supplies, materials, and equipment necessary for construction, and release from all military and civil duties for Company workers and employees.

90 The proposal included a request for a fifty-year lease on the main railway, 25,000 hectares in exchange for each kilometer built, and land settlement for new (non yellow or black) settlers in agricultural or industrial colonies. The benefits for the national government included, among others, no fees for the transport of public and official correspondence, express trains for the president and his cabinet, half-price fees for transport of government or municipal goods (Unos Imparciales 1903).

91 From early years of republican life, residents of the province of Loja had requested a route to the coast. In 1865, the national government approved funds for a road to Peru, but work was delayed and suspended repeatedly due to border conflicts or lack of money. Regional congressional representatives lobbied without success for inclusion of the road in the national budget (Jaramillo Alvarado 1955, 415-416). 
Caminos de Loja (Loja Roads Board) to coordinate actions to facilitate the construction of the road to the coast. ${ }^{92}$ Clark $(1998,80)$ highlights that "as indigenous labourers petitioned central state authorities to protect them from the abuses of local officials, orders were passed down the administrative hierarchy to constrain the activities of the local authorities, leading to a gradual strengthening of the central state and undermining the local forms of political power." The Loja Roads Board would remain in existence over the years, but the abolition of the special labour tax after the Liberal Revolution of 1895 and the greater reliance on income from the central government affected public works. ${ }^{93}$

In the early $20^{\text {th }}$ century, transport infrastructure and economic prosperity were seen as parallel objectives. Authorities and residents of El Oro and Loja provinces lobbied for two railways: one along the coastal plains (Ferrocarril del Pacífico) and another heading to Loja (Ferrocarril de la Frontera Austral). The Province of Azuay also asked for a railway connecting Cuenca to the coast via Huigra or Sibambe. However, the technical challenges of the route, budget shortfalls, and regional disputes ended any possibility of a railway to Loja or

92 This board was created in 1886 and chaired by the Governor of Loja. The Junta Directiva (board of directors) included representatives from the municipalities of Santa Rosa and Zaruma to oversee construction of the route to the coast. A public official, the colector de fondos de puentes y caminos (bridges and roads funds collector), was responsible for coordinating the work and verifying its progress (Rueda and Romero 2002). The teniente politico had to supply workers, as established by a special tax (Andrade 1923).

93 On December 28, 1895, a presidential decree abolished the special labout tax that forced indigenous populations to work four days per year on public works. 
Cuenca (Jaramillo Alvarado 1955, 420). The tensions associated with the railway would later become crucial in the regulation of the mining industry.

The railway to the mining district was declared a matter of national interest, which demonstrates the power of the economic groups lobbying in the area. Chambost, represented by Carlos van Isschot, was awarded the contract to build the railway from Jambeli to Minas Nuevas. ${ }^{94}$ The government facilitated the expropriation of land and granted privileges to those holding mining claims. The train would carry ore and also provide service to the public by transporting goods and passengers. The railway contract stipulated that the concessionaire would not pay taxes, customs, or duties. The government did not guarantee the permanence of such laws; this was a time of political confusion and constant changes in the regulatory framework. The central government was cautious about corporate practices and established a clear mechanism to prohibit the sale or transfer of duty free items, with verifying procedures and a timeframe to finish the project. Again, this did not happen. The false appraisal in the cost of building this transportation system demonstrates the gap between the state's will to regulate and its actual ability to realize projects that require substantial investment.

94 "Contrato de Construcción Ferrocarrilera entre el Supremo Gobierno del Ecuador y el señor Carlos van Isschot," in: Registro Oficial, № 546, July 2, 1914, 1524-1527. 
In 1910, SADCO signed a contract with the Liberal government of President Eloy Alfaro to build the road between Santa Rosa and Zaruma. ${ }^{95}$ The agreement established a two-year period to submit plans and a six-year timeframe to finalize work. By 1917, SADCO had partially opened a road to a place called La Chilca, but tropical storms and landslides destroyed it (Jaramillo Alvarado 1955, 417). SADCO argued that the civil war in Esmeraldas, World War I, and alcohol consumption by workers hindered progress. ${ }^{96}$ The American businessmen were unable to fulfill the contractual terms and the construction period was extended for another six years. By 1923 the road was not yet finished and the Congress called in guarantees and signed a transaction agreement that allowed the company to offset its obligations by providing 130 kilometers of rail materials. ${ }^{97}$

95 The institutional implications of the renegotiation will be discussed in subsequent chapters. A complete debate about this case is included in: BEAEP. "EI Gobierno del Ecuador y las compañias extranjeras. Documentos relacionados con la Reclamación Ecuatoriana" in: "Memorandum. El Gobierno del Ecuador y la South American Development Company. Proyecto de Solución de Negocios," Imprenta del Ministerio de Gobierno, Quito, 1938, 11.

96 High levels of alcohol consumption were reported as a constant problem, leading to absenteeism and supervisory measures to control the work force. Source: BEAEP. "Breve exposición de los trabajos hechos por la South American Development Company en el Ecuador," 1923, 5.

97 "Contrato entre el Supremo Gobierno de Ecuador y la South American Development Company," in: Registro Oficial, Nº 952, December 17, 1923, 2324-2327. 
Throughout the 1920s, the decline in government revenues resulted in the near paralysis of all public works projects. ${ }^{98}$ Public expenditure was limited to the improvement and expansion of some roads and the completion of the railroads to Ibarra in the northern Andes and to Portovelo in the southern Andes. At that time, transport infrastructure was built by hand, with intensive use of manpower and long delays. In 1924, Raúl González, member of Congress and native of Zaruma, informed the local population that the railway would not reach the city (Rueda and Romero 2002). Immediately, local demands appeared in the main newspapers in Quito and Guayaquil. The municipality reacted by lobbying national officials and raising funds to build the Portovelo-Zaruma road to link the urban center to the train station. The municipality financed the construction of bridges and mule paths with funds from its annual budget and the road was finally opened to traffic in 1930 (Madero 1934c, 110). The railway from Puerto Bolivar to Piedras was finished in 1938, shortening the trip from Guayaquil to Portovelo from five days to 20 hours. until 1948, when banana production took a leading role in the national economy (Quintero and Silva 1991, 402). Witch's broom disease wiped out cacao plantations in 1922 and production from African cacao plantations caused a drop in international market prices (Larrea 2005). The foreign trade deficit created by the collapse of export earnings resulted in a drop in capital inflows and an inflationary process: the price of the U.S. dollar stood at 2.25 sucres in 1920, rose to 5 sucres in 1926, 10 in 1934, and 13.50 in 1949. 
Photo 5.12. Train at the Piedras station, circa 1938

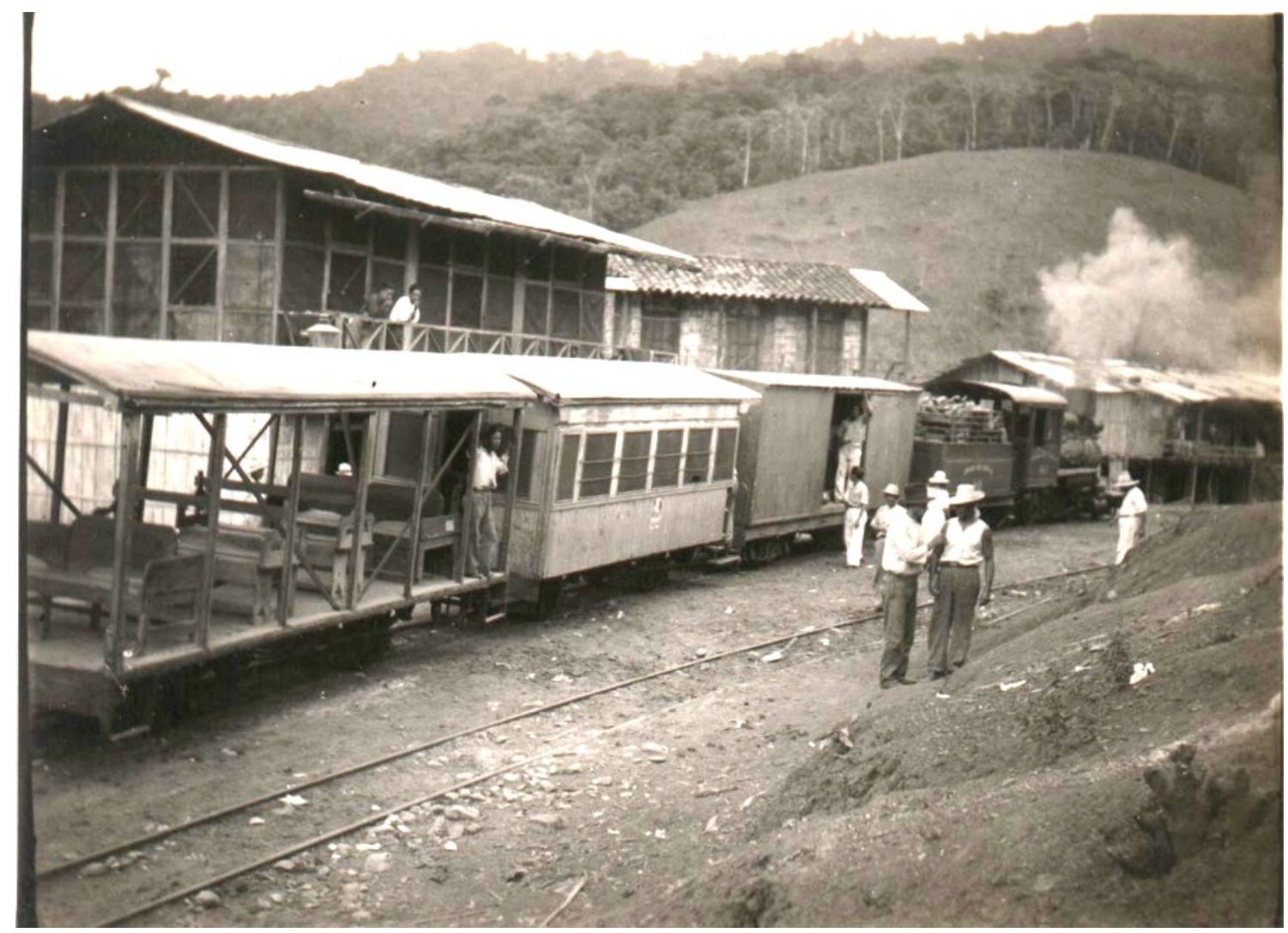

Note: The railway to Piedras was opened in 1938 after almost four decades in the making of a direct route capable of accommodating heavy loads from the mining district to the seaport of Puerto Bolívar. The construction of the high-cost infrastructure was made possible through indirect financing from national, provincial, and municipal governments, which also produced a rescaling of local transportation needs to national politics.

Source: ETSA, circa 1938.

The importance of transportation infrastructure for the mining sector is evident. Large mining projects are often located in remote areas and mineral concentrates are usually shipped by road or rail. In view of these circumstances, mining companies have to make significant investments in complementary infrastructure. However, the investment needs can sometimes outweigh the needs of the mining sector and building high-cost infrastructure may take many 
months and even years. Of course, politics also plays a role in large infrastructure projects. In this particular case, national, provincial, and municipal governments supported the construction and financing of transportation infrastructure to the Portovelo mining district. The time-space compression resulting from the material integration of the mining district into the national space not only favoured foreign capitalists, but also led to greater regional connectivity with domestic markets and social processes. In the long run, increased accessibility resulted in the transformation of regional space, migration to Portovelo and the emergence of a new urban hierarchy. Moreover, greater connectivity favoured the rescaling of Portovelo in national politics as the central government questioned contractual arrangements, claiming their right to participate in mining profits.

\subsection{Conclusion}

The construction of a company town is a place-making project that involves material practices and regulatory practices at the regional and urban levels. The production of the mining enclave as a distinctive kind of place was done with the appropriation of land through legal or extra-legal means by powerful groups to exercise control over space. In Ecuador, the legal system favoured a property regime and a mining claim system whereby land and underground resources were transferred to private owners who would put them to productive use. It is worth noting that the extension of the concession area was possible given the technological innovation for mining. The case presented 
herein reveals the exclusionary nature of the political and legal system, whereby the land titling process lacked or diverted the mechanisms for consultation with local communities. Moreover, the politics of ownership and control relates not only to subterranean mineralized deposits but also to ecological processes in a more extensive hinterland.

The place-making project included the construction of an urban settlement: the Portovelo camp. The transnational firm developed a particular territoriality, which resembled "a state within the state". The camp was deliberately designed in the hope of delineating social relations that would facilitate continuous mining operations. Life within the enclave was regulated through the application of modern forms of a combination of spatial engineering, discipline, and social control. The proximity to Zaruma determined relations of cooperation and competition between the two villages. The implementation of a modern sanitary project or the beautification of the urban landscape represents two distinct strategies to control the labour force and the accumulation of wealth at the local level. These phenomena are important to analyze for the current expansion of the mining industry as long as new extractive sites are located close to urban centers.

The material transformation of the built environment focused on overcoming regional isolation. Regional elites, national governments, and foreign investors insisted on building infrastructure that would allow trade and commerce as a means of economic development. The regional landscape was reshaped to 
facilitate the flow of goods, labour, and capital. Together, these phenomena contributed to economic growth, the creation of a domestic market, and the structuring of a new urban hierarchy in the southern provinces of Ecuador. This approach supplements Deler (2007) by recognizing processes of territorial articulation that serve in the consolidation of a national space.

Finally, I would like to highlight that the physical transformation of the regional landscape during liberal administrations (1895-1925) and the cacao crisis (1925-1950) is usually characterized as two critical moments in the process of state formation. I contend that, from a socio-spatial perspective, the period between 1895 and 1950 represents a single process: the territorial integration of regions into a national state and a single regulatory project. ${ }^{99}$

99 This analysis is consistent with Prieto (2004) who also argues that between 1895 and 1950 there is continuity in liberalism as a government tactic. By the end of this period, individualism and collective rights had been simultaneously enshrined. 


\section{The social relations of production: Contradictions in the production of space, 1895-1950}

...the passage from one mode of production to another is of the highest theoretical importance for our purposes, for it results from contradictions in the social relations of production which cannot fail to leave their mark on space and indeed to revolutionize it.

(Lefebvre 1991, 46)

The history of space and its production qua "reality" is not to be confused with a causal chain of "historical" events but understood as a struggle arising from the transformation of the mode of production. Within regulation theory, the advent of wage relations is a thread running through the history of the $20^{\text {th }}$ century (Aglietta 1998). From this perspective, labour relations help to understand the transition between modes of production and reveal the contradictions in the production of space. Therefore, the generation and breakdown of social relations of production accentuate differences within space.

The consolidation of the mining enclave included a series of legal and extra-legal mechanisms used to ensure the reproduction of the conditions of production. The Portovelo camp - as a particular kind of place produced in the attempt to back the American dollar with gold stocks — was embedded within a geographical and social context that shaped the possibilities of external 
accumulation and that produced resistance, reinterpretation, and the reworking of socio-spatial relations at different spatial scales.

In the mining district, capitalist accumulation was ensured through a complex combination of social engineering, wage labour, discipline, and charity. The success of the industrial venture was dependent on flows of people and supplies from beyond the boundaries of the mining camp or the depths of the mining claims. The high concentration of workers made Portovelo a privileged site for the creation of collective consciousness, the spread of socialist ideas, and union organization. In Zaruma, paternalism and patronage helped foster political relations with national elites. Throughout Ecuador, the central government sought to consolidate the bureaucratic apparatus through kinship networks, government allocations, influence peddling, and electoral manipulation (Ramón and Torres $2004,87)$. In addition, the modernization of society through Western practices, values, and cultural expressions reshaped social inequalities.

The company town was not an isolated enclave of self-rule but rather a place where people and ideas circulated, transforming the conditions of production and social reproduction. Portovelo was embedded in, but not bound to, its physical location. The spatiality of the enclave was linked to the politics of the resource economy, which in its geographical determination was selective, reinforcing specificity, specialization, and differentiation in its location. Overall, I assert that we have to understand the slow, progressive, and combined 
transformation of geographical and social realms that enable mining enclaves to exist as a porous enclosure.

In this chapter, I analyze how such a place is dialectically produced along with a wide array of structural relations and cultural transformations that help sustain the mining enclave, mainly the proletarianization of the work force within a hierarchical division of labour. Insofar as capitalist accumulation entails contradictions in the exploitation of land and labour for the appropriation of surplus value, socio-political struggles are likely to arise. The labour movement in Portovelo reflects both emergent socialist ideals and structural limitations to attempts to impose regulations on private accumulation at a time when benevolence and paternalism served as a means of social control. This chapter is based primarily on government records on administrative and labour disputes, the minutes of the Municipal Council of Zaruma, written memoirs, and the private correspondence of the mine manager.

Here, I problematize assumptions about transnational mining companies as independent actors with the power to build a company town and secure the conditions necessary for sustained resource extraction. In reality, foreign companies stimulated by the high profits associated with international markets faced a range of difficulties to getting established and operating in Latin American countries such as Ecuador. During the process, different rationalities shaped the production of space in the gold mining district of Zaruma and Portovelo. As a place-making project, the mining enclave depended on existing 
socio-spatial structures. Although technology and management practices in

industrial mining camps have changed, this perspective helps in visualizing some of the ongoing contradictions in the establishment, construction, and operation of extractive enclaves over the long term.

\subsection{The proletarianization of the work force}

The employer-employee relationship is the separation which renders a body of free individuals incapable of becoming private producers within the market economy... Subordination to the capitalists occurs in the realm of production, which is not a place of exchange. The fact is that the labour contract entitles capitalists to have their employees work under their control.

(Aglietta 1998, 48)

Studies based on regulation theory emphasize how labour produces social value and the process by which surplus value circulates within a capitalist economy. In the case at hand, SADCO required a disciplined labour force as mining involves a high degree of specialization and hierarchical relations. The mine, the mill, and the cyanide plant all operated 24 hours a day, seven days a week. The siren announcing each working shift ruled life within the company town; it could be heard several kilometers away. Mining engineers supervised the works during the day and night shifts.

\subsubsection{Mestizaje as a condition of production}

Unlike colonial processes that led to structurally organized and compulsory labour, republican liberalism favoured a wage system and economic migration as expressions of individual freedom. The mineworkers came from 
different places, primarily, from the rural areas of Loja, Cañar, and Azuay, particularly from non-indigenous sectors such as Oña, Nabón, Macará, Celica, Chilla, Manú, and Catacocha, as well as from the Saraguro indigenous group (Murillo 2000, 80). Colloquially, mestizos were called capiros, chazos, chaparanos, serranos, paisanos, longos, and cholos. ${ }^{100}$ The Saraguros, disparagingly called guandungos or cutos, did the hardest jobs and did not mingle with other groups; they maintained their traditional dress and braids. ${ }^{101}$

100 Mestizos have been characterized in different ways in Ecuador (Cervone 2010; Ibarra 1992). Urban mestizos were usually called longos or cholos; peasant mestizos from the central provinces of Bolivar, Cotopaxi, and Chimborazo were called chagras; and those from the southern provinces of Loja, Azuay, and Cañar were called chazos. Serrano is the generic term for people from the highlands, while paisano refers to people from the same place. The capiros came from the colonial Capiro hacienda. The meaning of chaparano is unclear; it is usually used in reference to people from Chile, but there are no record of Chileans in the area except for some mine-holders and service employees who lived there prior to SADCO's arrival.

101 Guandungo refers to a worker who is exploited; there may also be a connection with guango, the kichwa word for braid. The term cuto means black, a reference to the clothing of the Saraguro ethnic group. 


\section{Photo 6.1. SADCO's General Manager observed by a group of indigenous people}

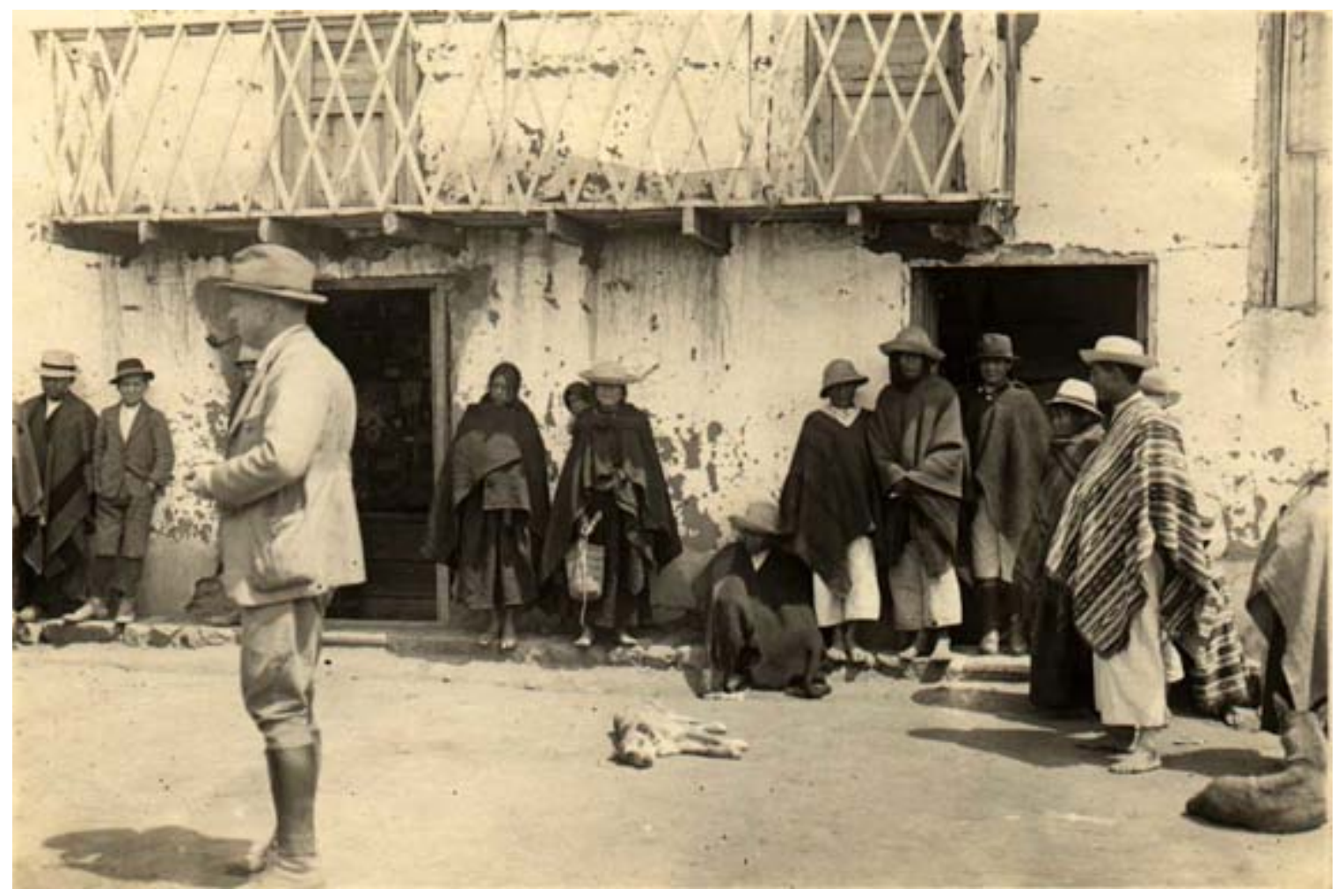

Note: A.M. Tweedy in riding gear, smoking a pipe in front of a group of indigenous people who observe him. The photograph was probably taken in Zaruma, in the late1930s. At the back-left, the man wearing a suit and boots is probably a cholo who performed urban services. At the center back, there are Saraguro women wearing black ponchos and skirts, and Saraguro men in black ponchos and white trousers. To the right, the man standing with a black and white poncho with short hair is probably from the Paltas indigenous group. Racial mixture was key to transforming the social relations of production.

Source: ETSA.

Clark (2005) highlights how the participation of Ecuador in international markets had a bearing on the incorporation of subordinate groups into an imagined national community. Leaders of the liberal revolution encouraged mestizaje, racial mixture, as a symbol of reconciliation and as a tool of national integration. Liberal governments promoted the transformation of the land regime and the end of debt peonage, to which a large portion of the indigenous work 
force in the highlands was subject; this produced a pool of potential wage labourers.

The political processes of the $19^{\text {th }}$ century brought significant changes to the labour regime and transformed structural relations of production. The abolition of slavery (1854) and the Indian tribute (1857) had been a first step in changing the legal status of the lower classes (Henderson 2008; Williams 2003). The granting of the rights enjoyed by white or mestizo society to the indigenous population began slowly after the abolition of subsidiary tax labour ${ }^{102}(1897)$, the introduction of lay, free, and compulsory education (1897), the adoption of civil marriage (1902), the abolition of tithes and oblations (1903), and the expropriation of properties belonging to religious orders (1908). By 1918, through the Ley de Jornaleros (Day Labourers Law), the state abolished peonage and debt imprisonment, imposing contractual agreements entered into freely as a basis for labour relations and thus creating an Andean work force available to the export agriculture sector on the coast and the manufacturing and service sectors in urban and industrial centers such as Portovelo.

102 Henderson $(2008$, 84) explains, "Many accounts of Ecuador's tax structure, however, omit another source of revenue creating discord during García Moreno's first term: the trabajo subsidiario, originally intended to fund local public works. Created in 1825 , this tax replaced the mita labor levy of pre-Hispanic origin requiring all subjects to labor for the state each year on public works." 
Roitman (2008) expands on the importance of understanding the sociopolitical context and tensions from which mixed identities emerge to visualize the power dynamics and exclusionary narrative they entail. In Portovelo, the configuration of a mestizo identity was crucial to legitimize industrial capitalism, but mestizaje — as a cultural hybridization process — was also a strategy for those groups whose member had fewer political rights than those held by the white elite or even the indigenous population. This approach is relevant to the mining enclave as capitalist relations of production allowed a degree of class mobility while reasserting the privileges of the few.

Apparently, there were no labour shortages in the mining sector. By 1929, peasants arrived in the mining camp voluntarily, "from the extreme regions of the southern provinces of Loja, El Oro and Azuay, after a 6 day journey, without enganche or recruitment ... in greater numbers than we can hire" (SADCO 1929, 15). The cacao crisis had led to unemployment and migration in the lowlands, creating a new wave of available workers. The transformation of the national economy pushed workers to the mines and the mineworkers had enough resources to alternate between periods spent working in the mines with periods working their plots in their own communities.

There is not enough evidence to provide a detailed analysis of the agricultural roots of miners, but there are records that speak to fluctuating work force requirements and the fact that some workers left the camp for farming (SADCO 1929, 15). The Portovelo enclave created opportunities and constraints 
for the differentiated integration of rural sectors into the mining economy. Apparently, peasants and miners developed strategies to capitalize on the mining boom, a feature common to mines in Peru (Long and Roberts 1984). There was seasonality in the mining works, as the rainy season demanded extra effort for mine drainage and the dry season required workers for road construction. It is safe to assume that the transformation of labour relations had an impact in a regional hinterland insofar as the miner was part of a wider community with economic activities beyond the enclave itself. The mines provided jobs with wages higher than those earned in agriculture. On the one hand, peasants worked on a temporary basis in the mine to earn money and supplement their income. On the other hand, permanent workers were able to save a part of their earnings or work as sharecroppers or on rented plots in the southern province of Loja.

These facts have to be taken into account in analyzing the proletarianization of the mining work force within a broader process of capitalist development and state formation. The establishment of a wage-based employment system transformed the institutional conditions for the control of the work force, enabling foreign capitalists to regulate the labour market. This represented a departure from colonial practices where the control of the work force was associated with land ownership. However, access to wage labour, the adoption of liberal concepts, and racial mixing contributed not only to capitalist exploitation, but also to mobilizing a greater sense of belonging in a national community of citizens with rights. 


\subsubsection{A hierarchical division of labour}

The technical nature of the mining industry and the wage regime promoted stratification of the work force, whereby the "position in the industrial hierarchy specifies the amount of authority vested in the occupation, the wage, and the prestige accorded to it" (Lucas [1971] 2008, 147). In Portovelo, responsibilities and privileges were based on occupations organized in a fairly vertical structure: managers, heads of department, engineers, technicians, mechanics, electricians, blacksmiths, drillers, surface workers, and underground miners. Unskilled and transitory workers were key during construction stages, and later as manual labourers to haul equipment, lift ore sacks, push carts, and dig trenches. The muleteers, loggers, and merchants provided ancillary services. In Zaruma and Piñas, shopkeepers, teachers, doctors, lawyers, and clergy created a parallel job market articulated with the circulation of revenues from the mining industry.

In 1923 the camp employed 800 labourers working, on average, 300 days a year (Murillo 2000, 86). In its heyday of the 1930s, SADCO employed almost 2,000 people and another 3,000 provided indirect services (Paredes [1938] 1970, 13). The proletarianization of the work force was a basic condition for the success of the mining venture. The wage relation created a temporary bond between employer and employee based on a day's pay for miners and a contract for those providing auxiliary services. No work, no payment.

In 1937, the minimum daily wage for underground miners was 3.3 sucres and 2.2 for surface workers (Paredes [1938] 1970, 42-44), substantially more 
than the minimum wage officially established on the coast at two sucres daily for artisanal workers and 1.2 sucres for agricultural workers. The average monthly income for $72 \%$ of the work force was around 200 sucres, approximately US $\$ 17$. Miners performing specialized jobs - carpenters, plumbers, air compressor operators, cart drivers - could earn up to six sucres a day. Those holding the best-paying surface jobs - carpenter, sanitation foreman, and chemistry laboratory worker - could earn up to 8.5 sucres a day and a general foremen could get up to 25 sucres daily. The income gap with foreign officials was huge: a junior engineer could earn almost ten times a general foreman's salary, around 2,130 sucres, and the heads of department earned 4,537 sucres a month. American employees had additional benefits, such as free food and housing, annual vacations, and fares for international travel. The Ecuadorian employees earning the highest salaries were Ernesto Witt, at 3,163.5 sucres a month, and the engineer A.B. Mora, at 2,817 sucres. The resident manager, R.P. Luke, earned $14,161.5$ sucres monthly, roughly equivalent to US $\$ 1,200$, and the mine superintendent, 9,579 sucres, about US $\$ 820$. In addition, executives received generous bonuses under profit sharing plans authorized annually by the Board of Directors. ${ }^{103}$

103 ETSA. Letter from A.M. Tweedy to R.M. Emmel, May 2, 1930. 


\section{Photo 6.2. Human power used to haul heavy equipment}

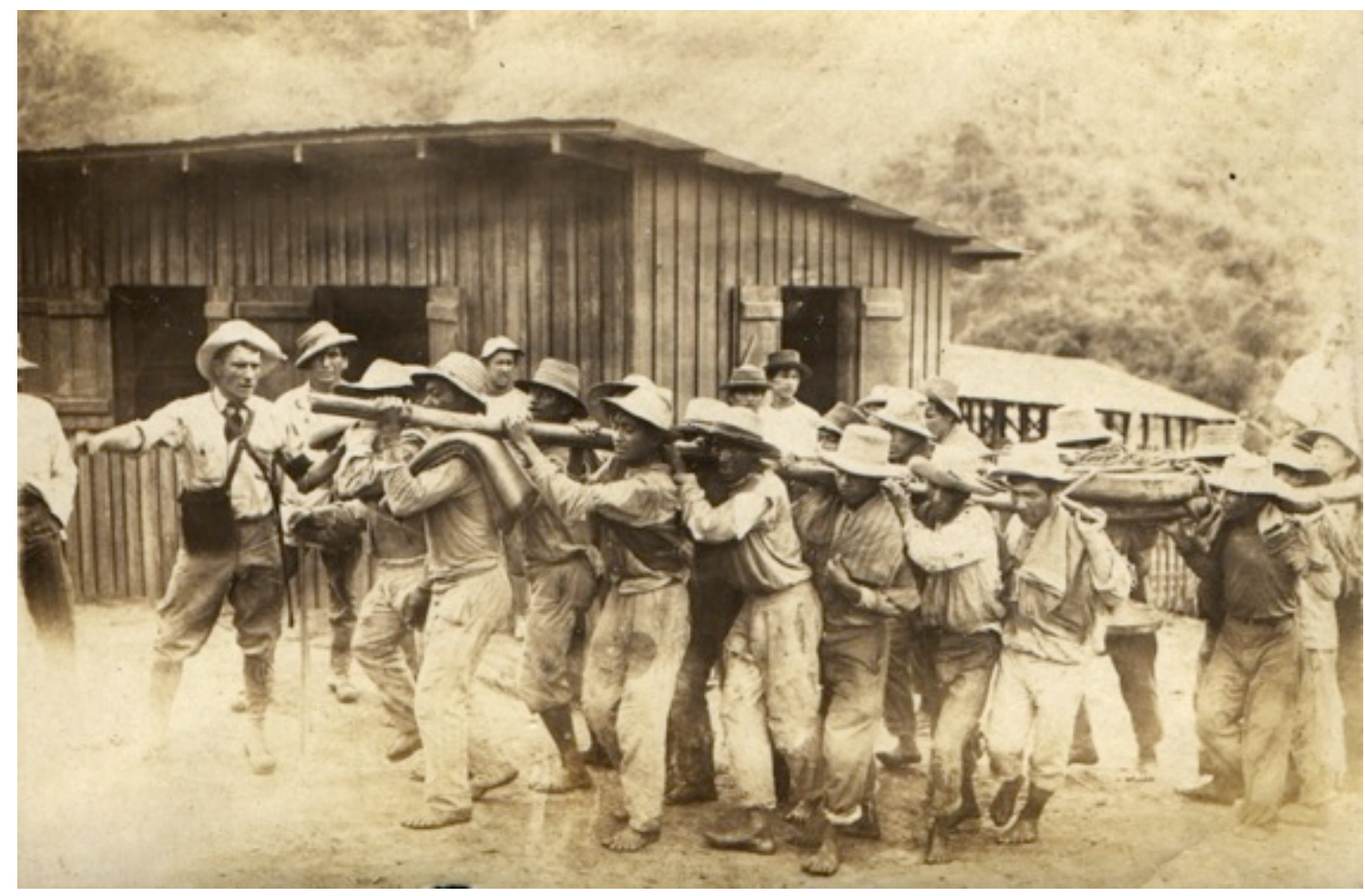

Note: The industrial camp had a hierarchical and disciplined male work force overseen by a small group of foremen and technicians. The mestizo identity was crucial to legitimize industrial capitalism, and also favoured class mobility for some members of the subordinate groups.

Source: ETSA, circa 1917.

Mid-level personnel exacerbated social inequality; foremen and technicians made sure that the lower class work force fulfilled their heavy manual tasks in satisfactory fashion. Despite liberal reforms, the recruitment and retention of the labour force did include traditional mechanisms such as the 
enganche and debt peonage. ${ }^{104}$ Unskilled construction workers were enlisted from throughout the southern provinces to build the road to the coast and transport industrial equipment. In those cases, recruiters used threats and/or advanced loans to retain the work force. Runaways were jailed. Security guards, charged with detaining and/or dismissing those not complying with industrial discipline, served as a coercive mechanism for internal control.

Lucas ([1971] 2008, 151) argues that single industry towns, usually built by absentee owners with capital, had a high rotation of the technical work force. This was not the case in Portovelo. The resident managers were shareholders in the company and some members of the American staff lived in Ecuador for relatively long periods. Andrew Mellick Tweedy was the company manager in different capacities for 27 years, from 1916 until 1938; the superintendent, Fritz McGonigle, lived in the camp for more than eight years and was its manager between 1939 and 1943; and Dr. Eduard Kingman served at the Curipamba Hospital for 10 years (Cortázar and Lavanda 2008). Some developed strong ties with local society and were praised for their work in improving living conditions.

The New York headquarters selected the American managers, geologists, and technical officials. Young engineers used this post to develop their professional careers as "soldiers of fortune," since gold mining combined the 104 BEAEP. Documentos relativos a los contratos... 1923ca. 
spirit of adventure, the ethic of service, and the allure of wealth (Tweedy and Strong 2004). John Baragwanath, for example, a mining engineer who graduated from Columbia University, had his first job with SADCO from 1910 to 1912, then worked for Cerro de Pasco Copper Corporation in Peru for seven years, and subsequently became president of several mining companies in the United States. Describing his career, he states, "As I look back now over the first half of my professional career I realize that most of it has been prosaic and uneventful. Most of it was plain hard work and much of it lonely work. Still, through it all runs a glamorous thread." 105

105 "Mining Men and Their Activities. About men who are well known and prominent in the mining circles of the western states," The Mining Journal, December 30, 1930, 8. 


\section{Photo 6.3. American engineers developed geological surveys}

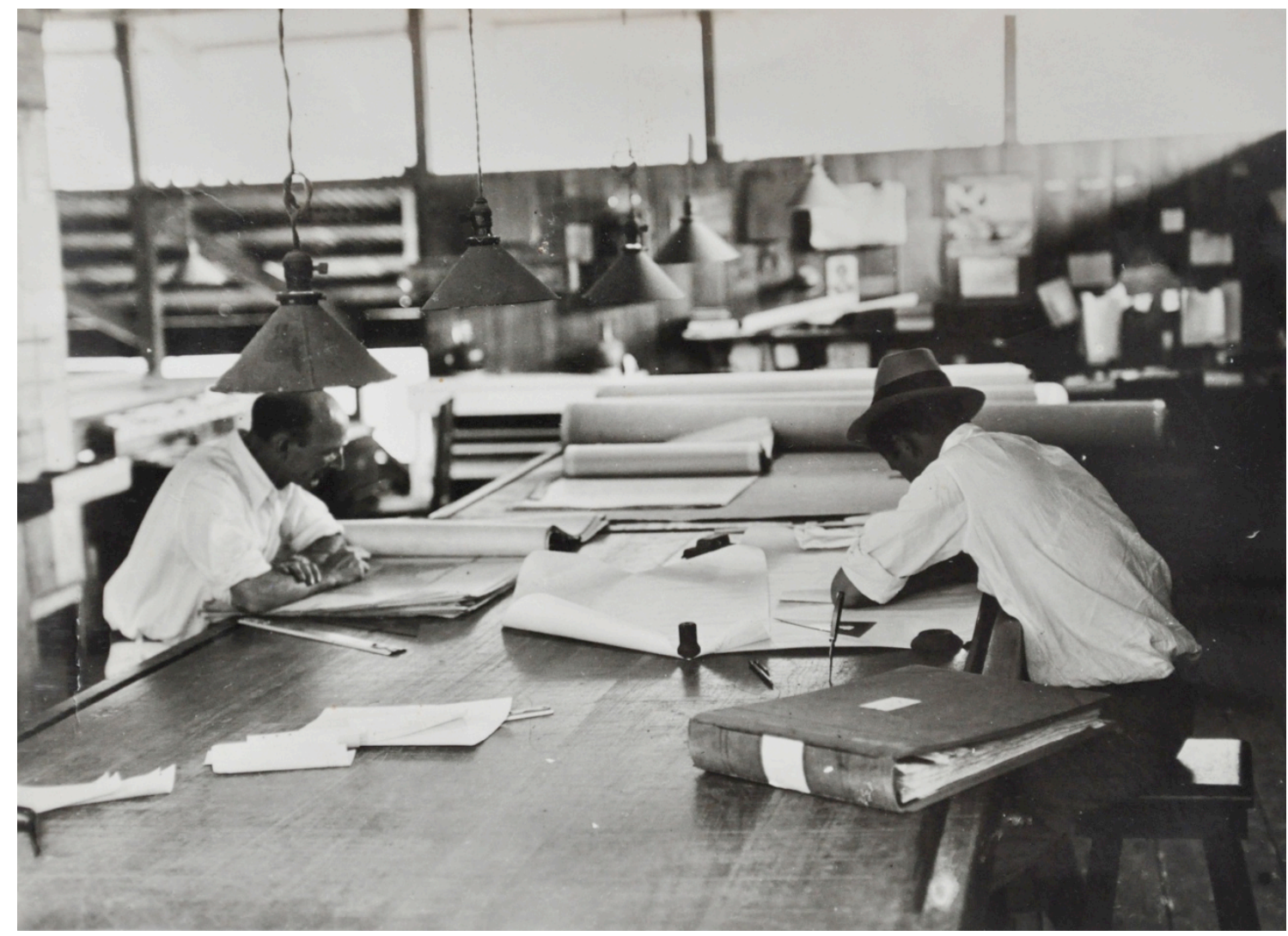

Note: Young engineers worked in Portovelo to develop their professional careers; gold mining combined the spirit of adventure, the ethic of service, and the allure of wealth. Technical employees conducted geological surveys and produced maps, supposedly under the precepts of respect, order, discipline, and cleanliness. Mineralogical results were coded and stored to prevent theft.

Source: Cortázar Crespo private collection, published in Cortázar 2005, 78.

Ecuadorian citizens were progressively included on the payroll as employees in administrative and technical positions. The presence of national officials was intended to help control internal discipline and create links with regional and national elites (Murillo 2000, 87). National staff members were selected based on their educational profile, family background, and political influence. Employees had to have a high school degree or come from wellpositioned Ecuadorian families. The national employees were allies and 
defenders of SADCO's interests, and they were also less mobile than the international technicians and developed political and economic relationships to serve their own interests. In the long run, the existence of a national work force and technical staff created a counterbalance to the local elite and contributed to the continuation of mining in Ecuador after the American company left.

Brothers Ernesto and Enrique Witt illustrate the linkages between foreign capital with national elites and the local work force. Ernesto Witt worked closely with the Americans in daily camp activities. He introduced new officials to the country, served as a language interpreter, organized expeditions, purchased archaeological pieces, ${ }^{106}$ and traded in wild animals, ${ }^{107}$ and his family socialized with the wives and children of foreign officials (Kellogg 1933ca.; Williams n.d.). He also served as an intermediary with loggers, negotiated real estate purchases for the company, ${ }^{108}$ and entertained the work force with productions in the Portovelo theatre. Enrique Witt's role was political; he provided legal advice, particularly during contract negotiations at the national level, ${ }^{109}$ and served as a

106 A.M. Tweedy and other American officials were interested in silver pieces, such as crowns, pins, and pitchers, and bought carvings of saints for their own personal collections. Souce: ETSA. Letter from A.M. Tweedy to Ernesto Witt, September 17, 1929.

107 There was a small zoo in the camp, with two bears, a monkey, a fox, an ocelot, and a fawn. Source: ETSA. Letter from A.M. Tweedy to Florence Tweedy, September 25, 1933.

108 ETSA. Letter from Ernesto Witt to A.M. Tweedy, April 10, 1929.

109 ETSA. Letter from Enrique Witt to A.M. Tweedy, October 2, 1929. 
source of information on electoral politics and potential political alliances. ${ }^{110}$ In 1929, he was appointed Government Labour Inspector with the authority to deal with labour matters arising in the camp and helped pass new regulations at the national level at A.M. Tweedy's behest. ${ }^{111}$ However, the brothers' relations with SADCO were not problem-free. In 1935, the union demanded that Enrique and Ernesto Witt be expelled from the camp due to their despotic procedures and because they treated workers like pack animals (Paredes [1938] 1970, 215). The Witt brothers were members of the local elite involved in the creation of the Diez de Agosto Social Club, the Portovelo Club, and a savings cooperative. Wealthy members of local society would later create CAMINE, an entity that would purchase SADCO's assets upon the departure of the transnational company.

There was also a pool of government bureaucrats and elected officials who supported mining, enabling linkages between the foreign industry and politicians in Quito. They included lawyers, senators, congressmen, and even presidents. David Guzmán, for example, was SADCO's lawyer and a senator from 1916 to 1919; Federico Páez, as Director of Public Works in 1912, approved the Company's operations; later, he supported the industry in his position as Supreme Chief between 1936 and 1937. Carlos Alberto Arroyo del

110 ETSA. Letter from Enrique Witt to A.M. Tweedy, November 5, 1929.

111 ETSA. Letter from A.M. Tweedy to Florence Tweedy, May 16 and July 16, 1929. 
Río, SADCO's lawyer for over a decade, subsequently served as President of Ecuador from 1940 to 1944 . But there were also activists and politicians who reported injustices resulting from mining activities. The most prominent persons were Ricardo Paredes, leader of the Socialist and Communist Parties and congressman; Angel Felicísimo Rojas, socialist writer, author of Curipamba, a novel based in the Portovelo camp; Manuel Romero Sánchez, socialist congressman for El Oro Province; Colón Serrano, socialist congressman who also served as Minister of Labour and Social Welfare and Minister of the Economy; and General Alberto Enríquez Gallo, chief of state from 1937 to 1938. Their influence was decisive in the regulation of the mining industry via labour rights and public domain of mineral assets, as will be explained below.

\subsubsection{A gendered division of labour}

A highly gendered division of labour reinforced the hierarchical structure and cultural hybridity of the mine work force. In short, the entire work force was male. Initially, the company preferred bachelors without families or commitments, since the camp, in physical, social, and moral terms was not a family environment, and inadequate basic services were not conducive to the development of community and domestic life (Murillo 2000, 85). However, the company needed strong and healthy workers, and the relatively well-paying jobs, free housing, and social services attracted families and single women.

The breadwinners - men - provided all of the family's income and did the shopping at the weekly market. Women were confined to private and 
domestic spaces for childrearing, religious practices, and the organizing of private parties. A few women worked in administrative positions and as rural teachers and librarians (Romero 1999). As for mining, Gier and Mercier $(2006,4)$ document how societies, workers, and employers "normalized the exclusion of women from working underground through an elaborate set of superstitions, beliefs, traditions, sexual metaphors, and seemingly rational justifications." Even though women were banned from most of the underground and other paying jobs, they were able to affect aspects fundamental to the social regulation of the mining industry.

After World War I, some single American women came to the camp to serve as nurses and teachers. The company needed nurses to help organize the Curipamba Hospital. Florence Dahl, one such woman willing to travel around the world, was a radical feminist linked to Margaret Sanger's Planned Parenthood movement (Tweedy and Strong 2004). Shortly after her arrival, Florence married mine manager Andrew Mellick Tweedy. Rather than for her courage in providing nursing services in a tropical region, she was admired for her "lightheartedness, unselfishness, level headedness and tact." ${ }^{112}$ Despite her professional training, Florence - as an upper class married woman - was expected to do housework and organize teas, dinners, and parties for married couples and American

\footnotetext{
112 ETSA. Letter from Alice Lovell Kellogg to Florence Tweedy, Portovelo, November 28, 1917.
} 
bachelors (Kellogg 1933ca., 16). Middle and upper class women were mostly

excluded from political activities, though they were allowed, eventually, to serve as school teachers or volunteers in the Female Red Cross, an institution that became more prominent after the war with Peru in 1941.

\section{Photo 6.4. Florence Dahl on the trail upon her arrival to the Portovelo camp to work as a nurse in the Curipamba Hospital, 1917}

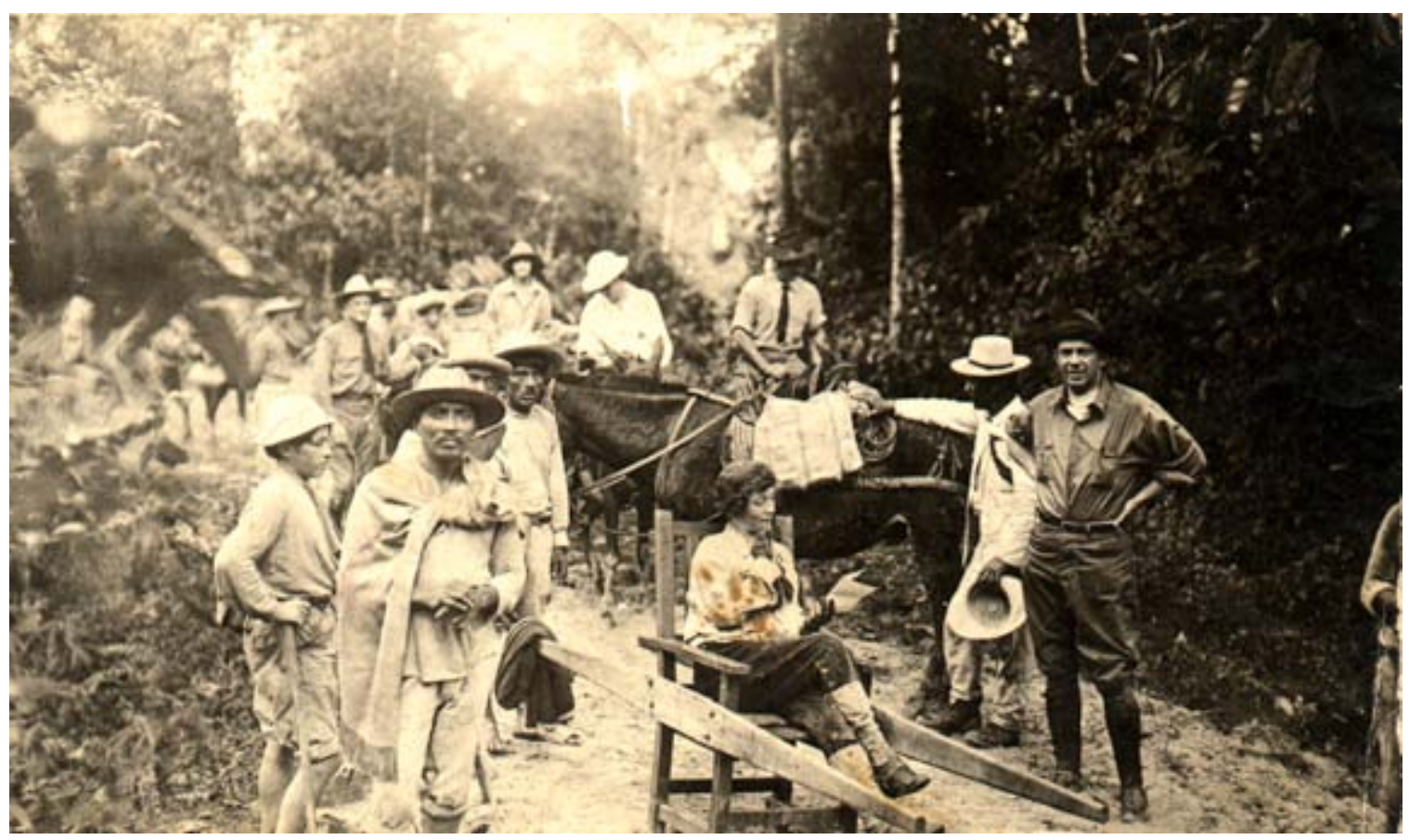

Note: The gendered division of labour reproduced internal hierarchies. As a single woman, Florence Dahl (seated), arrived in the camp to serve as a nurse at the Curipamba Hospital. In 1917 she married the mine manager Andrew Mellick Tweedy (standing to the right).

Source: ETSA, 1917.

During the 1920s, lower class single women also settled in Portovelo to work in the market, as laundresses, or as domestic servants in the homes of the wealthy, helping raise children, cleaning, and cooking. The ethnic and gendered division of labour was instilled in children from an early age and reinforced social 
stratification. Schraps (n.d, 38) describes the fate of children, who had to engage in daily work:

the cholo babies were always very precocious ... but as they grew older, due to the hardships and privation of their lives, they had to assume the family burden. The little girls at a very early age became little mothers to the babies, their siblings, and carried them around on their hips. I've seen small boys very efficiently helping to handle a mule, train or a boat.

Such was the case of Rosa Vivar, daughter of a single mother from a poor family in Cuenca, who went to Portovelo at the age of 12 along with her five brothers and sisters (Poma and Paredes 2013). Rosa and her older sister Angela worked for the Tweedy family for over a decade and travelled as maids to help Florence on the family's return to North America. The native girls were trained to satisfy the family's whims and habits; A.M. Tweedy refers to Rosa as a "slave."113 Among Portovelo miners, Rosa Vivar became a legendary figure. Her husband went to work in the mine and never came back. She never received clear information about his whereabouts or whether he was dead or alive (Rojas 2010). The disparities between workers and managers were more pronounced for those working directly for American families. Rosa encouraged Otillia Romero Mejía, and Gricelia and Amelia Ortiz Zambrano Peñaherrera to form the first female group within the Portovelo workers' union. In 1935, Rosa travelled to

113 ETSA. Letter from A.M. Tweedy to Florence Tweedy, January 1938. 
Quito and Guayaquil representing the miners before the Socialist and the

Communist Parties and led a workers' strike, as explained in the next section.

Photo 6.5. Angela Ortega and Rosa Vivar, who served as housemaids and nannies for the Tweedy family

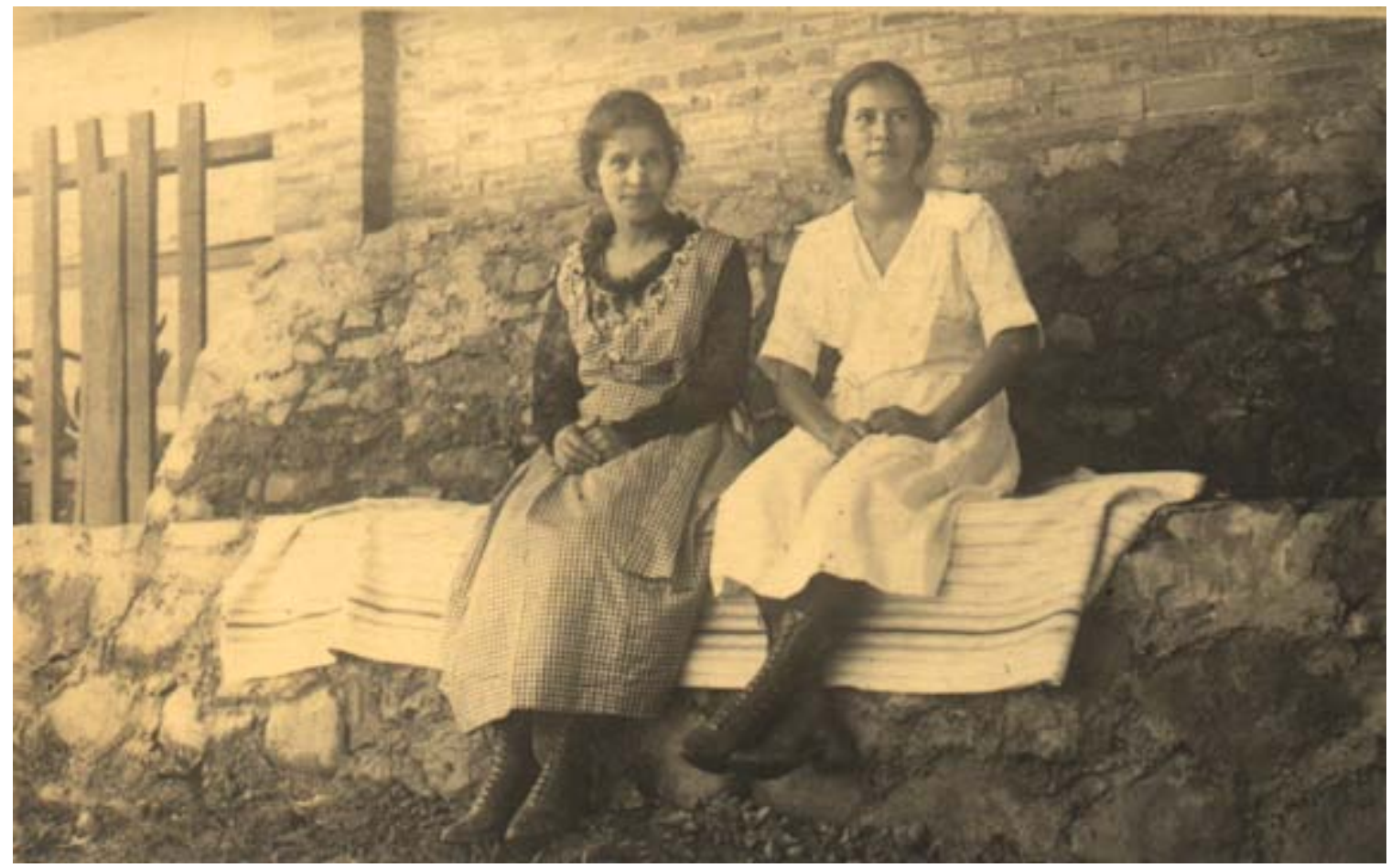

Note: Rosa Vivar (right) is a legendary figure in Portovelo. She was a union organizer and secretary of the workers' association. In 1935, she travelled to Quito and Guayaquil, representing the miners before the Socialist and the Communist Parties and led the workers' strike. Here she is pictured in her youth, with Angela Ortega (left), at the bungalow of the Tweedy family in Portovelo prior to their trip to the United States to serve as maids and nannies for them.

Source: ETSA.

In Zaruma, the social structure and gendered roles differed from those in Portovelo. The local elites were relatively restricted groups with strong family ties and roots in the area. The family served as the basic nucleus for reproducing social relations and promoting links among family networks based on social class and surnames (Romero 1999). Women had a prominent role in the social 
reproduction of the family through housework and social and civic celebrations. Networks of the Maldonado, Machuca, Carrión, Salazar, Zambrano, Espinosa, Guzman, and Reyes Romero families engaged in mining and trade, and, as hacienda owners, controlled the municipality of Zaruma. ${ }^{114}$ These families concentrated political power until the early $20^{\text {th }}$ century. Politicians with surnames other than those of traditional Zaruma elites would only appear in the 1960s, when the Viteri, Galarza, Crespo, González, Astudillo, Aguilar, Hidalgo, Toro, Morales, and Sanchez families became members of the Municipal Council.

María del Pilar Maldonado was the first woman councillor for the municipality of Zaruma; she was appointed by the Revolución Juliana (July Revolution) in 1925. Despite being the member of a family that had been associated with the municipal power structure since the $19^{\text {th }}$ century, she did not conform to the stereotypes of her time, and resigned after a few months. Chroniclers highlight her virtues as an intellectual, art lover, and musician, member of social clubs and advocate of integrity in the county, but note that she was poorly understood because of her "manly spirit" (Madero 1934 in: Romero $1999,88)$. Clark $(2005 b)$ notes that in the early $20^{\text {th }}$ century being accused of sexual transgressions served to disqualify women pioneers in new areas of

114 This interpretation comes from the recurrence of these surnames in the minutes of the Municipal Council of Zaruma. 
public activity. Four years later, with the 1929 Constitution, Ecuador was the first country in South America to give women the right to vote and serve as elected representatives.

To sum up, the structure and composition of the work force and the institutional forms of the employment system are the preeminent means for regulating an enclave economy. The disciplined, hierarchical, male work force is the consequence of factors that go beyond payroll structures and population statistics. The inequalities between American officials, administrative personnel, and political intermediaries on the one hand, and the native population on the other were obvious to the workers, and led to organizing to demand labour rights. Throughout this process, the gendered division of labour reflected camp hierarchies. However, women were not passive witnesses of the process, but protagonists in the reproduction of social conditions of production through education, the transmission of cultural values, service work, and union activism. In this context, industrial labour, the wage regime, harsh working conditions, unhealthy living conditions, and socialist ideas came together to create class awareness and solidarity.

\subsection{The Portovelo labour movement}

Harvey (2014) asserts that any dominant mode of production and its political articulation creates the form of its own opposition. Low salaries, backbreaking, dangerous work, frequent accidents, and the unhygienic conditions of 
underground galleries caused unrest among the work force. In Portovelo, members of the labour movement presented the company with a series of demands, including an end to unfair dismissals and the provision of health care, disability pay, and retirement pensions. At the time, there was no legislation covering these matters in Ecuador. Coronel (2013) states that between 1925 and 1945, social conflict pertaining to labour rights in Ecuador led to institutional and legislative changes benefitting workers. In this section, I explore how the collective action of miners' organization was a means of manifesting the apparent self-regulating autonomy of the enclave, and also contributed to the building of the nation-state. 


\section{Photo 6.6. The body of a worker, victim of a mining accident}

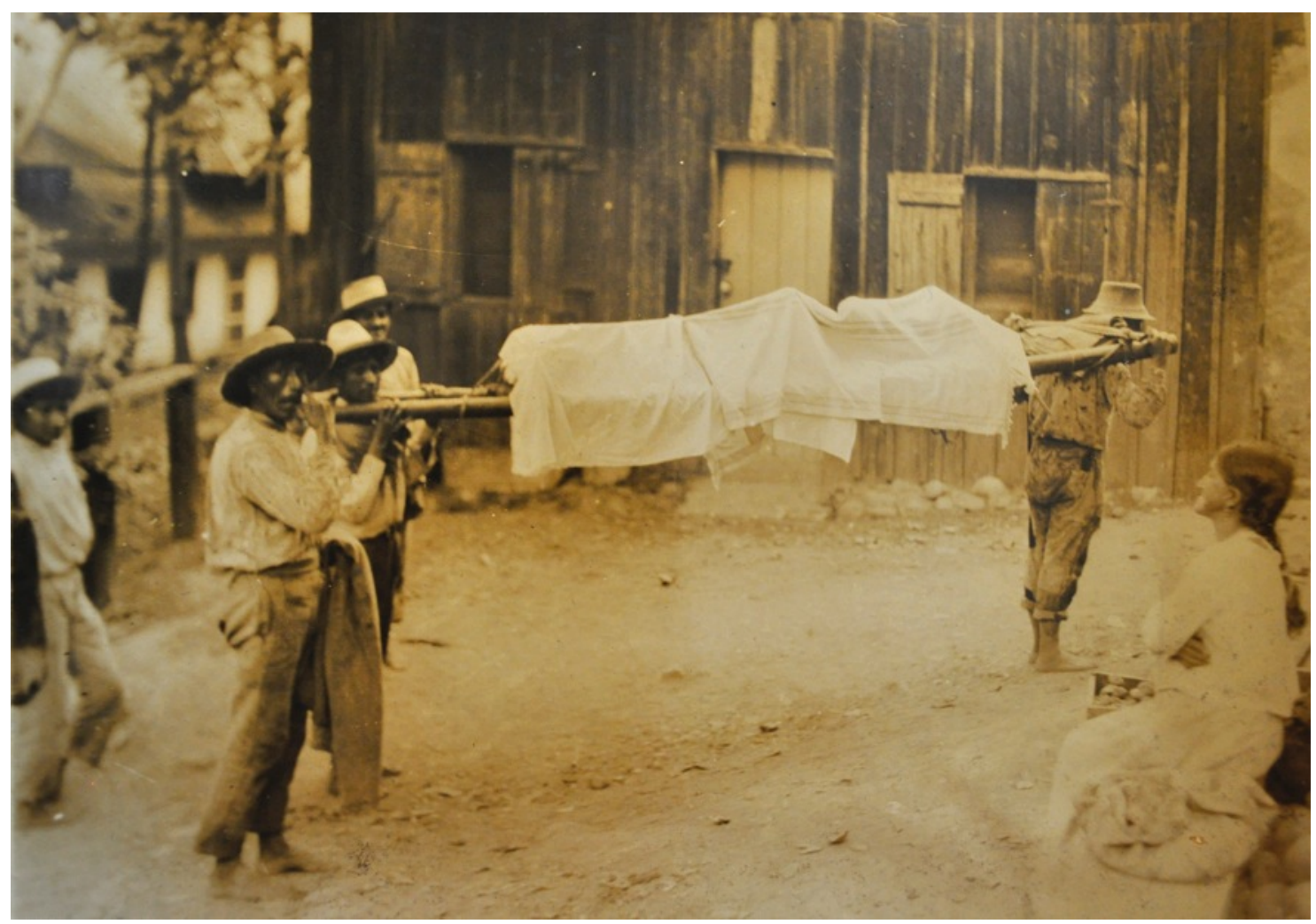

Note: Fatal accidents are first recorded in a 1904 letter from the mine manager explaining a flash flood in the mine that killed fifteen workers. The labour organizations and local and regional newspapers reported allegations of a number of work place accidents on other occasions. The company always denied or minimized such incidents and claimed to compensate the victims' families.

Sources: AH-MC. Communication from J.W. Mercer to Leonidas Plaza, President of Ecuador, February 1, 1904. Photo: ETSA. 


\subsubsection{Class consciousness and collective struggles}

The beginnings of the labour organization in Portovelo are uncertain. ${ }^{115}$ The first sign of class-consciousness, subsequently manifested in collective struggle in Portovelo, took place in 1919 (Paredes [1938] 1970, 102-103). The company changed the method for calculating compensation of machine drill operators from days worked per month to meters drilled. According to Aglietta $(1998,50)$, "capitalism unleashes conflicts which obstruct its own development, [but] it also summons up forces opposed to its desire for accumulation." On July 8, when miners returned to work after a holiday, they refused to accept the new conditions and went to Zaruma to complain to the jefe político, Carlos Manuel Astudillo, and the sheriff, Arsenio Crespo. ${ }^{116}$ The Asociación Protectora del Minero (APM, Association for the Protection of the Miner) presented a typewritten copy with their demands for better wages and safe working conditions.

115 Cortázar and Lavanda $(2008,51)$ report the existence of the Centro Minero (Mining Center) established in 1908, the creation of the Asociación Protectora del Minero (Association for the Protection of the Miner) in 1912, subsequently changed to the Sociedad Protectora del Minero (Society for the Miner's Protection) in 1929.

116 ETSA. Communication from A.M. Tweedy to Wm. A. Kissam, July 21, 1919. The letter includes the names of Manuel Eloy Molina, Aurelio Idrovo, Porfirio Pineda, and Adrián Soto as the strike leaders and a reference to Dr. Agustín Romero Zambrano as the lawyer who had provided advice on how to present the complaint. The mine manager characterized the leaders as troublemakers, alcoholics, and members of the lowest class of workmen within the camp. As for Dr. Romero, he was identified as "the old bullion robber whom we could never get punished." 
Correspondence between the mine manager, A.M. Tweedy, and SADCO's president, William A. Kissam, denotes the strained relations between the capitalists and local authorities. Tweedy writes,

[I] went to the Comisario begging him to either seize and hold the leaders in Zaruma or at least warn them they would be responsible for any violence. I also asked him to close the "Cantinas" which he said he would but did not. I asked the Jefe Politico to come down to Portovelo and help us there in case of trouble. He refused to do this. ${ }^{117}$

In his letter, Tweedy stresses he had "the usual trouble of getting the men started after their promises had been made." The vagueness of the language avoids making direct statements about corruption incited by the Americans. Moreover, "the Zaruma authorities would not take any action whatever to protect us and it developed into a question of fight or accept their demands." The mine manager seemed annoyed by the fact that "the Zaruma authorities also tried to prevent the police from Loja from coming to Portovelo." These phrases suggest that the authorities in Zaruma were not totally taken by transnational capital and were allying themselves with the workers. Moreover, they suggest a degree of power and differential performance within patron-client relations between the city council and the mining company; the situation was complicated by the fact that the parties now in conflict had just signed an agreement for the installation of an

117 ETSA. Communication from A.M. Tweedy to Wm.A. Kissam, July 21, 1919. 
electrical plant in Zaruma. ${ }^{118}$ Moreover, Tweedy complained that the Governor of El Oro, Francisco Ochoa Ortiz, made light of the affair since "he is very much of a politician and needs particularly the support of the men in control in Zaruma in order to be elected Senator .... To get any real action from him it will be necessary to bring pressure to bear from Quito." Ramón and Torres (2004, 9495) note that during the first half of the $20^{\text {th }}$ century the local powers regained their territorial control and partially reversed the "penetration" of the central state by transforming ethnic difference into a class-based alliance in order to achieve greater electoral legitimacy through modernizing public works.

The miners took SADCO facilities by force, disarmed the private guards, suspended telegraph communications, turned off the electric plant and the water pumps, and forced the manager to sign a document agreeing to their demands (Ycaza 2007, 77-78). Alice Lovell Kellogg, wife of an American manager, reports:

The natives have all gathered in the valley below our residence shouting viva and huelga. Mr. Tweedy gave the order for all the gringos to leave their homes and gather in his house. By noon the ensemble group was slowly climbing up the hills, screaming and shouting obscenities. They soon surrounded the house and were pounding on the walls with their weapons. At the very moment when blood shed seemed imminent, there came riding rapidly down the hill Mr. Tweedy with the priest and some influential citizens. The priest addressed the mob admonishing them and scolding them for their action and very shortly he had persuaded them to disband quietly away (Tweedy and Strong 2004, min. 30:21).

118 AHM/Z. MMC, T.22, July 3, 1919, 68-72. 
This event was the one of the first strikes led by industrial workers in Ecuador that calls into question the embeddeness of structural forms that regulate labour relations in the mining enclave. In Portovelo, the mine manager was held for ransom and had to temporarily agree to workers' demands despite the support of some of Zaruma's prominent citizens and the clergy. However, there was a distinction between local class interests and regional powers. The company established direct contact with the governors of Loja and El Oro and the President of Ecuador, declared that the agreement with workers was signed by force, threatened a general shutdown, and persuaded the government to protect its assets by sending troops and firing those who had actively participated in the strike. At a regional level, liberals and conservatives, journalists and landowners joined supported repression of the revolt (Fauroux 1983, 239). Regional elites had common class interests despite their political differences. The strength of the traditional ruling class began to diminish only after 1925 , when the cacao crisis caused widespread unemployment and the labour movement gained national presence.

At this juncture, Ecuador harboured a fractured society. The Liberal Revolution's national project was impeded by oligarchic regionalism, growing dependence on foreign capital, weak national identity, and political instability (Quintero and Silva 1991). In addition, Larrea (2005) argues that this period signals the fragility of the Ecuadorian staples economy linked to primary products, with the predominance of extensive technologies and little technical knowledge. In addition, a plague ravaged cacao plantations in Ecuador, causing 
a dramatic drop in production while the introduction of African cacao in the international market reduced its price.

In response to these tensions, young progressive military officers led an uprising on July 9, 1925. The July Revolution called for structural reforms and public welfare policies. Revolutionary leaders attempted to strengthen the state by favouring national over private interests. President Isidro Ayora (1926-1931) promoted institutionalization and modernization of the public sector. The centralization of political and economic power involved the reorganization of public finances and administrative procedures and the creation of technical capacities. Macroeconomic reforms, based on advice from American economist Edwin W. Kemmerer, included the formulation of monetary, exchange, and finance laws and the creation of the Central Bank, the Superintendency of Banks, and the Comptroller General's Office (Rodríguez 1985). In 1931, the crisis reached its peak when the financial system collapsed, the Central Bank lost its gold reserves, and the trade balance registered a deficit, all of which was exacerbated by the Great Depression. In response, the government devalued the national currency and abandoned the gold standard; all of this in the context of political chaos, with 22 presidents between 1931 and 1948. As noted above, some crises involve disconnected yet correlated factors, and the institutional steps taken to resolve them had uncertain outcomes (Harvey 2006, 432).

Despite economic problems, the July Revolution created new political spaces for those on the Marxist left (Becker 2008). The revolutionary 
government's social reforms included the creation of the Ministry of Labour and Social Welfare, the Pension Fund, and the Boards of Hygiene and Health. This period also saw the proliferation of civil society organizations for intellectuals, the independent press, universities, labour, and peasants. Furthermore, the foundation of the Socialist Party (1926) and the Communist Party (1931) stimulated civil society and union organization, and unions across the country. ${ }^{119}$ Throughout the 1930s, the labour movement gained unprecedented "national" power and, simultaneously, the conservative populist leader, José María Velasco Ibarra, developed his electoral base throughout the country. Under these conditions, the labour movement in Portovelo became fertile ground for political parties and dissent, which developed close links among industrial workers, urban social organizations, and peasant movements that emerged throughout the country. ${ }^{120}$

119 This period was a time of significant social upheaval. Other important class-based demonstrations included the brutally repressed popular protest in Guayaquil in 1922, the peasant uprising in the indigenous area of Colta and Columbe in 1929, and the strike at the Internacional textile factory in Quito in 1934. For a detailed history and analysis of the Ecuadorian labour movement, see: Coronel 2011; Milk 1997; and Ycaza 1991.

120 Ricardo Paredes is a key figure of this period (Becker 2008; Guerra and Rodas 2011; Ycaza $2007,1991)$. He was a physician, grassroots organizer, and founder of the Socialist Party (1926) and the Communist Party (1931) of Ecuador. Paredes had first-hand knowledge of the suffering of mine workers after he conducted medical examinations in Portovelo. As a member of the Socialist Party, he was actively engaged in union organizing within the mining enclave and, through the Federación de Obreros de Machala (Workers Federation of Machala), supported the first Workers and Peasants' Congress of El Oro, with delegations from across the province, on November 8, 1930, to join forces with those exploited by capitalists. See: "Congreso Obrero y Campesino de El Oro," La Época (Zaruma), November 26, 1930, 9. 


\subsubsection{Velasquismo, communism and the heroic deed of the Portovelo labour movement}

In February 1934, President-elect José María Velasco Ibarra visited Portovelo and Zaruma. This was the first time the charismatic leader was elected Chief of State; he would subsequently be elected on four more occasions. Velasco Ibarra travelled Ecuador to encounter his clientele in cities, towns and rural sites, both in the Sierra and the Coast. He had no coherent governmental plans whatsoever, but promised public works and social services as he addressed marginal populations striving with everyday needs. The Velasquismo is a complex political process that goes beyond the caudillo. The political leadership of Velasco Ibarra was rooted in the dependency and vulnerability of capitalist accumulation, and developed as a means of equilibrium of a weak and fragmented dominant class (Cueva 1970, 93). 


\section{Photo 6.7. Reception of President-elect José María Velasco Ibarra, 1934}

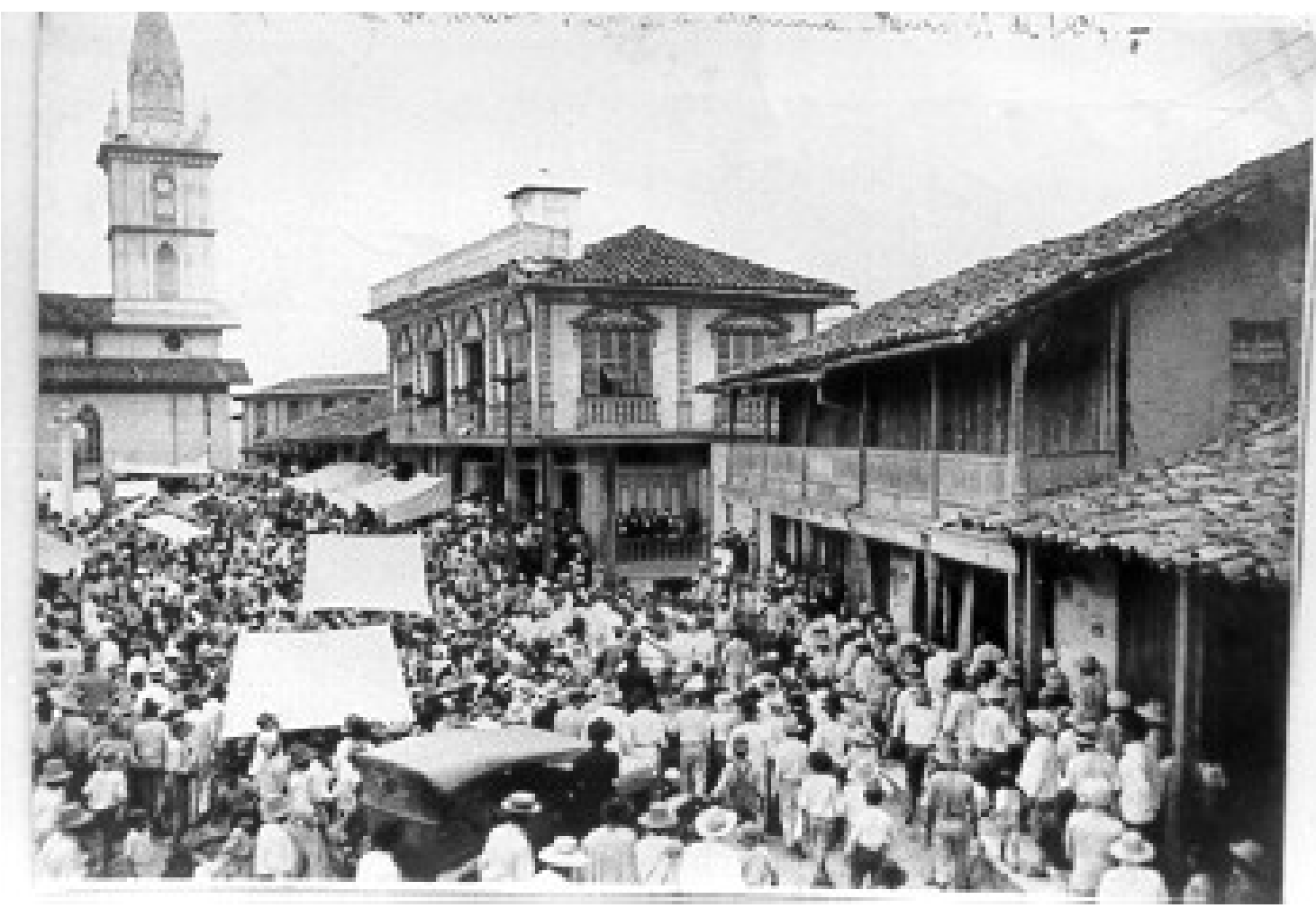

Note: A massive crowd receives President-elect José María Velasco Ibarra in Zaruma's central plaza in 1934. His journey through different regions of the country introduced new political practices creating tremendous support for his brand of populism. Despite popular backing, he was removed from office after completing less than a year of his term.

Source: Romero 1999, 133. Photographer: unknown, 1934.

Velasco Ibarra was the first president to visit Zaruma, a personal initiative to ascertain the primary needs of the region. A massive crowd that included students, members of community centers, associations, unions and residents in general received Velasco. The Municipal Council declared him an honorary 
guest. ${ }^{121}$ In turn, Velasco Ibarra promised public works and encouraged workers to organize for the defense of their rights. The Asociación Sindical Obrera (ASO, Association of Workers' Unions), formally established on September 12, 1934, brought together the labour force whose member wrote a statement supported by the Communist Party of Ecuador (Murillo 2000; Paredes [1938] 1970). The company tried to prevent these and other actions by workers through imprisoning and firing some of the leaders, ${ }^{122}$ and paying workers to inform on their colleagues in order to sow distrust. At the same time, the village priest launched a campaign to discredit the association, accusing it of being anti-religious and Communist.

At the workers' request, the Velasco Ibarra administration sent a commission to assess complaints, evaluate living conditions, and prevent further conflicts. Incorporation of the lower classes to the national project included formalizing the mechanisms for resolving labour disputes and the institutionalization of popular sectors to promote capitalist interests. Joaquin Figueroa, personally selected by the President as workers' delegate, says,

121 AHM/Z. MMC, T. 32, February 12, 1934. 
"unions are not to be considered harmful forces but bastions of mutual understanding given that a business will have more success dealing with a serious association than with isolated individuals."123

By 1935, there was growing unrest throughout the camp. On the union's first anniversary, ASO called for general mobilizations. In the meantime, the Guayaquil bourgeoisie conspired with the Army to depose Velasco Ibarra on August 20 and subsequently dissolved Congress on September 26. The American entrepreneurs requested protection from the military government and threatened, again, to suspend mining operations (Murillo 2000, 91). ASO was divided into two factions: one called for a strike and the other opposed any type of confrontation. The company downplayed the union, stating that it did not represent the mine workers but, rather, was a front for strangers and unemployed persons attempting to use the work force for profit and revenge. ${ }^{124}$ On

122 The leaders of ASO, José Permañer, Néstor Ordóñez, Manuel Lara, Víctor Vivar, Gonzalo González, León B. Viviar, Antonio Pacheco, and Carlos Cevallos, became targets of persecution and dismissal. Permañer, a Spanish anarchist, was deported due to his uncertain immigration status. See: "Información de testigos seguida ante la judicatura de letras del cantón Zaruma, para descubrir infracciones cometidas en el asiento minero de Portobelo las mismas que se han seguido por orden del señor gobernador de la provincia de 'El Oro'," AlMPS, C.112, R.440. "Documentación referente al campamento minero de Portovelo, Acompáñase 9 anexos," Al-MPS, C.149, R.996.

123 Communication from José Figueroa to the Ministerio de Gobierno y Previsión Social, May 16, 1935, Al-MPS, C.112, R.440.

124 Communication from R.P. Luke, General Superintendent, in: Paredes [1938] 1970, 124. 
September 1, ASO's radical faction staged a torchlight rally; approximately 800 people chanted revolutionary songs, discussed demands, and called for a general strike (Paredes [1938] 1970, 118-119). Union leaders sought the support of workers living in El Faique, Osorio, Barrio Machala, and Zaruma. The loggers' association also joined the protests and social unrest spread. ASO protesters were seconded by other trade unions, especially in Guayaquil and Quito, and the Communist Party of Ecuador provided support to the organizing process.

\section{Photo 6.8. The workers' commission prior the strike of 1935}

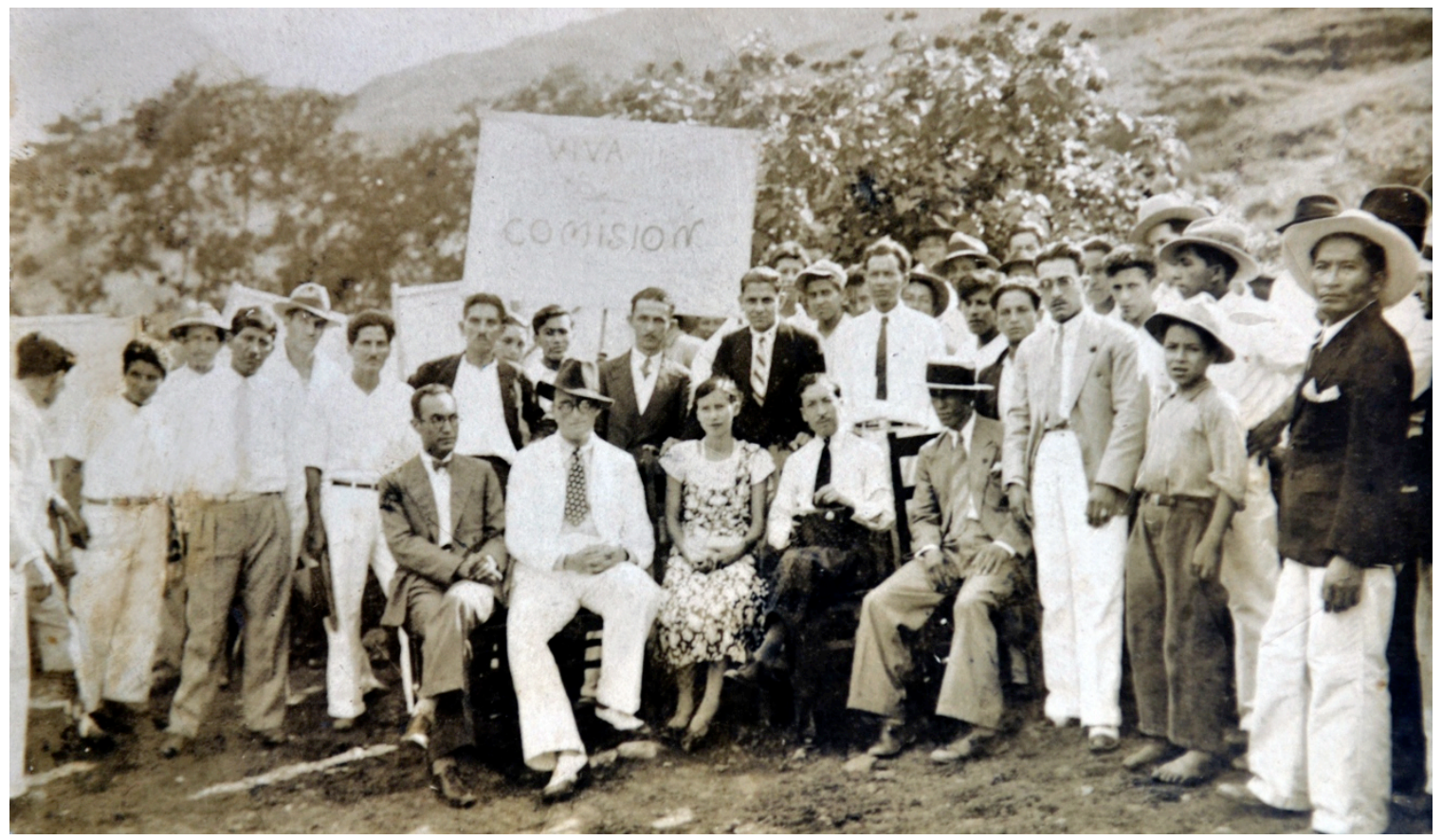

Note: The workers organized a commission that brought together union leaders representing different sectors to bargain with the American Company. Rosa Vivar (seated at the center) was the only woman on the commission.

Source: Romero Witt private collection, circa 1935.

The workers' association brought together half of the miners and influenced loggers and unorganized labourers (ibid., 129-130). A partial 
slowdown began on November 8, 1935, and two days later the radical wing of ASO issued a list of demands and declared a general strike. ${ }^{125}$ The workers shut down the hydroelectric plant and the military responded violently, threatening the population and firing guns. Several workers were injured and one miner died as a result of the clash. In spite of these efforts at intimidation, the striking workers reorganized and continued pressing the company for a response to their demands. This event corresponds to what Patricio Ycaza (1991) depicts as the "heroic phase" of labour history, when workers' demands were imposed through solidarity and militancy in the absence of legal channels for negotiation. The expansion of the state and the adoption of institutional forms as the Labour Code of 1938 would later mediate relations between employers and employees.

Union leaders, company executives, and local authorities formed a bargaining committee. Néstor Ordóñez, ASO’s General Secretary, the strike coordinators Rosa Vivar, Salvador Romero, and Miguel Capa, and the loggers' leader Braulio Carrión represented the workers (Paredes [1938] 1970, 130-133). SADCO's General Manager Fritz MacGonigle and Superintendent Russell Luke

125 The union sent a lengthy list of demands that included: the firing of a group of high-ranking national employees who oppressed the lay people; recognition of tuberculosis as an occupational disease; compensation for sick workers and unfair dismissal, as well as retirement pay; higher wages, up to a $100 \%$ increase for underground workers; one month of vacation every six months for underground miners; and the removal of timber middlemen. The petition also included demands for access to amenities such as: cinema, hot water showers, complementary meals for loggers, free education for orphans, and basic services for the Machala and Peru neighbourhoods (Paredes [1938] 1970, 214-221). 
represented the company. Despite previous attempts to bring national government representatives to the camp, the state was not present at the bargaining table. The labour inspector, agent of the central government based in the provincial capital of Machala, arrived after an agreement had been reached.

SADCO extended its lobbying by appealing to the recently established military regime of General Federico Páez. A.M. Tweedy notes that the "change in government is a relief as the gang in Congress was impossible and I could see nothing but a long fight with very dubious results. Don Federico on the contrary is friendly and it is generally easier here to treat with one man than with a group." ${ }^{126}$ In contrast to the workers' goal of collective associations, foreign capitalists preferred to deal with an authoritarian government. In this case, corporate agents used scaling-up strategies and political linkages with the executive branch to sustain the relations of productions and control the workforce. In effect, the new government sent the Febres Cordero cavalry regiment to safeguard the public interest.

The South American Development Company moulded perceptions of these events by disseminating a positive image of the camp in the mass

126 ETSA. Letter from A.M. Tweedy to Florence Tweedy, October 1, 1935. 
media. ${ }^{127}$ This is an example of how discourse may be used to help modify power relations by reframing the capacities of different actors according to the spaces and sources of revenue in question (Lefebvre 1991). Subsequently, national journals highlighted the importance of Portovelo as the largest gold field under exploitation in the country, with a work force over $98 \%$ national and an investment of over 25 million sucres. The leading national newspaper, El Telégrafo, stated that the company was characterized by the seriousness of its actions and merited the full confidence of the population. ${ }^{128}$ The strike was portrayed as a minor labour dispute within a buoyant regime of accumulation.

The strike in Portovelo was one among many events undertaken by civil society to regulate and stabilize the process of capitalist accumulation throughout Ecuador. It was a time of economic and political turmoil with successive coups d'état, bringing to power various administrations without a clear direction. Ten days after the strike, the dictatorship appointed a new municipal council to control local powers. Shortly afterwards, the commander-in-chief, Federico Páez, visited Portovelo and Zaruma; General Páez was himself close to the mining enterprise. As director of public works, he had approved the Santa Rosa-Portovelo road in 1912. In a speech during the visit, he declared himself a staunch "foe of

127 Tweedy's personal correspondence throughout the years supports speculation that the company itself sponsored the publications. Source: ETSA. 
communism and vigorously condemned the libellous use of the nation's symbol which he observed intertwined with Soviet symbols in the offices of the Workers' Trade Association, near Portovelo." ${ }^{129}$ Consequently, he ordered the creation of the Portovelo police district, while the Zaruma Police District was abolished. ${ }^{130}$ By the end of 1936, President Páez promulgated the Ley de Defensa Social (Social Defense Law, also known as the National Security Law) that outlawed the Communist Party of Ecuador, ordered the imprisonment of leftist activists, prohibited the entry of foreign politicians, and approved closing some newspapers without legal process (Ycaza 2007). Mine-workers also won some benefits, but union leaders continued to be harrassed, arrested, and expelled from the camp (Paredes [1938] 1970).

The creation of the Portovelo Police District and officer turnover created unease among the police forces and uncertainty concerning the jurisdiction of the

128 Development Co," El Telégrafo, December 18, 1935.

129

130

Decreto Supremo, November 27, 1935. 
various authorities. ${ }^{131}$ In January 1936, a minor dispute initiated by three drunken policemen who had been fired led to a raid in Barrio Machala. The officer on duty began shooting; two children and the mother of one of them were killed and six people were wounded. The governor of El Oro dismissed the event, stating that it was without political importance and blaming "outside agitators" who had promoted unionism. ${ }^{132}$ During the 1930 s, political intermediaries were perceived as a threat to class interests and leftist activists were called "agitators" (Becker 2013, 112-114).

Workers, businessmen, and authorities blamed each other for instigating the deadly incident. However, the company manager asserted that the event "seems to have cleared the air and general prospects are more promising for peace than they have been for many months." ${ }^{133}$ This dispute resulted in new forms of control through intensified police action and measures applied within the camp. The company laid-off several workers and demobilized the union. A year

131 In 1910, the Zaruma Police District was created to "respond quickly to frequent disturbances in the Portovelo mining camp" (Madero 1934ca., 111). In 1918, a communication requested an honorary police inspector to serve in Portovelo, who was to be paid by the mining company. Source: ANE. Communication from Larrea, Gobernador de El Oro, to Ministro de Policía, Machala, January 12, 1918. Min. Interior, C.25. Until 1935, the political lieutenant, the representative of the national government, served as police inspector in Portovelo under the supervision of the provincial governor of El Oro.

132 ANE. Communication from Virgilio Vaca, Gobernador de El Oro, to Ing. Federico Páez, Jefe Supremo del Ecuador, Machala, February 1, 1936. Serie Min. Interior, C.31.

133 Letter from A.M. Tweedy to Florence Tweedy, included in the documentary Streams of Gold (Tweedy and Strong, 2004, 42:56). 
later, the local population was still complaining about the police detachment garrisoned in Portovelo. ${ }^{134}$ Abuses included unwarranted arrests, imprisonment, unjust fines, and authoritarian practices in circumstances beyond police jurisdiction. In 1938, Portovelo workers released a publication condemning "the existence of the electric chair in the mine, established by the Yankees to torture the workers." ${ }^{135}$ As argued by Foucault $(2007,335-40)$, the police presence resembled a permanent state of siege, with officers permitted to act within and beyond the law in the name of freedom.

These events created tensions between local and national levels of government. The municipal commissioner defended workers' rights and sued the police. The Governor ordered the arrest of union leaders and blamed local police officers for mishandling the situation: both the municipal commissioner and the police secretary were removed from their positions. ${ }^{136}$ The centralization of power included direct control over the public apparatus and regional statecraft. The regional representatives of the central government, along with the American entrepreneurs, supported the creation of a pro-company workers' association, the Unión Obrera Portovelo (Portovelo Workers' Union) as the legitimate

134 AHM/Z. "Los abusos de la policía nacional de Portovelo." El Municipio, [Zaruma], November $17,1937,1$.

135 El Comercio, [Quito], Febrero 23, 1938, in Cortázar and Lavanda 2008, 63.

136 ANE. Communication from Vaca to Páez, 1936-02-01. Serie Min. Interior, C.31. 
representative of the mineworkers and the Asociación Deportiva Portovelo

(Portovelo Sports Association) to promote physical wellness and culture within

the camp. ${ }^{137}$ Again, coercive mechanisms were combined with cultural activities as a means of disciplining the labour force, as will be explained later.

\subsubsection{Legal regulation of wage-labour relations}

At this stage of the dissertation, I leave the labour movement to explore the legal regulation of wage relations and related state obligations. For Aglietta $(1998,54)$, the subordination of the labour force to the production process has been normalized by the extension of rights. The spread of wage-labour required institutional forms to legitimize both the redistribution and the extraction of wealth. From a genealogical perspective, laws do not only emerge from a dominant class or from a governmental initiative, but also through micro-powers and placebased social struggles. In this sense, we see a transition from a heroic phase of labour mobilizations to the legal regulation of labour relations whereby the state guaranteed rights while also limiting collective action and union protest.

137 The National Government approved the creation of civil society organizations. The statutes of these organizations forbade politically motivated activities or events that could affect the prestige and the harmony of the camp. Source: ANE. Communication from A.A. Bayas, Ministro de Gobierno y Justicia, to J.C. Aguilar et al, February 19, 1936, and communication from MacGonigle, Sub-Superintendente South American Development Co. and Julio C. Freire, Vice-Presidente to Federico Páez, Jefe Supremo de la República, Serie Min. Interior, El Oro, C.31. 
Until 1926, the institutionalization of labour norms was a piecemeal affair, included in civil legislation, and employment contracts were combined with rules for property leasing (Páez 1996). In the aftermath of the July Revolution, the government passed laws related to individual employment contracts, working conditions for women and children, working hours, dismissal, and work accidents. Labour regulations progressively moved from the private to the public sphere. The Ecuadorian Constitution of 1929 guaranteed worker protection and freedom (art. 151, clause 18), the freedom of association and unionization, and the establishment of conciliation and arbitration commissions for the resolution of conflicts between capital and labour (art. 151, clause 24). These norms laid the foundation for the Labour Code of 1938, under the government of General Alberto Enríquez Gallo, with support from the Third National Workers' Congress held in Ambato that year. Some members of the ruling class also yielded to popular pressure on the legal superstructure that regulated work relations in that it suited their interests to tie the working class to the realm of bourgeois legality while creating confidence - mostly unwarranted - in certain state agencies (Ycaza 1991, 46).

The code in question transformed wage-labour relations, creating the possibility for the regulation of private accumulation. Under the code, trade union organizing was legal and a degree of redistribution of the surplus value generated by industry was achieved through binding collective agreements and profit sharing leading to greater social justice (Labour Code 1938, art. 158-167). Thereafter, unions could benefit through bargaining from increases in 
productivity. However, the very same code restricted strikes and lockouts, requiring that attempts at conciliation be exhausted prior to any action affecting production.

The code regulated the purchasing power of the labour force by establishing a minimum wage and periodic raises. It also mitigated exploitation of the work force by limiting the work day to a maximum of eight hours, and 44 hours weekly, and workers were to be compensated for a 48-hour week, with bonuses for night work and vacation pay. The worker was granted one full day of rest per week and 15 days of paid vacation after one year of service (art. 220). In addition, the company had to affiliate the work force to the Social Security Fund, to guarantee income in case of illness, unemployment, or retirement. Finally, companies such as SADCO had to provide health services, work tools, and industrial safety clothing. 
Photo 6.9. Labour shift ends and workers leave the American Shaft, circa 1940

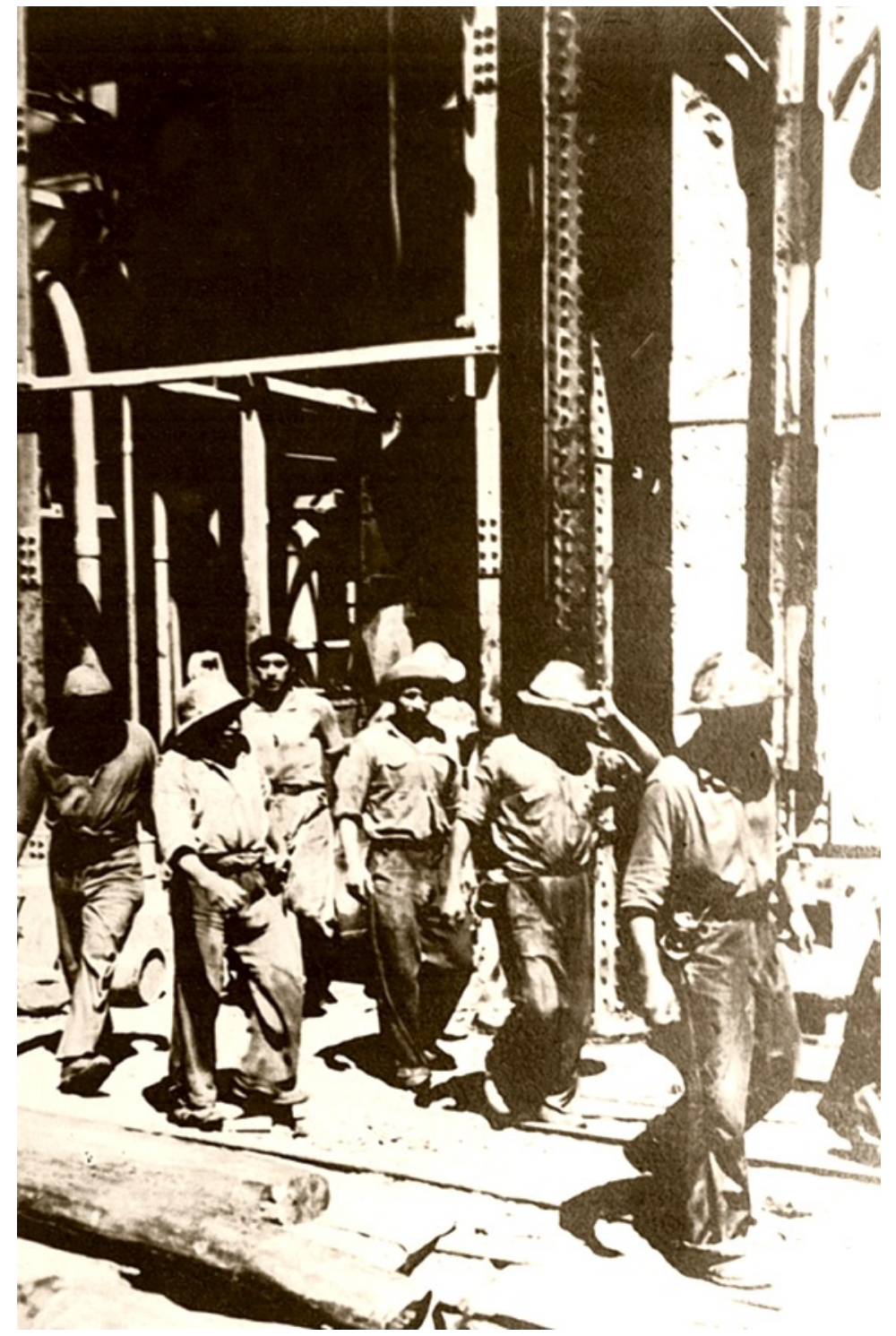

Note: After labour laws were passed, SADCO implemented additional industrial safety measures and provided work clothes. Note helmets, boots, flashlights, and clothing different from that in photo 6.2.

Source: ETSA, circa 1940.

Some of the specific issues raised by workers' demands, labour inspections, and socialists in Portovelo were included in the code. For example, wages had to be paid in legal tender only (art. 49), industrial firms had to provide 
compulsory apprenticeships in skilled labour operations (art. 103), and the law included provisions related to risk factors and occupational diseases directly related to mining activities (Title IV).

Despite the national character of this regulatory framework, localized forms of negotiating wages and working conditions persisted in subsequent years. Municipalities continued to have indirect influence on the management of labour relations. In provincial and county capitals, the state established Comisiones de Salario Mínimo (Minimum Wages Commissions) responsible for setting salaries and wages in their respective jurisdictions with the participation of representatives of employees and employers (art. 57, 68). In addition, disputes over employment contracts had to be resolved by a Provincial Inspector of Labour, the labour commissioner with jurisdiction for the county, or the municipal commissioner (art. 455).

According to Coronel (2013), the formulation of labour rights offered an avenue for state intervention in areas where landed elites and transnational concessions held sway. In fact, the government issued provisions requiring foreign companies to pay pensions to employees after 20 years of service, which the United States diplomatic representation to Ecuador deemed discriminatory and "an unusual hardship on American companies already established in 
Ecuador."138 The Ecuadorian government dismissed the request since the norm provided for equal treatment of foreign and national investors.

There was a gap in national regulations and the international system had no specific provisions on state responsibilities regarding foreign investors. Thereafter, the principal topic of contention and the main cause of friction in international relations had to do not with labour rights, but with the issue of public domain of mineral resources and the government's participation in the profits of mining activities, as described in chapter seven. Yet, the demands of the lower classes linked popular sectors to the government in that the state made decisions on the legality or illegality of labour claims and the existence of workers' organizations. It took almost a decade for the miners to reorganize the union under the provisions of the new Labour Code and independently from the company.

The electoral fraud of 1939 that gave Carlos Alberto Arroyo del Río the presidency, the war with Peru in 1941, and subsequent turmoil focused greater attention on national politics. Arroyo del Río, a former lawyer for America companies such as SADCO and Anglo Oil, represented the economic interests of the private banking sector dependent on capitalism (Quitero and Silva 1991,

138 AH-MREMH. Memorandum from the Legation of the United States in Ecuador to the Ministry of Foreign Affairs of Ecuador, January 20, 1938, B.18.28. 
457). Opposition to the Arroyo del Río administration resulted in a coalition that brought together heterogeneous sectors, including antifascists, communists, socialists, liberals, conservatives, workers, indigenous people, intellectuals, and students. Institutional political channels took a back seat to marches, rallies, and demonstrations in the name of exiled former-President Velasco Ibarra, the "Great Absentee" (De la Torre 1994). In May 1944, the Revolución Gloriosa (Glorious Revolution) became a milestone in the active participation of popular sectors in the restructuring of social movements and political parties. This multi-class, multiparty revolt brought back to power the charismatic figure of the populist caudillo.

In Portovelo, social activists recovered strength and began organizing Socialist and Communist cells after the Glorious Revolution. This aspect of workers' organization is perhaps the least studied in Portovelo. Francisco Mora, president of the Bakers Union and one of the most active Communists in Guayaquil, joined Salazar, a Communist barber from Puerto Bolívar. Together they became the principal organizers of the gold mine workers and formed the Federación de Trabajadores de Portovelo (Labour Federation of Portovelo) to which two-thirds of the employees belonged. ${ }^{139}$

139 National Archives Records Administration, Record Group 59, 822.00B/9-1746, 4, College Park, Maryland. 


\section{Photo 6.10. Second visit of President José María Velasco Ibarra to Zaruma after the Glorious Revolution, July 29, 1944}

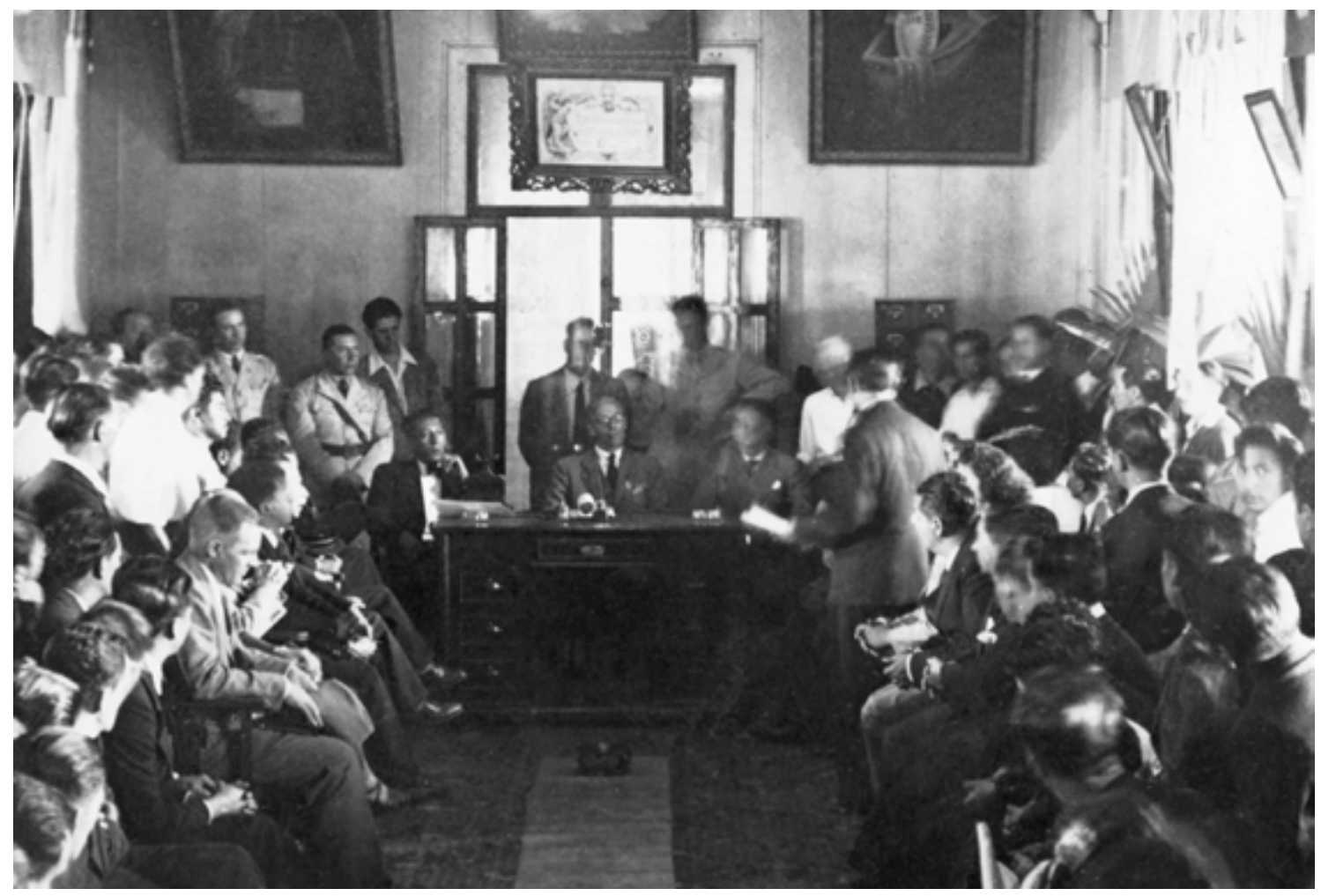

Note: In July 29, 1944, Velasco Ibarra returned to Zaruma to cement popular support after the Glorious Revolution (La Gloriosa). The photo features the solemn session in which Celso Jijón Ramírez, president of the Municipal Council, described the needs of the county and declared Velasco Ibarra Guest of Honour. SADCO workers were given days off to participate in the festivities, including the reception parade.

Source: "Después de la Gloriosa," Cevallos 2011, 106. Photographer: León Jiménez Ramírez, 1944.

In June 1947, the Labour Federation filed a petition against SADCO concerning wage demands and collective rights guaranteed by the Labour Code of 1938 and the recently approved Constitution of 1946 . Diplomatic communications report that officials of the company "have been quite serious in 
their threat to close down entirely if their labour and taxation difficulties are not solved in the near future." ${ }^{140}$ Both the collective agreement - as a reflection of gains in labour rights - and the mine closure - as a reflection of the transformation in the mechanisms of capitalist accumulation - would come into effect in subsequent years, under the development-oriented government of Galo Plaza Lasso, the first president to finish his term of office in more than two decades.

\subsection{Benevolence, paternalism, and social control}

Within the camp, the workers were recipients of social benefits that were rare amenities in most of rural Ecuador; these included subsidized food, health, and education. Investment in social services was a mechanism to ensure the social reproduction of the labour force while exercising disciplinary control over the population, even during non-working hours when sports as well as cultural, and other recreational activities were available. In addition, the construction of a favourable environment for enclave mining as the dominant mode of production included the development of patron-client relations in the building of urban infrastructure in Zaruma, as a means to keep local elites happy. The strategies

140 Communication from John. F. Simmons, National Archives Records Administration, Record Group 59, 822.504/7-2347, College Park, Maryland. 
herein described represent corporate forms of self-regulation, aimed at normalizing social relations of production. However, the very same practices that helped ensure the conditions of production would later become matters of dispute.

\subsubsection{The political economy of subsidized food and controlled markets}

The provision of food was a key strategy to attract, retain, and control the labour force. Alice Kellogg (1933ca., 24) reports that "in the beginning it had been difficult to get laborers, and the plan for free food was started, with magnificent results as far as the labor problem was concerned. Men flocked in to get the great quantities of boiled meat and rice which was [sic] served without limit." During the initial stages, the offer of a wage was not sufficient to attract workers. In 1912, the company implemented a fonda, or dining room, where workmen ate a free meal every day at noon. SADCO bought all the rice produced in the county, acquired the Hacienda El Tablón for livestock and crop production, monopolized regional production, and imported supplies duty-free (Andrade 1923, 11). 


\section{Photo 6.11. A massive soup kitchen provided meals to the workforce}

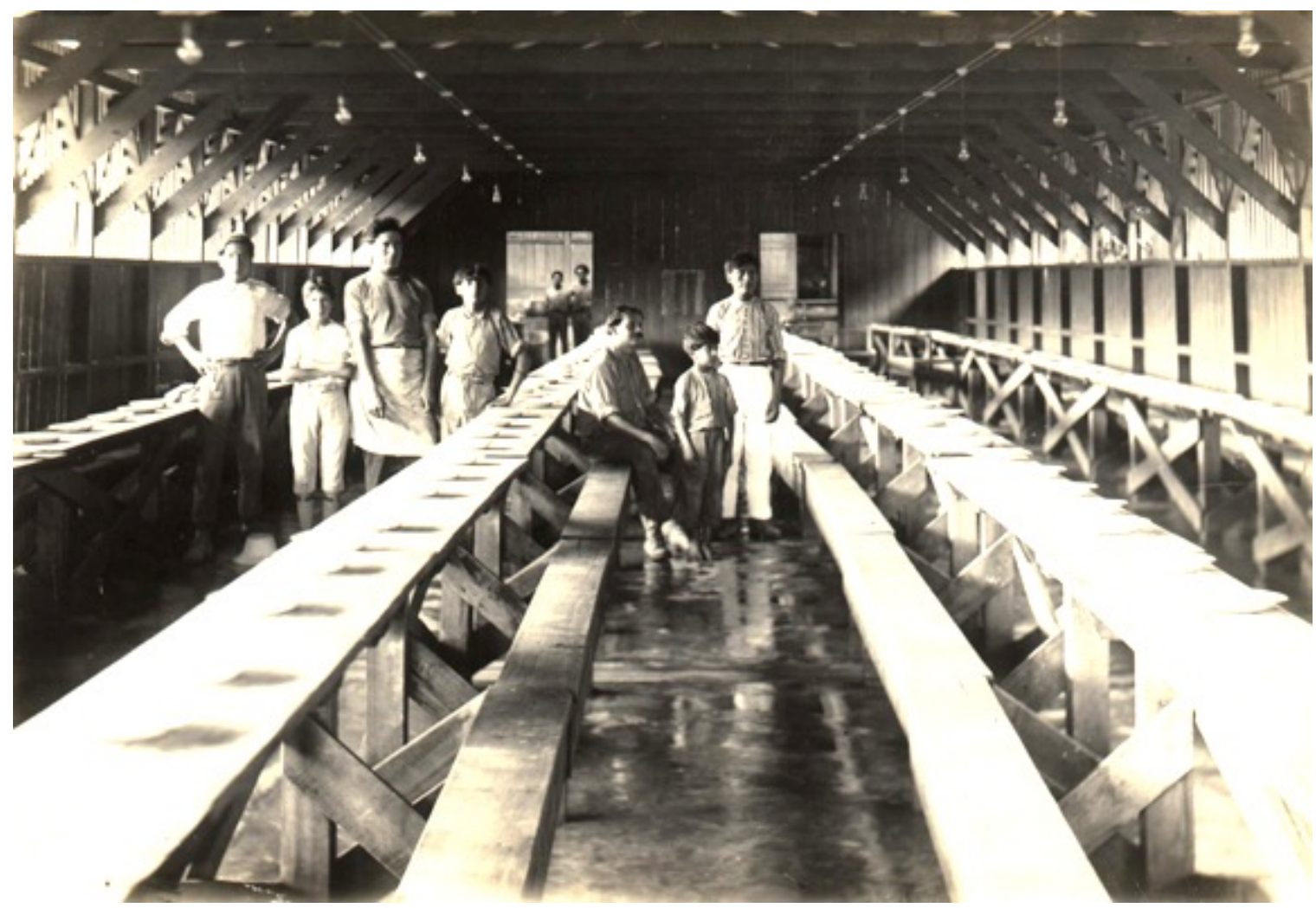

Note: The company established the Fonda Nacional, a massive soup kitchen that served meals at a subsidized price. The provision of food was a key strategy to attract, retain, and control the labour force.

Source: ETSA.

After the strike, the company stopped providing free food. Schraps (n.d., 101) mentions that this was a deliberate disciplinary strategy as workers "had definitely felt the pinch of hunger and were happy to work in the mines once more. ... Deprived from [sic] that meal, the peon workman soon realized what the company's bounty had meant to him." Insofar as labour was paid a wage, the company was able to control the work force, expand profits, and ensure a profit within a controlled — albeit subsidized - market. Thereafter, spaces for wageearning labour and capitalist consumption were partially confined to the camp. 
SADCO subsequently changed its strategy to a monetary system of subsidized food. The company issued ration cards for workers and provided high-calorie meals at the Fonda Nacional. The general store sold low-cost rice, sugar, cereal, flour, condensed milk, and meat of higher quality and more attractive packaging at the same price as products available in Zaruma or Portovelo. The store also sold American processed food, clothes, liquor, and household appliances, as the company imported goods duty-free. The company store was a key element in the spread of monetary transactions as well as the persistence of pre-capitalist relations through mechanisms such as loans and debt imprisonment.

Mining executives compressed the time-space relation of monetary circulation, reduced options for producing capital outside of the mining enclave, increased profits from the sale of essential goods, and disciplined the labour force through a credit regimen. The company implemented a token system for deducting workers' purchases at the company store and, in 1937, SADCO issued scrip redeemable at the company store, dubbed "Pattersons" by workers, after the company's superintendent. The currency was equivalent to one sucre and circulated in neighbouring counties. In 1938, General Enríquez Gallo decreed a 50,000 -sucre fine for the emission and circulation of illegal currency as part of a 
broader strategy to reassert the value of legal tender and regulate the mining industry's profits. ${ }^{141}$

However, the relationship between the production of value and its realization in the market was not fully controlled by the enclave economy, insofar as wages, service contracts, and local taxes allowed for local forms of accumulation. ${ }^{142}$ Since colonial times, municipalities established, collected, and delegated tax collection and patent fees (Ayala Mora 2011). Markets were regulated and administered by municipal authorities who verified weights and measures, licensed and taxed traders, maintained order and sanitation, examined the quality of food, and collected garbage.

141 Decreto No 20, in: Registro Oficial, January 28 and 29, 1938.

142 In 1937, the company spent 300,000 sucres (US $\$ 25,700$ ) per month to pay employees, $1,000,000$ sucres (US $\$ 85,700$ ) annually to pay loggers, and an additional significant amount to pay muleteers (López Saa 1937, 43). 
Photo 6.12. Zaruma's Sunday fair in the new marketplace, 1937

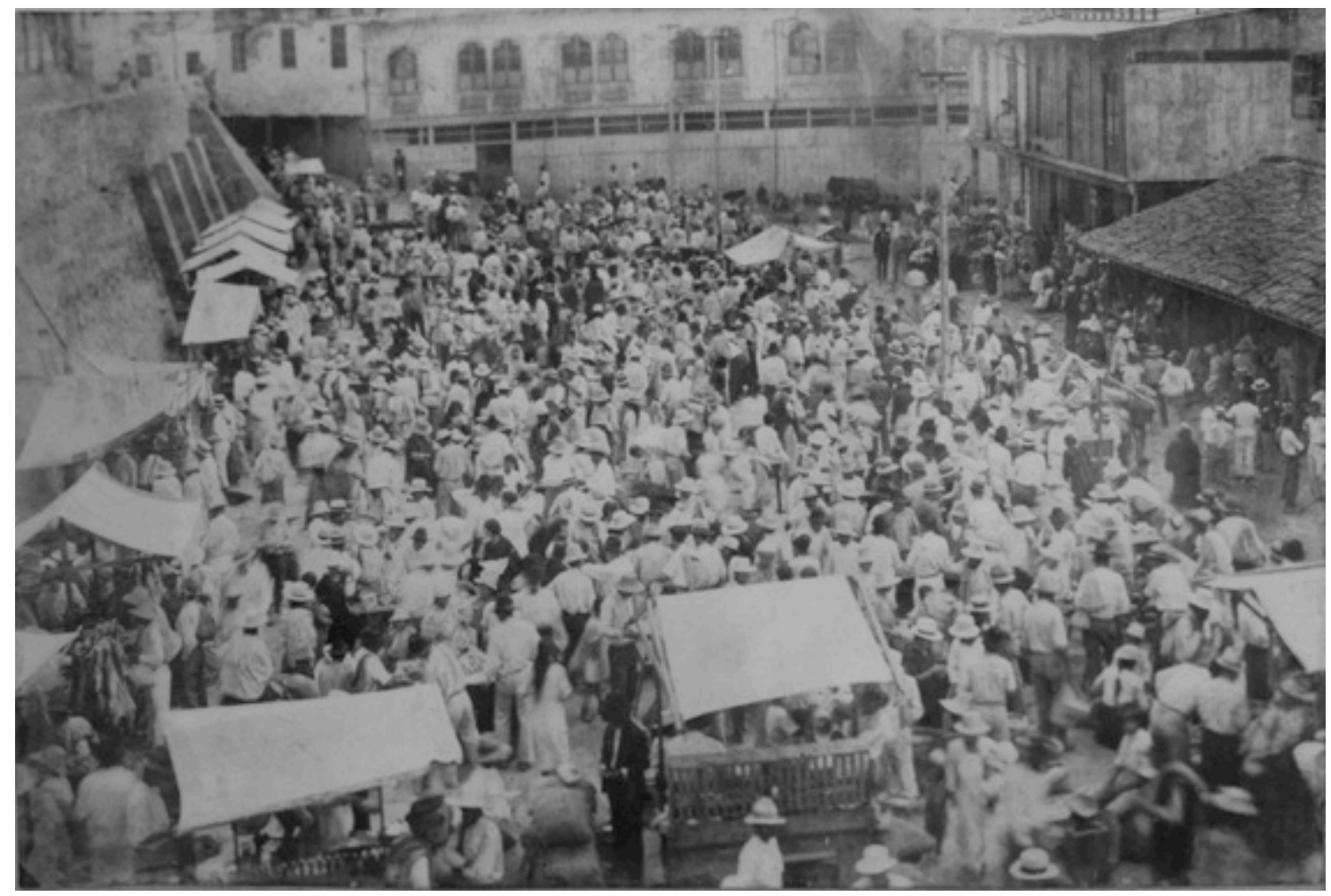

Note: Local residents and the work force of the Portovelo camp came to Zaruma for the Sunday fair. The clothing is not associated with any particular ethnicity although the use of straw hats denotes a connection with Cuenca's hat manufacturing centers. The municipal taxes and mining royalties financed the building of a new marketplace in Zaruma in the late 1930s.

Source: AHM/Z. "Feria dominical en el nuevo local del mercado, Stbre - 1937," Album Municipal, T.I., 1931-1944; Cevallos 2011, 56.

Special laws created taxes on Portovelo camp transactions and the circulation of capital associated with mining. Taxation included a bidding process through which the municipality awarded the collection process to private parties. In the case of SADCO, the municipality agreed that the company would pay a 
3,000 -sucre tax for all goods therein provided by the company for consumption in the camp, while the municipality would directly tax merchants who did business in the market held in the camp. ${ }^{143}$

The alternatives to the company store were the shops and the weekly markets in Zaruma, Portovelo, and Piñas. Zaruma had several stores with over 100,000 sucres in capital, Piñas had a warehouse with over 200,000 sucres in capital, and the sale of alcohol in the county represented more than 150,000 sucres a year in taxes (López Saa 1937, 44). At the weekly markets, fresh produce was considerably more expensive than in other cities, with significant seasonal variation. ${ }^{144}$ High wages made possible consumption of basic products and luxury goods, and prices were among the highest in the country (Paredes [1938] 1970; Utreras et al. 1933). Merchants were a separate class whose

143 For example, in 1935, before municipal participation in mining royalties, the City Council collected the Tarifa in Zaruma (9,722 sucres), Portovelo (5,000 sucres), and Piñas (4,215 sucres), the tax on wood (30,000 sucres), the tax on the sale and consumption of alcohol $(26,700)$, the tax on coffee, horses, mules, and commercial establishments in Portovelo (2,400 sucres) and mine patents (3,700 sucres). These values represent 81,737 sucres, equivalent to 58 percent of the municipal budget, estimated at 141,084 sucres for that year. Source: AHM/Z. "Ordenanza de Presupuesto Ordinario para el año de 1935," MMC, T.33, 5871.

144 Paredes ([1938] 1970, 37) provides a comparative chart of meals and food prices in Zaruma and Quito for 1937. 
members had the wherewithal to comply with taxes established by the local government since they were also profiting from the mining boom. ${ }^{145}$

\subsubsection{The apolitical use of leisure time}

The company's influence moved beyond work- and subsistence-related areas and into the daily life of the community, moulding interactions through religious worship, sports, and cultural activities. Alice Kellogg (1933ca., 24) points out that "to keep the labour contented [the company] built a chapel and had a resident priest." The cement and brick Catholic chapel — built after the first workers' protests in 1919 and finished in 1924 - with its 200-person capacity was noteworthy for its American-Protestant architectural style: the dome was made of wood and zinc, and painted silver, with straight, unadorned lines. The general manager was an Episcopalian who described himself as a "missionary," willing to move beyond his own faith to promote civilized sociability. ${ }^{146}$ The presence of the Catholic priest, paid by the company, was "remarkably improving the social condition of the camp" (SADCO 1929, 17). The company encouraged the celebration of traditional Catholic rituals but changed the day dedicated to the

145 Street vendors and merchants with permanent locales in Zaruma paid taxes directly to the municipaity while for those in Portovelo the municipal government of Zaruma delegated tax collection duties to SADCO. Street vendors paid fifty cents a day while vendors with stalls in the market paid one sucre a day per square foot (Paredes [1938] 1970, 36).

146 ETSA. "Miner and 'Missionary'. Mellick Tweedy reminisces on his 25 years in Ecuador," Standard-Times, San Angelo, Texas, Sunday, May 9, 1948. 
Virgen del Consuelo from mid-July to July 4 to coincide with the United States independence celebration.

\section{Photo 6.13. Good Friday Procession in the Portovelo camp}

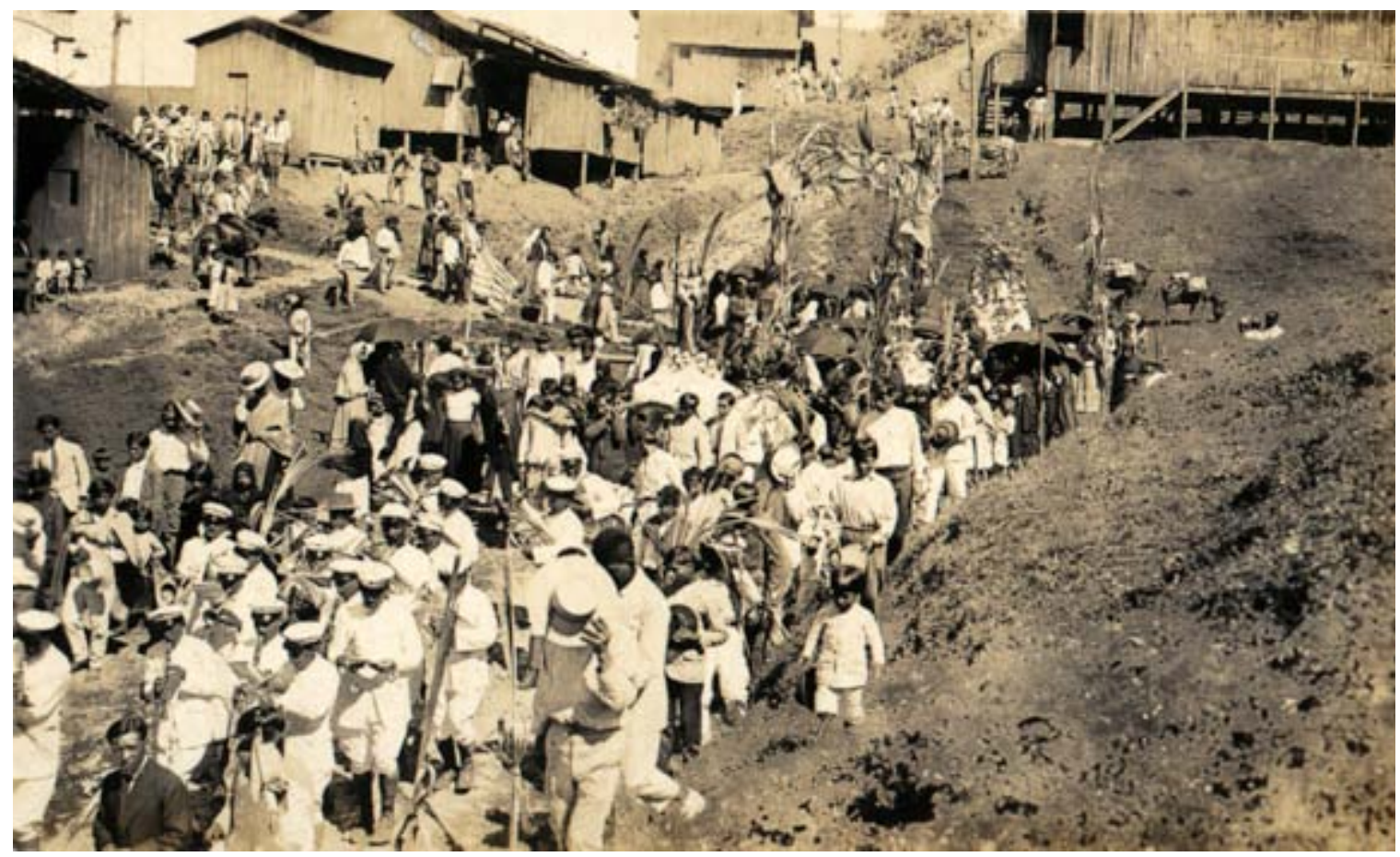

Note: Religious rituals reinforced company-prescribed community interactions designed to instil "moral values". The band preceded the ceremony, followed by men wearing suits and carrying the statue of Christ on a litter. Bringing up the rears are women wearing black, their heads covered, shaded by umbrellas.

Source: ETSA.

Expressions of religious and traditional beliefs were never eliminated but, rather, transformed by the new foreign aristocracy to include festivals and parades. On July 4, the miners wore white and took the Virgin's image through the streets, accompanied by music and waving palms fronds. The Virgin, declared the patron saint of miners in 1606 , was widely venerated among peasants (Murillo 2000, 86). However, the modernization of social relations 
shifted the financing of the celebration to the working class. This event had no priostes (festival hosts funding the religious festivity); instead, the company deducted each worker's contribution from his monthly wage (ibid., 33).

The celebration combined religious rituals with recreational activities imported from the United States; a neo-colonial practice that speaks to the extralocal spatiality of the enclave. The United States' national anthem and the raising of that country's flag followed the procession. Thereafter, the population participated in sporting events. The Americans played polo and baseball while Ecuadorians played basketball or soccer. Portovelo had the best teams in the region, and matches were hotly disputed events, particularly with the teams from Zaruma. Internal hierarchies and varying skills were also present on those occasions, as each department marched with floats and workers sent letters and post cards congratulating company executives (ibid., 33). Finally, fireworks lit up the night sky while the band played popular tunes. Gradually, the celebration lost its religious connotations and became more commercial, with travelling merchants introducing gambling and games of chance and selling their wares. The religious festivities and cultural activities underwent a process that transformed them into hybrid performances, blending traditional conservative practices and modern values. 


\section{Photo 6.14. Baseball team with women at the sportsfield}

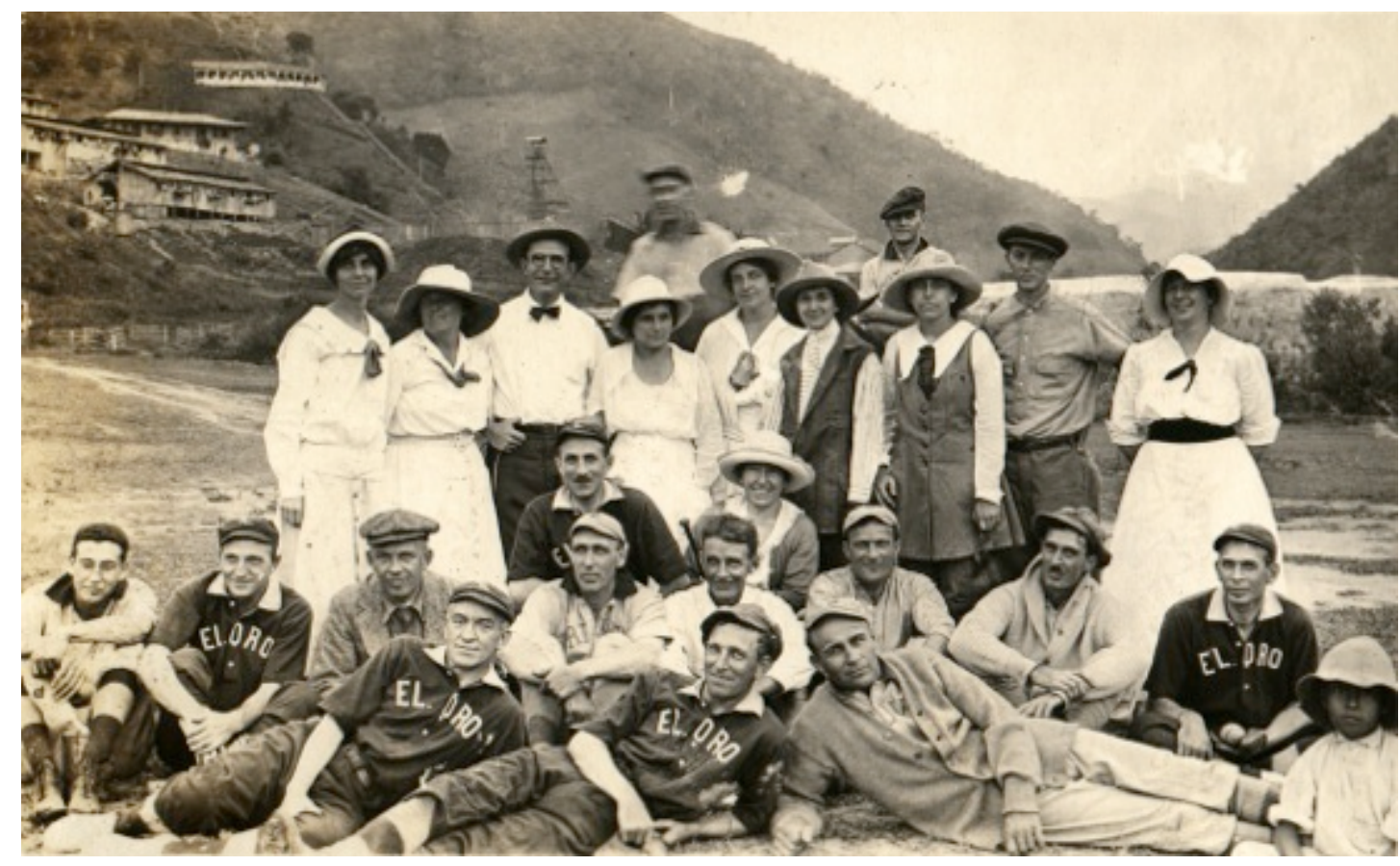

Note: The Americans introduced "modernizing" practices, which included sports such as baseball, polo, and golf, foreign to Andean communities. Modernity brought a relaxing of the segregation between men and women. In the photo we see single women fashionably dressed.

Source: ETSA.

Mechanisms of social regulation extended to everyday life to include leisure time, which served to discipline the work force, with spare time dedicated to competitive sports. The company promoted a fit lifestyle intended to relieve pressure from the labour routine, to promote a local identity, and to reap adherence to teamwork. Portelli (1991, 153 and158) notes that "the visibility which sports confers to the local community is a powerful antidote to internal conflict," which also helps with "separating the care of the body from the realm of work and moving it into the realm of leisure." Foreigners practiced sports such as tennis, swimming, golf, and polo. SADCO sponsored the soccer, basketball, and 
baseball teams by providing grants for uniforms and necessary equipment so that team members were able to develop their athletic skills. The camp had the best sports field of the region and two arenas, one of which was also used as a theatre and cinema. The matches between the teams of Zaruma and Portovelo are still remembered as events that reaffirm the prestige of each town. Even now, the soccer field of Portovelo is a feature of the town, a patch of green in otherwise dusty surroundings.

Capitalist modernity propelled new forms of apparently apolitical social organizing that reinforced social stratification. Modern leisure activities included hiking trips, social clubs, balls, and cultural events intended to increase sociability within classes. In Portovelo, life unfolded according to access to social organizations. The Newberry Club, established for the American engineers and high-ranking employees, organized the New Year's Party and a Halloween Masquerade. The Portovelo Club welcomed most professional employees and the upper-classes from Zaruma. ${ }^{147}$ The social clubs based in Zaruma planned

147 The main labour and social organizations of Portovelo included: Centro Minero (1908), Asociación Protectora del Minero (1912), Sociedad Protectora del Minero (1929), Asociación Sindicalista Obrera (1935), Organización Obrera Portovelo (1936), Federación de Trabajadores de Portovelo (1945). Other clubs included: Club Social Deportivo Avenida del Ejército, Centro Cultural Obrero de El Castillo, Comité Pro-Mejoras del Barrio Machala, Comité de San José. 
sporting events and helped organize civic festivities, parlour games, and charitable dances (Rueda and Romero 2002). ${ }^{148}$

While cultural activities served to reinforce an apparently docile and stratified population, they also encouraged the questioning of the status quo. In any case, it is important not to assume that the company was a sort of "master puppeteer" of cultural traits, ideals and values. For example, during a party organized by the Portovelo Club "there was some kind of fuss over people invited from Zaruma and the officers resigned." ${ }^{149}$ Because some people were excluded from certain activities, there was uneasiness among colleagues. When people socialized in large groups, often the consequences were unpredictable. Such was the case with the movie theatre sponsored by SADCO. The arrival of films and the exposure to foreign influences brought new social influences and clothing styles. Women began wearing outfits that featured shorter skirts, plunging necklines, bare arms, and accessories, and adopting short hair-dos and poses resembling the "chemise" fashion (ibid. 2002). In turn, restricted access and the high cost of the movie theatre became a point of contention in labour negotiations.

148 In Zaruma the most prominent social institutions included: Club Diez de Agosto (1909), Unión Obrera 19 de Marzo (1918), Boy Scouts (1920), Círculo Deportivo El Trébol (1934), and Centro Social Deportivo Sucre (1943).

149 ETSA. Letter from A.M. Tweedy to Florence Tweedy, November 23, 1931. 
In Zaruma the dynamics were rather different. The Municipal Council did not have the company's power or the resources needed to impose new habits and thus was limited to organizing and sponsoring programs for national holidays. Festivities honouring the independence movements of 1809 (August 10) and 1824 (May 24) and commemoration of the day the central government proclaimed EI Oro a province (November 26, 1882) were the most important local holidays. ${ }^{150}$ Celebrations included school parades, gymnastic performances, and artistic evenings, and were financed by SADCO. On such occasions, the municipality inaugurated public works and high-ranking authorities gave speeches. On these occasions we observe not only the differentiation of social activities, but also signs of paternalism, with senior mining company officials honoured as town patrons.

Before proceeding, I offer a brief analysis of formal education as fundamental to inculcating social values. Schooling was a matter of great concern to both company and municipal officials. The company had two daytime schools, one for boys and another for girls, a bilingual school for the children of American employees, and a night school for workers. ${ }^{151}$ The company paid the

150 November 26 became a formal local holiday in 1937, a year after the riots that ended with three deaths in Portovelo.

151 In 1948, the John Dewey Boys School had 409 students and 12 teachers; the Federico Froebel Girls School had 409 students and 11 teachers; the bilingual school Mary MacGonigle had six students and one teacher, and the Eugenio Hostos Night School for men had 172 students and three teachers (Barriga 1948, 22). 
salaries of teachers and administrative personnel, as well as for students'

uniforms and school materials. ${ }^{152}$ The schools implemented a disciplinary system based on "efficiency, individualism, and competitiveness" in which good manners and moral values, such as order, discipline, work, and safety, were taught (Murillo 2000, 143). Beyond the usual subjects, students received classes in basic agriculture, music, and sports. Although many miners were illiterate or semi-literate, attendance at the adult night school was minimal (Utreras et al. 1933, 41). Parents wanting a better education for their children sent them to study in Zaruma. The city had a long-standing reputation for its faith-based school system, financed by the Catholic community, taxes on mining supplies, and later, mining royalties. ${ }^{153}$

State intervention in daily life was achieved through the regulation of social organizations, as indicated above, and a greater presence in the education system. While this did not directly affect the schools under SADCO's control, Zaruma was affected by national transformations in the schooling system. In

152 For example, notebooks were specially ordered by SADCO from a company in Guayaquil, with the company logo on the cover, to build ties between students and the company (Murillo 2000, 119).

153 From the early years of the republic, the municipal council encouraged compulsory education for children and supported the establishment of Catholic schools. The liberal reforms included the establishment of public, secular education throughout the country. The municipality controlled education through the appointment of teachers, the construction of facilities, the funding of training courses, and student grants. These elements would become prominent when the national government later decided to regulate municipal administrative expenses and collect royalties at the national level. 
1897, the leaders of the Liberal Revolution determined that primary education was to be public, free, compulsory, and secular. However, both the Catholic Church and the municipalities continued to have a significant role in this sector. This pattern would only begin to change after 1914, when the first German education mission was hired to reorganize the educational system on the basis of scientific principles consistent with the positivism of the era. A second mission arrived in 1922 to reinforce the concept of the Active School according to which students should develop analytical capabilities in order to apply what they learned. Sports and gymnastics became important to developing both body and mind. At the national scale, Fernández (2006) argues that this was a political and social project associated with ideas of hygiene, racial regeneration, modernization, and cultural homogenization, implemented by public institutions for the purpose of incorporating rural schools into national culture. 
Photo 6.15. Gymnastics at the Gabriela Mistral School for Girls, 1941

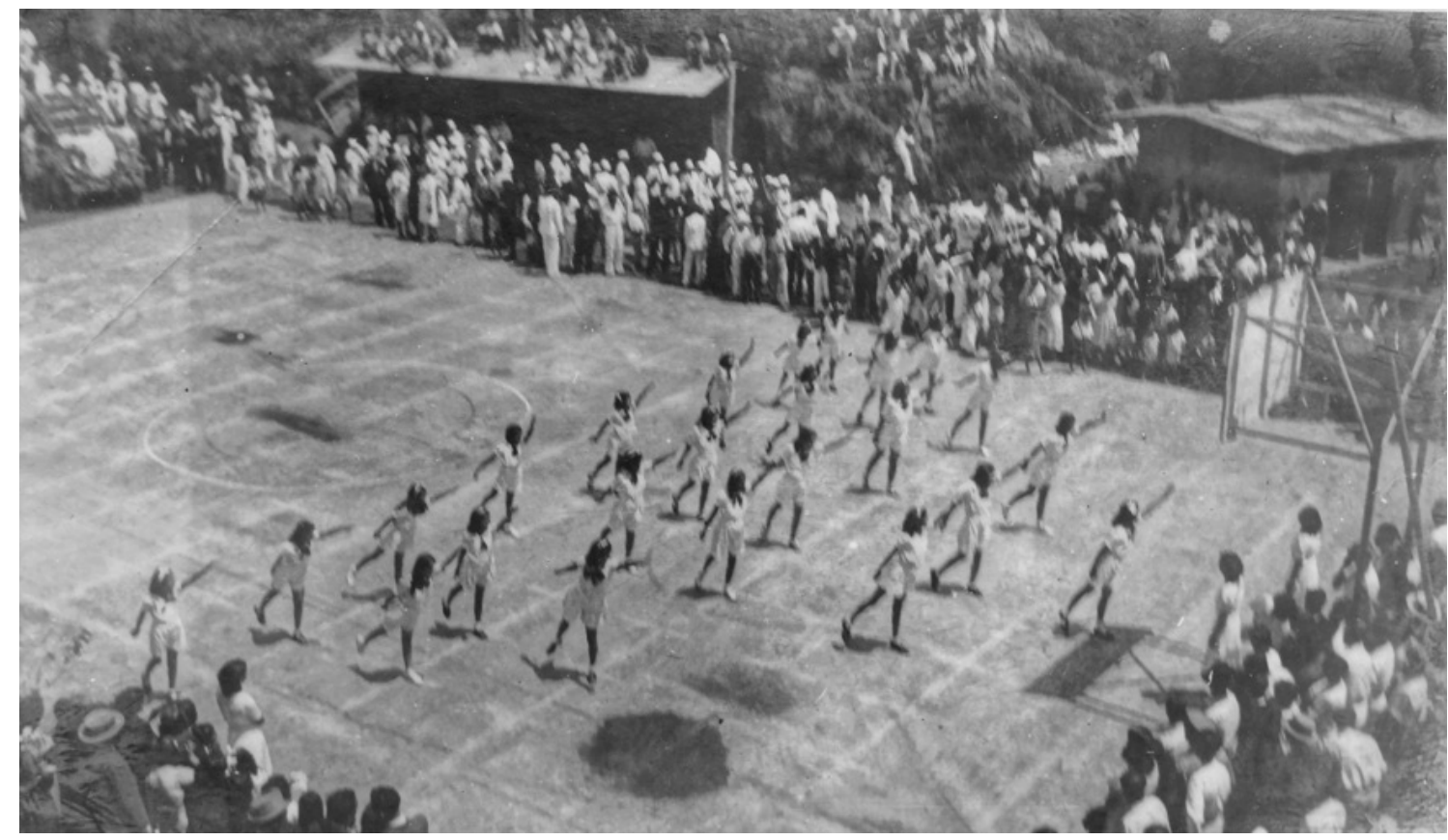

Note: Gymnastics were part of the school curriculum. The Gabriela Mistral School was named after a leftist Chilean poetess, indicating interest in the arts and Latin American intellectuals as well as a distancing from religious education.

Source: AHM/Z. "Gimnasia - Escuela Gabriela Mistral," Album Municipal, T. I., 19311944. Photographer unknown, 1941.

In Zaruma, the municipal budget reflects its keen interest in education.

There was a progressive increase in taxes earmarked for this purpose, including taxes on alcoholic beverages, on the sale of imported goods, and on timber dragging. The municipality of Zaruma introduced changes in the curriculum and provided scholarships for students to study at the Institutos Normales, the teacher training schools located in major cities. The scholarship recipients made a commitment to return to teach in municipal schools. The concern for quality education created a population with critical thinking skills and contacts beyond the county, which would become crucial to the development of the mining 
enclave. In fact, the importance of education was such that the provincial deputy for the province of El Oro and a native of Zaruma, Manuel Romero Sánchez, argued for a share of mining royalties to be earmarked for this purpose. In a speech to Congress, he said,

[as regards] the honesty of municipalities in the management of public funds and the way they have prioritized cultural development, [Zaruma] is one of the few in the country that spends on education a percentage higher than that specified by law, dedicating $45 \%$ of its ordinary funds to this purpose....

As noted, cultural, social, and educational activities can be used as regulatory mechanisms serving to legitimize class relations, but they can also lead to unforeseen results, producing contention. They are far from being apolitical in that they transform the politics of everyday life by introducing new ideas and mechanisms for social interaction. These structural forms of regulation act in two dimensions: they enter the sphere of the private, or domestic life, and they also create new relations and networks of power among levels of government where decisions about the form, content, and financing of cultural activities are made.

154 "El treinta por ciento de la explotación minera para Zaruma," Adelante, [Zaruma], December $17,1944,3$. 


\subsubsection{Patronage in the building of urban infrastructure}

As in other single-industry towns, "the development, maintenance, and reproduction of the entire enterprise depended quite heavily on forms of benevolence and paternalism" (Striffler 2002, 46-47). But unlike Striffler's report on the United Fruit Tenguel Hacienda, the father figure in this case not only provided services for the stable labour force living in the enclave but also developed a relationship with the city of Zaruma. Physical proximity of camp and city in a place that was otherwise isolated required condescending action towards urban elites. It goes without saying that SADCO was not motivated by benevolence alone, but by the need for relations favourable to the extraction of wealth.

The provision of electrical energy is particularly noteworthy as a mode of productive patronage, in what now would be called a public-private partnership. During the month of the first strike in 1919, the mining company agreed to build the municipal hydropower plant, using the hydraulic force of the Galvez channel. A.M. Tweedy was a cunning businessman particularly sensitive to the whims and political character of the local elite. The company agreed to purchase and install a generator, a transmission line, and a transformer to supply electricity to Zaruma at cost. The municipality - through loans from affluent residents and local taxes — funded the infrastructure; in this instance, no resources were provided by the national government. SADCO provided technical guidance, imported machinery, and supplies duty-free, and got the hydropower plant up and running. The council obtained the site, placed the poles, built the power station, and installed street 
lighting and user connections. In 1921, the inauguration took the form of a fourday Light Jubilee (Rueda and Romero 2002, 79) and the municipal board declared the mine manager a distinguished person (Murillo 2000, 85). With this "gift", the company gained the support of Zaruma. However, the service was not offered for free. SADCO had first rights on energy to power the mine pumps, the cooling system, the metallurgical plant, the mechanics workshop, and the Portovelo camp (Andrade 1923, 138). In addition, the company used municipal poles to extend lines and provide power to the Arrastre and Sesmo mines near Zaruma. Furthermore, the company issued a monthly bill to the municipality for the labour force and the supplies needed to operate the plant. More importantly, the municipality assumed protection of the infrastructure and electrical equipment. Otherwise, the whole city would sleep in the shadows, as indeed happened in 1945 and 1967. 
Figure 6.1. Detail of the Portovelo powerhouse, 1929

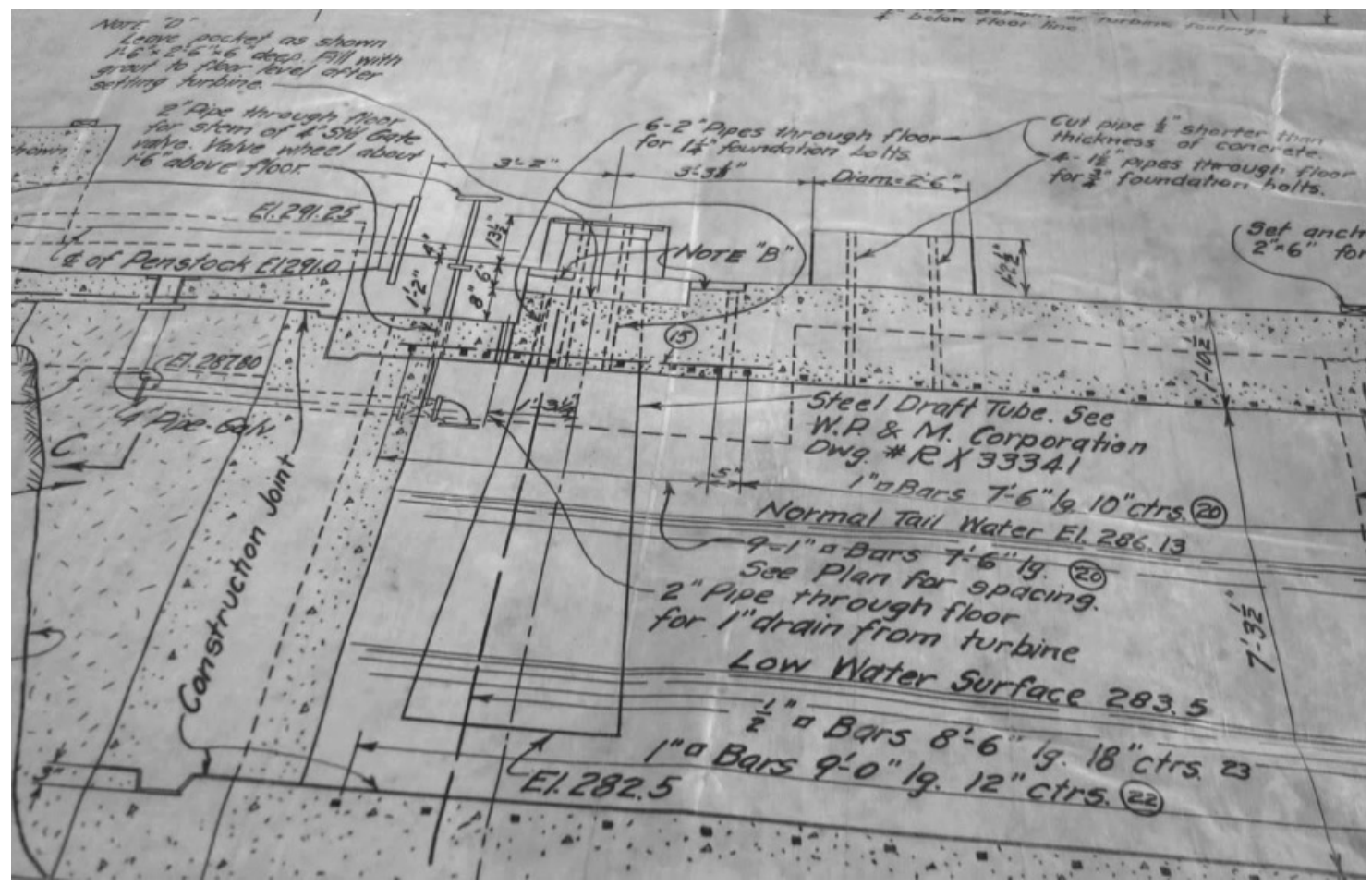

Note: SADCO created patron-client relations and a knowledge-based dependency in the building of urban infrastructure, notably for electric power and potable water systems. The company performed all technical studies in English, limiting access to knowledge by nationals. The Mining Code of 1937, article 67, stated that the concessionaire had to deliver technical reports to the government, keep accounts in Spanish, and train the work force in handling the machinery (an early insistence of technology transfer).

Source: Quimbalate Museum. Charles B. Hawley \& Co. Inc. Consulting Engineers, Washington D.C. Traced from blue print by E.\& L.Y. February 23, 1929. No. 824. Drawer No. 6. File No. 55.

SADCO created a knowledge-based dependency based on advice from foreign engineers for the design, construction, and management of urban infrastructure throughout the county. The mining company also built and maintained the Calera hydropower plant (1937) and the Amarillo River 
hydropower plant (1948), and its technicians assessed the structural design of bridges, roads, and public buildings. ${ }^{155}$ In addition, the foreign company served as a contractor for the construction of Zaruma's potable water system (1929) and as an intermediary for international purchases of equipment for other public works. Beyond covering the costs involved, SADCO had the capacity to procure equipment overseas, deal with state administration, and import duty-free. For imports, the company was able to deal with administrative procedures such as insurance, ocean freight, port charges, unloading, railway freight, and mule freight.

American managers and high-ranking employees were considered philanthropists of the community and distinguished citizens of Zaruma. Aid and gifts to individuals reinforced that perception. ${ }^{156}$ Municipal records indicate the fluid communications and prominence of the mining entrepreneurs in a separate section for correspondence with the company. A direct telephone line connected SADCO's headquarters and city council offices. The company also provided construction materials for municipal works, including sand and gravel for the main plaza, wood for the marketplace, and cobblestone for the road near the

155 AHM/Z. "Informe de Labores," MMC, T.40, December 1, 1940, 6-22.

156 For example, Dr. Eduardo Kingman and his wife donated plots for the construction of Zaruma's hospital in 1918. The council honoured them as "patriots and benefactors" and organized a public farewell upon their permanent departure to the United States. See: AHM/Z. MMC, T.21, August 30, 1918, 139-141. 
Calera River. The company supplied implements such as brooms and soccer balls, lent tractors and tools, and helped repair public equipment.

Benevolence, cultural activities, and sports served as a distraction provided by the company, but they also represented a risk in that they offered a space for the work force to organize and to forge a common identity, elements that could be turned against the company should discontent arise, which, in fact, occurred. By mid-century both the landscape and society had changed, and social organizations and local authorities demanded better living conditions and the redistribution of mining profits.

\subsection{Conclusion}

In developing the mining district, the company had to deal with existing socio-spatial structures and emerging social powers, which transformed the dynamics, the productivity, and the outcome of the overall industrial venture. The corporate actor fostered wage labour, introduced Western practices, forged political alliances, influenced decision-making, controlled populations, managed prices, and bargained for the terms according to which new investment would take place. This cultural transformation helped to create conditions for a profitable mining enclave ruled by foreign investors, but this process also entailed proletarianization and class solidarity among Ecuadorian workers. The influence of socialist and Marxist ideas challenged the status quo, resulting in class awareness, organization, and mobilization. Moreover, the labour movement 
resisted the oppressive nature of both capitalism and the state to put forward demands that would eventually result in new formal institutions and norms, such as the Labour Code of 1938.

In many ways, corporate benevolence, patronage, and philanthropy preceded current corporate social responsibility; both are based on the argument that the best regulation is self-regulation. ${ }^{157}$ In this case, corporate philanthropy was an array of instrumentally motivated practices used to increase profits or enhance public image. These practices served to establish a corporate presence in support of social and community services, while also disciplining the work force and building alliances with local politicians.

In view of these considerations, I maintain that the transformation of the physical and social landscape associated with the "penetration" of state and capital, and the relative autonomy of local governments and social movements, created supportive conditions for securing nationalist claims over natural resources and restructuring the geographies of resource regulation in Ecuador. This venture required the active agency of the state in different capacities and at

157 CSR has been "characterized by the evolution of an ever-increasing array of voluntary codes, standards, and alternative accountability mechanisms as well as by the exponential growth of CSR experts, auditors, and consultancies" (Coumans 2010, 30). The standards and codes that pertain to corporate social responsibility have multiple and not always mutually compatible procedures and do not necessarily enforce accountability mechanisms to assure respect for human rights or support and promotion of community agency in protecting social, economic, and environmental values (Bebbington et al. 2008; Coumans 2010). 
different levels of government. The national government facilitated land appropriation and subsidized productive infrastructure. The public administration acted as a space for the settlement of disputes linked to regional rivalries between the elites of Azuay and Loja, but had a minimal presence in the actual mining district. In this context, local authorities and pressure groups rearticulated their territorial spaces of local domination and became a clientele for additional public works and a recipient of increases in local revenues. 


\section{The public domain of mineral resources: The restructuring and rescaling of national regulations, 1925-1950}

Ecuadorians who want to be a free people, master of our own economy, need to observe each of the subtle or crude ways in which imperialism is gradually subjugating us. The most visible form of imperial domination is embodied in the exploitation of our subsoil by powerful foreign companies.

(Paredes [1938] 1970, 8)

In 1938, the General Secretary of the Communist Party, Ricardo Paredes, published a book entitled El imperialismo en el Ecuador. Oro y sangre en Portovelo (Imperialism in Ecuador. Gold and blood in Portovelo). Paredes was a member of a generation of Marxist intellectuals, anarchists, utopian socialists, and critics of liberalism in Ecuador. They advocated for critical reflection of social problems in the country, and condemned foreign exploitation of natural resources and the looting of national wealth. Paredes called for the nationalization of the means of production and the enforcement of labour laws. The Socialist Party, the Communist Party, and the movement Vanguardia Revolucionaria invited popular forces to join the government against multinational corporations operating in the mining sector, the oil sector, and banana plantations. They believed that foreign companies exploiting natural resources embodied imperial domination. Temporarily, military regimes and leftist movements forged alliances to 
strengthen state institutions and address the "social question" from an anticorporate and anti-imperialist point of view (North 2006; Paredes [1938] 1970).

In seeking to understand the restructuring of mining codes, I look at key elements of regulation theory. This approach postulates a tight relation between the regimes of capitalist accumulation and the social modes of economic regulation (Aglietta 1976; Boyer 2002; Lipietz 1987; Jessop 1996). The regime of accumulation requires adjustments to the regulatory framework in order to sustain a specific mode of production. Insofar as this process involves intentional social practices, it is also dynamic and prone to internal contradictions. The internal contradictions eventually lead to crises in the political and institutional system. These crises can sustain or alter the accumulation regime. In this view, mining regulations hold a privileged status: they are the tools by which the organizational and technological aspects of extractive capitalism are fixed and imposed in concrete time-spaces to sustain accumulation. However, they are also a stage in the dispute over the transformation of the political and ideological paradigm.

The production of space and the construction of regulatory frameworks occur at different tempos. While the first includes the gradual transformation of the physical and social landscape, mining regulations come into being at historical junctures informed by political processes and social coalitions. However, in SADCO's sphere of influence, there was a difference between the approval of these regulations and their enforcement. Myriad micro-powers 
existed and transformed norms through socio-political struggles, everyday practices, or administrative procedures. From this perspective, the state and society have no unitary existence - as the champions of the regulatory approach argue - but, rather, exist in relational fashion as a juxtaposition and as a hierarchy of different, specific, local and regional powers (Foucault 2010, 156157). In the case at hand, the Ecuadorian state's performance in the operation of the American mining enclave was erratic, involving legal, political, and military means that sometimes worked in favour of the company's interests and at other times against it. This chapter problematizes the assumption that the state is a coherent capitalist institution, shedding light on the dynamic, contingent, and contested nature of mining regulations. In this regard, I am particularly interested in understanding law as a means to produce the temporal stabilization of sociospatial relations, connecting sources of power at different scales, and creating particular scalar arrangements.

In this chapter, I explore two dynamics resulting from nationalist regulations in the mining sector: the upscaling and diffusion of international policies to protect foreign investment, and the downscaling of social externalities whereby local actors become responsible for the consequences of deindustrialization. Throughout this period (1929-1950), the state forged a system of rights and strengthened its presence in its outlying territories, devising a new role for municipal governments as providers of public works and social services, and advocates of local development. I begin with a chronological and critical discussion of the origins and the successive restructuring of national frameworks 
establishing "public domain" over mineral resources. The main documents on which this story is based are the Constitution of 1929, the Mining Law of 1937, and contractual agreements of 1923, 1932, 1938, and 1950 between the Ecuadorian government and the South American Development Company. Based on this discussion, in the second part of the chapter I explore the series of events, multi-scalar connections, and institutional arrangements that led ultimately to de-industrialization, the nationalization of the mining concession, and the geographical confinement of the employment crisis within the Portovelo and Zaruma region.

\subsection{The "inalienable and imprescriptible" public domain of mineral resources}

The public domain of mineral resources is a salient principle of most constitutions and mining legislation in Latin America (Chaparro 2002). However, the relation between mineral resources and the state is a complex one. Theoretically, the state, as an institution committed to furthering the aims of capitalism, facilitates mining operations by defining and defending ownership of concessions, subsidizing the costs of resource exploration, and deploying legal, political, and military means to control access to natural resources (Robbins 2008; Whitehead et al. 2007). Yet, there are few studies that investigate the politics that underscore the emergence of the aforementioned constitutional principle. In this section, I address this gap from a historical perspective by analyzing the origins and restructuring of legal frameworks governing the 
extraction of mineral resources in Ecuador. In the case of Portovelo, I contend that targeting American-owned foreign companies went beyond "rent-seeking" attempts to encompass a broader project to establish the objectives of the development state.

Vergara Blanco $(1992,2006)$ argues that state ownership of mineral resources has an intimate connection with Spanish colonialism and its civil law heritage. The exploitation of mineral concessions was guaranteed by the political and administrative organization of the Spanish Crown. This produced a "patrimonial" link between sovereign and underground resources; the mines were an asset and a royalty of the political apparatus. Vergara Blanco insists that republican legal texts not only continued this tradition, but also employed more emphatic language to reaffirm state ownership of mines. I argue that mining regulations of the late $19^{\text {th }}$ century have been overlooked in this analysis. This case is relevant to understanding contemporary political concerns and conflict at a time when extractive industries are expanding their reach in Latin America. Moreover, in Ecuador there is an inherent contradiction between nature as a subject of rights, granted by the Constitution of 2008, and the appropriation of nature for productive processes. 
The Ecuadorian Mining Code of 1886, a replica of the Chilean Mining Code of 1874, facilitated the expansion of private ownership and extractive imperialism in the mining sector. ${ }^{158}$ Ecuador developed a res nullius regime whereby mines became private property granted to the first discoverer and applicant. The system considered legitimate property that which was productively worked; mine holdings were given to individual legal subjects in perpetuity as long as owners could demonstrate the active development of mineral deposits. Only in the event of abandonment of mining works were holdings returned to the state. Moreover, the state subsumed other ecological processes and land uses to mine productivity.

In 1892, reforms to the Mining Code included, in article 1, this provision: "the state owns all mines ... notwithstanding ownership by corporations or individuals of surface land under which they are located." For progressive liberal regimes of the period, the recognition of such a principle represented a triumph over colonial regulations. The republican state was recognized as the legitimate owner of all mineral deposits, but could grant concessions through a royaltybased system. These provisions played an important role in opening up spaces for the operation of export-oriented industries and the dispossession of local

158 The res nullius regime introduced an entitlement system linked to common law and British imperialism. For a detailed explanation of different doctrinal systems pertaining to property regimes applicable to mine holdings, see: Campbell 1956; Ossa Bulnes 1999; and Vergara Blanco 1992. 
communities in the name of economic progress during the late- $19^{\text {th }}$ century (Chacón 2001; Ramón and Torres 2004). Harvey $(2014,55)$ notes that private ownership, a requirement for the expansion of capitalism, depends on the existence of state authorities and legal systems for encoding, defining, and enforcing the contractual obligations of individual legal subjects. Yet, in Ecuador, political decisions and regulations underwent constant change. Gold mining was marginal to the national economy, and the organizational terrain was characterized by contradictions among political actors that sometimes worked for the company and sometimes against it.

In Latin America, nationalist mining regulations emerged in the early $20^{\text {th }}$ century. ${ }^{159}$ Moran (1992) claims that economic nationalism in developing countries and the demand for renegotiation of mining contracts result from the reduction of risk and uncertainty after projects requiring large capital investment prove successful. Furthermore, Otto and Cordes (2002) state that bargaining power in the mining sector is related to the structural vulnerability of mineral investments insofar as they are capital-intensive, cannot be relocated, use relatively stable production technologies, and have limited competition. I

159 Legal reforms aimed at sovereign control over mineral resources are usually associated with expanding mining capacity in the aftermath of World War II and the nationalistic policies of the Cold War period, from the 1950s to the 1970s (Otto and Cordes 2002; Williams 2005). For a historic analysis relevant to Latin America on the connections between resource-based economies and nationalist policies, see: Cardoso and Faletto 1971; Furtado 1976; and Thorp 1998. 
problematize this approach by highlighting the fact that nationalist legal reforms and mining policies were ideologically motivated to restrict the long-term rights of foreign-controlled mining companies with few obligations and little accountability to the government, limited technology transfer, and little redistribution of wealth at the national level, although they served very diverse political purposes in different periods and geographical contexts. ${ }^{160}$

Although Ecuador reasserted public domain of mineral resources, specifically in the Constitution of 1929 and the Mining Code of 1937, I argue that such a process was effectively mediated by recurrent negotiations with the South American Development Company, SADCO. The American-owned mining company, a subsidiary of the Vanderbilt Group, operated the Portovelo gold mines between 1896 and 1950. To examine this argument, I begin by describing the politics of the Ecuadorian Constitution of 1929 in which the then-progressive public domain of natural resources was, in fact, mediated by negotiations with the company. Second, I explain the centralizing features of the Mining Law of 1937 and how the institutional framework affected application of the law. Third, I

160 In Mexico, the 1917 Constitution reasserted state ownership of natural resources and regulated foreign investment in the oil sector, obliged mining companies to acquire inputs locally, collected tax revenues, and facilitated the expansion of the state apparatus (Brown 1993). In Chile, the early development of state capacity regarding taxation of the mining industry allowed investments in infrastructure and public services useful for industrialization and improved working conditions (Paredes M. 2010). In 1937, after the Chaco War, the Bolivian government expropriated Standard Oil Company facilities and sold them to YPF, an Argentine company, as a means to secure the international border (Philip 1982). 
explore how the rise of leftist social movements and authoritarian governments came together to force contractual renegotiations and protect public over private interests. My purpose is to illustrate the background of regional tensions, ideological discussions, and influence against which nationalist mining regulations came into existence in Ecuador. I base my case on primary sources, including legislative materials, government records, corporate documents, and private correspondence. Overall, the section problematizes the domain of the state over natural resources by shedding light on the contested nature and multiscalar arrangements of mining regulations.

\subsubsection{The public domain of mineral resources}

The state owns all minerals or substances which - in veins, strata, or ore - constitute deposits whose nature is different from soil components. In the case of the preceding clause, the state's domain is inalienable and imprescriptible and usufruct may only be granted to individuals and civil or commercial societies under terms specified in the respective laws, provided that they establish ongoing work for the exploitation of these elements.

(Constitution of Ecuador of 1929, article 151: section 14)

In 1929, Ecuador's National Assembly declared mineral deposits to be the inalienable and imprescriptible domain of the state. Under this provision, mineral wealth was the absolute and exclusive patrimony of the state. This norm gave rise to a concession system, restricted foreign investment, and re-established royalties and continuous mining as basic conditions to maintain mining claims. Technically, foreigners were no longer allowed to own or acquire mining concessions, land, or water resources within 50 kilometers of international 
borders. In addition, all contracts between foreigners and the government of Ecuador included a clause in which the concessionaire renounced diplomatic claims and the right to appeal to a foreign jurisdiction.

The legislature requested that all contracts granted under the previous mining laws be reviewed and questioned the operation of foreign companies as they "get privileges that circumvent Ecuadorian laws and fail to meet their commitments." ${ }^{\prime 61}$ The Constitution promoted the active role of the state in regulating the economy and requiring industry, trade, and commerce to follow a new set of labour regulations. The Assembly appointed a special committee to provide legal advice, with specific reference to the South American Development Company and the Anglo-Ecuadorian Oilfields Limited. The companies were the largest foreign investors in Ecuador's mining sector during the first half of the $20^{\text {th }}$ century (Albornoz 2001).

Thereafter, laws governing mineral resources were tailored to the interaction between the national government and major corporate actors. The attorney general declared prior agreements null on the basis of inappropriate

161 ABANE. Cámara de Diputados, Sesión extraordinaria, Acta № 37, September 23, 1923. 
administrative procedures. ${ }^{162}$ SADCO's general manager, Andrew M. Tweedy, described the move as an "abstruse legal technicality" and called the legislature "entirely irresponsible, semi Bolshevik and decidedly anti-American." ${ }^{163}$ The company manager consulted with renowned lawyers who had influence in the legislative and judicial branches of government. The lawyers noted that the American-owned company had not received any special privileges in comparison to other mining companies. On the contrary, the lawyers argued that the company had exceeded financial obligations stipulated in the original agreements and that the contractual renegotiation that the legislature requested was not applicable (SADCO 1929).

SADCO's representatives argued that their actions were not only legal but also beneficial for the whole country. The American businessmen financed the publication of announcements arguing their case in mainstream newspapers, stating that the company,

162 In 1923 SADCO signed a contract that required the company to deliver materials to construct $130 \mathrm{~km}$ of railway connecting the seaport to the mining district. Administratively, such a contract should have been approved by the legislature, not by the executive, since any decision modifying tax collection or affecting public finances was the exclusive responsibility of congress. See: Communication from M.C. de Vaca to Remigio Crespo Toral, Informe del Procurador General de la Nación, July 16, 1929 in: Utreras et al. 1933, 58-59; Decreto Legislativo, June 26, 1929, in: Registro Oficial, N 77, July 17, 1929. 
...has turned the south-eastern district of the province of El Oro, a mortiferous, impoverished backwoods, where not even highland natives descended to trade, into a populous agricultural region, whose haciendas and farms of well-cultivated fields, multiply day by day, beautifying its broad valleys and extensive slopes decorated with natural richness of which any country would be justly proud. ${ }^{164}$

The Portovelo camp was discursively and actively presented as the engine for local and regional development and welfare. Mining was seen as a key player in fostering progress by reducing poverty, creating employment, and expanding social policies, which in turn contributed to satisfying local demands. The foreign enclave was portrayed as a dynamic and modern industrial site with positive influence on the economy of the southern provinces of El Oro and Loja. This is a strategy commonly applied by extractive industries, whose spokespersons have developed a discourse intended to counter perceptions that these industries are detrimental to social and environmental development (Bridge and McManus 2000; Kirsch 2010).

In addition, the company appealed to local identities for support, feeding discrepancies among regional elites, and resisting state control over the mining industry. The American businessmen argued they "had thought of doing good" by accepting suggestions made by "distinguished personalities" of Zaruma and Loja,

164 BEAEP. Communication from Tweedy to Ministro de lo Interior y Obras Públicas, Documentos relativos a los contratos... 1923ca., 28. 
and had "proposed to the Executive to exchange their former commitment for the betterment of the region" (SADCO, 1929, 9). Since the Liberal Revolution, the railway had been a symbol of progress, but also a matter of intense dispute among authorities in Loja, Cuenca, and El Oro. Moreover, the commitment to build a train from Puerto Bolívar to Zaruma ruled out a direct route from the lowlands to Cuenca.

Senator Agustín Cueva, from Loja, president of the Senate in 1929, referred to the case as a "problem of national civilization" that had transformed into a problem of "regional ignorance." This discursive representation refers to a historical regional dispute between Cuenca and Loja, which was being exacerbated by rumours from Cuenca that the "Yankees' gold" was a source of corruption in El Oro. Cueva called for solidarity among the provinces in question:

There are, let us speak frankly, in some souls in the sister province, an unconscious or concealed feeling of the superiority of Azuay over Loja and El Oro. And that is where we find the root of dissension, the muddy source that clouds the crystal clear, harmonious development of the three provinces. All imperialisms even the small ones - are the rotting sore infecting social solidarity (cited in Jaramillo Alvarado 1955, 423).

The situation reflected tensions between the executive and legislative branches as well as among representatives of the southern provinces. The foreign mining executives were unable to control politicians or to come easily to agreements with the legislature.

Contrary to previous contractual experiences, the mine manager himself was stationed in Quito, working on a favourable agreement. Tweedy noted that "if 
I had not been up here, I do not think there is much doubt that already some wild legislation would have been passed which it might have taken years to undue [sic]." ${ }^{\text {165 }}$ SADCO's general manager reported there was "no one you can believe or trust". ${ }^{166}$ President Ayora offered support to the mining company but took few steps to implement executive promises. In the legislature, personal squabbles among members delayed a decision. Tweedy developed close relations with some members of the senate, the diplomatic corps, and the upper class, but reported that "they are a minority in Ecuador, and a decision in favour of a gringo is never popular." ${ }^{167}$

Ecuador continued to be a state characterized by regionalism, without an elite able to unite to achieve compliance with national commitments and the state apparatus could not enforce administrative decisions throughout the national territory. The central government was unable to bring together regional interests. The "small imperialisms" coexisting in Ecuador gave way to a series of political debates, legal consultations, and technical inspections. In the meantime, liberal hegemony was dissolving as cacao exports declined, the balance of payments recorded deficits, and the landed elite lost power. President Isidro Ayora was

165 ETSA. Letter from A.M. Tweedy to Florence Tweedy, May 25, 1929.

166 ETSA. Letter from A.M. Tweedy to Florence Tweedy, May 1, 1929.

167 ETSA. Letter from A.M. Tweedy to Florence Tweedy, May 20, 1929. 
overthrown in 1931 and five different heads of state took office during $1932 .{ }^{168}$ Ecuador was plunged into a political and economic crisis, giving rise to new forms of political patronage and negotiation between regional authorities and the central government (Cueva 1981; Maiguascha 1991; Quintero and Silva 1991).

In 1932, Manuel Romero Sánchez, socialist congressman and a native of Zaruma, launched a new campaign against SADCO, framing it as a defense of national interests against extortion by international companies. Congress requested another report and issued a decree "disapproving" the 1923 contract. ${ }^{169}$ Again, congress noted that contractual obligations were inconsistent with the benefits SADCO received. The decree urged the executive to pursue a new contract on the basis of the following criteria: public participation in mining profits, customs exemptions only for mining supplies, and enforcement of labour regulations. Furthermore, in the event that the company decided to suspend work, the state could take over the mines. The regional representative of the Socialist Party presented the case as a struggle between imperialist domination and the national control of natural resources.

168 The Congress refused to recognize president-elect Neptalí Bonifaz, and this resulted in violent protests known as the "Guerra de los Cuatro Días" (Four-day War), from August 28 to September 2, 1932.

169 Resolución, November 12, 1932; Decreto Legislativo, December 1, 1932 in: Utreras et al. 1933, 62-64. 
The threat of nationalizing the mines involved inputs at multiple scales, ranging from local claims for greater revenues to hemispheric policies towards Latin American countries (Epps 2009). The United States diplomatic corps in Ecuador recognized that their government's direct participation in negotiations between private companies and the Ecuadorian Government should be resorted to in extreme cases only. The announcement of a Good Neighbour Policy, subsequently adopted in 1933, reasserted the commitment to non-intervention and non-interference by the United States in the domestic affairs of other countries. As a result, diplomats serving in Ecuador had limited ability to offer overt support to SADCO. Instead, they suggested that the company seek political allies within the government.

Contract renegotiation continued, a tour-de-force as opinions differed from one branch of the government to another. From one side, the parliamentary opposition - composed of socialists, conservatives, and emergent populist leaders - demanded a review of all previous contractual agreements detrimental to national interests. On the other hand, President Martínez Mera (1932-1933) stated that a contract implied the concurrence of two wills; the company could refuse to renegotiate the contract in which case there would be a legal and physical obstacle to a new agreement. Moreover, the president indicated that under Ecuadorian Civil Law, declaring a contract null or flawed was the 
prerogative of the judiciary; in light of this, he expressed his "willingness to search, within legal frameworks, for an arrangement or agreement that protected national interests." 170

The Ecuadorian state was riven with dissension among the president, the congress, the senate, and the military. The opposition censured virtually every minister, the Riobamba battalion revolted, and government credibility was undermined by the Leticia conflict between Colombia and Peru. In the midst of the cacao crisis and a monetary devaluation, legislators lamented that "nothing is more heartbreaking than retaining enormous wealth underground, and being obliged to fund our budgets with loans from [private] banks" (Utreras et al. 1933, 8). By the end of 1933, the Senate impeached President Martínez Mera and congress authorized a new contract. SADCO would pay $6 \%$ in mining royalties, sales tax, and income tax, but retained duty free privileges as granted in previous contracts.

In the context of the fiscal crisis, the nationalist claim over natural resources and the possibility of stabilizing the economy were linked to gold royalties and keeping bullion in the country. The Ecuadorian government demanded that royalties, taxes, and other domestic expenses be paid to the

170 Communication from J.D. Martínez to Congreso del Ecuador, December 7, 1932 in: SADCO 1938, 4-5. 
state in gold and that for all purchases within the country be paid for in sucres, the nation's currency, acquired by exchanging gold at the Central Bank at the official rate; that rate being, of course, far below that offered on the black market. This procedure would increase national reserves by almost US $\$ 500,000$ per year and avoid money flows to the foreign exchange market (Utreras et al., 1933, 103). However, SADCO paid operational costs in Ecuador by cashing checks in dollars from a New York bank account. The company argued that government measures were inefficient and that, in any event, it was impossible to refine goldbearing materials locally; thus SADCO avoided paying royalties with gold bullion. ${ }^{171}$ SADCO also looked for ways to lower Ecuadorian taxes and foreign expenditures by claiming deductions. ${ }^{172}$

The legislature earmarked mining royalties to finance transportation infrastructure until a railway or a road was finally completed connecting Puerto Bolívar and Loja. The new contract required that SADCO mortgage all of its property in Ecuador as a guarantee of its obligations. ${ }^{173}$ Andrew M. Tweedy, SADCO's general manager, deemed that the revised contract was not

171 After the installation of the cyanidation system in 1924, the company exported gold-bearing percolates. In fact, amalgamation changed in the mid-1920s after two episodes of robbery of gold bullion, one by American officials and another by locals (Kellogg 1933ca.).

172 These included the operating costs of offices in New York and profit-sharing bonuses paid to American employees (Memorandum, 28, in: Utreras et al. 1933, 102).

173 The mining company assumed a mortgage comprising all its assets, which included 43 hardrock mines, 318 mining claims, 12 placer mines, and 143 tracts of land as well as other belongings (Cortázar and Lavanda 2008, 73-74). 
confiscatory in nature and that it would still be possible to operate a profit-making venture despite increased costs. ${ }^{174}$

In the meantime, José María Velasco Ibarra was elected president of Ecuador in $1934 .{ }^{175}$ The charismatic leader obtained the backing of a conservative alliance and enjoyed popular support throughout the country. Political instability meant that SADCO was continually seeking support from politicians and renegotiating contracts. The company was cautious about the new chief of state who, on the one hand, encouraged workers to organize and, on the other, asked superintendent R. P. Luke "as a personal friend to accept the changes made in the contract by the (1934) bill." ${ }^{176}$ By 1935, Velasco Ibarra signed a new decree requiring the company to pay $6 \%$ royalties on gross production from its mines, but exempted the company from the Currency Seizure Law in effect since $1933 .{ }^{177}$

174 Communication from Chapin to Hull, December 8, 1933, NACP, Central File 1930-39, Box 5690, Record Group 59, in: Epps 2009, 36.

175 José María Velasco Ibarra became a key figure in Ecuadorian politics, and his periods in office were "Velasquismos". He was elected five times, but completed only one presidential term, the third, without being removed from office: 1934-1935, 1944-1947, 1952-1956, 1960-1961, and 1968-1972.

176 Communication from Chapin to Hull, January 3, 1934, NACP, Central File 1930-39, Box 5673, Record Group 59, in: Epps 2009, 39.

177 The company earned a profit, even with royalty increases, as it was no longer forced to cash $25 \%$ of the U.S. dollar checks at a fixed exchange rate below market value. See: Decreto Ejecutivo 116, February 2, 1935,Registro Oficial, № 173, March 29, 1935. 
This case reflects the transformation of interests within national public policy. The first contracts, of 1910,1917 , and 1923 , emphasized connectivity through transportation infrastructure, first the road and then the railroad. That was a time of expansion of the nation-state towards remote territories, but also responded to regional lobbying for specific public works. The creation of a domestic market and the significant urban growth experienced by Quito and Guayaquil weakened the elites of Cuenca and Loja. The 1934 contractual agreement expresses this transformation by focusing on royalty payments to finance the budget of the central government rather than regional public works. This process also reflects the volatility of both legal and political arrangements. The mode of regulation is not a set of fixed rules imposed on concrete timespaces, but a process involving ongoing negotiation that connects different sets of interests across scales. Different actors make concessions so that, while changes come about, the existing powers remain.

\subsubsection{Centralizing features of the Mining Law of 1937}

The emergence of what appears to be a progressive legal concept does not guarantee, in and of itself, changes in political practice. Thus, public domain of mineral resources, as established in the Constitution of 1929, was always limited, dependent on contract negotiations, administrative interpretations, and the politics underlying resource accumulation. Institutional arrangements to enforce nationalist resource regulation had not yet been implemented. The Mining Law of 1937 demonstrates the tensions, administrative interpretation, and 
progressive centralization of the state apparatus that created, in turn, a network of actors willing to support or resist the expansion of the mining industry.

The mayor of Zaruma wondered, "What is the meaning, scope, and purpose of the constitutional provision?"178 There was an internal contradiction with existing regulatory frameworks: according to the Constitution, the state was the absolute owner of underground resources, granting individuals or corporations usufruct rights as long as the mine was being worked. In contrast, $19^{\text {th }}$ century mining codes allowed miners to own property in perpetuity. Thereafter, mine ownership required payment of an annual patent; there were no other requirements. The mayor's inquiry above suggests the interactive nature of resource regulation, and highlights the contradiction between the two legal bodies. The normative texts were distributed, interpreted, and transformed across institutional domains.

As the Constitution took precedence over the law, the Mining Code of 1892 was tacitly abrogated. The Supreme Court declared that all residents had the right to report mines not being worked and to request the concession in question "because individual selfishness, protected by ancient mining laws, has led to the country's economic stagnation, hindering exploitation of mineral

178 ANE. Communication from Francisco Palacio O., Mayor of Zaruma, to Superior Court of Loja, February 2, 1935, Serie Minas, Caja 6, Expediente 10. 
wealth. ${ }^{179}$ Exploitation of mineral resources was linked to ideas of altruism and progress. ${ }^{180}$ Individuals holding mining claims were required to put them to work, providing employment. This decision pushed mine owners located in the region of Malvas, Muluncay, and Minas Nuevas to resume mining operations.

Thereafter, public domain of natural resources was perceived as a means to development and wealth, at both national and local levels.

However, unrest caused by budget deficits, high unemployment rates, alienating foreign investment, and unstable government extended to the whole political arena. The discourses concerning these struggles were framed in opposition to imperialism, propelled by internal political rivalries, and sustained by leftist and populist leaders who gained momentum in different regions of Ecuador. After eleven months in office, Velasco Ibarra was overthrown by the military after attempting to dissolve congress and assume dictatorial powers. The military junta named the minister of public works, engineer Federico Páez, commander-in-chief.

President Federico Páez (1935-1937) was pro-foreign investment, a racist and colonialist, and an important ally of the American mining enterprise. He said

179 ANE. "Dictamen que el Tribunal Superior de Loja, firmado por Máximo A. Rodríguez, Abelardo B. Aguirre, and José Miguel Carrión, somete a consideración de Vicente Enríquez, presidente de la Corte Suprema del Ecuador," March 14, 1935, Serie Minas, Caja 6, Expediente 10. 
that Ecuador needed the "immigration of foreign capital and white men" and added that, "looking to improve the lot of the Ecuadorian worker, I protected everything in my reach for the sake of what were called the 'Large Foreign Companies'." ${ }^{181}$ The Páez administration crushed mine-worker protests, granted mineral concessions, and provided legal guarantees for the exploitation of natural resources. The Mining Law of 1937 restricted the constitutional concept of the state's inalienable and imprescriptible domain of mineral resources by linking that notion to a concession system. This system tied up access to vast tracts of land, clearly for the appropriation of subterranean resources, for considerable periods of time: companies received 30-year mineral concessions in exchange for payment of an annual royalty. The politics of value reasserted the role of underground resources as a source of government income. The law favoured institutionalization, centralization, and the modernization of decision-making procedures in the mining sector.

At the institutional level, this was done through the Dirección General de Minería y Petróleos (General Office for Mining and Petroleum), created in 1933 and located in the Ministry of Public Works. In this office, individuals and

180 ANE. Communication from Alberto M. Arias, Ministro Fiscal of Loja, to Máximo A. Rodríguez, President of the Superior Court of Loja, March 12, 1935, Serie Minas, Caja 6, Expediente 10. 
companies applied for mining and oil concessions. The office managed all technical, administrative, and financial aspects of the extractive sector. The decision to grant mining concessions was the central government's responsibility; a change from the past when the provincial mine judges had the authority to oversee mines and to collect mining patents. Consultations with local authorities about mining grants were minimal. The law required that applicants and the national mining authority announce the discovery in the official gazette, allowing thirty days for objections, in the absence of which a concession was granted. Eventually, the tenientes políticos (justices of the peace) in mining regions were instructed to post public notices in towns in the area of the concession. I have found no trace of the implementation of these legal requirements in the archives. Public consultation with local communities appears not to have been common.

Cartography was a key element of modernized mine-claiming procedures that made legible the interests of the state. Space became a subject of government control through mapping (Crampton and Elden 2006; RoseRedwood 2006; Scott 1998). Under the new law, the prospective mine entrepreneur was required to submit a technical report prior to concession,

${ }^{181}$ Páez, Federico, “Explico,” Editorial, El Comercio, Quito, 1939, 31. 
exploration, and exploitation of mineral deposits. This involved preparing topographical maps indicating the boundaries of the concession, based on maps produced by the Geographic Military Service or the map of Ecuador sketched by Theodor Wolf in 1892. The geological surveys and topographical maps had to be signed by mining engineers. The law effectively limited the application process to companies with technical expertise and capital, and there were few Ecuadorian geologists or civil engineers with the financial wherewithal to undertake the expensive exploration process. ${ }^{182}$

The 1937 Mining Law provided for a concession system based on mining royalties applicable to all mine-holders irrespective of nationality. The base royalty was $6 \%$ of the gross value of the mine product. A concession was granted upon proof of payment of all guarantees, patents, and royalties to the National Treasury in Quito. This change implied a centralization of tax collection in the national capital. Together, these measures weakened the ability of municipal and provincial authorities to oversee the mining industry.

182 For example, the School of Geology and Mining was created at the University of Cuenca in 1934 with political support from senators and deputies who represented the province of Azuay, However, it was never fully operational due to financial limitations and the lack of professionals able to teach the courses. By 1942 there were five students enrolled in the fifth year; university authorities decided to close the school and, instead, award scholarships so that students could finish their studies in Chile (Chacón 2001, 77-85). 
Mining enterprises continued to benefit from tax deductions for investments in the construction of regional infrastructure. Roads and railroads were essential to the mining industry but also helped satisfy local demands. However, the concessionaire, in exchange for the concession, had to mortgage holdings in favour of the national government as a guarantee. ${ }^{183}$ The mortgage included all property, machinery, and equipment in the mining camp and became effective in the event of expiration of the concession period or abandonment of mining works. This particular topic would prove to be crucial at the end of SADCO's activities in Ecuador in the late 1940s.

Mandatory annual technical reports and financial statements, providing mining operation details as well as expenses and income, were essential to the centralization of administrative procedures. To guarantee national interests, the mining authority supervised mineral exploitation and bookkeeping. The rules required that the information be submitted in Spanish; previously foreign companies had done surveys and accounting in English. The state was entitled to resort to domestic or international legal means for the supervision and verification of data, despite constitutional restrictions on presenting lawsuits in foreign jurisdictions. In fact, mining laws created bureaucratic networks and administrative mediators willing to support, and sometimes challenge, companies

183 Mining Law of Ecuador of 1937, articles 63 and 66. 
with concessions: a team of officials able to produce and approve maps, reports, and accounts.

Angel Felicísimo Rojas, novelist and socialist politician, illustrates scepticism regarding these bureaucrats and official reports, in a scene in which a fictional mine inspector advises his successor (2010, 39-43):

What's a poor inspector who's got the job because someone has done him a favour, next to the company, which is in charge even in the government? If you're good, everything is fine. They're friendly.

In exchange for what? Ah, my boy. In exchange for ... you letting them write the report for the government themselves. ... Monthly they bring you some typewritten papers full of numbers, and they say: sign here. And you sign. They themselves take the trouble to post them, they don't even let you pay for the stamps...

No, my friend. When the opportunity arises, take the money. To the devil with your scruples. The public employee who wastes the opportunity to get rich is a fool. ...

Because these gringos, damn them, are at base the cause of the nation's corruption. They debase us. They debase congress. They debase the government. They debase the authorities. The have debased me.

Based on this narrative, we could signal the subjective representation that American gold transformed the internal regionalisms and the designation of inspectors who reported directly to the ministerial apparatus expanded and transformed traditional power networks.

Beginning with independence, the state's presence in the internal affairs of indigenous and peasant communities in rural parishes was accomplished 
through tenientes políticos (Guerrero 2010, 17-99; Williams 2003). Corruption

was widespread, as indicated in this communication from the governor of El Oro:

The justices of the peace assigned to parishes also demand a more acceptable wage more in line with their difficult administrative work. Their modest income is the primary reason for improper procedures in the performance of their duties. ... I believe that the administration's view of economics in this case is mistaken as in saving money by paying miserly salaries rather than a more just compensation; we cannot hire capable, moral, worthy public officials, but are left with persons who take advantage of their position to make the most evil of deals, compromising not only their personal dignity, but also the decency of government institutions. ${ }^{184}$

These accounts speak to corruption and to the incipient processes of differentiation between the existing state work force and a new class of public servants. This could be interpreted as an early attempt to professionalize the state apparatus and enforce national regulations and policies, reducing reliance on local power structures. From this time on, political access required to undertake mining was no longer the exclusive prerogative of the upper classes, and control of labour disputes was no longer restricted to local ruling elites.

To sum up, the new mining law reinforced and centralized the institutional apparatus but this process also created new networks of power connecting the 
national capital and the mining district. Formal legal measures resolved some of the problems associated with the granting of mining concessions and the payment of royalties for the national treasury, but they also left loopholes in the law. In addition, mining companies could take advantage of technicalities and illegal practices to increase profits.

During this same period, awareness of structural inequalities perpetuating dependency began to grow throughout Latin America. By 1937, the government of Federico Páez was completely discredited due to extravagant expenditures, patronage, and persecution of leftist groups. On October 23, the military removed President Páez and named General Alberto Enríquez Gallo as Chief of State. The new administration, intent upon asserting national sovereignty, immediately came into conflict with the South American Development Company and other foreign-owned companies.

184 The median income of public officials ranged from 80 to 200 sucres monthly. The salaries of tenientes politicos, the representatives of the national government in rural territories, amounted to a mere 65 sucres. Central government public servants earned salaries lower than those of municipal officials and even of miners, who had an average monthly income of 150 sucres plus housing, utilities, schooling, and meals. Source: ANE. Communication from Luis D. Gonzaga to the Minister of the Interior, Serie Min. Interior, C.31, № 924, October 5, 1935. 


\subsubsection{Economic nationalism and the upscaling of resource regulation}

In December 1937, General Enríquez Gallo launched a campaign to limit the profits of American-owned companies operating in Ecuador and to regulate industrial relations for the benefit of the national economy. The mining enclave, once isolated from domestic markets and national politics, became the site for asserting economic nationalism and for restructuring international politics. The president sought the means by which "the mineral wealth of the Ecuadorian people will benefit, as it should, the Ecuadorian state, contributing to the nation's economy." 185

The military administration concluded that the $6 \%$ royalty rate being paid by SADCO and other mining companies was completely inadequate and proposed a $100 \%$ increase. Mining companies had also been exempt from state and municipal taxes. Under the new rules, SADCO would pay $12 \%$ royalties as well as income tax, sales tax, and import duties, and would be subject to fines if found in violation of monetary laws. The government requested a $2 \%$ advance on royalty payments for the following 15 years. This amounted to US\$800,000, a figure based on 1937 mineral production levels. Additionally, the company would have to pay 50 sucres per kilogram (equivalent to US $\$ 4.30$ per kilogram) for the

185 Communication from General Enríquez, Supreme Chief of Ecuador, to SADCO January 5, 1938, in: Ministerio de Gobierno 1938, 5. 
export of gold-bearing ores as well as customs duties for the import of equipment, machinery, and tools. The government framed the changes in the language of equity and justice, and gave SADCO five days to answer the memorandum detailing the new policies and to reach a settlement, or review the concessions.

Russell P. Luke, SADCO's resident manager, expressed his view of the measures in these words: "popular fantasy believes that [the company] does nothing other than take gold out of the country..." ${ }^{186}$ Luke noted that the gross value of the mine product reached a total of US $\$ 2$ million for 1937 , of which mining royalties represented almost US $\$ 120,000$. The manager added that operating expenses, taxes, and equipment purchases reached almost $75 \%$ of the gross product, leaving the company with minimal profits.

Tax requirements and the threat of mine seizure led to a restructuring in the scale of regulation; the nationalist request appeared so drastic and onerous that company executives decided to seek assistance in their negotiations with the administration. A.M. Tweedy, SADCOs general manager, approached the Department of State in Washington "to prevent the matter from coming to a head

186 Communication from R.P. Luke to General Enríquez, December 16, 1937, in: SADCO 1938, 13. 
so as to obviate more serious difficulties later." ${ }^{187}$ In doing so, the company bypassed traditional diplomatic routes. Up until that date, the United States delegation in Quito had not been directly involved in private negotiations. There were few established diplomatic practices regarding investment protection overseas. Constitutional provisions and hemispheric policies banned diplomatic interference in domestic affairs. Epps (2009) argues that disregard for contractual agreements and anti-imperialist discourses concerning the case of SADCO provided reasons for disquiet within the Division of the American Republics of the US State Department at a time when both Bolivia and Mexico had nationalized the oil industry.

The polite language of official communications underscored tensions regarding divergent understandings of legal concepts and political processes. Tweedy reflected on the seriousness of previous agreements, explaining that "it would be difficult to find a contract in which a greater number of senior authorities and public officials have been involved, and who are familiar with the contract in all its details, and who, it must be said, demonstrated the patriotism, ability, and honesty necessary for the defense of national interests." ${ }^{188}$ Perceptions of legal

187 Communication from McDonough to Hull, January 13, 1938, FRUS, 1938 V: 538, in: Epps 2009, 48.

188 Communication from A.M. Tweedy to General Enríquez, January 21, 1938, in: SADCO 1938, 12. 
obligations and the ability to renegotiate contracts entailed two substantially different and incompatible approaches.

The company based its response on an appeal to the world order imposed by Western democracies and capitalism. For the American entrepreneurs, a contract was considered a fundamental legal instrument facilitating industrial development, investment, and commercial transactions. A contract was deemed a binding agreement that could not be dismissed unilaterally. Without this legal relationship, "business would come to a halt, trade and credit would decline greatly, and cooperative effort, which is the foundation of any society, would suffer greatly." ${ }^{189}$ Mining was considered a high-risk business requiring minimal guarantees for investment, which included the stability and protection provided by concession contracts. In addition, SADCO's general manager believed that, "attacking foreign companies is always popular with the pueblo and it looks as if [General Enriquez's] campaign is largely motivated by a desire to gain political support." 190

Economic nationalism allowed for the targeting of the foreign concession insofar as the state was seen as a legitimate actor capable of protecting public over private interests. The military viewed gold exports as a "weapon turned

189 Communication from A.M. Tweedy to General Enríquez, January 21, 1938, in: SADCO 1938, 19. 
against the national economy." ${ }^{191}$ Ecuador was facing internal problems related to its trade deficit, its foreign debt, and skirmishes on the southern frontier with Peru. The gold deposits were being exhausted, providing few economic benefits to the country; a situation that could not continue. As General Enríquez explained, "export of precious metals, especially gold, cannot be free since that works against the country, disturbing its trade balance." 192

The Enríquez administration considered SACDO's position regarding the inviolability of the original contract to be unacceptable, especially at a time of socio-political transformation. According to General Enríquez, "the history of all contracts denotes the Company's intention to renege on its commitments and, in addition, ignore the rights of the state." ${ }^{193}$ General Enríquez also emphasized the "pretexts," the "artificial stipulations" used to extend deadlines, and the "surreptitious efforts" developed by the Company in favour of its own interests. SADCO had abandoned its long-term commitments but remained in possession of mining claims. The executive reasserted that the money invested could never

190 ETSA. A.M. Tweedy to Florence Tweedy, January 20, 1938.

191 Communication from General Enríquez, "Contestación del Gobierno del Ecuador a las alegaciones presentadas por la South American Development Company," January 28, 1938, in: Ministerio de Gobierno, 1938, 26. lbid.

193 Ibid. 
be regarded as fair compensation for the concessions. The government sent two army battalions to Portovelo; the state would nationalize all properties in the event the company decided to suspend industrial activities.

The American diplomats were still reluctant to intervene, but SADCO was one of the United States' largest investments in Ecuador at a time when All American Cables, the United Fruit Company, and the Anglo Ecuadorian Oilfields Limited were expanding. The diplomats considered the whole process to be a discursive tactic by the Ecuadorian government to distract attention from internal weakness and finance military purchases. With utmost caution, Sumner Welles, US Undersecretary of State, drafted a letter to the Embassy of Ecuador in Washington DC expressing his desire that the parties reconsider the contract in a friendly manner (Epps 2009, 54). All procedures were framed as an attempt to prevent harmful situations and build hemispheric solidarity within the framework of Roosevelt's Good Neighbour Policy.

The company worked to exhaust political and diplomatic options prior to responding. A.M. Tweedy cabled a message expressing "the serious desire to contribute to the economic life of Ecuador as much as possible and cooperate to achieve an equitable arrangement." ${ }^{194}$ Simultaneously, the US diplomatic

194 Communication from A.M. Tweedy, "Cablegrama de New York al Señor Jefe Supremo de la República," February 5, 1938, in: SADCO 1938, 35. 
representation to Ecuador reasserted the company's "willingness to consider sympathetically the urgent financial needs of the Ecuadorian Government and to attempt to work out an arrangement satisfactory to all concerned." ${ }^{195}$ The proposal included provisions to: increase mining royalties by $3 \%$; allow customs exemptions for 20 basic mining supplies; permit income and sales taxes to be paid according to terms established in previous years; and guarantee 10 years of operation without contract changes. General Enríquez Gallo rejected the proposal emphatically, stating, "Do understand that I have no desire for the South American Development Co. to do us any favours with economic aid to Ecuador; the Government demands only that which belongs to it by legitimate right, without ever having asked anyone to do it the favour of fixing its economic situation." ${ }^{196}$

SADCO demanded that an arbitration tribunal or the Supreme Court review the matter. ${ }^{197}$ There were legal gaps regarding contractual renegotiations. The Ecuadorian government passed the Concessions Law, stating that contracts awarded to national or foreign companies to exploit underground resources were concession agreements, to be guided by the principles of public law -

195 AH-MREMH. Communication from Gerhard Gade, Chargé d'Affairs ad interim, to Colonel Guillermo Freile, Minister of National Defense, Acting Minister of Foreign Affairs, February 5, 1938, B.18.28.

196 Communication from General Enríquez, to A.M. Tweedy, February 5, 1938, in: SADCO, $1938,36$.

197 Communication from O.P. Ebeling, to Jefe Supremo República del Ecuador, February 14, 1938, in: SADCO, 1938, 36-37. 
specifically, the 1887 Mining Law and subsequent reforms. ${ }^{198}$ These legal frameworks recognized the state as the owner of the mines, although the wording was slightly different in the 1929 Constitution and the 1937 Mining Law. This law required the state to enforce concessions under the principles of equity and common interest.

Subsequently, the military issued a decree doubling annual royalties to $12 \%$, to be paid every trimester beginning April $1,1938 .{ }^{199}$ The army backed the nationalist approach to resource governance. Battalions were stationed in Portovelo, ready to pressure mining entrepreneurs if necessary, to comply with these requirements. SADCO officials expressed concern over the forceful, peremptory, and unilateral violation of the contract, but agreed to continue mining in Ecuador under the new regulations (SADCO 1938, xx).

The military government was able to reassert national sovereignty. The doctrine on permanent sovereignty over natural resources was apparently in force, despite private and foreign interests in mineral grounds. Rómulo Betancourt, leftist leader and future president of Venezuela, highlighted the "stubborn determination of the [Enríquez] administration to demonstrate to company shareholders ... that Ecuador is an autonomous, sovereign nation, in 
possession of its own destiny." ${ }^{200}$ Leftist regimes in Latin American countries such as Mexico, Bolivia, and Ecuador proved successful in nationalizing or regulating the extractive sector, an attempt at moving away from foreign tutelage. ${ }^{201}$

However, it would be an exaggeration to suggest that these successes marked the demise of hegemonic capitalism and foreign tutelage. A few weeks later, General Enríquez issued new norms, in more conciliatory language, favourable to foreign investment. The president noted that the spirit of the Concessions Law was in "defining reciprocal obligations, guaranteeing public trust, and providing all types of guarantees to investors interested in business with the Government of Ecuador, harmonizing the permanent interests of the state with those of the private in a more equitable way." 202 Thereafter, the state continued regulating other extractive industries but without the harsh terms

199 Decreto Supremo № 14, March 11, 1938, in: Registro Oficial, № 118-119, March 18-19, 1938, 2941-2942.

200 Betancourt, Rómulo, "El Gobierno del Ecuador y el capital extranjero," Diario Ahora, May 2, 1938, from SABER UCAB:Repositorio Institucional de la Universidad Católica Andrés Bello, accessed June 20, 2015, http://saber.ucab.edu.ve/handle/123456789/45084

World War II marked a turning point for US policy toward Latin America, and a greater presence to secure regional hegemony, expressed at the Eighth Pan American Conference, held in Lima in 1938.

202 Decreto Supremo No 9, March 2, 1938, in: SADCO 1938, 40. 
applied to SADCO. ${ }^{203}$ Royalties had to ensure a fair return proportional to earnings, up to $12 \%$ of the gross product. Moreover, other properties under control of junior companies, subsidiaries to SADCO, such as the Cotopaxi Exploration Company and the Calera Exploration Company, continued paying the $6 \%$ royalty.

The corporate mining business used media pressure, administrative strategies and political pressure to extend negotiations and increase profits from ongoing operations. SADCO distributed printed materials arguing the negative implications of the dictatorial decree and tax payments. On July 4 of that year, six aircrafts landed on the Portovelo airstrip to celebrate the independence of the United States in the American camp (Murillo, 2000). The move was embraced by the work force but viewed apprehensively by the government, as it occurred amid border disputes between Ecuador and Peru. One month later, on August 5, General Enríquez indicated that prior measures had not been intended "to extort or trample" SADCO's rights and endorsed his verbal offer to reduce annual

203 For example, the Anglo Ecuadorian Oilfields Limited, operating in the Santa Elena Peninsula, had to increase royalties from $6 \%$ to $10 \%$ on the production of crude oil, $8 \%$ on gasoline and twice the 1937 fee for surface rights. Decreto Supremo No 10, March 9, 1938, in: Registro Oficial, No 118-119, March 18-19, 1938, 2940-2941. 
royalties to a cap of $40 \%$ of profits. ${ }^{204}$ That same day, the government granted a concession to 211 mine holdings to Fernando Maulme, a figurehead of SADCO, in an area called Minas Nuevas. The Minas Nuevas contract committed the government to "keeping the concessionaire in tranquil and peaceful possession of national lands and mineral deposits comprised within the concession, and defending the awardee against any third party claims on surface rights to the same lands." 205

The new contract represents an example of state responsibility to foreigners and their property, which included government protection and compensation in case of expropriation. Seemingly, General Enríquez's sudden change of mind relates to the approach of Peruvian troops on the southern border, which required an alliance with American diplomacy and investors to address a potential attack. The anti-capitalist discourses shifted with the rise of fascism and the imminence of war. In the last pages of his book, Paredes ([1938] 1970, 211) states:

204 Communication from General Enríquez to R.P. Luke, August 5, 1938, in: SADCO 1938, 4243. General Enríquez issued a new decree ratifying this agreement on August 9, but the decree was never published and thus did not go into effect (SADCO 1948, 6-7). Enríquez Gallo transferred power to a new administration and the National Assembly, installed on August 10 declared null and void all decrees unpublished by August 9 .

Decreto Supremo, August 5, 1938, in: Registro Oficial, August 8, 1938, 189-192. 
... our tactics against imperialism need to change. Our struggle should be directed towards requiring the great imperialist countries which maintain democratic forms to intervene with their capitalists operating in our republics, so that they cease their abuse and extortion, and stop interfering in our internal politics.... We must demonstrate in a practical way that we are not opposed to foreign investment, but not under conditions of slavery [emphasis in the original].

Ecuador was at a crossroads, unable to solve domestic inequalities, involved in a war with its southern neighbour, and with no sign of economic recovery in sight. In July 1941, Peru invaded Ecuador, focusing attention on national sovereignty. Ecuador was unprepared for the attack on its southern provinces.

The company found a way to benefit from the international conflict. SADCO provided shelter and health services to displaced people and Ecuadorian troops. Shortly after the ceasefire, President Arroyo del Río, a former SADCO lawyer, repealed the 1938 decree and reinstated benefits established in the 1934 contract; however, SADCO would continue paying a $12 \%$ royalty until a new contract was signed. ${ }^{206}$ The government sought international support to enforce territorial sovereignty by providing economic preferences and guaranteeing the concessions of American investors in Ecuador. Later, in 1942, the president agreed to the creation of US military bases, on the peninsula of Santa Elena and in the Galapagos Islands, for defense in the Pacific front during 
World War II. In this context, the public domain of natural resources is called into question, contingent upon capitalist interests and hemispheric domination.

From a regulatory perspective, the case of Portovelo represents an example of the historical setting and regional context whereby economic nationalism gave rise to the upscaling of policies pertaining to foreign direct investment so as to create an international system able to enforce state responsibility for injury to foreigners and their property. Sornarajah $(2010,36)$ states that the "early rules on diplomatic protection were devised in the context of injuries suffered by US citizens in Latin American states." As such, the conflict between nation-states and multinational corporations had a role in the shaping of international law.

Policy choices and diplomatic intervention in cases like this one, between SADCO and the Ecuadorian government, can be viewed as predecessors to bilateral investment treaties. The risk of property seizure gave rise to the doctrine of compensation, whereby the foreign investor was entitled to diplomatic protection for prompt, adequate, and effective remediation in case of nationalization, or conflict resolution before an international tribunal if national conciliation mechanisms proved inadequate. At the same time, Latin American states demanded equal treatment in national laws for both foreign and national investors. Stiglitz (2007) notes that international trade agreements and commerce obligations do not stop governments from changing regulations, taxes, or public polices but they may require compensation, renegotiations or 
application of sanctions that place limitations on the adoption of new legal frameworks.

\subsection{Portovelo: From foreign enclave to municipal workers association}

Harvey $(2014,78)$ states that "the history of capital is rife with stories of localised booms and crashes in which the contradiction between fixed and circulating capital, between fixity and motion, is strongly implicated." Indeed, the construction of the mining enclave included the fixing of productive capital in infrastructure and equipment that could not be relocated. However, deindustrialization in Portovelo was not related to the outright exhaustion of gold deposits, but rather to the technological challenges of low-grade ore, the taxation of the mining industry, labour demands, and rising operation costs which, together, strained the industry to the point of "creative destruction." In this context, the industrial decline and the mobility of foreign entrepreneurs required localized arrangements to recover the investment with as little political unrest as possible. The involvement of the state in mediating labour disputes and the easing of the labour crisis was crucial to that effect.

In this section, I intend to demonstrate that resource cycles are not based solely on the availability of mineral deposits, but are also a by-product of structural forms of regulation, including institutional practices and political commitments. Moreover, resource regulation and resource governance are two distinctive features involving different actors and political interests across scales. 
To examine this issue, I have organized this section as follows. First, I analyze how royalties transformed municipal income, creating financial dependence. This process transformed patron-client relations towards a greater reliance on the central government, which replaced the father figure role assumed by the company in previous years. Then I explain the factors influencing the drop in productivity, the withdrawal plan, and the bargaining process, lasting for over five years, whereby the municipality and the workers would become shareholders in the mining company. Finally, I argue how the decline of the staples economy transformed center-periphery relations, giving way to a development discourse and institutional arrangements that required the involvement of the highest public authorities. The mining enclave became an important center of political decisionmaking. Paradoxically, the strengthening of a state system of rights and the administrative decentralization entailed the displacement of externalities of the bust cycle to local actors.

\subsubsection{Municipal incomes and the restructuring of local governance}

In the late-1930s, national pride was associated with taxation of foreign

mining industries. The economic nationalism of the period included the upscaling of resource regulation with the involvement of diplomatic missions and hemispheric policies. However, resource regulation and resource governance were two distinctive features involving different actors and institutional forms across scales. In Zaruma, the pride generated by sovereign decisions reclaiming control of natural resources soon changed to disenchantment. Towards the end 
of 1938, the municipal board complained that the National Assembly, "with unspeakable injustice, arbitrarily distributed the proceeds of these levies without taking into account Zaruma, which has a legitimate right of participation." ${ }^{207}$ Nationalism was bringing no benefits to the local level. The legislature had allocated the majority of royalties to the construction and maintenance of transportation infrastructure in the southern provinces, which did not benefit the mining district directly. ${ }^{208}$ The mayor of Zaruma complained that the county remained a "region neglected by the central powers," and asked for the application of specific clauses from contracts prior to $1938{ }^{209}$ The centralization of mining rents was perceived as discriminatory to a region that began experiencing the externalities resulting from mining. The scalar tensions in the regulation of mining profits led to negotiations between levels of government. The municipality, along with the provincial government, lobbied national authorities to earmark royalties for local public works.

207 AHM/Z. Sánchez, Ángel Polibio. 1938. "El Momento Histórico." Consejo Municipal de Zaruma. Zaruma: Album Municipal, T.I, 1928-1944.

208 The National Assembly allocated resources to finance the Pasaje-Girón and Loja-Girón roads. A year later Congress determined that all mining royalties - equivalent to 2.8 million sucres - were to be used for the construction and maintenance of the Piedras-Pindo, PindoLoja, Loja-Saraguro-Cuenca, Loja-Macará Veracruz-Catacocha, and Loja-Valladolid roads, and for road maintenance in the provinces of Loja and El Oro.

209 AHM/Z. Sánchez, Ángel Polibio. 1938. "El Momento Histórico," Consejo Municipal de Zaruma. Zaruma: Album Municipal, T.I, 1928-1944. 
Federalist ideas resurfaced in the presence of substantial monetary resources. Provincial elites formed the Junta de Autonomía Regional, an organization created to lobby for greater economic autonomy and the devolution of income from other road-related levies. Local priorities were more pressing than the nationalist demand for recovery of mining royalties by the central government. The municipality was interested in providing infrastructure and social services; and mining royalties were fundamental in a context of increased migration, rapid urbanization, and the national fiscal crisis. In order to achieve its purpose, the city council developed strategies to recover revenues.

The centralization and modernization of the state led to a new role for municipalities. By mid-century, the municipality was an ill-defined entity; with high turnover at the directive level, budgetary constraints, and indirect control over rural localities. Municipal councils were elected annually and councillors served without remuneration. The activities of the municipal board were mainly focused on the urban area, as councillors had to live within 15 kilometres of the county seat. Rural parishes were controlled remotely through recolectores de fondos (tax collectors), celadores (constables), and instructores (instructors). The Catholic Church had a strong presence in the mining area, which was conservative. The municipal government of Zaruma worked for the consolidation of its territory and struggled to avoid the separation of wealthy rural parishes whose residents pressured for secession; Piñas achieved recognition as a separate county in 1940. In this context, municipal income and public works were 
key in legitimizing the management capacities of elected authorities but they also created dependence on state funds.

The structure and composition of the municipal budget changed significantly. In the early $20^{\text {th }}$ century, the municipality financed a significant portion of its annual budget through the tarifa, or municipal fees and levies, and other taxes directly or indirectly linked to the mining industry. ${ }^{210}$ The main sources of local public revenue included the timber, alcohol, and urban taxes. ${ }^{211}$ The municipal budget increased substantially through lobbying for transfers from the national government. In 1937, the central government approved an increase in the timber tax, the coffee tax, and other levies in Zaruma County. ${ }^{212}$ The legislative representatives of El Oro and wealthy business people from Zaruma living in Quito lobbied for earmarking mining taxes. Socio-spatial interactions

210 The tarifa, municipal fees and commercial levies, on the Portovelo camp rose steadily. In 1915, Portovelo first appears as a separate category within municipal tax records. In 1916, Zaruma retrieved a total tarifa of 4,603 sucres, of which the Portovelo camp contributed only 1,260 sucres. By 1940 the mining camp contributed 8,000, sucres while Zaruma collected a total tarifa of 10,000 sucres. The importance of the tarifa progressively diminished in the overall financial balance, but it highlights the increasing importance of Portovelo over other rural parishes and even over Zaruma, the county seat.

211 In 1900, the timber tax represented almost $62 \%$ of municipal income. In subsequent decades, the local government diversified its income, but timber and alcohol taxes remained a significant portion of the annual budget. By the late 1930s, the timber tax represented $16 \%$ of the annual budget. The absolute value of these taxes increased from 32,000 sucres in 1937 , to 62,000 sucres in 1940 , and over 90,000 sucres in 1942 . Alcohol consumption - also related to the presence of mine workers - represented almost $19 \%$ of municipal income during the mid-1930s, reaching a peak equivalent to $32 \%$ of municipal revenues in 1940 . Source: AHM/Z. Municipal budgets for the years indicated.

212 Decreto Supremo № 256, August 9, 1937, in: Registro Oficial, № 7, August 18,1937; AHM/Z. "Ordenanza reglamentaria para el cobro de impuestos a las maderas de construcción, café y establecimientos comerciales de Portovelo." MMC, T.35, 1937, 204-206. 
between local elites and the central government proved successful. Congress allocated 200,000 sucres to the city of Zaruma for the provision of a potable water system, the construction of a modern school building, and the construction of water systems for the parishes of Piñas, Malvas, Paccha, Ayapamba and Guanazán. The amount represented an additional $51 \%$ over the 1940 municipal budget, originally estimated at $392,649.74$ sucres. Portovelo was not included in the legislative mandate. The mining enclave remained a space of private rule and the provision of public services was considered the exclusive responsibility of the foreign mining company.

However, the economic crisis, border disputes, and the slowdown of the mining industry reduced municipal income. ${ }^{213}$ The 1941 invasion by Peru strained the provision of basic services. SADCO slowed production, laid off workers, and reduced wood purchases. ${ }^{214}$ To finance the military campaign, the national government rationed food and centralized tobacco and alcohol taxes, a significant source of municipal income. The central government, endowed with extraordinary powers, also established a $5 \%$ tax on municipal revenues to

213 AHM/Z. "La situación económica municipal y la educación pública." El Campamento, [Zaruma]. April 12, 1943, 7.

214 At that time, SADCO became an important benefactor, providing shelter for refugees from the lowlands, supplying army battalions, and treating the wounded at the Curipamba Hospital. Company oficials painted the American emblem on the rooftops of the industrial facilities and raised the United States' flag in various places to protect the camp from air attacks (Murillo $2000,100)$. 
finance the national budget of 1942 . The municipality had no money left over to finance public works or repay loans; and the reduction in municipal revenues threatened the local government with financial collapse.

The budgetary deficit was especially onerous for municipal councillors, as they were legally responsible — collectively or individually — for the use of municipal resources. Municipal income, especially related to the timber tax and royalties, was critical for the provisions of public services and the prestige of local elected authorities. Local authorities defended their right to a share in mining royalties, arguing the need for social services and transparency in the allocation of public budgets. The local newspaper asked residents of Zaruma to "take a firm and determined stand in facing, with patriotism and serenity, the impending tragedy."215 Zaruma claimed a percentage of mine tillage.

The local provision of services could not be achieved simply with a managerial approach. Financing was required. The municipality of Zaruma became an active agent in identifying new ways to retain industrial revenues, compete for capital, create jobs, and encourage local development. Hence, entrepreneurialism was not exclusive to neoliberal urban governance, as

215 AHM/Z. “¿A dónde va Zaruma?” El Campamento, [Zaruma], April 12, 1943, 2. 
suggested by Harvey (1989). ${ }^{216}$ The municipal council joined forces with local elites to establish a permanent political presence in Quito. The committee worked to "exert as much influence as much as possible in the national press so as to pull all possible strings with the aim of getting for Zaruma what today more than ever [the county] yearns for vehemently."217

Efforts to redress the inequitable distribution of mining royalties were successful. The mining enclave was no longer an isolated community, political parties disputed leadership of the industrial work force, and President Velasco Ibarra visited the mining district a second time in $1944 .{ }^{218}$ The National Constitutional Assembly decided that Zaruma should receive $30 \%$ of the socalled mining tax levied on mines located within its jurisdiction. ${ }^{219}$ The urban core was entitled to two-thirds of these royalties while the remaining portion was to be redistributed among the six rural parishes. Until 1944, all municipal revenues came to barely 300,000 sucres annually; that figure more than doubled in 1945 ,

216 In Ecuador, decentralization is commonly studied as: a feature of democratic governance after 1980, the adherence to neoliberal policies promoted by multilateral organizations, and the enactment of the 1998 Constitution, which called on municipal governments to apply for policy responsibilities (Barrera et al. 1999; Carrion F. 2007; Ojeda 2000).

217 AHM/Z. “¿A dónde va Zaruma?” El Campamento, [Zaruma], April 12, 1943, 2.

218 The delegation, including Carlos Guevara Moreno, Minister of Government, Carlos Mancheno, Minister of Defense, and Francisco Arízaga Luque, president of the National Assembly, visited Zaruma and Portovelo. See: AHM/Z. "La apoteósica recepción al doctor José María Velasco Ibarra en Zaruma," Adelante, [Zaruma], September 13, 1944, 5.

219 Decreto Legislativo, November 25, 1944, in: Registro Oficial, № 160, December 13, 1944; AHM/Z. "Decreto por el cual asignan a Zaruma el 30\% del Impuesto Minero," Adelante, [Zaruma], December 17, 1944, 4. 
to 769,149 , and skyrocketed to $2,152,058$ sucres in $1947 .{ }^{220}$ A series of legislative decrees sanctioned special revenues and rural parishes began to manage funds directly. 221

The new revenues created a temporary incentive for local development, public works, and the expansion of social services. The main investments included the construction of the public market, the slaughterhouse, and a new hydroelectric power plant. The additional resources provided for the construction of a cemetery, the prison, city hall, a new municipal hospital, the construction or remodelling of school buildings, paving of streets, and the construction of a working-class neighbourhood. By 1948, almost 338,000 sucres, equivalent to $23 \%$ of the overall municipal budget, were committed to public education (Carrión 1948, 7-8). Rural hamlets benefited from the installation of potable water, public restrooms, and laundry areas. The municipality established public transportation from Zaruma to the Portovelo camp to facilitate the daily commute and consolidate the urban center. All these investments represented a heavy burden

221 The Municipal Regime Law of 1945 significantly increased the functions of municipalities and the 1946 Constitution incorporated rules on municipal economic autonomy. These entities assumed the role of urban development corporations for the provision of local public services. In particular, article 40, paragraph 2 of the 1945 Municipal Regime Act, encourages authorities to muncipalizar (municipalize) light, locomotion, potable water, and telephone services. Municipalities also assumed the obligation of having a development, or master, plan, and of building affordable housing for workers, which suggests the ideological orientation of the law. 
on municipal finances, which were to come from future mining royalties. The flow of royalties, however, would not last long.

\subsubsection{Technological challenges, labour laws, corporate restructuring, and the decrease in mine productivity}

A massive upsurge of subterranean thermal water in the mine affected productivity and the fate of the whole mining enterprise at the end of 1944 . The flood destroyed mining works on the ninth level of the main shaft, which yielded almost $20 \%$ of gold production. The mine owners allocated all resources to minimize losses and pump out the floodwaters at a rate of 1,800 gallons per minute. The Calera hydro plant generators burned out on January 22, 1945 , leading to the suspension of all millwork for three months. ${ }^{222}$ In the meantime, the company used the municipal hydropower plant, leaving Zaruma and nearby hamlets with energy shortages. Flooded shafts were not a new phenomenon in Zaruma; dewatering the mines had represented a challenge to mining operations since colonial times (Anda 1960; Lane 2004). The gold-bearing ore was under groundwater and the richest veins were under the Amarillo River. While the technical details were finally controlled, overall operation costs increased and profitability declined.

222 By April 22, 1945 one generator bad been successfully repaired while the second resumed operations in July. By the end of the year, incoming water on the ninth level stabilized at 800 gallons per minute, and the miners were pumping an average of 1,489 gallons per minute from all underground water sources (SADCO 1946, 2). 
In addition, labour laws came into effect. The Labour Code of 1938 included wage increases, vacations, holidays, and a weekly day of rest, plus payment of unemployment compensation, public insurance, and pensions. Enforcement of these provisions finally occurred during President Velasco Ibarra's second administration (1944-1947). In 1945, the caudillo promoted the writing of a new Constitution, progressive in nature, that included mine workers as a focal group. ${ }^{223}$ Provisions benefitting workers included a daily six-hour limit on underground labour and a working shift for miners no longer than seven hours. ${ }^{224}$ The 1946 Constitutional amendment prescribed that miners be paid weekly rather than daily. Those who worked Saturday afternoons, Sundays, or holidays had to be paid overtime. More importantly, collective agreements achieved a special status providing unionized workers with a $5 \%$ share of netprofits. ${ }^{225}$ The American mining company considered these fair measures, but complained about the expense of recurrent negotiations.

The company implemented austerity measures, including reduced mine investments, and increased labour turnover to ensure profits and minimize

223 Right-wing opposition described the 1945 Constitution as an instrument of "international Communism" (Egas 1975). After it was enacted, Velasco Ibarra criticized the Constitution for its technical defects, ideological contradictions, and dialectical failures which, he claimed, prevented effective governance. A year later, Velasco Ibarra proclaimed a new constitution and began the persecution of leftist leaders. Constitution of Ecuador of 1945, article 148, e.

225 Ibid., article 185, n. 
worker benefits. The direct payroll expenses went from US\$85 per tonne of goldbearing ores in 1940 to US $\$ 121$ per tonne in 1946 , representing a $25.1 \%$ increase in mining operation costs (SADCO 1946, 5). The company restructured the taskforce and dismissed workers. This processes implied a monthly turnover of 20 to $25 \%$ of the labour force and an effective reduction of 113 jobs between 1946 and 1947 (Barriga 1948, 17). ${ }^{226}$

The Ecuadorian Constitution of 1945 included a suggestion of impending economic nationalism: the state had the right to limit property rights based on public interest and social need. The constitutional norm encouraged the state to exploit mineral resources directly and all mineral concessionaires had to guarantee the fair and equitable participation of the state in mining profits. In addition, concessionaires required governmental authorization prior to transferring claims to third parties. These provisions were relevant at a time when SADCO was going through an internal restructuring of its Portovelo operations.

As the original shareholders retired, new organizational patterns came into effect. Andrew M. Tweedy was SADCO's general manager and a permanent resident in Ecuador for almost 26 years, between 1917 and 1943.

Simultaneously, William Kissam, board president since SADCO's creation,

226 At the beginning of 1946 , the payroll included 1,500 people; the company hired 325 workers but dismissed 353 in the course of the year. In 1947, 277 workers were hired and 390 dismissed, for a balance of 1,402 workers by the year's end. 
retired in 1947, at the age of 79 . The businessmen represented a generation of US entrepreneurs who applied Fordism to mines in Latin America. Transnational capitalists ensured that mining revenues went back to the company's home country, and perpetuated neocolonial relationships of dependency. ${ }^{227}$

Global economic and political reconstruction after World War II involved the integration of markets, the expansion of transportation systems, and the elimination of tariff barriers. The Bretton Woods agreement included the creation of the International Monetary Fund which implemented mechanisms for financial control and accountability. ${ }^{228}$ Deverell $(1975,172)$ argues that productivity within the mining sector is also related to monopoly power, political manipulation, suppression of competition, and preferred status with financial institutions. These international institutional arrangements were relevant to the mining industry in Ecuador insofar as they kept the price of gold stable, limited export of gold bullion, and controlled exchange markets at a time when both the company and national regulatory mechanisms were being restructured.

In 1946, SADCO's board elected a banker as its president and general manager. Robert McLean Stewart represented a new generation of mining

227 In 1935, the company expanded its mining interests to the Kelowna Nickel Mines in British Columbia, Canada; many of SADCO's US employees joined the administration and engineering team there after the 1938 threat of nationalization. 
businessmen with ties to financial interests, minimal bonds with domestic affairs at mining locations, disengagement from the wellbeing of local residents, and constant travel to New York headquarters. ${ }^{229} \mathrm{He}$ was a well-positioned, pragmatic man who prepared the way for a profitable withdrawal operation. McLean took the lead in the defense of US gold importers, arguing that "it is out of all reason to believe that gold is still worth $\$ 35$ an ounce" despite the fact that "prices and taxes are up." ${ }^{230}$ Apparently, McLean obtained authorization to export gold refined from imported gold-bearing material while restrictions remained for other gold suppliers. ${ }^{231}$ At the same time, the company became the "South American Development Mines Company Inc." registered under the laws of the state of Delaware, US, on August 29, 1947. A year later, the Ecuadorian government officially approved the transfer of mining rights without a review of

228 At the time, the United States captured about two-thirds of world monetary gold reserves, the price of gold was stable while the dollar experienced increasing pressure from the foreign exchange market to finance Europe's reconstruction (Bordo 1993; Schwartz 1997).

229 "Highways and Byways of Finance," The New York Times, March 20, 1949, F3, ProQuest Historical Newspapers: The New York Times.

230 The U.S Treasury Department started hearings on proposed amendments to the Gold Reserve Act of 1934. See: American Chamber of Commerce Journal, September, 1947, 155.

231 Gold prices remained stable in the US until 1972, and then rose to US $\$ 38$ and US $\$ 42$ in 1973. After 1974 the United States abandoned the gold standard and the price began to fluctuate freely in the market. In 1948, SADCO's gold prices increased from US $\$ 39$ to US $\$ 45.75$ per troy ounce, although details on the price of final sales are uncertain (Barriga 1948, 10). 
contractual agreements, although the company had already announced its departure from the country.

The company "claimed justice" and "begged" for the signing of a settlement agreement that included tax-cuts and direct subsidies. The corporate business used administrative strategies, media pressure, and lobbying to prolong negotiations and divert a financial audit. Lengthy debates concerning minor technical concepts - such as how to assess the gross product of the mines and royalties - maintained profitability during the disinvestment stage.

In October 1946, the South American Development Company published a booklet entitled Los problemas de Portovelo (The Problems of Portovelo). The introduction began with these words:

The mines of Portovelo have been in production for a period of fifty years. Every mine, at a certain point, comes to an end, as does the life of a man who, at an advanced age, cannot perform duties beyond those which his age permits. If his duties are too great, his life quickly ends. Clearly, the age of the Portovelo mines now makes them comparable to that of a very old man.

Unless some burdens and fees and other costs - levied on the mines a few years ago - are not lowered in the near future, the continuation of operations may not be possible.

The publication highlighted that ore extraction had been profitable due to the presence of high-grade quartz, but that the process could not be maintained without drastically reducing the lifespan of the Portovelo mines. The geological surveys pointed to the existence of low-grade mineral ores distributed through deep vertical distances, narrow veins, and embedded deposits covering large 
areas. Almost $21 \%$ of proven rich gold deposits were located beneath the Amarillo River, and after only three years, the deposits would be exhausted ${ }^{232}$

According to company estimates, royalties represented $51.3 \%$ of net profits, and the firm experienced net losses after 1946. To exert pressure on national authorities, the Americans noted the importance of foreign exchange currency for Ecuador's international trade balance and the need to reduce the tax burden to sustain low-grade mining operations. $\operatorname{SADCO}(1948,19)$ stated that ore

is no longer being extracted and considerable tonnes of low grade mineral have been lost, which would have been mined had taxes had been less severe and, therefore, operating costs lower.

The value of that ore, of what would have been paid into the Treasury in taxes, and in wages, payments, and investments in the national economy, is several times greater than the excess [royalty] tax obtained.

At the local level, the municipal government deployed strategies to secure revenues and responded with a public brochure with a discursive reference to mineral exploitation and the problems of Zaruma. The municipality acknowledged the importance of jobs, but highlighted the negative effects of the mining industry

232 The announcement created scepticism among old miners; geological surveys and expert mining practitioners indicated the existence of larger ore deposits. Presumably, the company began planning its departure from Ecuador in 1946 and removing the richest mineral grounds along the Amarillo River despite the geological instability caused by these operations (Barriga 1948; Reyes 1946 in: Carrión 1948, 32; SADCO 1946, 4). 
throughout the county due to intensive logging, desertification, occupational diseases, and mine leaks. Royalties flowed — temporarily — strengthening the national economy but finally they proved to be a mirage as they delayed government attention to the real problems of Portovelo. Upon mine closure, the mayor of Zaruma, Nelson Reyes (Reyes 1946 in: Carrión 1948, 18), expected "a large region will be mired in poverty and bewilderment, the people impoverished and sick, the earth parched, and all these problems hanging perennially over the country." The feeling of the local people was that it was not fair for the company to ask for compensation after two years of losses since it had not shared years of continuous profits.

The potential mine closure caused tension between the work force and the company. The Federación de Trabajadores de Portovelo (FTP, Portovelo Workers Federation) demanded job stability, the signing of a collective agreement, a $50 \%$ wage increase, and equal wages for workers who performed similar functions. The FTP demanded compliance with labour laws in the event of layoffs, travel pay for dismissed workers, and severance pay based on years worked. In addition, the union requested provision of clean, comfortable dwellings, clothing, and ration cards for bachelors.

The company expressed their reluctance to signing a collective agreement, stating that the "proposal is inappropriate for our industry ... it might be preferable to close the business rather than accepting impositions of this nature" (Memorandum 1947 in Murillo 2000, 103). President Carlos Julio 
Arosemena (1947-1948) settled the labour conflict without further negotiations by granting $7 \%$ of net profits to the workers. Finally, the FTP and SADCO signed a conciliation agreement on April 1, 1947. Again, $\operatorname{SADCO}(1948,26)$ threatened, in veiled fashion, to leave, arguing that the "absorption and adaptation of workers in other activities would mean a painful, lengthy, and costly process for the Ecuadorian state."

By 1948, rumours concerning the company's exit and fears about the resulting unemployment intensified in the mining district. ${ }^{233}$ After more than fifty years of mining operations, the mayor, pointing to the price the county had paid for mining, especially in terms of environmental devastation, argued that it was "imperative, urgent, to give the county a new life, so that its existence will be assured" (Carrión 1948, 10). Public officials anticipated a period of high unemployment and exodus that required a transition period so workers could join other industries and compensation could be settled progressively.

The mining camp was in a desperate situation by the end of the decade. The increase and centralization of mining revenues transformed socio-political relations, while the relative decline of mining profits encouraged extraction of sensitive ore reserves that reduced the life span of the mines. The company

233 This is a recurrent topic in municipal minutes and local newspapers beginning in 1946, one that appears with greater frequency after 1948. 
threatened to leave if its request for a reduction in royalties to $6 \%$ of the gross product was not granted. Unionized workers demanded wage increases, a share of net profits, and better living conditions. Leftist movements and political parties rallied against imperialism and questioned the company's financial reports. The municipality had assumed loans from private banks for large public works projects; unable to make payments, the municipality feared job losses, especially in the education sector. Finally, the Americans declared the mine unprofitable, announced that it would be closed, and put its assets up for sale.

In many respects, the Portovelo camp shares the fate of other mining towns. Commodity regions produce socio-spatial and institutional arrangements that are vulnerable to internal and external factors, including depletion of natural resources, technological challenges, labour disputes, taxation and other government policies, market fluctuations, and international regulation. In any case, companies seldom abandon a mine abruptly as a result of a single isolated phenomenon but, rather, as the result of a combination of factors that come together over time, and departure requires long-term planning and coordination among different actors. The mining cycle includes not only the exploration and production phases but also mine closure, a politically risky process that can cause severe impacts on local society, leaving residents without jobs and with a degraded ecosystem (Keeling 2010; Kuyek and Coumans 2003; Otto et al. 2006). 


\subsubsection{De-industrialization and the downscaling of the employment crisis}

The writing of SADCO's history is mostly a romantic reminiscence of Fordism (Cortázar and Lavanda 2008; Romero and Rueda 2002). A belief that there was a success in the dispute for labour rights and the redistribution of assets to the workers is somehow rejected. In fact, there was an industrial slowdown and a decline in manufacturing jobs, but CIMA operated the mines for another 27 years. In this case, the term de-industrialization — as an overarching and rapid process of economic restructuring — might be misleading. However, I follow Harvey's (2006, xxiv) suggestion of integrating highly localized placebased devaluations of capital into our understanding of the historical geography of capitalism. I contend that patterns of localized de-industrialization in mining industries help to unravel the gradual but global process of industrial restructuring which transformed the scales of social regulation in the extractive sector.

In 1948, SADCO initiated a partial slowdown and activated a withdrawal plan. The company continued exploiting rich ores under the Amarillo River, but the junior mining companies suspended all activities in Minas Nuevas and Macuchi. All American families left Portovelo. The company requested tax exemptions, a preferential exchange rate, and a direct subsidy. If demands were not met, the company manager suggested that the state could buy all properties - estimated at US\$600,000 - and continue mining operations (Municipio de Zaruma 1952, 29 in: Murillo 2000, 107). However, mine closing implied the 
enforcement of collateral guarantees. SADCO had a mortgage with the state. According to the Mining Law of 1937, the concessionaire would have to cede all facilities, machinery, and other equipment to the state. SADCO argued that the clause did not apply in cases of mineral resource depletion.

Locally, three actors were opposed to mine closure: members of the Comité Unico de Trabajadores de Portovelo, national employees belonging to the Junta de Promotores, and the municipality of Zaruma. The Junta de Promotores insisted on operating the mining works with advice from national technicians, provided that the state reduced levies and guaranteed the conditions necessary for mining activities. The municipality believed that SADCO's property should pass to the state, but there was no clear alternative to mining. The workers' committee was not opposed to these alternatives, as long as all workers received fair compensation in the case of mine closure, or better living conditions and wage increases in the case of continued operations. 
The election of US-born President Galo Plaza Lasso (1948-1952) $)^{234}$

paved the way for the "honourable" departure of the American mining company.

Other US business entities were investing in banana plantations and Plaza Lasso

fostered a transition towards democratic governance and development policies

after two decades of political and economic instability in Ecuador. SADCO's case

required a complicated arrangement involving the use of political capital and

strategic manoeuvres. The president had to convince congress to authorize the

executive to enter into a definitive contract based on a technical report issued by

the National Economic Council, as mandated by the 1946 Constitution. ${ }^{235}$ Until

the signing of the new contract, the legislature empowered the executive to grant

$50 \%$ tax credits on mining royalties for operational costs related to increased

salaries and wages. ${ }^{236}$ The tax burden was redirected to mediating labour

disputes and appeasing unionized workers. Additionally, the remaining $6 \%$

mining royalties were reallocated to the municipalities of Zaruma, Piñas, and

234 Galo Plaza Lasso, a wealthy landowner who studied in the US, promoted foreign direct investment and opened national territory to United Fruit banana plantations, the dominant commodity in the Ecuadorian economy until the late 1960s. The last president who had been democratically elected and finished his term was the liberal chief of state José Luis Tamayo (1920-1924). President Isidro Ayora ruled the country for almost five years - from 1926 to 1931 - but he had come to office as interim president after a military coup and resigned in response to a military uprising. During the 1930s, sixteen presidents ruled Ecuador. See appendix for a list of Ecuador's chiefs of state.

235 Decreto Legislativo, November 5, 1948, in: Registro Oficial, No 63 November 18, 1948, in: Cortázar and Lavanda 2008, 98.

236 The wage increase consisted of three sucres per day for underground workers, two sucres per day for surface workers and 2.50 sucres daily for employees with salaries lower than 800 sucres a month as suggested by the company itself in previous reports. 
Loja, in shares of $40 \%, 30 \%$, and $30 \%$, respectively. The formula facilitated political negotiations and won support from local governments and the provincial deputies of Loja and El Oro. The president appointed a commission to study definitive alternatives.

In April 1950, a presidential commission visited Portovelo for a site inspection; commission members recommended that gold mining continue. ${ }^{237}$ This option included the "municipalization" of the mining company with employees, workers, and local government becoming shareholders. The national government would sell unnecessary machinery and equipment, and the municipal mining company would pay for remaining assets with mining profits. All representatives, except for the municipal delegate, were in agreement with this option. The municipal council judged it harmful to the interests of Zaruma and the mineworkers; there were no guarantees regarding the profitability of ore deposits and no complementary resources to replace mining royalties. ${ }^{238}$

237 The committee was made up of Ángel Felicísimo Rojas, President; Clodoveo Jaramillo Alvarado, senator for Loja; Carlos Alberto Palacios, deputy for Loja; Julio B. Gallardo, deputy for El Oro; Alfonso Loayza, representative of the Federación de Trabajadores de Portovelo; Humberto Molina Astudillo, representative of the municipality of Zaruma; Augusto Sánchez, representative of the Comisión Planificadora de la Nueva Economía de Zaruma. Dr. Manuel Romero Sánchez was initially delegated to represent the municipality of Quito but excused himself due to a conflict of interests and schedules related with his appointment as superintendent of banks. See: AHM/Z. MMC, T.5, April 11, 1950, 367.

238 AHM/Z. "Problemas de Portovelo, Recomendación № 16 y Organización del Comité." MMC, T. 53, Acta No 32, April 22, 1950, 390-403. 
The municipality and workers requested a "fair, even-handed, and practical" strategy to address the emergency. ${ }^{239}$ The main elements included: parcelling arable land, leasing housing, and selling tools with payment facilities so workers could acquire those assets; developing employment opportunities within regional institutions; allocating premises to social clubs and institutions; and transferring the Amarillo hydropower plant, the Curipamba Hospital, the potable water system, the electric distribution system, and some buildings to the municipality of Zaruma. ${ }^{240}$ In addition, workers requested the establishment of "free exploitation areas" for placer miners.

Myriad micro-powers pulled in different directions and negotiators were unable to reach a definitive agreement. The municipality sponsored the Comité Pro-Defensa de los Intereses de Zaruma, a representative entity permanently established in Quito, which received monetary contributions and volunteer work of zarumeños living in the capital. Meanwhile, the Junta de Promotores de Portovelo formed the Compañía Anónima Minera Industrial Nacional Ecuatoriana (CAMINE, Ecuadorian National Industrial Mining Company, Inc.) and sought

$239 \mathrm{AHM} / \mathrm{Z}$. "Acta de convenio entre el llustre Consejo Cantonal de Zaruma y el Comité Único de Trabajadores de Portovelo." MMC, T.54, Acta Nº 48, 1950, 21-26.

240 These demands would become relevant when artisanal miners acquired property and began exploiting underground wealth in the late 1970s. 
authorization to purchase SADCO's assets. ${ }^{241}$ The workers allied with the Socialist and the Communist Parties of Ecuador.

The new legislators, who took office in August 1950, examined the case and received the news that the American company would definitely leave by the end of the year. ${ }^{242}$ Some legislators sympathized with local actors, but there was concern regarding the legal aspects of the acquisition of SADCO's assets. The uncertainty was related to the state's capacity to implement development programs and encourage an effective transitional economy in case of deindustrialization. Legislative delays in finding a solution for Portovelo could also be interpreted as a deliberate strategy which made possible the extraction of all high-grade ores and political arrangements favourable to the American-owned mining company.

The profitability of mining ores was not legally defined. According to preliminary estimates, there was about 40,000 tonnes of low-grade quartz, graded at 0.25 troy ounces of gold per tonne, which the American company

241 Most members of CAMINE were upper-class Ecuadorian employees and former members of the Portovelo Club, who had made profits through a local cooperative. These were the only actors with liquid resources to acquire a share of SADCO's assets. The American company sponsored the group and provided advice and political connections to encourage the purchase.

242 ABANE. "Se nombra una comisión para que estudie el problema de la South American Development Company." CP 1950, Acta № 29, August 29, 1950. 
deemed unprofitable. ${ }^{243}$ In December 1950, the Minister of Economy and Social Welfare decided that SADCO was entitled to keep all machines and facilities in the event of the depletion of deposits. The mining company was free of any contractual commitment, could dispose of its assets, and leave Ecuador. Whereas in the past the attempt to nationalize the mining industry had required the upscaling of political lobbying to gain support from the US State Department, at this point, the application of contractual guarantees and the potential embargo required that the company negotiate with the Ecuadorian legislature and other national actors.

Congress issued preventive measures against SADCO and its junior mining companies. All machinery, equipment, and other effects "could not be subject to any transaction and would remain on deposit under the care and responsibility of these companies and the government until the Legislature resolves, pursuant with law, their fate." ${ }^{244}$ Moreover, in the event of suspension or abandonment of mining works the government would "immediately take over "Antecedentes y texto del Decreto-Ley de Emergencia. DLE. No 004," in: Registro Oficial, No 767, March 19, 1950, 6307-6314.

244 Resolución Legislativa, in: Registro Oficial, № 666, December 16, 1950, art. 4, in: Cortázar and Lavanda 2008, 103-104 
the Portovelo camp, preventing its destruction and pursuing its maintenance as a town, and seeking all possible means for continuing gold exploitation."245

At the end of the mining cycle, the presidential palace became a center for lobbying. Galo Plaza Lasso called for a final conciliation meeting in Quito on December $16,1950 .{ }^{246}$ For the president, the establishment of a municipal mining company of local shareholders constituted an "interesting assay of social order." ${ }^{247}$ The national government would purchase SADCO's tangible assets and hand them over to the new enterprise. The municipality of Zaruma, national employees, and workers would acquire $35 \%, 35 \%$, and $30 \%$ of stocks, respectively. George A. Davison, a former American employee, would remain for one year as temporary manager to facilitate compliance with legal and technical requirements. The Artillery Corps received instructions to organize a police force, ensure that all assets were handed over, and establish a military camp in

245 Resolución Legislativa, in: Registro Oficial, № 666, December 16, 1950, art. 44, in: Cortázar and Lavanda 2008, 103-104.

246 The minutes of the municipal board document the events of that day. The cabinet received a phone call from another faction of Portovelo workers asking that the delegation present at the meeting be dismissed. The call did not change the course of events, but reflects internal divisions that were not resolved for years.

247 Communication from Galo Plaza Lasso, Presidente del Ecuador to Alberto Larrea Chiriboga, Presidente Nacional del Consejo de Economía, February 22, 1951, in: Registro Oficial, No 767, March 19, 1951, 6307-6314. 
Portovelo; in fact, the soldiers were more involved in preventing theft than in overseeing the formal transfer of assets from SADCO to CIMA. ${ }^{248}$

The process was not free of contradictions. SADCO's decision to terminate ore exploitation, in spite of the existence of sufficient mineral deposits to justify the creation of a national mining company, was a paradox. The withdrawal of foreign investment was not a matter of resource depletion but a strategy for the circulation of capital. Dr. Alberto Larrea, chairman of the National Economic Commission, argued that previous legislative reports suggested proceeding with the embargo. However, mining productivity was not legally defined, and the Ecuadorian president had already signed the agreement. Dr. Larrea considered the option a "joyful initiative" and a "thoughtful assay," but he also stated that his assent was given under pressure at a moment when the whole process had become a fait accompli. ${ }^{249}$

248 AHM/Z. "Asuntos de Portovelo." MMC, T.54, Acta Nº 6, January 2, 1951, Zaruma.

249 Alberto Larrea Chiriboga, Presidente Nacional del Consejo de Economía, to Galo Plaza Lasso, Presidente del Ecuador, March 16, 1951, in: Registro Oficial, № 767 March 19, 1951, 6307-6311. 


\section{Photo 7.1. Second visit of President Galo Plaza Lasso to Zaruma, 1951}

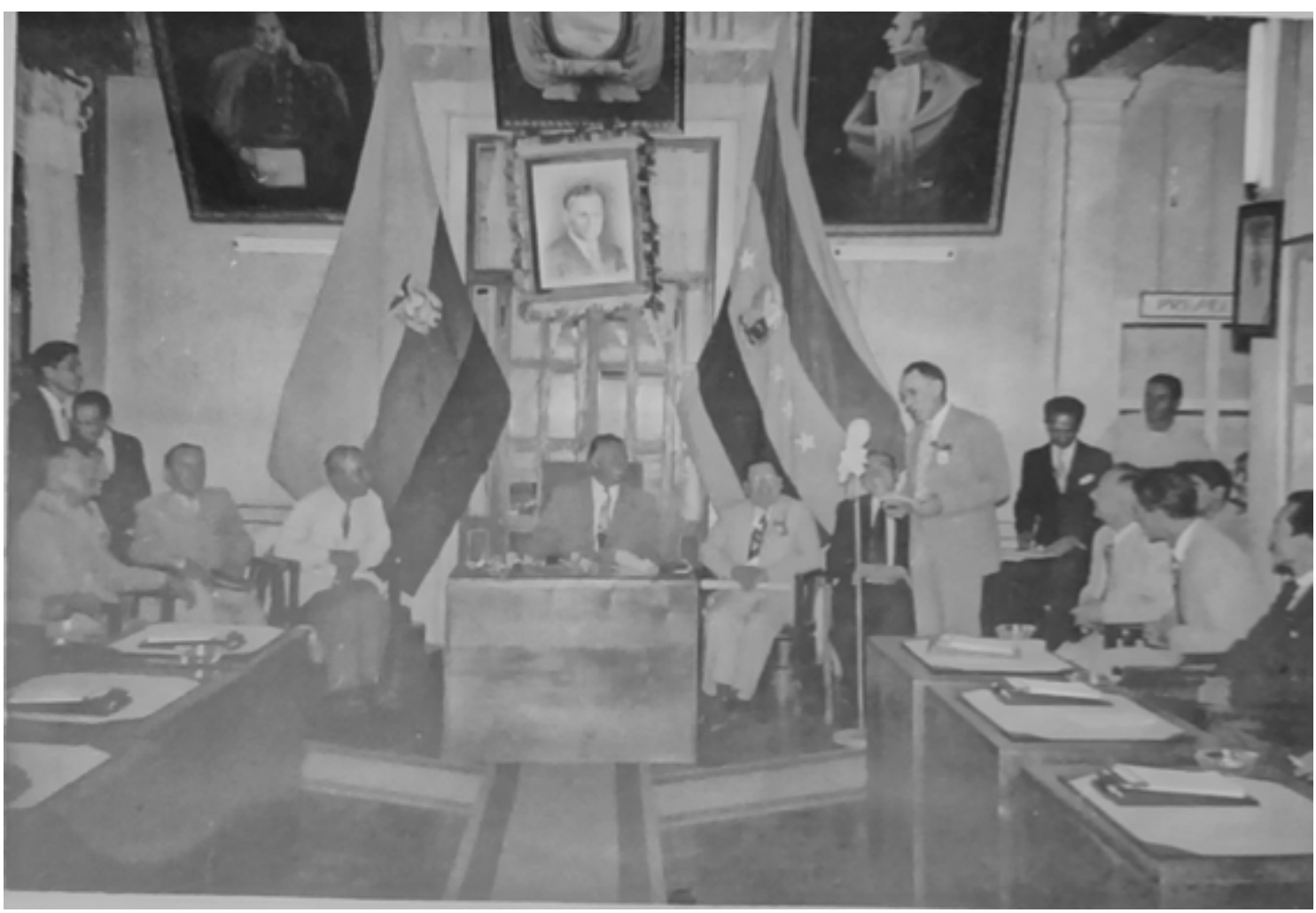

Note: Geo A. Davison presents CIMA's working report at the solemn session in Zaruma's Municipal Palace on November 26, 1951. Galo Plaza Lasso visited the camp for the first time on October 8, 1949, during the negotiation period with SADCO.

Source: AHM/Z. "Habla el Sr. Geo A. Davidson," Album Municipal, T. I. 1931-1944. Photographer unknown. 1951.

President Plaza legitimized the procedure through an executive decree. The transfer of SADCO's assets to the state was not, strictly speaking, a case of expropriation of private property. However, international standards for prompt, 
adequate, and effective compensation came into effect. ${ }^{250}$ The contract was signed again "without charge or claim whatsoever between the parties, [and] cancelled the mortgage on the property of the South American Development Company Inc., which had guaranteed the fulfillment of the Company's contractual obligations." ${ }^{251}$ The purchase price for all assets was 2.5 million sucres, to be paid within two weeks in payment for all royalties and taxes owed by SADCO and the Calera Exploration Company for 1950 . This process represented a debt swap; no money changed hands. The shareholders could not resell stocks for a two-year period, and the municipality of Zaruma would have first bidding rights, together with the National Development Corporation. As part of the transition process, SADCO loaned US $\$ 50,000$ to the new organizing committee to purchase essential materials for further work. The loan was to be paid when mining resumed. Finally, all acts, contracts, or profits derived from the decree were automatically and indefinitely exempt from royalties, duties, and taxes, whether national or municipal. This represents another contradiction in the whole process insofar as that was SADCO's very own condition for continuing operations in Ecuador.

250 Cordell Hull, U.S. Secretary of State, stated this to be the standard for compensation in a letter written after the Mexican expropriations in 1938 (Sornarajah 2010, 36).

251

Decreto Ejecutivo № 004, in: Registro Oficial, № 767, March 19, 1950, 6311-6314. 
The means of production were finally and effectively declared as a public domain, an asset of the state regulated by national authorities to stimulate local economic development. However, the nationalization of mining assets was accomplished as a transaction whereby the central government purchased the property of the foreign mining company, postponing the onset of an employment crisis, decentering the importance of mining, and transferring social and environmental externalities to local governments. This is also evident in the historical archives. Since 1950, it is far more difficult to find documentary sources of political disputes, labour claims, and requests for economic accountability by the mining industry, and there is a marked softening of the belligerent tone of critical actors such as the Socialist Party of Ecuador. The implications of the municipalization of the mining industry will be explored in the next chapter.

\subsection{Conclusion}

In this chapter, I contend that capitalist expansion is not performed independently of national or local groups, which are subordinated to the booms and busts of commodity markets. In fact, elites and workers do have a say in the regulation of the mining industry by developing relative autonomy vis-à-vis the enclave economy to press for the redistribution of wealth via royalties and wages. Public domain of mineral resources emerged as a radical legal concept to reclaim state capacities at a time when extractive imperialism was expanding. However, nationalist regulations within the mining sector in Ecuador were placespecific, constructed through the interaction among the state, foreign investors, 
and actors in socio-spatial struggles. At the same time, the institutional system, administrative practices, and historical junctures moulded the application of progressive legal principles, including the system of social rights, while enabling resource exploitation.

The emergence and selective application of legal concepts represent a particular mode of regulation. Both the state and corporations used these norms for their own purposes, with their views shaped by their ideological backgrounds. The foreign investors reasserted property rights and the contract as a key to sustaining progress and development. On the other hand, nationalist governments embraced the constitutional notion of public domain of natural resources to sustain government and national finances in the name of the common good. This approach challenges "weak governance" as a condition for the optimal performance of extractive industries, and explores the dynamic process whereby regulations are transformed to accommodate particular social and economic powers.

The mining laws of the mid- $20^{\text {th }}$ century reflect the restructuring of resource regulation, a transition that included international policies, national laws, corporate-based regulations and place-based resource governance. At the national level, the failure to comply with contractual obligations, the rise of populist regimes, the emergence of labour movements, and anti-imperialist discourses transformed the political arena. Together, these elements led to a nationalist restructuring of what was deemed as localized regulation and pro- 
company politics. The nationalist claim over natural resources was not an isolated case in Ecuador. Throughout this period some Latin American countries mineral industries were nationalized and the assets transferred to state-owned companies. These trends would ultimately lead to the upscaling of resource regulation through hemispheric policies and international instruments, including an international system able to enforce state responsibility for injury to aliens and their property. Such a doctrine comprised a more active presence of diplomatic representations lobbying for private companies, national regulations to protect mineral concessions, and bilateral investment treaties.

The case of the Portovelo camp also demonstrates the restructuring of resource regulation at times of crisis. The central government purchased the assets of the American company and transferred them to a municipal-workers industry that operated the mines until the late 1970s. The abandonment of mining operations was a corporate strategy supported by the state, which helped in mediating labour disputes and displacing the labour crisis to the local level. Thus, the regulatory regime can work, simultaneously, to up-scale decision-making to the national level and down-scale social and environmental externalities to local actors. 


\title{
8. The municipalization of the mining camp: The search for a new institutional fix, 1950- 1980
}

\author{
Portovelo was a town in complete harmony... . When CIMA was \\ there, the workers' company, it was almost a true paradise, close to \\ perfection. The company belonged to the workers themselves and \\ they worked, but at the same time the profits were divided between \\ the municipality and the shareholders. There were no bosses. The \\ mistake was that people distributed the profits, which were small \\ amounts, while the company ran out of capital. There was no \\ investment in technology or anything else in new exploration; the \\ ore had already been worked, things were obsolete, the veins were \\ deep, and [the company] had to close. The municipality of Zaruma \\ never did anything for Portovelo, all it did was benefit from the \\ profits, that was all.
}

(Interview, male, Portovelo, 2012)

The Compañía Industrial Minera Asociada (CIMA) operated the Portovelo mines from 1950 to 1980 , giving way to the "municipalization" of the transnational mining industry. The South American Development Company (SADCO) sold its property and paid its tax obligations by turning assets over to the state which, in turn, transferred the property to three shareholder groups: the municipality of Zaruma, the mineworkers, and SADCO's white-collar employees. The presidential decision was neither the result of popular demand nor a manifestation of national sovereignty but, rather, an option for the honourable departure of the foreign-owned mining company and a way to downscale labour unrest and unemployment problems. The Plaza administration aimed to provide 
guarantees for the expansion of foreign investment and export-oriented development in the banana and oil sector.

Brenner $(2004,72)$ highlights that state space is an "arena, medium and outcome of spatially selective political strategies". Insofar as the nation-state develops a particular state-project, it also develops spatial policies and political strategies that produce differentiated geographies of economic activity and state regulatory performance. In the same vein, MacLeod and Goodwin $(1999,716)$ argue that "the introduction and operation of the new institutions and processes of local economic restructuring can be positioned within a wider set of social and political forces, and understood as part of the continuing attempts to forge and sustain a 'successful' political project and scalar fix." State projects and policies are strategically selective in their geographical outreach.

Portovelo was no longer a catalyst of regional development or a source of national income, but a site of potential conflict and a burden for the expansion of the development state. Therefore, the municipalization of the mining industry provided a temporary means of subsistence for the work force, delayed mineclosure, and created new patron-client relations. Nevertheless, the archives also reveal widespread uncertainty during the transition and operation period of the municipal mining enterprise. The restructuring of the mining company gave way to complex interactions between alternative projects: the maintenance of the mining camp as an enclosure of self-rule, or the diversification of the economy to sustain local livelihoods. 
The municipalization of the enclave occurred in three stages. First, the national government decentralized business management, deferring deindustrialization and transferring labour disputes to local actors. The multiplication of actors allowed for the distribution of surface assets while the processing of mine tailings, the weakening of underground structures, and the increase in the international price of gold created conditions for the expansion of artisanal mining. Then, military regimes took over mine management but allowed for parallel economic activities, such as agriculture and livestock. In this period, local elites resumed territorial control over the city of Zaruma and disengaged from the Portovelo industrial camp. Finally, CIMA's financial collapse and the creation of Portovelo as an independent municipality transferred the responsibilities for the provision of basic services and dealing with the externalities of the mining industry to the newly-constituted local government.

During interviews about CIMA, many participants spoke about the heroic nature of Portovelo's transformation into a rural parish. I had not included that issue in the interview script and the books I had read about the mining enclave barely mentioned this process. The emergence of new jurisdictions is documented for mining boom times; the province of El Oro was created in 1882 (see chapter four) and the county of Piñas was established in 1940 when municipalities began to receive royalties (see chapter seven). The local autonomy movement succeeded in declaring Portovelo an autonomous administrative jurisdiction, as a parish, in 1968 and as a municipality in 1980. However, there is little analysis about rural parishes and their role within the 
modern state in Ecuador. ${ }^{252}$ After hearing the interviewees' perspective, I infer that rural parishes and municipalities were the result of a society disputing unequal access to resources and political power.

In this chapter, I analyze the ongoing production and transformation of space in Zaruma and Portovelo in the context of industrial decline. The mining enclave was undermined by the progressive informal occupation of both surface and subsurface mining assets. The absence of a strong local elite or a single corporate agent able to rule the camp gave way to a new territoriality. I argue that the spatial regulation of the extractive industry reconfigured social relations that resulted in new administrative jurisdictions. Oral accounts support this argument, whereas archival materials, newspaper articles, and other secondary sources provide the empirical background necessary to substantiate this story.

\subsection{The break up of the mining enclave}

... to stop the historical narrative at just the moment when subordinate groups have achieved some long-sought-after goal is not only populist, and dangerously so, but bad history. It is to replace processes with events.

(Striffler 2002, 110)

252 It is worth noting the seminal work of Andrés Guerrero $(1980,2010)$ about tenientes politicos in the $19^{\text {th }}$ century as state agents entrusted with ethnic administration and tax collection, and with powers as justices of the peace. 
My research explores how global forces are grounded and transformed by local processes. After a half-century of American domination, the mining enclave was bought by the national state and transferred to local actors. Throughout fieldwork, interviewees entangled the American company with the national mining enterprise. Rather than faulty memory, Portelli $(1991,19)$ suggests that the time displacement of oral accounts serves to heal people's wounds. I decided to continue analyzing the evolution of the mining enclave. Extending the history of the Portovelo until 1980 entailed the deliberate choice to make evident particular processes of de-industrialization, as well as helping to build novel theoretical insights.

De-industrialization, plant closures, and job relocation are commonly associated with the neoliberal policies and corporate restructuring of the late 1970s (Bluestone and Harrison 1982; Harvey 2001, 2003). The political stability and quarter century of economic growth after World War II, both in Ecuador and worldwide, barely leaves room for analyzing processes of localized disinvestment. I assert that the breaking apart and organizational uncertainty that befell the Portovelo mining enclave contributes to understanding early patterns of industrial restructuring and the role of the welfare state in the mediation of labour conflicts. Moreover, the physical dismantling of the mining enclave and the proliferation of artisanal mining coincide with the end of gold parity, in which gold comes to be traded at a free market price, giving rise to new spatial forms of capitalist accumulation. 


\subsubsection{Creative distribution of and dispute over corporate assets}

The productivity of the transnational mining enclave required the private appropriation of land-based resources and the socio-spatial engineering of the Portovelo camp (see section 5.2). The winding down of SADCO brought, again, a time of uncertainty. On this occasion, the turmoil was characterized by the lack of agreement between the shareholders and the creative distribution of surface assets, which undermined the unity, enclosure, and productivity of the camp. As a social construction, space evolved in tandem with the ownership and conditions for the utilization of the material world.

In 1951, the national government distributed the company's shares and the fixed assets to local actors. The municipality of Zaruma received $35 \%$ of the shares plus the Amarillo hydropower plant and the Curipamba Hospital. Over time, the local government would pay off the loan through investments in regional infrastructure, road maintenance, and urban development. ${ }^{253}$ The white-collar employees, members of the CAMINE, acquired $35 \%$ the shares. ${ }^{254}$ The

253 The municipality of Zaruma had to invest its equity share as follows: $407,970.05$ sucres in annual dividends of 100,000 sucres from 1952 onwards, 250,000 sucres for the ZarumaPiñas road maintenance; 50,000 sucres towards the improvement of Portovelo schools and the development of the Machala neighbourhood; 30,000 sucres for the Capiro bridge; and $62,614.60$ sucres as investments in El Tablón Hacienda.

254 CAMINE had three years to pay off equity, amounting to $783,498.80$ sucres, equivalent to US $\$ 52,233.25$, in the following manner: 200,000 sucres for an irrigation cannel in El Tablón Hacienda; 220,000 sucres in energy for Portovelo and Barrio Machala; 100,000 for sanitation, urban development, school repairs, and sports fields in the neighbourhoods of Portovelo, Machala, and El Castillo; 200,000 sucres for new tools and equipment; and 63,498.80 for repair of the Galvez channel and the Amarillo hydropower plant (Astudillo et al. 1980, 15-16). 
government disbursed $30 \%$ of the shares free of charge to the workers as compensation for unpaid profit shares established in the 1947 collective agreement, and gave the union a building. Among the work force, there were different criteria for participation in equity schemes and the records vaguely refer to the need for forgetting grudges. However, personal interests and political discrepancies among shareholders would persist for decades, as will be explained.

A transition committee, comprised of the Ministry of the Economy and Mines and stockholder representatives, organized the inventory, identified workers' entitlement to shares, and defined the company's by-laws. The Americans appointed Geo A. Davidson as mine manager for one year during the transition period. Local authorities and labour leaders emphasised the need for collaborative work against industrial decline at a time of life or death for the whole region. ${ }^{255}$ In July 1951 , stocks were distributed to 715 miners and employees, members of the Corporación de Accionistas de Portovelo (CAP, Portovelo Stockholders Corporation). ${ }^{256}$

255 BM/P. "Sesión Junta Directiva," UTAP, Tome I, January 25, 1951, 479-481.

256 Entitlement proceeded as follows: natives of Zaruma who had worked for SADCO for more than two years and Ecuadorians who had worked for SADCO over 10 years could claim one share, worth 1,700 sucres. Tradesmen, loggers, and other occasional workers were excluded from stock participation. Among the shareholders only 18 were women. 
The initial delay in fulfilling labour benefits and distributing stock created unrest, unemployment, and out-migration. The miners had become "wageearners," dependant on a regular pay-check, with no access to credit or any other means to maintain themselves and their families, and unable to set themselves up as autonomous producers (Boyer 2002, 75). Speculators arrived in the region to illegally trade labour settlements at discounted values. ${ }^{257}$ The transition committee established measures to prevent the clandestine sale or turnover of assets. ${ }^{258} \mathrm{~A}$ first step involved issuing restrictions on the purchase, sale, or transfer of property "to prevent undesirable elements from being introduced into the camp, and thus keep within it decent families that will not come to give an immoral example."259

The disintegration of the internal spatial order of the mining enclave occurred gradually. The Portovelo workers obtained a $20 \%$ reduction on the nominal value to acquire houses as private property with long-term payment facilities, no mortgage, and preferential access for current heads of households. This procedure limited access to housing to bachelors and those living in nearby squatter camps. To partially counterbalance this measure, the municipality

257 BM/P, "Sesión Junta Directiva," UTAP, T. I, Februay 19, 1951, 487.

258 AHM/Z. "Asuntos de Portovelo." MMC, T. 55, January 13, 1951,

259 BM/P, "Sesión Junta Directiva." UTAP, T. I., April 2, 1951, 504. 
offered to sell land in El Faique at preferential rates for workers living in Zaruma, but housing demand declined as emigration increased.

In the meantime, the government applied coercive mechanisms to oversee the municipalization of the camp. Soldiers were posted in Portovelo to safeguard camp properties and to prevent theft and violence ${ }^{260}$ Members of the military became unintended beneficiaries in the distribution of surface assets. To accommodate the military, CIMA yielded housing and training spaces to the Ministry of Defense. ${ }^{261}$ The transition committee suggested that all military spaces be located within a clearly marked perimeter to avoid friction between the armed forces and the civilian population, a stretch of land that would be later known as the Avenida del Ejército. ${ }^{262}$

CIMA also lost control over key infrastructure necessary for production, the export of ore, and political negotiations. Unprofessional management of the mining business resulted in the discretionary distribution of properties. The

260 The agreement was issued on January 17, 1951, as part of the transition process and before the official conformation of CIMA.

261 The Ministry of Defense received, free of charge, the buildings of the Portovelo Sports Association, the headquarters of the Guardia Civil, the Portovelo Club house, the homes of the American employees, the Fonda Nacional, and the muleteers' stables located within the Portovelo camp, as well as the cellar of El Tablón Hacienda house, the Guichiguichi landing strip $\left(76,200 \mathrm{~m}^{2}\right)$, and a property called El Osorio $\left(50,000 \mathrm{~m}^{2}\right)$. In 1959 , following the departure of the military to Machala, the above-mentioned properties were abandoned. Some families would eventually acquire the housing or occupy the buildings, but the plots remained vacant.

AHM/Z. "Asuntos de Portovelo." MMC, T. 55, January 2, $1951,7$. 
government sold the Calera diesel plant to acquire cash and pay initial expenses.

Prior to its departure, SADCO donated church buildings in Portovelo, Osorio, and Faique to the local community; CIMA thus lost any direct control over the imparting of moral values to the local community through religious services and cultural activities. The municipality of Machala received the seaport plot and warehouses in Puerto Bolívar as a donation. Other assets located in Quito and Guayaquil remained the property of the American company.

After four years of operation, ore reserves were dwindling, drilling and processing equipment was worn out, and profits further diminished. In 1955, CAMINE sold its stock for 1.7 million sucres, almost double what they had paid in 1951. ${ }^{263}$ The municipality of Zaruma had no financial resources to cover the down payment to become a majority shareholder. CAP provided those funds by obtaining a loan from CIMA's workers, who consented to their monthly wages being temporarily docked and subsequently reimbursed with annual profits. The workers covered the initial quota, but the municipality held $52 \%$ while workers retained $48 \%$ of the shares. To secure payment, the shareholders were forced to deposit $50 \%$ of the company's future net profits in a special account at the Banco Nacional de Fomento, and mortgage the Hacienda El Tablón and the Calera 
Hydropower Plant. ${ }^{264}$ It is worth pausing to reflect on the implications of such an arrangement, as it would deeply influence the turnover of the whole company.

Figure 8.1. Chart of CIMA's administrative structure, circa 1960

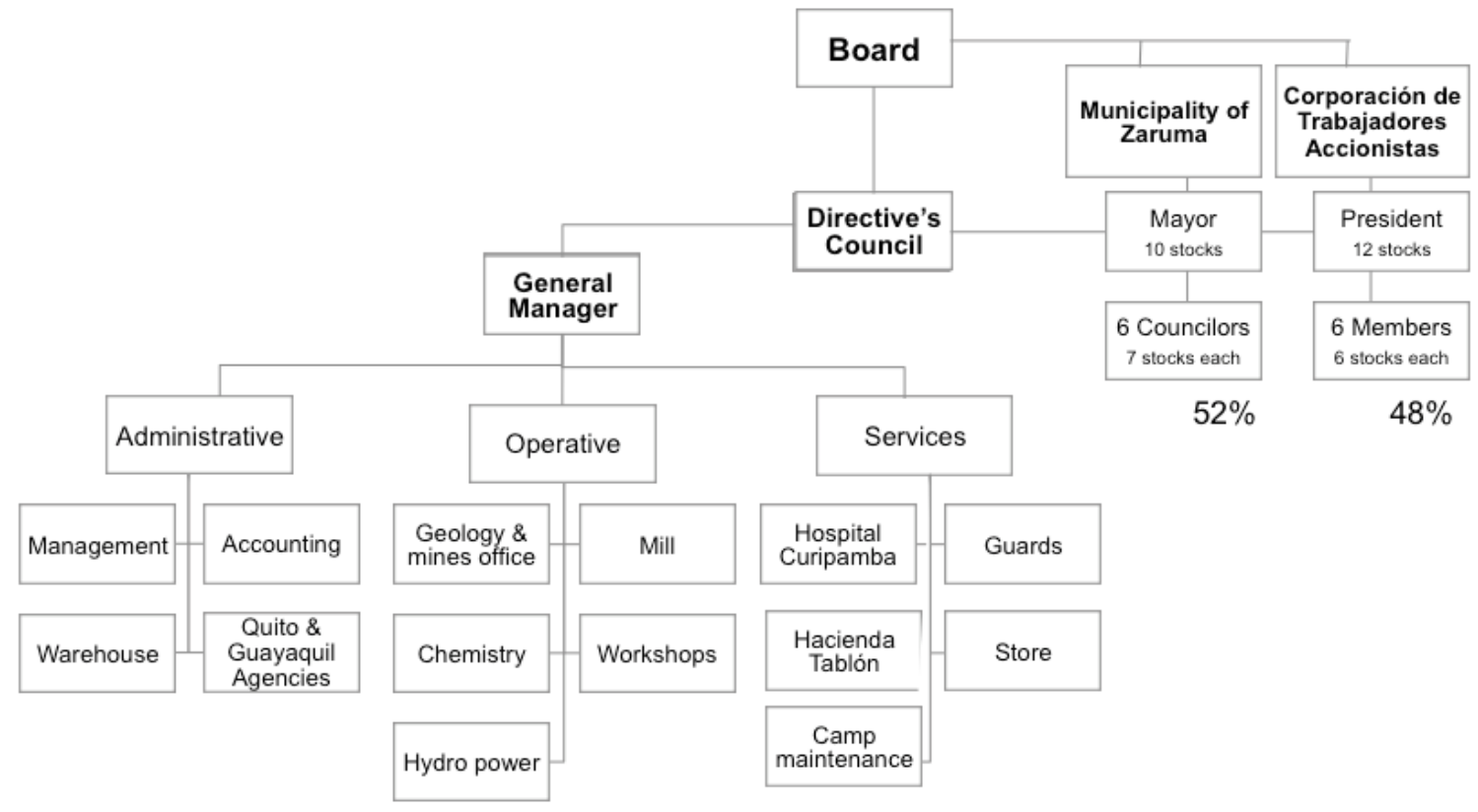

Note: CIMA had governing body divided between the Municipality of Zaruma and the miners' association. The municipality established itself as the majority shareholder but failed to consolidate legitimate political management.

Based on: Astudillo et al. 1980.

263 The transaction was carried out under the following conditions: 500,000 sucres on signing the contract, 250,000 sucres by December 31,1955 , and two instalments of 375,000 sucres each, payable in July and December 1956 . The remaining 200,000 sucres were to be invested in equipment for the Curipamba Hospital over two years, and the facility would be transferred to the municipality of Zaruma in case of liquidation.

264 These two properties were later embargoed and auctioned to cover payments due to the Instituto Ecuatoriano de Seguridad Social (IESS, Ecuadorian Social Security Institute). 
The company's administrative structure created a permanent conflict that generated disputes between the workers and the municipality. ${ }^{265}$ The municipality established itself as the majority shareholder but failed to consolidate legitimate political management; CAP was the lender that provided the means for the deal and the vote of CAP's president had a greater weight than the mayor's vote on CIMA's Board (see figure 8.1) ${ }^{266}$ CIMA's board and directors' council were renewed each year, based on electoral turnover and/or the political aspirations of the shareholders. Commonly, municipal representatives had little knowledge about mining or business administration, and CIMA's general manager rarely finished his period.

In fact, CAP became the leading entity within the company, both at the administrative and economic levels. CAP's general assembly was a keystone for decision-making and a political event within the camp. The chronicles reveal the importance of these gatherings as spaces of intense debate among shareholders, which would lead to consensus or to rioting (Cortázar and Lavanda

The municipality had systematic difficulties in determining permanent representatives and defining guidelines for industrial management. Nobody seemed able to assume the responsibility linked to mining operations and the municipal board would not consent to appointing a non-elected civilian to oversee the enterprise. Throughout the records, it is evident that politics prevailed over technical capacities.

266 At the time, local elections were held every two years to select, alternately, majority and minority councillors who, in turn, elected the president of the council. During the military dictatorships (1963-1966 and 1972-1979), the authoritarian governments appointed municipal councillors directly and the provincial military governor attended key sessions. The president of the municipal council had to manoeuvre and negotiate with a range of pressure groups. This dynamic involved both the municipality and CIMA in local power struggles. 
2008, 128-130). Emergent leaders argued for what each deemed "the common good" and developed strategies to continue mining operations.

What is to be made of all of this? From a Marxist perspective, we would applaud the redistribution of the means of production to the workers and local shareholders. From a corporate view, the foreign investors and the national employees managed to negotiate favourable conditions for the recovery of private investments in fixed capital. Overall, the transition included deep insecurity and the misuse of industrial assets, despite the government's attempt to continue mining activities. Those involved in the mining enterprise failed to develop the managerial, financial, and technical skills necessary for keeping the company alive. In other words, political will is not enough to uphold resource governance insofar as the transfer of industrial assets and the continuation of mining operations both demand technical knowledge, legal bases, and clear procedures, which needed to be in place before - not after - the departure of foreign investors.

\subsubsection{The persistence of mining as a subsistence enterprise}

Mining went on after the half-century profitable operation of the American company town, and continues even today. There was no outright depletion of underground resources, but rather a decrease in the ore grade of known deposits, requiring new investments in technology and knowledge, or exposure to risk. Therefore, the political decision to pursue extraction was a historical construction based on the social value of jobs over capitalist productivity. Overall, 
CIMA became a municipal, subsistence mining enterprise, looking for ways to generate economic returns.

Figure 8.2. Tonnes of gold from Ecuador sold on international markets, 1913-1976

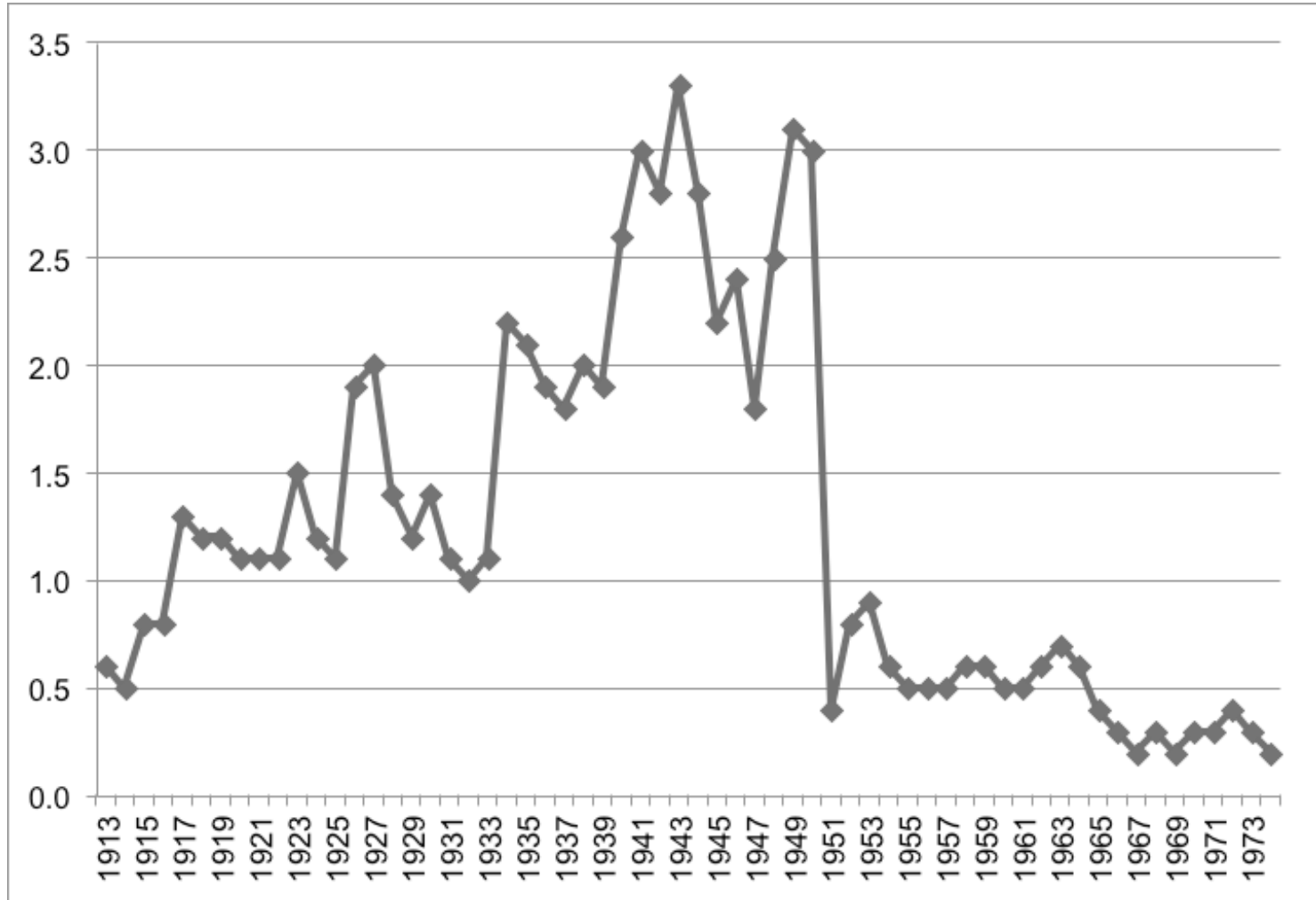

Note: The sharp decrease in gold sales reflects the transition from SADCO to CIMA as mine operator.

Based on: Schmitz 1979.

At the beginning of the transition phase, prospecting and exploration activities came to a full stop, and documentation on ore reserves was not fully transferred to the Ecuadorian administration (Astudillo et al. 1980, 48).

Apparently, Geo A. Davidson was responsible for flooding the lower levels of the main mine. It remains uncertain whether he deliberately sabotaged the new mining company's operations or the flood was the result of the weakened 
geological structures beneath the Amarillo River due to exploitation. Yet, CIMA achieved reasonable levels of production, generating returns in the early years of operation (figure 8.2). ${ }^{267}$ Mineral extraction followed the deep vein structures in Minas Nuevas, Vizcaya, Ayapamba, Portovelo, and Sesmo. However, the minimal investment in the exploration of existing reserves, the lack of technological upgrading, and the low recovery of non-metallic minerals directly affected the outcome of the mining company.

267 In 1953, the company processed 250 tonnes daily with a gold grade of 0.23 ounces per ton. In addition, the ore contained $1.10 \%$ zinc, $0.36 \%$ lead, $0.29 \%$ copper, and 30 to 35 grams of silver per ton (Stoll 1962, 804). 
Figure 8.3. Dollar value of CIMA's metallic and non-metallic production, 1951-1976

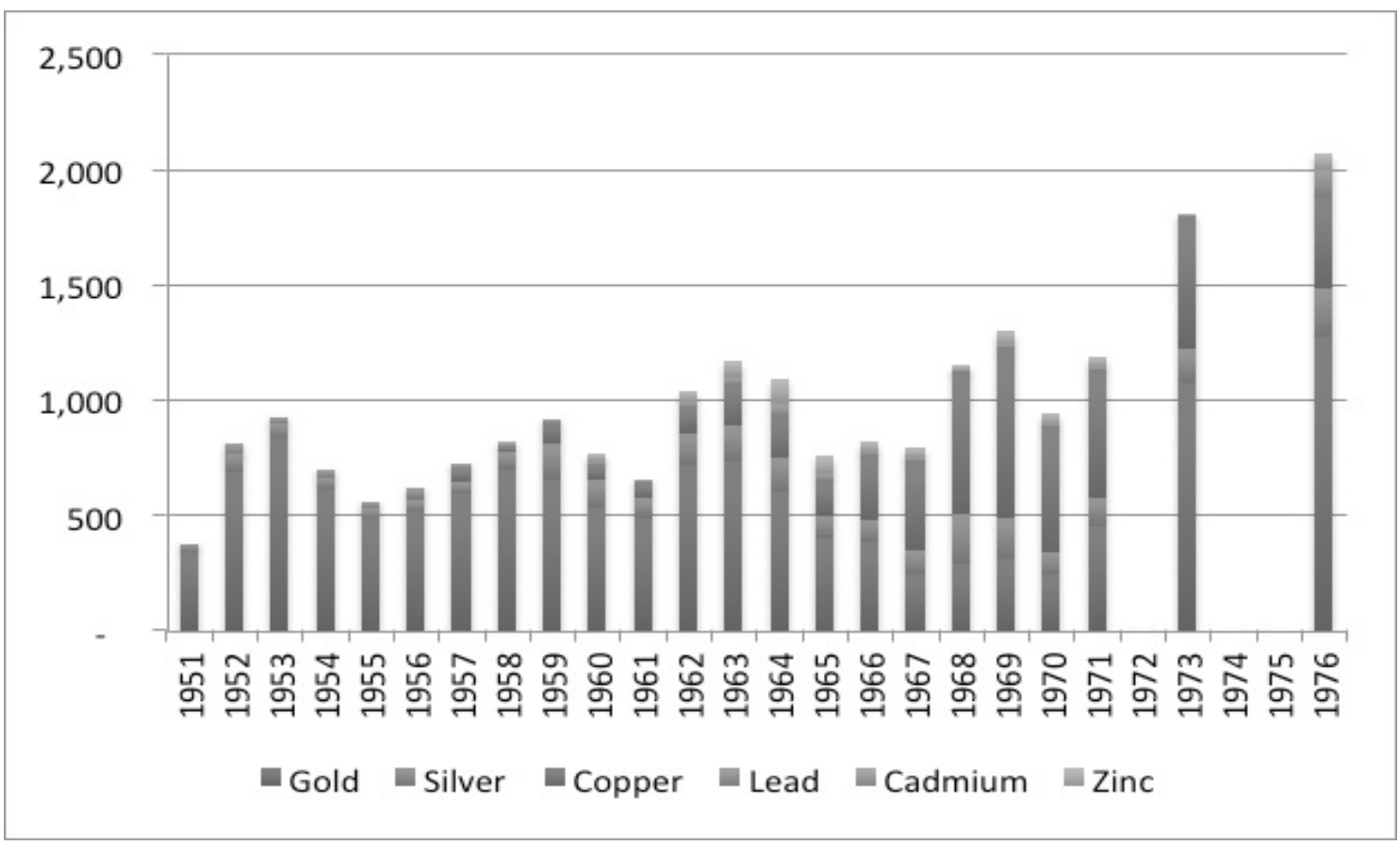

Note: Metallic and non-metallic production expressed in thousands of U.S. dollars at the official exchange rate, reported for the full year. Values reported for 1973 and 1976 include, apparently, the production of the previous unreported years.

Based on: Astudillo et al. 1980.

Eventually, the municipality aimed to transform CIMA into an agent of local development. After the 1945 Municipal Regime Act and the 1946 Constitution, municipal governments acquired greater responsibilities for the provision of basic services, were required to have a development, or master, plan, and to build affordable housing for workers. The company planned to buffer the disorderly effects of the mining crash by developing Brahman-Cebu cattle and forestry, or establishing small-scale factories to produce marmalade, steel nails, barbed wire, glass, and woven sisal. None of the above activities prospered; the shareholders 
pressed to receive profits rather than reinvesting in the company or in any other entrepreneurial activity.

The emergence of what is colloquially called cuarzo petrolero, the quartz recovered by artisanal miners, produced a temporary bonanza in the early1960s. The Americans had used a technique whereby structural supports and pillars remained in tunnels despite the ore grade. Artisanal miners hollowed those structures to recover ore containing high levels of gold. ${ }^{268}$ The cuarzo petrolero had 0.504 ounces of gold per ton whereas quartz mined by CIMA yielded only 0.214 ounces of gold per ton. In 1961, the quartz mined by artisanal miners represented $25.5 \%$ of overall gold production. ${ }^{269}$ This demonstrates that, contrary to what Lovitz (2006, 15 and 59) and other scholars have maintained, small-scale operations did not begin in the late 1970s but, rather, much earlier.

Artisanal mining was not intrinsically irresponsible, irrational, or illegal. As Portelli $(1991,53)$ notes, "acts considered legitimate and even normal or necessary in the past may be ... now viewed as unacceptable." The foregoing

268 In 1961, there were around 70 private miners working in the following mines: Abundancia, Tablón, Cantabria, Miranda, Agua Dulce, Vizcaya, Minas Nuevas, Jorupe, Pacchapamba, Barbasco, Tres Reyes, Arcapamba, Tamayo, Lacar, Curipamba, Sesmo, Toscón Blanco, Castillo, Fortuna, Pacay-Hurcu, Quebrada Veta, Malvas, and Mercadillo. CIMA acquired 6,516 tonnes of quartz, reported 2,957 ounces of gold and profits reached almost 640,000 sucres after purchase and processing expenses (Mosquera 1962, 392).

269 In addition, the official exchange rate rose from 15 to 18 sucres per U.S. dollar in 1961. The macroeconomic policy was beneficial for the company as the metals produced $20 \%$ more monetary revenues than in previous years while wage increases were not significant. 
information demonstrates how corporate actors were permissive and encouraged these practices to finance CIMA and to delay its own decline. These purchases were considered beneficial as they provided income for local families and saved the company from economic crisis. The scope and reach of artisanal mining would indeed intensify after 1980, when the state reversed CIMA's concessions and industrial facilities, the government implemented neoliberal policies deregulating the economy, the international price of gold increased, and agricultural workers faced an El Niño event in 1983.

As a subsistence mining company, CIMA found creative ways to generate profits with little investment. In 1967, CIMA's workers began carving SADCO's tailings in the pampa de arena (sand flats) near the Amarillo River. The company removed the top level sands, $85 \%$ of which contained copper sulphide (Mora $2008,70)$. In addition, the chance discovery of the Agua Dulce vein system provided a partial, temporary recovery of the mining enterprise during the early 1970s. Between 1951 and 1976, earnings after operating expenses amounted to US $\$ 3.5$ million, of which US $\$ 923,000$ were profits (figure 8.4). 
Figure 8.4. CIMA's profits and losses in thousands of U.S. dollars, 1951-1976

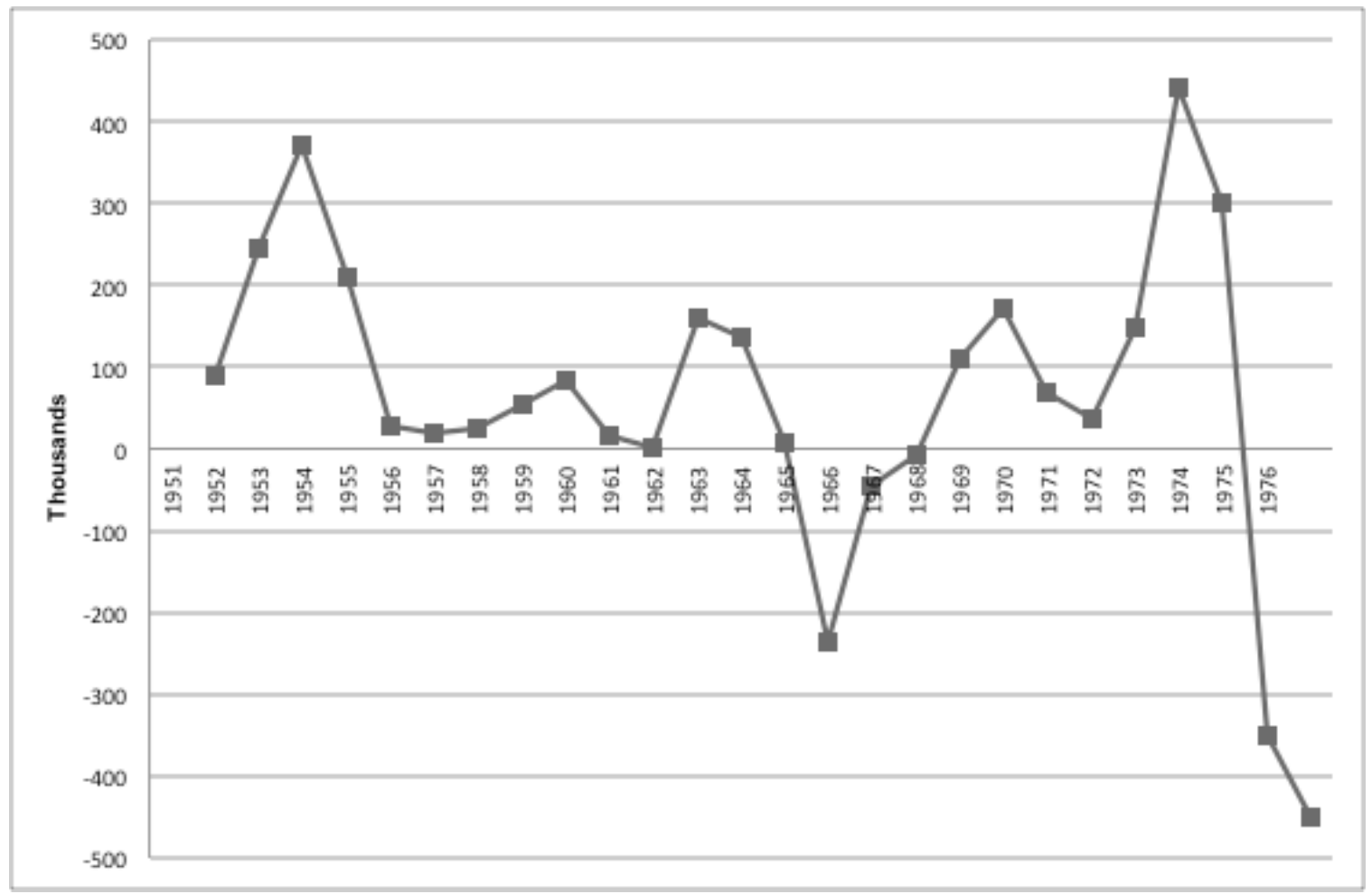

Note: CIMA could not maintain profitable production. The figure demonstrates the boom and busts of the mining industry expressed as profits and losses in thousands of U.S. dollars. The higher revenues relate to the discovery of new deposits followed by successive stages of de-capitalization.

Source: Astudillo et al. 1980, 27.

During the 1970s, CIMA requested government support to capitalize the company, renew equipment, and conduct technical studies. ${ }^{270} \mathrm{CIMA}$ was never a

270 "Proyecto Minero," a UN Special Fund project for Ecuador comprised six field activities, called operations. Pierre Goossens was the lead researcher for Operation $\mathrm{N}^{\circ} 4$, its objective being to identify and evaluate silica deposits suitable for glass making. The final report was published in English only and, apparently, not given to CIMA's managers as several municipal communications ask the Ministry for the final mineralogical survey (Goossens, 1967). 
state-owned company but required state support to maintain the social role of the company and its financial viability. The military regime of General Guillermo Rodríguez Lara (1972-1976) issued the Mining Development Act in 1974 and signed a partnership agreement with profound impacts on the performance of the mining company. ${ }^{271}$

The partnership agreement was an operational tool for stimulating investment through geological surveys, equipment and machinery renewal, flora and fauna protection, and the prevention of water pollution. However, the agreement also reduced the concession area to 4,000 hectares, about half the surface granted in 1951, and abolished tax privileges, creating new duties for the company. ${ }^{272}$ The agreement was another policy experiment, uncommon to the mining industry. ${ }^{273}$

The management structure changed significantly. The directive level included a management committee including the director general of mines or his

271 Decreto Ejecutivo № 419, May 20, 1975, in: Registro Oficial, № 813, May 29, 1975, in: Astudillo et al. 1980, 20-21.

272 The new rules created additional expenses, including a 10-cent tax per tonne of ore, 200,000 sucres per year for surface rights, mining royalties based on the ratio between gross profit and investment, and travel expenses, housing, and per-diems for four interns working in the mining industry for at least 30 days. See: Decreto Ejecutivo No 101, December 28, 1973, in: Registro Oficial, N 484, January 31, 1974. 
delegate, who presided and had voting privileges, a representative of the National Geological and Mining Service, two representatives of CIMA, and a delegate of the Joint Chiefs of the Armed Forces. The representative of the army was responsible for organizing and managing the business, supervising ore sales, and verifying administrative and accounting reports. General Rodríguez removed the civil manager and appointed an officer, Infantry Major Daniel Espinoza, as company director.

273 Partnership agreements became more prominent during the 1980 s and 1990 s as both internal and external factors led to the restructuring of the mining sector (Andrews 1998, 119). Internal factors include mergers among multinational companies, new geographies of resource extraction, and lower operating costs. External factors refer to the shrinking role of the state, the rise of interest groups, the empowerment of local communities and indigenous peoples, and the reduced influence of mine labour. 


\section{Photo 8.1. General Guillermo Rodríguez Lara in Portovelo, 1972}

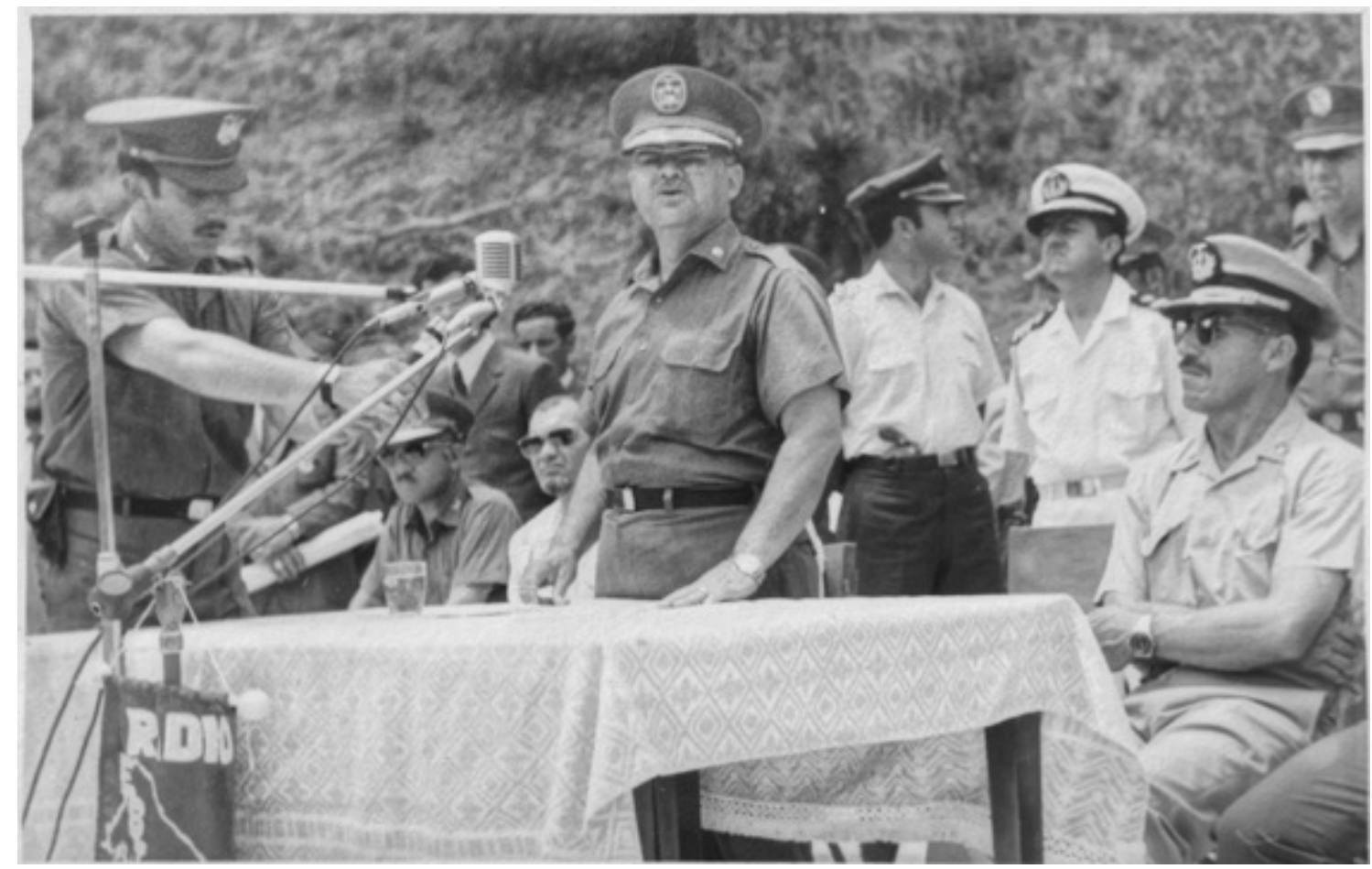

Note: Chief of State General Guillermo Rodríguez Lara at the unveiling of the monument to the Ecuadorian soldier in Portovelo.

Source: AMH/Z. "Intervención del Sr. Presidente de la República," Album Municipal, T. IV, 1966-1978. Panupali, September 18, 1972.

The military had no experience in business management. People recall lavish parties, home renovations, and travel. ${ }^{274}$ The expenditures were the result of the lack of accountability in handling finances, losses in retail sales at the company store, and corruption (Astudillo et al. 1980, 27-29). In addition, the flooding and collapse of several mining shafts in the Soroche vein and the

274 Interviews with residents, see also Astudillo et al. (1980, 30) and Cortázar and Lavanda $(2000,140-142)$. 
Amarillo River - probably linked to inappropriate technical measures and the weakening of underground structures - decreased mine productivity. The provision of free public services - such as health and education - became a matter of financial concern and would eventually be a factor in the company's demise. Trends in the mining business brought an end to corporate welfare in self-sufficient camps and the beginning of state provision of social services.

CIMA was in serious debt to banks. Credit plays a crucial role in providing continuous financing to maintain spending levels in the face of inflation and income erosion (Guttman in: Boyer and Saillard 2002, 60). In Portovelo this process was accompanied by asset deflation. By 1977 CIMA processed only 100 tonnes of ore daily. The company was reporting losses and the mill was in need of costly repairs. The crisis was the result of many things: ancient equipment, lack of geological explorations, corruption, and tensions among shareholders. In addition, subsidies from the central government showed no results, social security had not been paid for over ten years, and miners had not received their wages for almost five months.

The unpaid mine workers declared a general strike on September 3, 1977. Members of the Workers Business Committee and the Workers Union demanded payment of overdue salaries and the nationalization of the company; they 
rejected further subsidies of any kind because, they argued, the funds would be wasted rather than benefitting mine workers. ${ }^{275}$ Workers' organizations, such as CTE, CEOSL, and CEDOC, as well as the Army action plan, supported these demands. Under pressure, the Ministry of Natural Resources and Energy met with representatives to analyze the case. ${ }^{276}$

The General Director of Geology and Mines decided to apply guarantees. All mining concessions and all industrial facilities, transportation equipment, tools, and machinery reverted to the state. ${ }^{277}$ People were not evicted or displaced; the government would not claim any private property. Three years later, on February 12, 1980, the Minister of Natural Resources and Energy officially terminated the partnership agreement for the exploitation and processing of minerals. ${ }^{278}$ The state appointed a mine auditor to undertake an inventory and proceed with the handover of all of the assets and items of value. The Ministry of Natural Resources and Mines would settle all legal and contractual obligations, and the Ministry of Finance and Public Credit would collect outstanding taxes. The Ecuadorian Social Security Institute (IESS)

275 “Trabajadores de CIMA merecen más atención,” El Nacional, [Machala], September 14, 1977, 3.

276 The Joint Committee included members of CAP (Arturo Aguilera, Norman Orellana, Aldo Alvarado), the Civic Junta (José Tinajero), the municipality (Guillermo Cely Romero, Germán Gallardo Cabrera, Rubén Sánchez), and the workers (Marcos Cabrera, Ángel Pacheco, Íntimo Cisneros). See: "Viajó Comisión de Portovelo," El Nacional, [Machala], September 15, 1977, 2.

277 The decision was based on article 73 of the Mining Development Law of 1974. 
embargoed the Hacienda El Tablón. Sauer (1980ca) reported, "it is doubtful if any operation will be resumed on a large scale... You might as well burn your stock if you have any in your portfolio."

SADCO's departure had been difficult, but even more traumatic was CIMA's dissolution. During an interview, a mining engineer working for the state recalled citizen opposition to ministry control of the gold mines; there were marches, dynamite blasts, traffic barricades, and industrial stoppage to oppose this from taking place. ${ }^{279}$ The state would eventually continue operating some of the mines until 1986, but the industrial enclave totally collapsed. There was chaos, dispersion, and misuse of industrial assets, which were confiscated, illegally sold, or simply disappeared from the camp. According to an interviewee,

...with bankruptcy came a kind of looting. Although the military were guarding the property, the facilities suffered the consequences, like the mill, which had been one of the best in America. Houses were dismantled, everything was a true disaster. Here in Zaruma nothing happened, but bad things happened in Portovelo. ${ }^{280}$

280 Interview ID-2012-04 (male, Zaruma) 


\section{Photo 8.2. Destruction of industrial facilities, circa 2000}

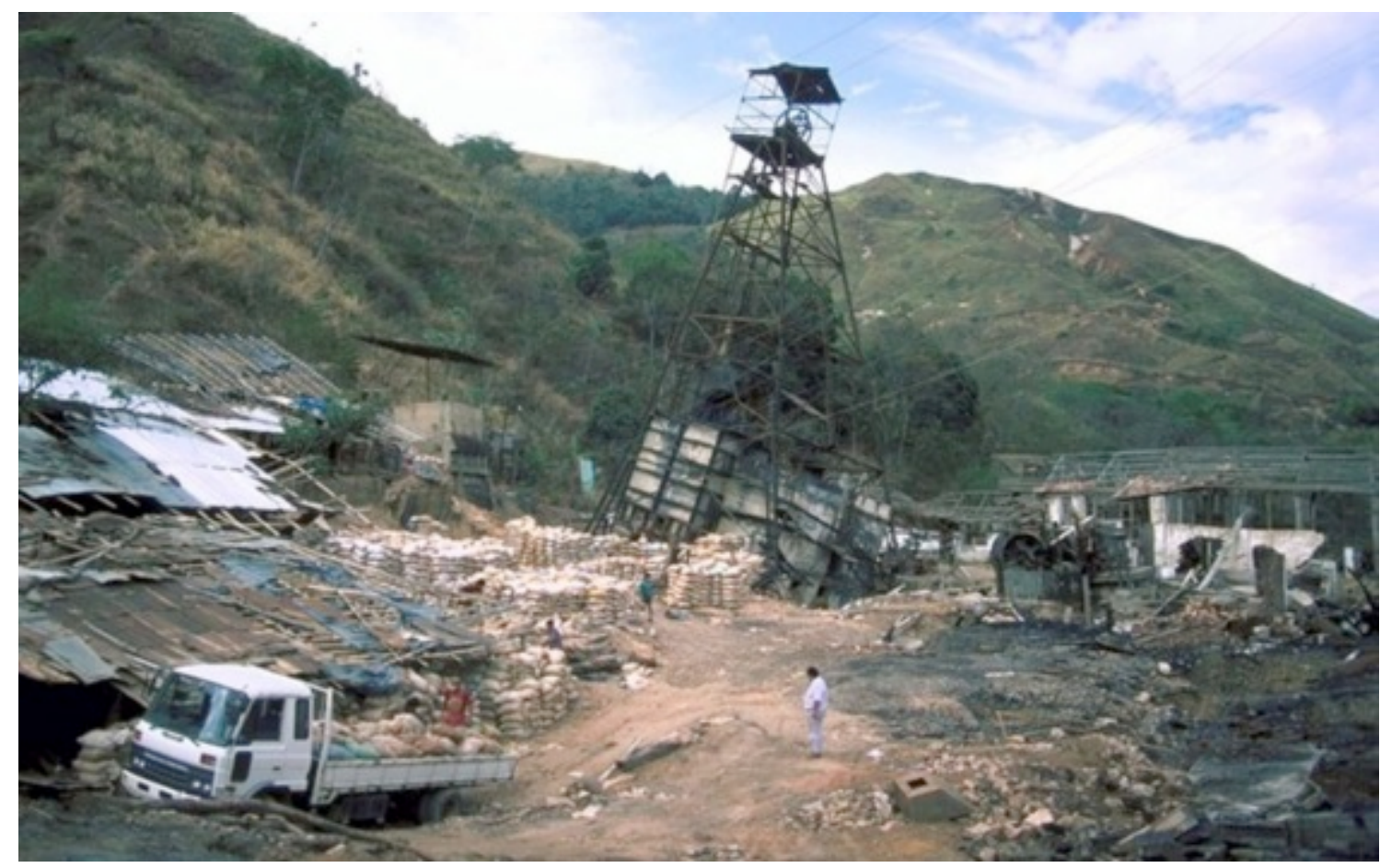

Note: The illegal occupation of the American industrial complex and the proliferation of artisanal mining are commonly perceived by interviewees as a time of destruction, looting, and loss of identity.

Source: "Leyendas y tradiciones de Portovelo," Gobierno Autónomo Descentralizado Municipal de Portovelo, photogallery, accessed February, 2015, https://www.flickr.com/photos/53199817@N03/

The greatest source of nostalgia among residents pertains to the progressive dismantling of the Pique Americano. The American Head shaft had been the pride of the industrial facilities. Shortly after, the Zaruma and Portovelo gold district resembled "gruyere cheese." 281 Sandoval $(2001,3)$ reports, "the illegal occupation of the concessions abandoned by CIMA was a response to 
unemployment and the crisis the mine workers were going through, which was frequently encouraged by metals speculators who financed equipment and inputs." The miners carved the earth without studies, guidance, or management. This process was followed by the emergence of new installations that offered services such as crushing and beneficiation plants that dumped tailings into the aquifers, producing severe contamination.

The Portovelo enclave was thus dismantled. There was a sharp difference between the withdrawal of SADCO and CIMA's collapse. The obsolete machinery was worthless, the government took over the mines and did not compensate the miners while allowing artisanal and small-scale mining to continue and shifting responsibility to local actors. In addition, the transition to democracy and the writing of a new constitution delayed the liquidation process, further aggravating the plight of the mining camp. This process gave way to a period characterized by the spread of artisanal mining throughout Ecuador. ${ }^{282}$

282 The Portovelo miners explored other mining districts, discovering the rich gold ores of Nambija, in the Amazon Region, and in Ponce Enríquez, north of Portovelo (Guerra 1987). Some of them formed cooperatives and members of these joined forces to establish companies with capital from commercial and agricultural interests. Others followed the gold rush, living in shanty towns and working in hazardous conditions characterized by total disregard for health, safety, and environmental protection (Appleton et al. 1999; Lovitz 2006). Artisanal miners in this period were mostly former CIMA employees or members of their families. 


\subsection{The politics of space and resource regulation}

A state's territoriality is not a fixed asset, the pre-given or pre-destined basis of the nation-state (Jessop 2008). The concept of territoriality, as formulated by Sacks $(1983,55)$, is much more, involving the "attempt to affect, influence, or control actions and interactions (of people, things, and relationships) by asserting and attempting to enforce control over a geographic area." Such a definition provides insights into territoriality as action, and this action is not limited to the state but, rather, embedded in social relations that can be partially stabilized in time and space. In this vein, the economic prosperity of the lowlands resulted in greater reliance on intermediaries able to lobby for the redistribution of national revenue. The emergence of populism favoured electoral clienteles and bureaucratic-authoritarian regimes created greater dependence on technicians and public officials involved in national decision-making. In the meantime, in Portovelo, de-industrialization reconfigured power relations among local elites, social movements, political parties, and institutional actors, all establishing their own spatial range of action.

The paradox of localized de-industrialization, as explained in the previous section, and national economic growth indicates the absence of coordination among processes of development at different scales. Throughout Ecuador, the production of bananas for export led to an economic bonanza, the expansion of the domestic market, and a strengthening of the state apparatus. From 1940 to 1952 exports increased from US $\$ 10$ to US $\$ 79$ million while imports increased 
from US $\$ 11$ to US $\$ 56$ million (Quintero and Silva 1991b, 8). Public investment increased from $16 \%$ of the national budget in 1950 to $22.5 \%$ in 1955 , and the GDP increased 4.4\% between 1960 and 1969 (Ojeda 2000; Ramón and Torres 2004, 104). Public investment improved connectivity between Quito and Guayaquil, which promoted regional development but also intensified regional inequalities (Deler 1980). The state provided credit for industrial development, rural modernization, and the expansion of the agricultural frontier.

By the mid- $20^{\text {th }}$ century, municipalities took on the role of development corporations for the provision of local public services. The Municipal Regime Act of 1945 significantly increased the functions of local governments and promoted the "municipalization" of electrical energy generation and distribution, public transportation, water systems, and telephone networks. ${ }^{283}$ The 1946 Constitution introduced rules on the fiscal autonomy of municipal governments. In addition, the government's focus on development led to centralized planning supported by regional development corporations. Ramón (2004) argues that the existence of autonomous corporations required negotiation with regional elites and led to the duplication of efforts by different levels of government, both features detrimental to national integration. However, I argue that these very same processes constituted a milestone in the formation and consolidation of the Ecuadorian 
unitary state. To mitigate disputes and build clienteles at all scales across the political spectrum, the state created new provinces, counties, and parishes. ${ }^{284}$

This was the result not only of historical legacy and population growth, as noted by Pierre Gondard (2005), but also of the politics of space (Lefebvre 1991, 2009).

\subsubsection{Differential articulation with the development state}

CIMA was seldom able to achieve decision-making independence from national and municipal authorities. The mining company was not a state-owned enterprise but depended on state support and subsidies. ${ }^{285}$ The Portovelo mines were marginal to the national economy and local officials began their "pilgrimages to Quito" to deal with administrative and political obstacles to the granting of financial resources for public works. The local representatives would go from office to office, patiently dealing with government bureaucrats. During their travels, local representatives developed networks with national authorities as well as legitimacy at the local level. This process could be seen as a way to connect levels of government, but also as a means to discredit and reinforce the

284 To this effect, the most prominent regulatory frameworks of this period include the 1945 and 1966 Municipal Laws, the 1960 Special Law for the Oriente, and the 1968 Rural Parishes Law.

285 In 1952, the government authorized CIMA to invest liabilities for up to 407,970 sucres, to resolve social and economic problems in Portovelo. In 1955, the municipality of Zaruma's 875,000 sucres debt for the portion of the shares (35\%) it had acquired in CIMA was forgiven because it had invested similar amounts in providing potable water for Portovelo and Barrio Machala and in other public works. See: Decreto Ejecutivo No $518-\mathrm{G}$ in Registro Oficial No 781, December 8, 1952, and Decreto Legislativo in Registro Oficial, January 1, 1955, in: Cortázar and Lavanda 2008, 130-131. 
specificity of each niche. Given their dependence on the central government, regional elites were no longer in a position to promote separatist movements or even a federal state; instead, they contributed to the idea of a united, corporate state.

Routine and seemingly inconsequential events are, in fact, important moments defining the substance of administrative relations between the municipal and the national government. For example, in 1951 the mayor of Zaruma traveled to Quito to meet with the minister of economy to expedite the decrees for CIMA's creation and operation. The minister transferred the request to the Legal Department and authorized local officials to draft the documents. However, municipal officials reported setbacks, giving "the impression that [the lawyers] were blocking the process. Faced with this situation, we tried to interest them by offering a tip to facilitate their work, managing thus to get the three decrees drafted." ${ }^{286}$ Subsequently, the decrees were delayed by administrative procedures. Given this kind of situation, local bureaucrats became involved in national decision-making and corruption during their many trips to the capital.

Until the 1970s, a round trip from Zaruma to Quito and back took nearly a week. High administrative costs, frequent delays on the part of national authorities, and personal commitments preventing travel turned the process of 
lobbying for national funds into a long, drawn-out affair. The municipality eventually hired lawyers, and tramitadores - private individuals who specialize in cutting through red tape - and resorted to "tipping" public servants to expedite bureaucratic processes. In addition, the municipality paid a group of zarumeños living in Quito to facilitate political contacts, a tactic that became possible as emigration increased. This practice created to a group of intermediaries and politicians with tight connections between the national capital and rural locations.

Machala and Guayaquil also acquired a prominent role in local decisionmaking insofar as taxes, loans, and profits began to be managed by public and private banks located in those cities. ${ }^{287}$ The municipality received public funds in the form of checks drawn on the Central Bank branch in Machala. Those funds were then transferred to accounts in private banks in Guayaquil. In addition, individual shareholders also deposited their profits into accounts at the Banco La Previsora of Guayaquil. Because it lacked operating capital, CIMA requested loans to continue mining. By 1977, the company owed 2.1 million sucres to the Banco Nacional de Fomento (Astudillo et al. 1980, 73). Currency flight

286 AHM/Z. MMC, T. 55, June 22, 1951, 203. 
decapitalized the region and hastened the decline of the mining industry insofar as financial capital had no interests in the area.

Changes in production and differential articulation with the capitalist economy changed the regional positioning of the mining district within the country. Elites from areas at the higher altitudes of El Oro Province lost legislative seats and access to national decision-making. At the same time, the emergence of social movements and political parties created alternative networks amongst subaltern groups. The absence of a hegemonic group or a single corporate agent gave way to a new territoriality expressed through the dispersion of artisanal mining, the urban concentration of public works, and the designation of Portovelo as an independent parish.

To counter industrial decline, the state established public agencies and programs to promote agriculture. ${ }^{288}$ Development projects, the opening of roads

287 Machala consolidated its role as the capital of the province with strong links with exportoriented agriculture, financial elites in Guayaquil, and transnational companies such as United Fruit. This process also reflects a shift in economic power from the Sierra to the Coast as well as changes in the labour regimes (Striffler 2002).

288 Some of the entities established include the Banco Nacional de Fomento (National Development Bank), the County Agricultural Center, the National Federation of Coffee Cooperatives, the Bank of Machala, and others (Rueda and Romero 2002). 
to rural parishes, and the allocation of land through land reform policies ${ }^{289}$ were instrumental in dealing with the economic depression. In the lowlands of El Oro Province, banana and pineapple plantations and shrimp farms were established, while in the highlands, small farmers engaged in subsistence agriculture. ${ }^{290}$ In the Zaruma area, local and the provincial authorities encouraged coffee, cattle, and milk production, and farmers continued to grow traditional products such as sugar cane.

289 In 1964, the military junta issued the first Agrarian Reform and Colonization Law and established the Instituto Ecuatoriano de Reforma Agraria y Colonización Ecuadorian Institute of Agrarian Reform and Colonization). In 1972, General Rodríguez Lara signed a new Agrarian Reform Law that emphasized the regionalization of land redistribution which had a particular impact on the coastal lowlands, the Amazon region, and the southern region of Ecuador. For discussion of the implications of the agrarian reforms, see: Barsky 1984; Chiriboga 1988; Gondard and Mazurek 2001. For a detailed study of banana plantations, see: Striffler 2002; Larrea 1987.

290 In upper section of El Oro Province, peasants had loose community organizations and occupied farms widely scattered over vast territories, unlike the densely populated spaces of the northern highlands of Ecuador (Fauroux 1984). There were few indigenous people in El Oro, most of them Saraguro from the nearby provinces of Loja and Azuay. 
Figure 8.5. Total provincial gross value of the primary sector by product and type of landscape. Province of EI Oro, 1974

\begin{tabular}{lrrr}
\hline $\begin{array}{l}\text { Sector and } \\
\text { subsector }\end{array}$ & Lowlands & Highlands & Province \\
\hline \hline Agriculture & $119,454.0$ & $4,536.9$ & $123,990.9$ \\
Banana & $106,103.2$ & 442.1 & $106,545.3$ \\
Cacao & $5,249.6$ & 583.3 & $5,832.8$ \\
Coffee & 406.5 & $1,045.2$ & $1,451.6$ \\
Sugar cane & 464.1 & $1,083.0$ & $1,547.1$ \\
Beans & 24.2 & 24.2 & 48.4 \\
Cassava and & & & \\
vegetables & 640.3 & 449.6 & $1,089.9$ \\
Corn & 625.4 & 705.2 & $1,330.6$ \\
Other & $5,940.7$ & 204.4 & $6,145.0$ \\
Livestock & $1,369.4$ & $1,346.8$ & $2,716.2$ \\
\hline Cattle & $1,131.8$ & $1,131.8$ & $2,263.7$ \\
Domestic animals & 237.6 & 215.0 & 452.5 \\
\hline Fisheries and & & & \\
shrimp & $23,366.9$ & - & $23,366.9$ \\
\hline Mining & - & $4,019.8$ & $4,019.8$ \\
\hline Total & $144,190.3$ & $9,903.5$ & $154,093.8$ \\
\hline
\end{tabular}

Source: Predesur 1980, T.3, 253 and 257.

Modernization of the rural sector transformed social and political relations.

The agrarian reforms of 1964 and 1973 favoured the acquisition of small plots.

The Ecuadorian army influenced the way in which the agricultural frontier was settled in El Oro, a strategic province occupied by Peruvian forces in 1941 (North 2006). Peasants, miners, and local entrepreneurs invested in coffee plantations, 
allowing rent captures and becoming a new interest group. The Zaruma Coffee

Festival became a nation-wide celebration that brought together small producers from all over the country. It could be argued that coffee was one of the few cash crops produced by small farmers that provided resources to meet their basic needs (Castillo and León 1979; PREDESUR 1980, T.9). The diversification process led to a reduction in the number of political representatives of the mining sector and an increase in representatives of the cattle and coffee sectors.

The developmental state adopted import substitution policies and fiscal reform to centralize tax collection, an administrative reform to rationalize the public sector, and a national planning system to streamline public intervention. The state also adopted norms establishing the rights and responsibilities of pubic sector employees (1952) and created the Junta Nacional de Planificación y Coordinación Económica (JUNAPLA, National Planning and Economic Coordination Council), in 1954. This institution had a central role in national planning and promoted autonomous corporations in order to generate support mechanisms for regional development. ${ }^{291}$

291 The first was the Center for Economic Conversion Azuay (CREA, 1958) created in 1958; subsequently, the following were created: the Board for Reconstruction and Development of Loja and Morona Santiago (1961), the Reconversion Center of Manabí (CRM 1962), and the Center for the Development of the Guayas Basin (CEDEGE 1965). Initiatives for the southern provinces of El Oro, Loja, and Morona Santiago will later be joined in the Regional Programme for the Development of Southern Ecuador (PREDESUR), created in 1980. 
Ecuador, like other Latin American states, applied centralized measures to maximize revenues and the redistribution of wealth; these included nationalization of resource-extractive industries (Reed 2002), higher taxes and royalties, and limits on the repatriation of profits (MMSD-IIED 2002). These measures were adopted simultaneously with the emergence of post-Fordist industrialization and urbanization, the expansion of domestic markets, the generation of added value, the formation of fixed capital through infrastructure, and the export of industrial products. In this context, exploration for and exploitation of raw material was a response to growing international demand for commodities.

State intervention included direct control of strategic economic sectors, such as hydrocarbons. In Ecuador and elsewhere, oil was considered basic to nurture the state and large-scale industrialization through vertical specialization and integration in world trade (Grebe 1985). Socialist regimes and nationalist democracies were seen as a challenge to US imperial claims in the region and resource wealth facilitated the consolidation of authoritarian governments (Wantchekon 2002). Argentina, Bolivia, Brazil, Chile, Ecuador, and Peru were ruled by dictators, and these regimes opened markets, liberalized labour, and quashed any resistance. While many of the reforms mentioned were not directly intended for Portovelo, the model was accompanied by a nationalist, modernizing discourse; the objectives were integration of domestic space and direct control of industry. 


\subsubsection{Self-determination and the search for a new institutional fix}

The "municipal" mining enclave became a space of political struggle for self-determination. ${ }^{292}$ Harvey (1989) notes that any attempt to democratize and disperse political power entails some kind of spatial strategy and a politics of space and place. Zaruma, as a county, had a multilayered system of rule composed of the municipality, an autonomous authority representing urban local elites; agents of the central government who protected national interests and enforced regulations; and CIMA, ruled by an unstable coalition of workers and municipal government representatives. The miners wanted Portovelo to be independent of Zaruma in order to increase its social standing and political decision-making power. This was not an isolated aim. In Ecuador, the restructuring of national and local powers linked to economic phenomena such as the banana boom and political trends such as Velasquismo resulted in a new administrative territoriality. Between 1940 and 1970, the state created 306 rural parishes and 43 counties, an increase of $39 \%$ and $33 \%$, respectively. ${ }^{293}$

292 The foreign company had been the main obstacle to turning the camp into an independent administrative jurisdiction. The Americans used existing systems of power to back social control, as explained in the previous chapter. It was easier to control the work force through patron-client relations, coercion, a high turnover of the electorate, and the cooptation of representatives on the municipal council.

293 This figure corresponds to the date of constitution of each jurisdiction, according to the information published in the Registro Oficial. 
Figure 8.6. Coat of arms of the county of Zaruma

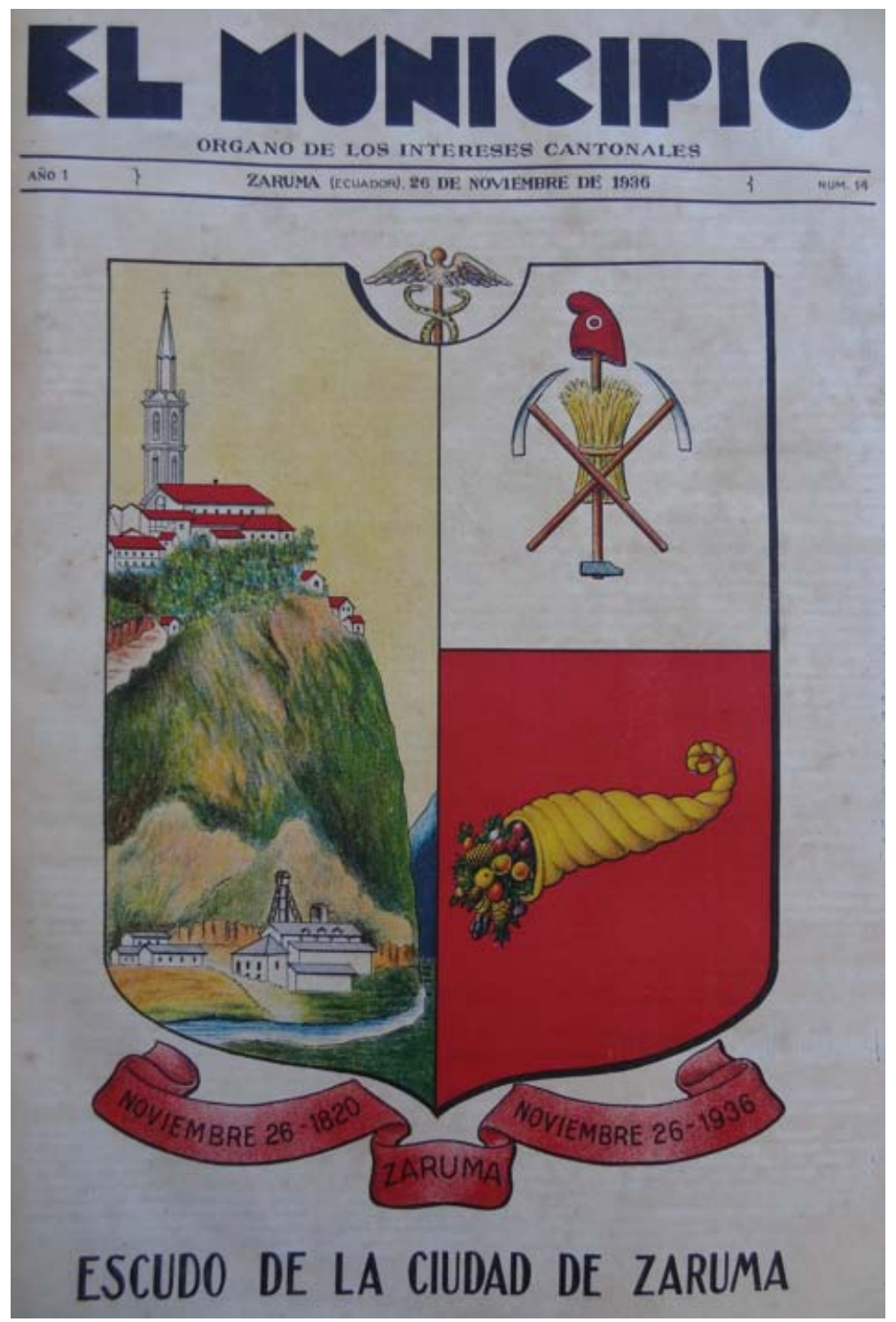

Note: The coat of arms of Zaruma was transformed for the anniversary of its foundation during the mid-1930s. The motto reads: November 26, 1820 - Zaruma November 26, 1936. The identity of the county was forged in the tension between the colonial villa of Zaruma, the mining enclave of Portovelo, and agricultural production in locations such as Piñas. Each of these places would become an independent jurisdiction throughout the twentieth century.

Source: AMH/Z. "Escudo de la Ciudad de Zaruma," El Municipio, [Zaruma], November 26, 1936, 1:14, 1. 
From a historical perspective, administrative boundaries and jurisdictions have to be understood as a legacy of the Spanish empire (Gondard 2005). Since independence, successive processes of centralization, decentralization, civil war, international conflict, populism, and dictatorship changed the spatiality of the state and the political landscape. After the war with Peru, in 1941, pride in national territory was exalted through civic expressions, ideographic symbols, and claims to self-determination and sovereignty (Jonhston, Knight, and Kofman 1988; Radcliffe and Wetwood 1996). The Ecuadorian state initiated a policy of fronteras vivas (living borders) that facilitated the colonization of the Amazon basin and the creation of administrative jurisdictions. By the late-1960s, the territoriality of the state became a political category to be distributed, bordered, controlled, and disputed through local politics. Throughout this process, the roles and functions of administrative areas were mediated, negotiated, redefined, and/or imposed, resulting in ever-changing forms of geographical organization and in territorially shifting forms of governance ${ }^{294}$ As Lefebvre argues, there was a politics of space because state space was, in itself, political. 


\section{Photo 8.3. Zaruma's Children Battalion during the war with Peru, 1941}

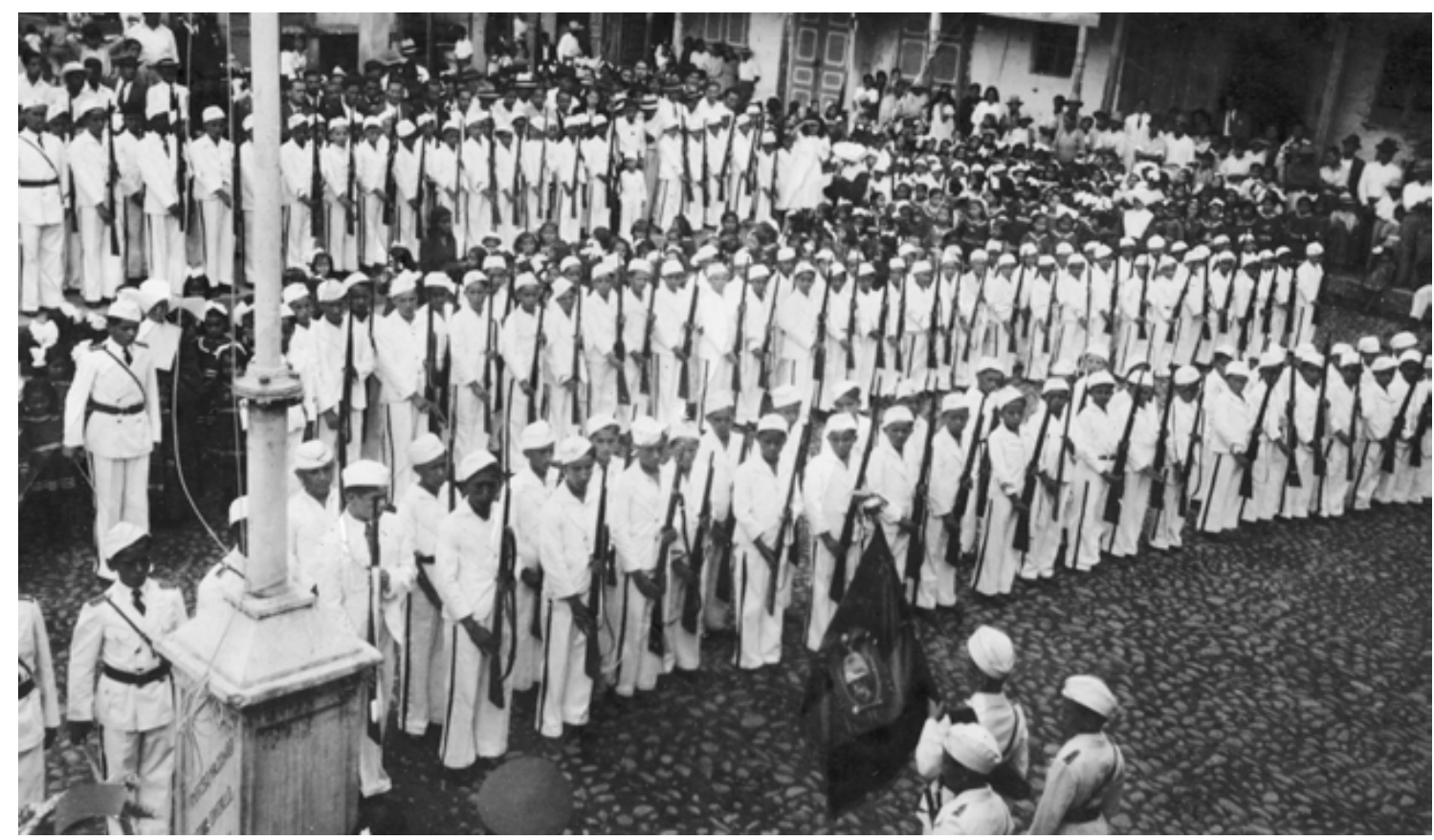

Note: Nationalist sentiments were expressed through civic demonstrations. For example, the Children's Battalion composed of students in the upper grades of the Municipal School. Here they wear white military uniforms with red trim and carry wooden riffles as they take the oath of allegiance during the civic events of November 26, 1941. The Peruvian invasion had a deep impact on collective memory in southern Ecuador.

Source: AMH/Z. "Batallón infantil del Centro Escolar Mpal," Album Municipal, T. I., 1931-1944; Cevallos 2011, 96. Photographer: León Jiménez Ramírez, 1941.

The first attempt to create an independent jurisdiction involved moving the offices of the Catholic vicariate from Zaruma to Portovelo. ${ }^{295}$ The citizens of Portovelo had relative autonomy in appointing religious representatives since

295 The departmental capitals had an ecclesiastical archdiocese, the provincial capitals had a diocese, and major cities maintained an apostolic vicariate. Zaruma was one of the few counties that had an apostolic vicariate due to the longstanding importance of the colonial villa but the camp had only a church and a priest. 
SADCO had donated all religious property and the miners paid — through deductions from wages - for all services. Jorge Guillermo Armijos, the new priest who supported the miners, achieved the transfer. The Catholic community of Zaruma, led by Clemencia Carrión de Maldonado, was outraged. From her perspective, the priest's action was political and she accused him of working with the proletariat for personal interests. The parishioners appealed to the local government as the political entity able to defend what they considered the interests of the entire county to intercede with the provincial archdiocese of Loja.

The central government gradually extended its geographical reach, with overlapping systems of rule and partial control in southern Ecuador. Loja continued being the source of social, religious, and judiciary influence for the upper counties of El Oro, and Zaruma was the source of income for the Catholic Church in the region. The municipality responded to the congregation's request by organizing a joint trip to Loja. ${ }^{296}$ Upon arrival, the bishop of Loja noted that the relocation was a secondary administrative act, a transient request, not intended to affect Zaruma's religious community. He questioned the cleric; his specific duties required explaining theological matters, not meddling in politics. ${ }^{297}$ The issue might seem a minor local problem, and it barely registered in administrative records. Nonetheless, it demonstrates a subtle transformation in the

296 AHM/Z. "Cambio de la Vicaría de Zaruma." MMC, T. 55, March 4, 1951, 119-121. 
administrative ordering of space and internal tensions in the enforcement of moral values despite efforts to separate the state apparatus from the religious institutional structure still prominent in southern Ecuador.

Still, Portovelo's desire for political independence from Zaruma remained an issue for years. As a resident recalls,

promises, more promises, but no one cared until 1967 when the sons of Portovelo, who were returning form the capital city, from Guayaquil, Quito, Machala, Cuenca. They came back prepared. They organized and met for a night of drinks, friends, and laughter, a group of older people with Gonzalo Díaz Aguilar, and formed the Comité Pro-Parroquialización de Portovelo. ${ }^{298}$

The story is far more complex than an informal manifestation of reactionary resistance to the municipal administrative practices. Lefebvre's $(1991,281)$ analytical insights suggest that the fragmentation of space underpins the restructuring of socio-economic relations and institutional arrangements as each new form of political power introduces its own partitioning of space.

Equity participation in the mining business created internal hierarchies and placed the labour force in a position of being both workers and partners of the

297 AHM/Z. "Comisión a Loja." MMC, T. 55, March 19, 1951, 127.

298 Interview ID-2012-17 (male, Portovelo). 
mining industry. The workers could not protest against their bosses, although miners complained of various hardships: heat, poor ventilation, rough treatment, and the ban on meetings. This internal contradiction led to a new organizing process and demands for labour rights. ${ }^{299}$ The first clandestine gatherings took place in 1955. A group of 22 workers joined the General Workers Union of Pasaje, located in a nearby county, and delegated Máximo Jaramillo as their representative to receive instructions on how to organize and defend their interests. Máximo Jaramillo was somebody emerging from the working class and assuming roles that required knowledge, class-consciousness, leadership, and decision-making capacities. The Partido Comunista Ecuatoriano (PCE, Communist Party of Ecuador) and the Confederación de Trabajadores del Ecuador (CTE, Workers Confederation of Ecuador) provided advice and leadership to organize the work force and draft by-laws. By 1960, Jaramillo helped shape the Sindicato General de Trabajadores Mineros de Portovelo (Portovelo Mineworkers Union) with over 50 members.

299 Some key figures in this process include: Máximo Jaramillo, Expedito Cisneros, Manuel Rogel, José Loján, Enrique Ocampos, Luis Espinosa, Expedito Cisneros, Luis Camacho, Víctor Silva, Vicente Salinas, Jubentino Romero, Jorge Meyer, José Vásquez, and César Villegas. Dr. Victoriano Toledo provided legal advice. See: Astudillo et al. $(1980,68)$ and Interview ID-2012-25 (male, Machala). 


\section{Photo 8.4. Street rally of the Socialist Party during the presidential campaign, Zaruma, 1960}

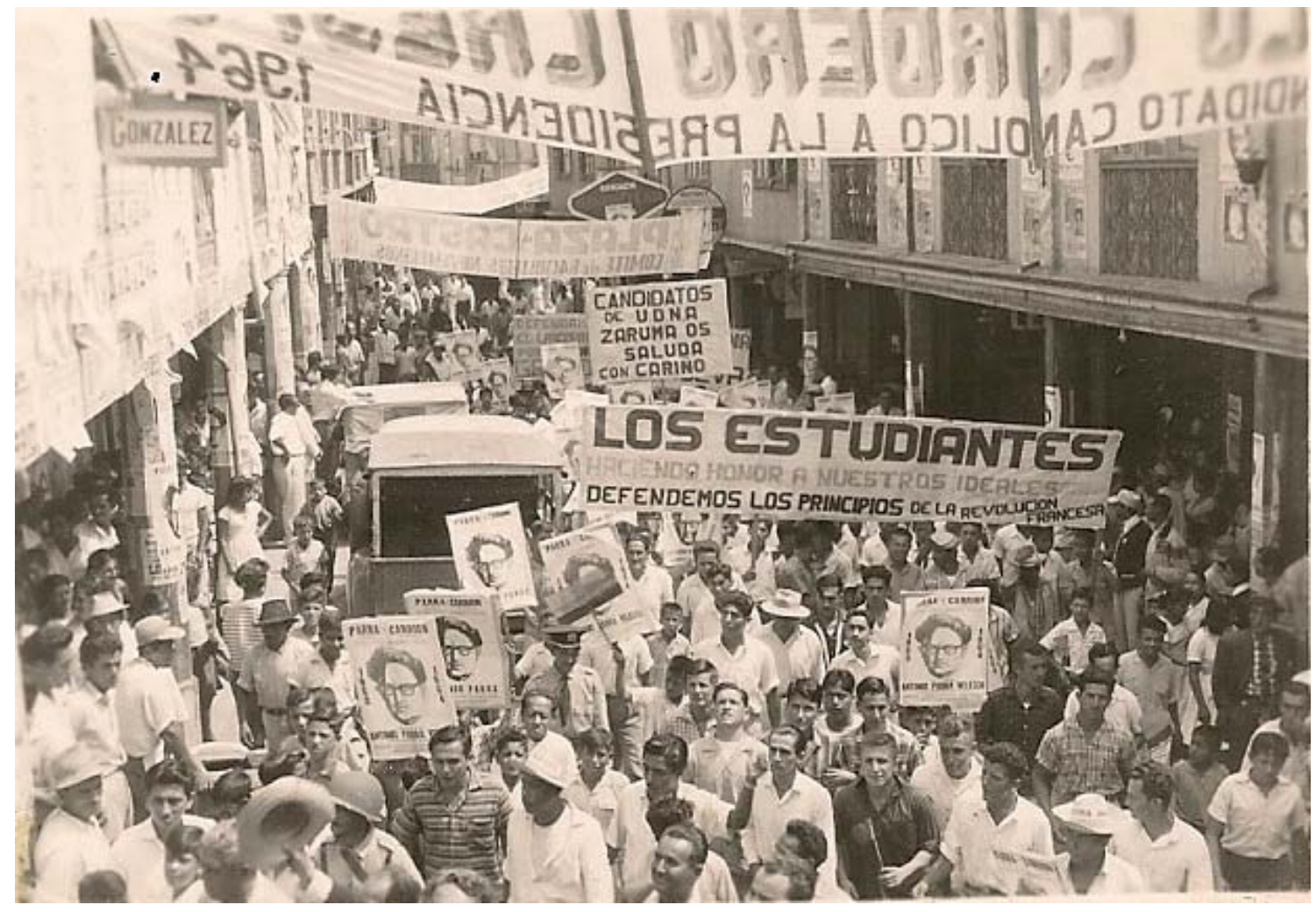

Note: My great-grandfather, Benjamín Carrión, ran for vice president on the Socialist Party ticket in the presidential campaign of 1960. The slogan "Parra-Carrión Revolución" spread as a symbol of hope among workers but the party won fewer than $6 \%$ of the votes at the national level, losing to Velasco Ibarra. However, representatives of the Socialist Party in Zaruma gained strength and won a seat on the municipal council of Zaruma in 1967.

Source: Archive of the Centro Cultural Benjamín Carrión.

CIMA rejected the workers' by-laws, arguing the unfairness of union organizations within a company owned by the workers themselves, and 
dismissed the union leaders. ${ }^{300}$ The firing of union leaders and mechanisms applied to control the work force were similar to the corporate practices that SADCO had implemented years before. Thereafter, some workers sold their shares in order to be free to organize and demand their rights. The PCE established a provincial cell based in Portovelo and Zaruma to support labour demands throughout the southern provinces. ${ }^{301}$ The General Union of CIMA Workers was formally established on August 28, 1966, with Expedito Cisneros as secretary-general. The PCE provincial cell organized workshops on unionism and participated in local elections with favourable results. Máximo Jaramillo became the first workers' representative on Zaruma's municipal board in 1967.

In addition, local governments were experiencing an institutional shift. A military junta ruled Ecuador between 1963 and 1967. The military implemented some progressive policies, such as the first Agrarian Reform (1964), ${ }^{302}$ but also introduced repressive, anti-communist, and authoritarian measures, including the direct appointment of municipal council representatives. In 1967, the return to

300 CIMA convinced the camp priest, Father Armijos Valdiviezo, to organize the citizenry of Portovelo and Zaruma to sign a petition against the union, arguing that many of its members were also shareholders. Oswaldo González, Conservative Party senator, and Luis Pallares, minister of social welfare and labour, supported the manoeuvre (Astudillo et al. 1980, 68-69).

301 CTE and PCE leaders also helped organize the Municipal Workers Union of Zaruma; the Fiscal Public Works Union of El Oro, based in Piñas; the Fiscal Public Works Union of Zamora Chinchipe; the Association of Residents of Huaquillas; and the General Workers Union of Huaquillas. Source: Interview, ID-2012-25 (male, Machala).

302 The law was designed to reduce conflicts and invasions in coastal provinces after the abolition of pre-capitalist social relations and the creation of a rural middle class (North 2006). 
democracy included the drafting of a new constitution that modified power relations among administrative jurisdictions. Municipalities maintained autonomy and rural parishes acquired more responsibilities, including the right to elect a board through direct and popular vote, monitor public services, and oversee funding for public works within their jurisdiction. Elections took place and local authorities took office on August 1, 1967.

The new municipal councillors opposed the previous council. From 1966 to 1967 , the military junta had appointed the city council. Appointees included three members directly linked to the mining camp: Gonzalo Díaz Aguilar, Eduardo Aguilar Romero, and Miguel Armijos Espejo. The nominations were part of long-standing personal bonds between the Conservative Party and the military regiment based in Portovelo since the early 1950s. The transition to democratic rule in 1967 led to personal grudges and retaliation among the then present and former councillors. The Municipal Council, formed by liberals and socialists, attempted to dismiss Dr. Díaz from his position at the hospital; Díaz responded by demanding that the camp be given parish status. Máximo Jaramillo, Socialist councillor and representative of the Portovelo workers, pointed out that when municipal councillors like Dr. Diaz had been in a position to pressure for parish 
status on legitimate grounds, they never raised the issue but that "it's now, due to personal hatreds, that they want to pressure the municipality."303

In fact, economic pressures were also an issue; CIMA reported losses, artisanal mining expanded, and the extended drought affecting the southern provinces of Ecuador created social strains and food shortages. To deal with budgetary constraints, the municipality attempted to increase taxes and charge service fees for housing and commerce. Residents, merchants, and small-scale entrepreneurs complained and joined forces against the municipality.

In January 1968, members of the Comité Pro-Parroquialización de Portovelo (CPPP) sent a petition with 1,033 signatures requesting that Portovelo be declared a rural parish. The municipal government of Zaruma responded with administrative and legal arguments. The Municipal Regime Act established requirements for rural parish status: at least 10,000 inhabitants, of which 2,000 had to be residents of the parish seat and mapped boundaries for the purpose of identifying political and administrative jurisdiction. These boundaries were to be based on rivers, streams, and watershed divisions, and were not to add to or subtract from national territory. Territorial demarcation would change power relations between towns. Zaruma and Portovelo together had only 15,430

303 AHM/Z. "Intervención de Máximo Jaramillo." MMC, T. 76, Acta № 38, May 10, 1968, 165. 
inhabitants; if they separated into two parishes, one of them would have fewer inhabitants than required by law.

Portovelo's request was denied. This made the local population unhappy while the national electoral process favoured temporary alliances. The Communist Party had a stronghold in the area and Velasco Ibarra had always had the support of the mining populace. Camilo Ponce Enríquez, presidential candidate for the Partido Social Cristiano (PSC, Social Christian Party), visited Portovelo on May 5 of that year. The Conservative candidate was for the creation of the new parish. ${ }^{304} \mathrm{~A}$ week later, residents of Portovelo and neighbouring communities joined forces to strike against Zaruma. The action was intended to isolate the county seat by blocking access to it.

High-ranking local authorities had differing opinions about this case. The municipal council reassured the public that it had no intention of hampering the legitimate desires of the local population and suggested forming a committee to proceed with a census and a border study. In addition, statutory requirements had to be met prior to the creation of a new jurisdiction. ${ }^{305}$ The civil judge of

304 In April 1968, rural parishes were declared legal public entities, with the right to hold assets and to perform legal acts. The parish council was expected to work with the city council to develop a joint program of public works, but the parish managed its own budget. Nominations for parish council candidates were scheduled for June 2, 1968. Source: Ley $N^{\circ} 038, C L$, in: Registro Oficial No 348, April 1, 1968.

305 AHM/Z. "En torno a la parroquialización de Portobelo," Sección Municipal, Atalaya, [Zaruma], May 12, 1968, 3. 
Zaruma applauded the people's desire for progress; the creation of a parish would allow for delegating the administration of justice to Portovelo. ${ }^{306}$ Others felt that parochialization would not guarantee, in and of itself, fulfillment of development aspirations. Portovelo needed sanitation, potable water, and roads. In addition, the creation of a parish council would lead to internal divisions. Máximo Jaramillo noted that the working class did not agree with the demand. The company provided free housing, water, electricity, and sanitation; becoming a rural parish would mean paying taxes and fees for basic services. ${ }^{307}$ The provincial governor declared, "We cannot go against them, everyone has the right to improve, we cannot tell them not to move forward." 308 The army was instructed to stay out of the conflict.

The city council opted for a defensive strategy: reasserting municipal autonomy, informing national authorities, requesting military support, discrediting protests, and calling on Zaruma's citizens for support. Municipal authorities asked the justice of the peace, the commander of troops stationed in the district, and CIMA's interim manager to mediate in order to bring about a meeting between the parties. The municipality refused to go to Portovelo, demanding, instead, that a delegation from Portovelo go to Zaruma to discuss alternatives.

306 AHM/Z. MMC, T. 76, Acta No 38, May 10, 1968,162.

307 AHM/Z. MMC, T. 76, Acta No 38, May 10, 1968,165.

308 AHM/Z. MMC, T. 76, Acta No 38, May 10, 1968,166. 
The venue was relevant to the negotiation as the area's particular geography acquired political meaning in this process. This was a struggle between the work force population living downhill in the mining camp and the Zaruma elites living at the top of the hill. The municipal council proposed inviting two delegations, work force representatives and members of the strike committee, to a private session. Portovelo's internal division could be used to favour municipal interests. On the other side, the strike committee tried to force local authorities to come down to Portovelo. Their numerical disadvantage would favour an agreement.

Local residents remember this event as a time of joy and courage; according to one participant, "to get parish status we went to war." opportunity to confront local authorities and redeem the wounds left by the failed mining company. The strike committee began mobilizations on May 11, 1968. Residents took over strategic locations to cut off supplies and isolate Zaruma. The measures included blocking all access roads and securing the bridge with carts loaded with dynamite. The hydro plant was another key post: the strikers cut electric power at dusk. The mines continued to operate partially to avoid additional economic losses. Foreign geologists from the UN Mining Project were detained in Portovelo as a pressure tactic. In addition, the residence of Guillermo

309 Interview ID-2012-17 (male, Portovelo). 
Celi, city council vice-president and one of the main opponents of the new jurisdiction, was attacked with stones during the night. In recounting these events, Portovelo interviewees continue to insist that the forms their struggle took, such as sabotage, were legitimate (Portelli 1991, 52).

On May $13^{\text {th }}$, the Bolívar military squad, commanded by Captain Santamaría, arrived to quell the protests. The company whistle announced the need for support. One interviewee recalls that Emilia Aguilar, mother of Gonzalo Díaz, went through the streets calling the women, "Let's go, let's go, they're breaking the strike." ${ }^{310}$ Everyone met at the bridge. Matilde Vargas wrapped herself in an Ecuadorian flag and began signing the national anthem. The men were behind the women, having agreed to set off the dynamite in the event of a confrontation. The military were confronted with a populace willing to give their own lives to the cause of jurisdictional independence. Capitan Santamaría interceded, taking strike representatives to negotiate a solution with the municipal council. The people of Portovelo followed, joining their representatives outside city hall. The epic memories must be confronted with the official records.

310 Interview ID-2012-18 (male, Portovelo). 
Photo 8.5. Women holding a poster in defense of Portovelo's interests, 1968

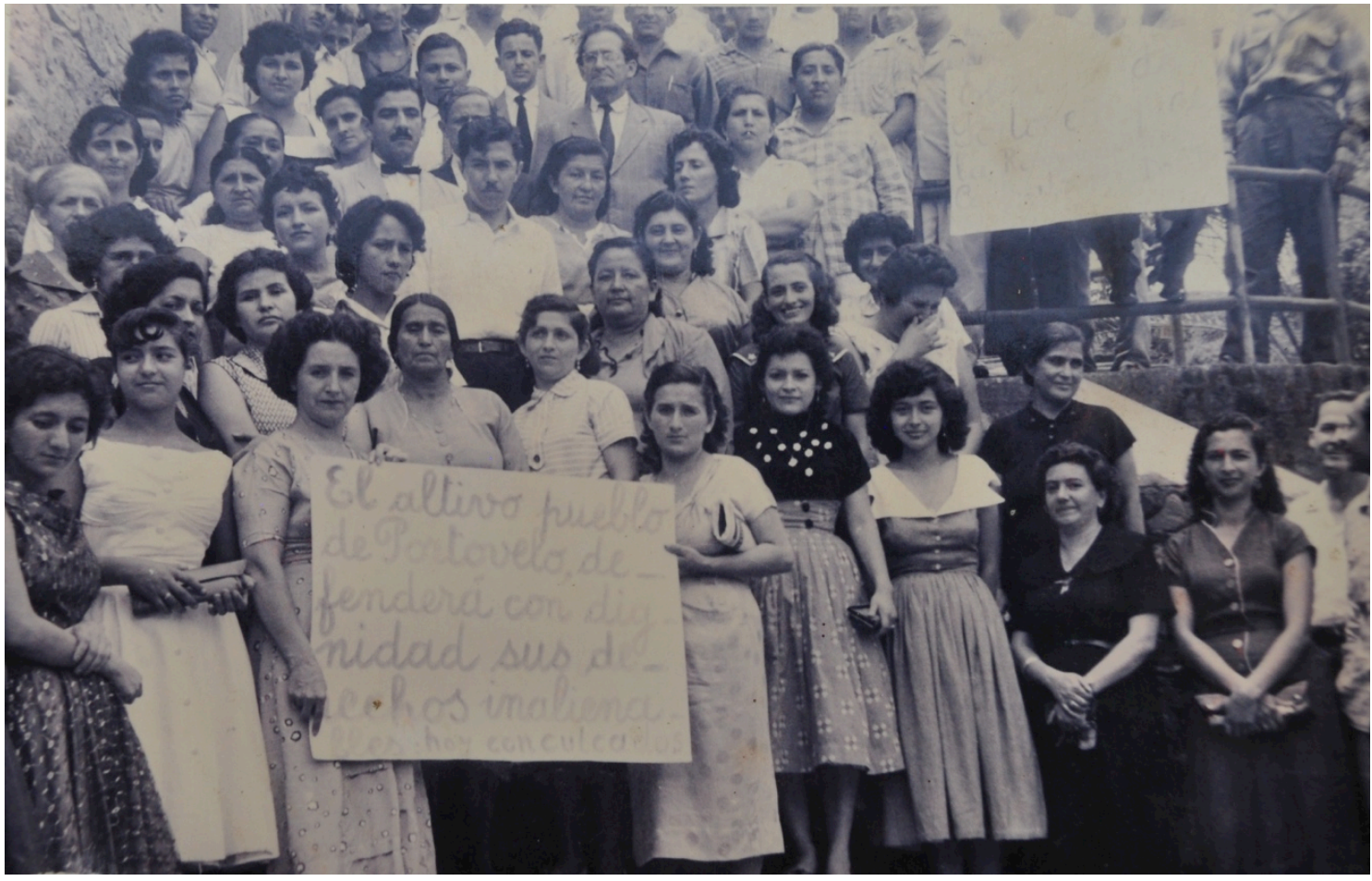

Note: Women of Portovelo were active participants in the demand for jurisdictional independence from the Municipality of Zaruma. The poster reads: "The proud people of Portovelo will defend with dignity their inalienable rights, today violated."

Source: Alex Rodríguez private collection. Photographer: Enrique Rodríguez, 1968. 
The municipal minutes include a plethora of insinuations and delaying tactics. ${ }^{311}$ The city council decided to appoint a joint committee to conduct technical studies to map the new jurisdiction and undertake a census. The committee would begin preliminary work on May 18, to prepare sketches, maps, and aerial photos that would latter substantiate the cartography. The actual fieldwork would begin on July 3, after elections, and the final proposal would be ready by July 30 . The municipal council would have to make a decision and issue an ordinance based on the information mentioned. ${ }^{312}$ In the meantime, the parties agreed that all forms of pressure would be suspended; the responsibility for maintaining public order was transferred to the provincial governor.

However, the municipal council could not come to a decision favourable to Portovelo. Some councillors argued that if Portovelo was recognized as a rural parish it would later insist on becoming a county. Others feared that, in the event of CIMA's dissolution, municipal assets would be transferred to the new parish board. CPPP representatives pushed for including the Calera hydro plant within

311 City council representatives included Guido Sotomayor, Guillermo Celi, Dr. Arturo Aguilar, Angel Espinosa, Eduardo Espinosa, and Máximo Jaramillo. The CPPP representatives were Dr. Gonzalo Díaz, Fausto Redrovan, Juan Zúñiga, Dr. Marco Novillo, Gilberto Macanehy, Dr. Carlos Burneo (legal advisor). Also present at the meeting were the provincial governor, Capitan Santamaría, the municipal secretary, and the municipal solicitor. See: AHM/Z. MMC, T. 76, Acta № 42, May 13, 1968, 205-222. 
the new jurisdiction. Two months later, municipal representatives presented a report arguing that Portovelo did not meet legal requirements for rural parish status. Councillor Aguilar highlighted the benefits of conferring urban parish status on Portovelo; that option included the same budgetary and legal prerogatives as those conferred on all rural parishes. Councillor Gallardo suggested negotiating with the newly-elected Velasco Ibarra administration to suspend, in Portovelo's case, requirements for becoming a rural parish or achieve compensation. Within the municipal council, no one wanted to be called a traitor to Zaruma's interests; therefore they shifted responsibility to the Ministry of the Interior. ${ }^{313}$

Velasco Ibarra was re-elected for a fifth time in 1968; his administration was keen to grant legal status to new jurisdictions. The CPPP appealed to the Tribunal of Constitutional Guarantees and to Congress' Permanent Legislative Committee. The activation of political networks was fruitful and Portovelo became

312 The residents of Zaruma were not happy with the possibility of another territorial cleavage. The municipality supported and funded the formation of the Comite Pro-Defensa de los Intereses de Zaruma (CPDIZ) as a counterforce to the CPPP. Braulio Carrión, former president of the loggers union, appears as CPDIZ's representative. The wealthy loggers, tradesmen, and merchants who had not received shares in the national mining company settled in Zaruma; tensions remained between this group and shareholders for several years.

AHM/Z. MMC, T. 76, July 29, 1968, 314-322 and August 6, 1968, 338-341. 
a rural parish on December 11,1968 . In fact, Velasco Ibarra created 144 rural parishes and 22 counties during his five terms of office.

Figure 8.7. Establishment of rural parishes in Ecuador, 1900-2000

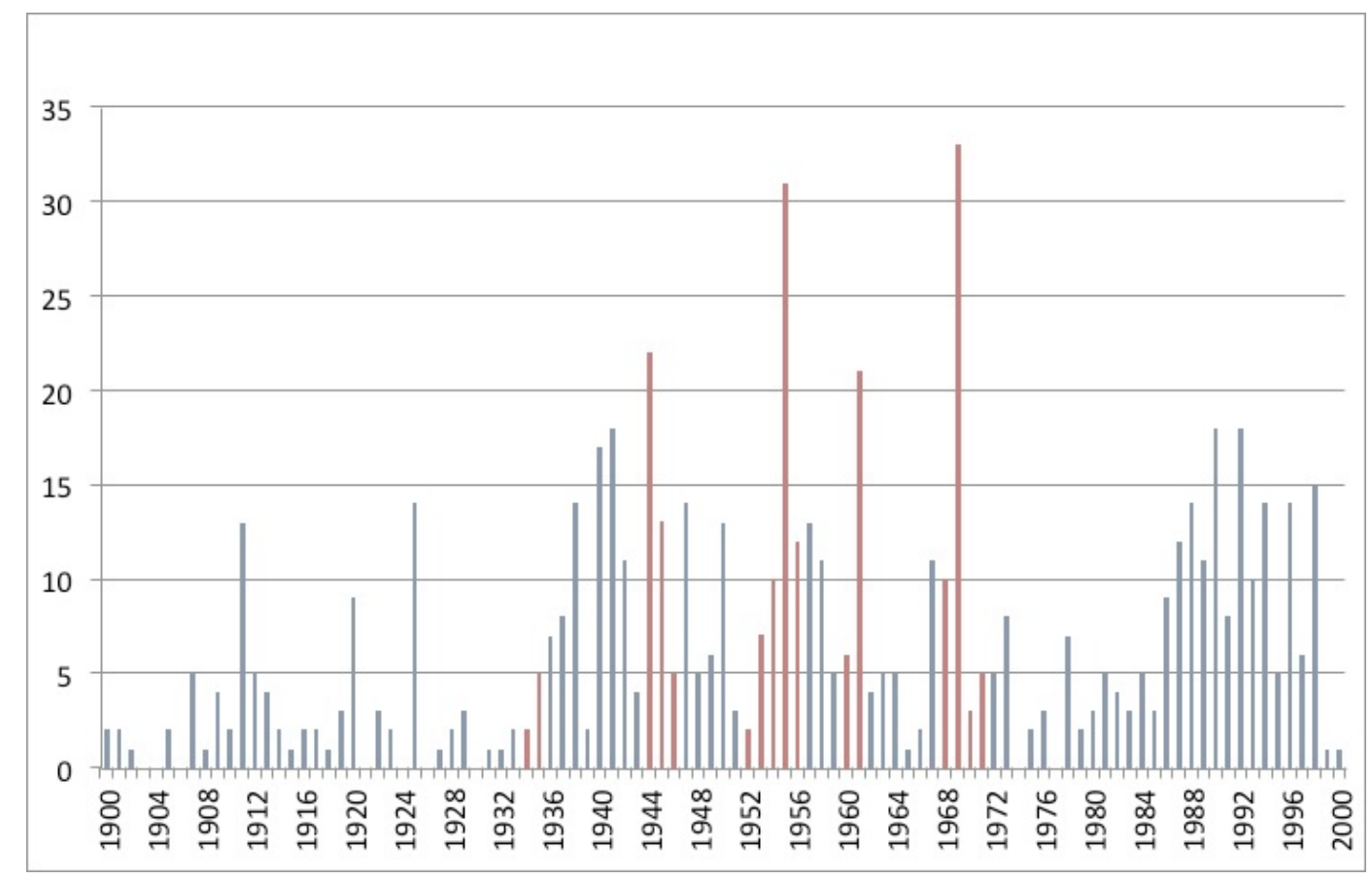

Note: Rural parishes were consolidated as a mechanism of political clientelism and administrative penetration of the central government. The tenientes políticos (justices of the peace) served to control the population in these territories and also to enforce national regulations, integrating caciques into the corporate state. The red columns in the chart indicate the presidential periods of Velasco Ibarra. Currently, Ecuador has 769 rural parishes, 224 counties, and 24 provinces.

Source: eSILEC. Registro Oficial, various numbers.

The process whereby the state created new parishes and municipalities (counties) reflects the diversification of production and the emergence of new social actors. The administrative jurisdictions of the $20^{\text {th }}$ century cannot be explained as the perpetuation of colonial institutions or a centralist desire to grant legal status to local despots and caciques (Deler 2007, 251-255). The incorporation of caciques into populist clientelism and the redrawing of internal 
borders was also a means to consolidate the nation-state. The municipal government was an obsolete institution controlled by the white-mestizo elite, a product of institutional inertia. Acquiring rural parish or county status allowed residents access to national resources, local tax revenues, and local income. ${ }^{314}$

On July 22, 1980, Congress proclaimed Portovelo an independent municipality. The county measures $284 \mathrm{~km}^{2}$, and includes the rural parishes of Portovelo, Curtincapa, and Salati. According to the national census of 1982, Portovelo had only 8,826 inhabitants, far below the legal requirement. The preamble justifying municipalization declares:

Portovelo is currently the necropolis of its rich gold deposits, its inhabitants struggle with poverty and oblivion. ... While the county seat looks attractive, Portovelo has a marked level of unmet needs. ${ }^{315}$

Portovelo was no longer the burgeoning transnational enclave of the Liberal regimes or an "interesting social test" of the developmental state, but rather an independent municipality without fiscal resources immersed in political disputes and allegations of corruption, and responsible for providing services to an impoverished population in a context in which the mining concession had

314 Piñas became a county in 1940 after more than 40 years of struggle with Zaruma to acquire independent political status. Other parishes became counties shortly after: Salati in 1945, Curtincapa in 1945, Huertas in 1948.

315 ABANE. "Exposición de motivos. Informe sobre la petición de creación del Cantón Portovelo en la Provincia de EI Oro. Propuesta de decreto legislativo suscrito por Assad Bucaram, Jorge Fadul, Carlos Falquez, Cleónedes Ollague.” I-79-263, October 1, 1979. 
reverted to the state. The local government would have to deal with the social and environmental liabilities of a toxic industry. ${ }^{316}$ Assad Bucaram, president of congress, ended his remarks on the day Portovelo was declared a county with these prophetic, and somewhat patronizing, words: "I hope, dear colleagues, that you come together to agree on the election of a good parish council, representatives who will always carry in their hearts that affection for their homeland. ${ }^{317}$ This case reflects a national trend to redesign the territoriality of the state, as $40 \%$ of current counties were created between 1980 and 2010 . In the meantime, Zaruma was declared a national heritage site due to its architectural landscape, as an addition to the city's historical memory, and also as a means of attracting financial resources in times of economic decay, when neoliberal restructuring favoured the downsizing of the state and the decentralization of social and environmental externalities.

\subsection{Conclusion}

In this chapter, I explained how decline in production and differential articulation with the capitalist economy changed the positions of Portovelo and Zaruma within the country between 1950 and 1980, in the cycle of expansion of

316 An analysis of this issue is beyond the scope of this work, but can be explored in: Appleton 2001; Loayza 2005; Sandoval 2001; Tarras-Wahlberg 2002.

317 ABANE. "Segundo debate del proyecto de cantonización de Portovelo, Vespertina del Plenario de las Comisiones Legislativas," PCL-79-80-036, Acta Nº 36, July 22, 1980. 
bananas and oil as the dominant staples in Ecuador. The municipalization of the mining enterprise worked, in discursive terms, differently than the nationalization of mining royalties. In this case, there was no direct linkage with national sovereignty, national patrimony, or a common public good. The new enterprise was not an element of modernization or the embodiment of economic development. Municipalization was a political compromise to delay deindustrialization, create local means for subsistence and inspire confidence in other potential American investors in Ecuador.

Brenner $(1997,275)$ argues that shifts in public policies are related to the ongoing reconfiguration of the spatial form of the state under global capitalism embodied in a transformation of the spatial scale on which state power is deployed. This process includes differential roles for state apparatuses and a transformation in spatial form, scale, and location of the targets of state intervention. In this regard, the municipalization of the mine was a complex combination of development policy, populist program, nationalist experiment, and emergent attempts to establish private-public entrepreneurship.

Territoriality is one among many geographical dimensions of state space and the scalar organization and the scalar divisions of state regulation evolve historically. In the case at hand, the production of space at the mining district of Zaruma and Portovelo included the continuous transformation of internal borders and the decentralization of resource governance. In Ecuador, the multiplication of administrative jurisdictions speaks to the restructuring of power relations, the 
transformation of socio-economic patterns, the emergence of active citizenship, and the endurance of local rivalries. The creation of Portovelo as a new jurisdiction did not imply, per se, a decentralization process that could actually empower local levels of government in the regulation of extractive industries. In many cases, the creation of new jurisdictions served to consolidate the central government or negotiate political leadership. 


\section{Conclusion: The spatial restructuring of resource regulation}

The current mining boom has brought back large-scale mining ventures, with the installation of camps that resemble (and yet differ from) the singleindustry towns developed in the $20^{\text {th }}$ century under Fordism. ${ }^{318}$ Mining enclaves are place-making projects; locations where the abstract concept of the "production of space" acquires concrete materiality. However, the company town - as a distinctive kind of space - cannot be mass-reproduced; it is not the same from one location to another. In this dissertation, I argue that the production of the space of the mining enclave must be understood fundamentally through a dialectical analysis able to grasp place-based struggles, multi-scalar processes

and meaningful practices. Through an extended case study of the Portovelo and Zaruma mining enclave, I have explored how institutional forms come into being and/or act to produce particular places as mining enclaves, and how the spatial

318 Canadian, Chinese, and Chilean mining companies, with support from the Ecuadorian government, plan to set up or are already setting up mining camps for projects such as Mirador, Fruta del Norte, Quimsacocha, Rio Blanco, Panantza-San Carlos, and Junin (now known as Llurimagua) (Chicaiza and Yanez 2013; Sacher 2015). At those locations, camps will include housing for workers and industrial facilities, including tillage areas, dumps, sedimentation pools, processing areas, and laboratories. 
restructuring of resource regulation transforms the accumulation regime at different scales.

The most important theoretical contribution of this work is the reassertion of the explicit connection between critical geography and regulation theory. At this point, I want to emphasize that land, property, and ground rents are key concepts within Marxist theory. Despite its Marxist origins, the French school of regulation neglects land-based regulations to focus instead on the institutions necessary for the appropriation of surplus value, such as wage-labour relations, the monetary system, the forms of competition, the international regime, and the form of the state (Boyer 2002, 1990). In this dissertation, I further analyze those institutional forms by acknowledging the importance of understanding their genealogy and variability across scales, while also focusing on the property regime and the territoriality of land-appropriation as a means of regulation necessary for the production of space within (and without) the mining enclave. In doing so, I politicize the spatiality of the enclave to demonstrate its imbrication with processes of state formation, the changing role of local governments, and the multi-scalar levels of governance.

Another contribution is my methodological approach to historical geography: I embrace a genealogical and ethnographic interpretation of regulation. My aim is not to use laws to question legal doctrine, to interpret state actions, or to demonstrate weak institutionalization, but rather to unravel the tensions in the production of space and place. My research contributes to 
understanding the spread, interpretation, and negotiation of mining codes and institutional frameworks in the late $19^{\text {th }}$ and early $20^{\text {th }}$ centuries by linking international trends, national regulations, and local processes. Such an approach includes a politicization and contextualization of the discursive practices whereby the ideological context acquires meaning and builds linkages between structural forms, legal documents, policy debates, and social mobilization. I was able to do this kind of analysis by working through archival materials from different sources and locations so as to explore the intersections among legal texts, municipal proceedings, union records, and the media. This approach makes possible the exploration of how texts come into existence through place-based struggles and how discursive practices create a sense of place, which may be claimed by national regulations and social mobilizations. On the basis of this understanding, it becomes clear that the "mode of regulation" is not an aspatial economic and political intellequia but, rather, something constituted vis-à-vis concrete processes in the production of space.

Here, in this last chapter, I return to my research questions to highlight the main arguments and principal conclusions of my investigation. By way of final reflection, I also discuss some of the implications for current processes related to the expansion of extractive industries in Ecuador and avenues for future research. I will not discuss normative planning policies intended to solve the problems with current processes but, rather, reflect on the importance of space and institutional frameworks for understanding the transformation of place-based social, political, and economic relations related to extractive industries. 


\subsection{Main arguments and contributions to Ecuadorian historiography}

I will revisit the main arguments and findings developed in each of the empirical chapters by making a direct linkage between regulation theory and the production of space. Here I also highlight contribution to Ecuadorian historiography.

Chapter four emphasizes the restructuring of the monetary regime, the transformation of forms of competition at the international and national levels, and their impact at the level of the mining district. In this chapter I analyze how the global expansion of financial capitalism based on the gold standard included not only the technological and corporate restructuring of the mining industry but also the transformation of regulatory frameworks in nations where valuable resources were located. Such a process included geological surveys, foreign expert knowledge, and the spread of laws governing access to minerals. In this chapter, I work with recent contributions to regulation theory pertaining to the diffusion of regulatory frameworks and the mobility and mutation of policy initiatives. In doing so, I am de-centering the power of the nation-state by showing how commodity markets (British, French, and American), rivalries between transnational corporate groups (Vanderbilt vs. Guggenheim), and regional entrepreneurs (investors from Cuenca and Chile) have a say in how foreign investments get grounded in particular mining districts. In the initial stage, the production of space is not a place-making project but, rather, the creation of regulatory conditions that enable the appropriation of land and the flow of capital. 
The state was by no means a coherent entity able to impose national regulations; the agency of particular interest groups in the legislature and the province shaped mining laws within a context marked by cleavage.

From a historiographical perspective, I am suggesting that Ecuadorian scholars demonstrate that state formation during the Liberal Revolution simultaneously included the centralization of decision-making, the penetration of statehood, and the reduction of local autonomy. This matter is developed at greater length in chapter 6 to address how local powers became unable to negotiate directly with foreign capital, and relied on bureaucratic clienteles and philanthropy to retain marginal profits from the mining industry.

In chapter five, I explore the restructuring of the geographical landscape at the regional and urban levels. The construction of a company town is a placemaking project that involves material practices. Research inspired by the regulation approach has promoted fruitful research about manufacturing industries and financial capitalism: however, it fails to address the ethnographic aspect of the production, decline, and spatial restructuring of particular places such as gold mining enclaves. This chapter begins with an analysis of the role played by institutions specializing in law and property matters in structuring resource extraction and its environmental outcomes. I then explore urban governance to address how the capitalist and the territorial logics of regulation yield different urban forms. I demonstrate that the modernizing project of the Portovelo company town is not applicable outside the enclave in spite of - or 
precisely because of - the fact that Zaruma is relatively close to the mining enclave. I move beyond the descriptive account of urban and architectural details - common to the study of single industry towns - to embrace the regional tensions and identity politics that sustain and differentiate Zaruma's beautification project from Portovelo's industrial landscape. In doing so, I also engage with Eduardo Kingman, an urban historian, to demonstrate how policies might work differently in villages than they do in Ecuador's main cities.

In chapter 6 I explain the restructuring of social relations of production at the level of the enclave, and how such a process is influenced by - and also influences - national regulations. The access to wage labour, the hierarchical and gendered division of labour, the adoption of liberal concepts, and racial mixing contributed not only to capitalist exploitation but also transformed the politics of everyday life, brought new political actors into the enclave, and helped to inspire a greater sense of belonging to a national community. Such a process was not free of contradictions. In this chapter, I focus on the agency of the labour movement to explore how collective action was a means of regulating the apparent autonomy of transnational capital, but also contributed to the building of a rights-based nation-state. I contend that institutional strategies as corporate benevolence, patronage, and philanthropy preceded current corporate social responsibility; both are based on the argument that the "best" regulation is selfregulation. 
My contribution to Ecuadorian studies includes recovering the history of the Portovelo mining enclave, analyzing the archival material rigorously, and rescaling this case to politicize its importance for the development of mining regulations and socialist ideas in the country. In studying this case, local historians emphasize chronological accounts, while political scientists tend to reproduce bits of the well-known empirical information. Progressive scholars know about Ricardo Paredes and his book, but none of them has worked to unpack and criticize his stance from a perspective that is able to grasp the genealogy of laws. I argue for linkages between the evolution of the labour movement in Portovelo, the shaping of socialist ideas in Ecuador, and the inclusion of particular claims in national regulations such as the Labour Code of 1938 or the Mining Code of 1937.

In this chapter I also question Velasquismo. Political studies generalize Velasco's period with a meta-narrative of the caudillo and do not work with a multi-scalar approach attentive to its political operation at the local level. I demonstrate how his presence in certain territories helped consolidate his political power at the national scale. This feature of my analysis might seem an overly empirical account, but it has not been explored before. I demonstrate that the restructuring of social relations of production and the regulation of municipal autonomy transformed how political power operated at the local level, giving way to novel forms of patron-client relations and political articulation between the nation's capital and distant localities. 
In chapter 7 I unravel the up-scaling and down-scaling of regulations conditioning the circulation of capital in the mining sector. Mineral stocks are geographically fixed, but mining investments are mobile. The tension between fixed capital, profitability, and revenue sharing is subject to regulation. In this chapter, I explore how the declaration of mineral resources as a public domain is not only a patrimonial and nationalist claim over the underground, but also more broadly related to the up-scaling of mining regulations in Latin America. Leftist governments throughout the region challenged foreign companies. The conflict between states and corporations had a role in the retention of revenues via royalties but also in the shaping of international law. The risk of property seizure gave rise to rules of diplomatic protection for foreign investment. Here I attempt to demonstrate that principles common to current bilateral investment treaties such as state responsibility vis-à-vis aliens and their property, which includes government protection and compensation in case of expropriation - were developed in light of particular place-based struggles. However, when profitability decreases, international capital tends to leave. In those cases, deindustrialization enforces national arrangements to recover the investment and displace the externalities to local levels of governance. In such occasions, the mining enclave becomes an important center of political decision-making, requiring the direct involvement of national authorities.

To date, I have not found any analysis of the genealogy of mining regulations in Ecuador in the early twentieth century (and I have searched extensively, encountering in the process many other valuable sources). The 
regulation approach helps examine the role of discourse in giving coherence to mining laws or making evident their contradictions. During the late 1930s, mining regulations became discursively constructed as a matter of justice, development, and progress through the retention of mining revenues. The state and corporations were powerful actors in achieving and normalizing such concepts, leaving aside the day-to-day impact on local livelihoods. The nationalist claim over underground resources challenged but also facilitated certainty and stability in the accumulation process, further providing conditions for the state to uphold the mining industry despite the threat of subsequent de-industrialization after mineral deposits are exhausted. At a given moment, the means of production effectively became public domain not only as a paper-based regulation, but also as an actual asset of the state. However, the "institutional fix" adopted for the redistribution of these assets represents a paradox that benefits transnational capital while postponing the onset of an employment crisis, decentering the importance of mining from national politics, and transferring social and environmental externalities to local governments.

Chapter 8 addresses the territorial restructuring of state space and its interaction with the mining enclave. Here I come back to Lefebvre's argument that every time there is a change in the dominant mode of production there is a transformation in the territoriality of state space. The administrative divisions are forms of political control that make territories dependent on kinship or bureaucratic networks. The fragmentation of space by the state is a means of 
centralizing revenues and political power while displacing externalities to the apparently autonomous local levels of government.

Pierre Gondard (2005) suggests that the internal bordering of state space in Ecuador - or the specific form of administrative jurisdictions — can be explained as a legacy of past administrative jurisdictions and the demographic evolution of the country. My research contributes to this literature by focusing on the novel exploration of the evolution of the rural parishes in Ecuador from an economic and regulatory perspective. I argue that history, demography, and administrative practices are not sufficient for explaining the role and evolution of

jurisdictions; I therefore add two other components to the analysis: the economic development of particular locations and the relation between local powers with national caudillos. The creation of a new jurisdiction includes the possibility for local elites to control the means of production and retain financial flows.

\subsection{The production of space in the mining enclave}

Upon cursory inspection, the Portovelo gold mining enclave appears to have been designed by transnational capitalist actors. The industrial facilities ensured the outflow of national wealth; the socio-spatial segregation reinforced distancing from the local society; the regional differentiation was functional to the extractive process; and the international arena reasserted capitalist accumulation in metropolitan centers. The space thus produced created center-periphery relations within the international division of labour. However, we have to avoid 
the misleading notion that peripheral locations are not important to the regime of accumulation: mining camps are central to capitalism and state formation regardless of their geographical situation.

Crucial to this point, however, is the critical analysis of the social relations of production. The American mining company was not a puppeteer, but a node within a network of complex social relations struggling with other actors for the conditions necessary to sustain production. Such a process occurs in a context whereby Ecuador was striving to evolve from its condition as a former colony into a modern state. In this regard, the proletarianization, the hierarchization, and the increasing racial mixture of the labour force were the most salient tactics used within the camp, along with the provision of housing and basic social services such as education and health care. High worker turnover, rigid working schedules, and socio-residential segregation mitigated (but did not eliminate) land-based ties. In turn, the workers developed class-based awareness and linkages with social movements demanding the spread of social rights at the national scale. Other strategies, such as patron-client relations and philanthropy, were helpful in creating alliances with local elites throughout a wider hinterland, but these very same practices led to demands for the redistribution of wealth through investment in infrastructure projects and higher mining royalties.

The mining enclave serves not only transnational capital but is also involved in the reproduction and reworking of an abstract state-space. The territoriality of regulation operated in a dialectical manner in the mining sector: on 
the one hand, the state required alliances with regional powers to open spaces for extractive industries; on the other, it needed to undermine regional powers in order to centralize state jurisdiction through a network of bureaucratic actors directly connected with the national government. Decentralization was a means for centralization. Under these circumstances, the fragmenting of space through mining concessions, administrative jurisdictions, and/or land use zoning became an arena for the dispute between capitalist entrepreneurs vis-à-vis local, regional and national powers. The fragmentation of space was a means of reorganizing social, economical and political power.

By way of example, the creation of El Oro Province was the result of an alliance of mining entrepreneurs seeking autonomy from Cuenca and Loja elites to retain control over concession areas (chapter four), while the creation of the counties of Piñas and Portovelo responded to local demands for selfdetermination from Zaruma, in the attempt to retain control over mining royalties, but also as a state strategy of territorial organization to build up clienteles and undermine regional powers (chapter eight). Stating that administrative jurisdictions are directly linked to mining cycles might lead to an underestimation of the other processes involved in their creation, but certainly the tensions arising from social conflicts and economic pressures associated with mining favoured territorial demarcation by political actors.

The nationalism that underscores resource regulation became particularly notable as the governmental apparatus claimed the right as the legitimate actor 
to regulate and enforce the public domain of mineral resources. In the case at hand, such a diffuse legal concept acquired different meanings with the passage of time: as a contractual negotiation to reinvest in transport infrastructure, as a nationalist claim to a patrimonial link to underground resources, as a mechanism to capture mining royalties, as an administrative power for determining concession areas, as a social right, and as a development policy to delay deindustrialization. In any event, private property and the concession system were a precondition for production and a means of reasserting control over national territory.

In addition, state intervention through territorial projects, national policies, and decentralized institutions allows the partial remedy of structural forms necessary for capitalist expansion. For example, the construction of transport and communications infrastructure alleviates production costs. Social policies that promote public education shift responsibility for the technical training of the workforce from corporations to the state. Municipal corporations allow investment in urban processes supporting the mining enclave, and also reduce the effects of social conflict in the event of de-industrialization.

This approach helps to "re-politicize" the territoriality of the enclave by looking beyond a single geographical scale of analysis, so as to understand broader political and economic circumstances, socio-spatial interactions, and the regulations that come into being and/or act to produce particular places. This approach also helps to denaturalize mining enclaves as enclosures of private 
rule by analyzing the porosity, fluidity, and multi-scale relations under which extractive locations come into existence, operate and change over time.

\subsection{The spatial restructuring of resource regulation}

The main reason I have spent so many pages focused on unraveling the minutia of mining regulations and contractual negotiations is to understand how multi-scalar power relations and institutional forms come into being and/or act to produce particular places and spaces. I have attempted to understand the restructuring of resource regulations through an extended case study, with a genealogical and ethnographic approach - a study that at the same time takes into account the broader forces of extractive capitalism central to my study of the production of space in a particular mining enclave. Once the spatial connections are placed at the center of our understanding of resource regulation, it becomes difficult to sustain that norms and institutional arrangements emerge as something exclusive to capitalist interests or ideologically coherent political coalitions. Moreover, we have to remember that the codification of social relations is not exclusively governed by economic logic but arises from the resolution of conflicts and the enactment of social ties at different scales (Boyer and Saillard 2002b, 37). Therefore, I maintain that formal institutions, laws, and regulations in the mining sector are mechanisms through which the state - in itself - is constituted in the interaction between economic and social powers at different scales. 
With this approach, we are able to address dialectically the relationship between economic structure and political superstructure. The variability of capitalist accumulation is conditioned by interaction between actors within the legal and political system in any given territory. However, the subordination of the historical to the economic is partial, always mediated by space and social practice (Lefebvre 1991, 324). This involves recognizing the structural limitations of capitalism and the processes and resistance that shape the specific ways in which capitalism acquires materiality in concrete locations. My study shows that the temporary fixation of certain places, scales, and topics for resource regulation responds to the active production of space.

I also highlight that crisis is not an anomaly in a stable economic and political system but, rather, the outward manifestation of internal or external contradictions, which may be latent, that exist not only in the field of production but also at other scales of accumulation and socio-political organization. Therefore, I emphasize that the nature and scope of the regulations themselves are transformed in space and time. We thus have to situate regulatory processes both geographically and historically insofar as such an understanding makes it possible to recognize and decipher the role played by place-based struggles in shaping both national and international regulations.

The linkages between the production and the regulation of space have to be developed conceptually, moving beyond an analysis of laws, formal institutions, or scales of regulation so as to understand the regulatory processes 
constituting the "history of space." Following Lefebvre's take on the history of space, gold mining enclaves may be seen as a distinctive spatial form of capitalism insofar as gold reserves have backed paper money and - despite the collapse of the gold standard - remain a potent symbol of social value. This approach reframes the periodization of mining cycles in dynamic tension between global processes of capitalist expansion and state formation at the national level.

The case of Portovelo was particularly suitable for informing this insight. The campground came into existence in 1896, four years after the U.S. adopted the gold standard and began its global quest for gold. Simultaneously, in Ecuador the Liberal Revolution shifted powers from the Sierra to the Coast while opening lands for export agriculture. The first attempt to regulate the transnational mining enclave, in the early 1930s, happened at a moment when Ecuador was implementing structural reforms, establishing the Central Bank, and moving away from the gold standard. Later, in response to the monetary regulations of the 1940s, SADCO underwent internal restructuring towards financialization.

The transnational enclave lasted until 1950, six years after the Bretton Woods agreement to regulate the international monetary regime through fixed exchange rates in parity with gold and the U.S. dollar. The transfer of assets to Ecuadorian nationals displaced production risks while Americans retained control of the gold trade worldwide. This process coincides with the spread of American investment and development policies in Ecuador and throughout Latin America. 
During the 1970s, the physical dismantling of the mining enclave and the proliferation of artisanal mining coincides with the end of gold parity, after which gold began to be traded at free market prices. The increase in the international price of gold, the downsizing of the state after the application of neoliberal policies, and the mining law of 1991 favoured the expansion of artisanal and small-scale mining throughout the southern provinces of Ecuador.

The Constitutional Assembly of 2008 launched a new regulatory regime within the mining sector. Shortly after, President Rafael Correa pushed largescale mining as landmark projects within the long-term national development strategy. Current public policies emphasize the rational and responsible use of natural resources, state sovereignty over strategic sectors, and the need to develop knowledge, leadership, and management skills to regulate mining (Senplades 2013). In the mining sector, corporate social responsibility (CSR) appears to be the leading strategy to improve the accountability of both public and private enterprises. CSR facilitates profitable production with minimal investment so as to reduce externalities while the state remains responsible for the regulation of the overall sector and the provision of social services needed for sustaining livelihoods. The free and prior consultation applies to projects that could affect communities environmentally or culturally (Constitution of 2008, articles 57 and 398). This perspective creates contradictions between the central government committed to using natural resources for promoting national development, the mining enterprises who seek to displace risks to the state, and 
affected local communities involved in lobbying to prohibit mining in indigenous lands, diverse ecosystems and headwaters (Moore and Velásquez 2011).

By way of example, large-scale mining requires surface easements on areas used for land-based resources (a principle which stems from colonial legislation). This conflicts with the constitutionally mandated protection of the rights of nature (a polysemic concept that could be understood as the human right to live in a healthy environment, the view of nature as sacred or Pachamamismo, environmental justice, or life in harmony with nature). This contradiction has generated a wide debate on the relevance and sustainability of the extraction of natural resources to meet human needs at the expense of the environment. The very same contradiction creates a space to assert national sovereignty, which is simultaneously portrayed as the self-determination of local communities, the common good, the redistribution of national wealth, and the regulation of transnational actors. In any case, resource governance is much more than the weak or strong institutionalization of mining regulations; it involves, rather, constant negotiation among actors operating at multiple levels.

\subsection{Avenues for future research}

The dissertation opens several avenues for future research. At the intersection of the production and the regulation of space, I am especially intrigued by the imbrication, dissemination, interpretation, and adaptation of laws, norms, policies, and institutions in regions beyond the national policy centers of 
Quito, Guayaquil, and Cuenca. In particular, there are three issues that I will continue to explore in different ways. Based on previous studies about the history of public services in Quito (Carrión, Goetschel, and Sánchez, 1997), I am curious about the spread of urban policies throughout Ecuador over time. In the case of the Municipality of Zaruma, the structure and content of the building ordinance of 1910, the attempt to hire architect Jones Odriozola (who wrote Quito's 1942 Master Plan) and the celebration of the First Congress of Restoration Architects of Ecuador in 1981 are the result of increasingly fluid relationships with the nation's capital.

From a historiographical perspective, I am fascinated by the physician and socialist leader Ricardo Paredes, and amazed by the lack of scholarly attention regarding the impact of the mining enclave on the formulation of the 1938 Labour Code. An interesting aspect of this dissertation is that it reveals this connection through the identification of occupational diseases related to mining activities. Thus, I have initiated a dialog with the Health History Workshop of the Simón Bolívar Andean University to continue unraveling the influence of Portovelo in the development of labour regulations at the national level.

Finally, an ambitious avenue for future research involves analyzing the consolidation of national space through placed-based studies that question how regionalism, the economy, and public policy began to change throughout the $20^{\text {th }}$ century. Attempts to understand state formation that take into account the importance of place-based sociocultural and political processes, like the one 
described here, would provide a more comprehensive and complex analysis that would call into question the argument of complete penetration by the state as an engine of national integration (Cueva 1970; Deler 2007; Maiguashca 1992). In the case of Zaruma and Portovelo, integration into the nation-state was accompanied by a weakening of provincial elites, the expansion of administrative techniques, and the intensification of micro-regionalism. However, full political domination over the national territory never existed; instead there was a constant process of negotiation among social actors as persons at different locations involved in extended networks competed for political and monetary resources by creating new administrative jurisdictions and influencing the mechanisms through which the state apparatus and policy-making acquired shape at the local level.

\section{Final remarks}

Throughout the doctoral experience, I have learned to appreciate the embedding of academic knowledge, by which abstract theoretical discourses have to be reframed and revisited to acquire meaning for different audiences. I have a personal obligation to translate this dissertation into Spanish and make available to the people of Zaruma and Portovelo the wealth of information I have compiled throughout the past five years. 


\section{Bibliography}

Abrams, Philip. 1988. "Notes on the Difficulty of Studying the State." Journal of Historical Sociology 1, no. 1: 58-89.

Acosta, Alberto. 1995. Breve historia económica del Ecuador. Quito: Corporación Editora Nacional.

—. 2009. La maldición de la abundancia. Quito: Abya Yala.

Aglietta, Michel. 1976. A Theory of Capitalist Regulation: The U.S. Experience. London; New York: Verso.

Aglietta, Michel. 1998. "Capitalism at the Turn of the Century: Regulation Theory and the Challenge of Social Change." New Left Review 232: 41-90.

Agnew, John. 1994. "The Territorial Trap: The Geographical Assumptions of International Relations Theory." Review of International Political Economy 1, no. 1: 53-80.

—. 2005. "Sovereignty Regimes: Territoriality and State Authority in Contemporary World Politics." Annals of the Association of American Geographers 95, no. 2: 437-461.

Aguilar, Eduardo. 1990. Las escaleras. Zaruma: Editorial Amazonas.

Albornoz, Oswaldo. 2001. Las compañías extranjeras en el Ecuador. Quito: Abya-Yala.

Allen, John. 2003. "Power." In A Companion to Political Geography, edited by John Agnew, Katharyn Mitchell, and Gearóid O'Tuathail, 95-108. Malden: Blackwell Publishing.

Almeida, María Rebeca. 1998. "Oscilaciones del dólar norteamericano en el mercado nacional durante 78 años." Revista Ecuatoriana de Historia Económica 2, no. 4: 253-264.

Anaya, James. 2011. Observations on the Situation of the Rights of the Indigenous People of Guatemala with Relation to the Extraction Projects, and Other Types of Projects, in Their Traditional Territories. Human Rights Council, United Nations, UN. 
Anda, Alfonso. 1960. Zaruma en la Colonia. Quito: Editorial de la Casa de la Cultura Ecuatoriana.

Anderson, Steven T. 2004. "The Mineral Industry of Ecuador." US Geological Survey Minerals Yearbook: 10.1-10.8.

Andersson, Krister P., and Elinor Ostrom. 2008. "Analyzing Decentralized Resource Regimes from a Polycentric Perspective." Policy Sciences 41, no. 1: 71-93.

Andrade, Manuel de Jesús. 1911. Cantón de Zaruma. Sus minas y sus bosques. Quito: Imprenta Minerva.

—. 1923. Provincia de El Oro. Monografías Cantonales. Quito: Tipografía de la Escuela de Artes y Oficios.

Andrews, Craig B. 1998, "Emerging Trends in Mining Industry Partnerships." Natural Resources Forum 22, no. 2: 119-126.

Anna, Timothy E. 1996. "Inventing Mexico: Provincehood and Nationhood after Independence." Bulletin of Latin American Research 15, no. 1: 7-17.

Appleton, J.D., T.M. Williams, H Orbea, and M. Carrasco. 2001. "Fluvial Contamination Associated with Artisanal Gold Mining in the Ponce Enríquez, Portovelo-Zaruma and Nambija Areas, Ecuador." Water, Air, and Soil Pollution 131: 19-39.

Arrighi, Giovanni. 2010. The Long Twentieth Century. Money, Power, and the Origins of Our Times. London: Verso.

Astudillo, Clodoveo. 2011. El sudor del sol. Historia de la minería orense. Machala: CCE Benjamín Carrión, Núcleo de El Oro; Universidad Técnica de Machala.

Astudillo, Clodoveo, César Alvarado, and José Miguel Montero. 1980. Sepultureros de CIMA. Causas socio-económicas de la paralización de la compañía CIMA. Machala: Universidad Técnica de Machala; Facultad de Sociología.

Ayala Mora, Enrique. 1995. Periodización de la historia del Ecuador. Vol. 13, in Nueva historia del Ecuador. Ensayos generales II. Nación, Estado y sistema político, edited by Enrique Ayala Mora, 213-250. Quito: Corporación Editora Nacional.

-. 2011. Ecuador del siglo XIX. Estado Nacional, Ejército, Iglesia y Municipio. Quito: Corporación Editora Nacional, Universidad Andina Simón Bolivar. 
Bakker, Karen, and Gavin Bridge. 2006. "Material Worlds? Resource Geographies and the 'Matter of Nature'." Progress in Human Geography 30, no. 1: 5-27.

Baldwin, Robert E. 1956. "Patterns of Development in Newly Settled Regions." The Manchester School 24, no. 2: 161-179.

Barbier, Jacques A. 1977. "The Culmination of the Bourbon Reforms, 17871792." Hispanic American Historical Review: 51-68.

Barnes, Trevor J. 2005. "Borderline Communities-Canadian Single Industry Towns, Staples, and Harold Innis." In B/ordering Space, edited by Henk van Houtum, Olivier Kramsch, and Wolfgang Zierhofer, 109-122. Aldershot \& Burlington: Ashgate Publishing Limited.

Barrera, Augusto, Franklin Ramírez, and Lourdes Rodríguez. 1999. Ecuador, un modelo para (des)armar. Descentralización, disparidades regionales y modo de desarrollo. Quito: CIUDAD.

Barriga, E. 1948. Informe que presenta la inspección de minas de Portovelo y Minas Nuevas a la Dirección de Minería y Petróleos acerca de las labores desarrolladas en el año de 1948. Concesión de la South American Development Company Incorporated. mimeo.

Barsky, Osvaldo. 1984. La reforma agraria ecuatoriana. Quito: Corporación Editora Nacional.

Baxter, Jamie. 2010. "Case Studies in Qualitative Research." In Qualitative Research Methods in Human Geography, edited by lain Hay, 81-98. Oxford: Oxford University Press.

Bebbington, Anthony. 2007. Minería, movimientos sociales y respuestas campesinas: una ecología política de transformaciones territoriales. Lima: IEP: CEPES.

Bebbington, Anthony, Denise Humphreys Bebbington, Jeffrey Bury, Jeannet Lingan, Juan Pablo Muñoz and Martin Scurrah. 2008. "Mining and Social Movements: Struggles over Livelihood and Rural Territorial Development in the Andes." World Development 36, no. 12: 2888-2905.

Bebbington, Anthony, Leonith Hinojosa, María Luisa Burneo, and Ximena Warnaurs. 2008. Contention and Ambiguity: Mining and the Possibilities of Development. Vol. 57. Brooks World Poverty Institute Working Paper. 
Becker, Joachim, and Werner Raza. 1999. "Theory of Regulation and Political Ecology: An Inevitable Separation?" Ambiente \& Sociedade II, no. 2: 5-17.

Becker, Marc. 2008. "Indigenous Nationalities in Ecuadorian Marxist Thought." $A$ Contracorriente: Revista de Historia Social y Literatura en América Latina 5, no. 2: 1-46.

—. 2013. "En busca de tinterillos. Intermediarios en el mundo indígena ecuatoriano durante el siglo XX." Procesos. Revista Ecuatoriana de Historia I: 97-124.

Bernstein, Peter L. 2012. The Power of Gold: The History of an Obsession. West Sussex: John Wiley \& Sons.

Bielschowsky, Ricardo. 2009. "Sesenta años de la cepal: estructuralismo y neoestructuralismo." Revista CEPAL, Abril: 173-194.

Bilion, Philippe Le. 2007. "Geographies of War: Perspectives on 'Resource Wars'." Geography Compass 1, no. 2: 163-182.

Billingsley, Paul. 1926. "Geology of the Zaruma Gold District of Ecuador." American Institute of Mining and Metallurgical Engineering 74: 255-275.

Blaikie, Piers. 1985. The Political Economy of Soil Erosion in Developing Countries. London \& New York: Longman.

Blainey, Geoffrey. 1970. "A Theory of Mineral Discovery: Australia in the Nineteenth Century." The Economic History Review 23, no. 2: 298-313.

Blomley, Nicholas. 2003. "Law, Property, and the Geography of Violence: The Frontier, the Survey, and the Grid." Annals of the Association of American Geographers 93, no. 1: 121-141.

Bloomfield, Arthur Irving. 1959. Monetary Policy under the International Gold Standard, 1880-1914. New York: Arno Press.

Bluestone, Barry, and Bennett Harrison. 1982. The Deindustrialization of America: Plant Closings, Community Abandonment, and the Dismantling of Basic Industry. New York: Basic Books, Inc.

Boon, Jan. "The Role of Governments in CSR." 2011. In Governance Ecosystems CSR in the Latin American Mining Sector, edited by Julia Sagebien and Nicole Marie Lindsay, 64-83. London: Palgrave.

Bordo, Michael. 1993. "The Gold Standard, Bretton Woods and Other Monetary Regimes: An Historical Perspective." NBER Working Paper 4310. 
Bordo, Michael D., and Anna J. Schwartz. 2009. A Retrospective on the Classical Gold Standard, 1821-1931. Chicago: University of Chicago Press.

Bourdieu, Pierre. 1998. Practical Reason. Standford: Standford University Press.

-. 2005. The Social Structures of the Economy. Cambridge: Polity.

Boyer, Robert. 1990. The Regulation School: A Critical Introduction. New York: Columbia University Press.

- 2002. "The Origins of Regulation Theory." In Regulation Theory: The State of the Art, edited by Robert Boyer and Yves Saillard, 13-20. London: Routledge.

Boyer, Robert, and Yves Saillard, eds. 2002. Regulation Theory: The State of the Art. Translated by Carolyn Shread. London: Routledge.

Brady, B.G.H., and E.T. Brown. 2004. Rock Mechanics for Underground Mining, 3rd ed. Dordrecht: Springer.

Bravo Lira, Bernardino. 2010. "La difusión del Código Civil de Bello en los países de derecho castellano y portugués." Revista de estudios histórico-jurídicos 7: 71-106.

Brenner, Neil. 1998. "Between Fixity and Motion: Accumulation, Territorial Organization and the Historical Geography of Spatial Scales." Environment and Planning D 16: 459-482.

-. 2001. "The limits to scale? Methodological reflections on scalar structuration." Progress in Human Geography 25, no. 4: 591-614.

-. 2004. New State Spaces: Urban Governance and the Rescaling of Statehood. Oxford: Oxford University Press.

Bresser-Pereira, Luiz Carlos. 2011. "From Old to New Developmentalism in Latin America." Edited by José Antonio, and Jaime Ros Ocampo. The Oxford Handbook of Latin American Economics (Oxford University Press): 108129.

Brianta, Donata. 2000. "Education and Training in the Mining Industry, 17501860: European Models and the Italian Case." Annals of Science 57, no. 3: $267-300$.

Bridge, Gavin. 2004a. Contested Terrain: Mining and the Environment." Annual Review of Environment and Resources 29: 205-259. 
-. 2004b. "Mapping the Bonanza: Geographies of Mining Investment in an Era of Neoliberal Reform." The Professional Geographer 56, no. 3: 406-421.

—. 2009. "Material Worlds: Natural Resources, Resource Geography and the Material Economy." Geography Compass 3, no. 3: 1217-1244.

Bridge, Gavin, and Phil McManus. 2000. "Sticks and Stones: Environmental Narratives and Discursive Regulation in the Forestry and Mining Sectors." Antipode 32, no. 1: 10-47.

Brown, Christopher, and Mark Purcell. 2005. "There's Nothing Inherent about Scale: Political Ecology, the Local Trap, and the Politics of Development in the Brazilian Amazon." Geoforum 36: 607-624.

Brown, Elspeth H. 2008. The Corporate Eye: Photography and the Rationalization of American Commercial Culture, 1884-1929. Baltimore: Johns Hopkins University Press.

Brown, Jonathan C. 1993. Oil and Revolution in Mexico. Berkeley: University of California Press.

Brown, Kendall. 2012. A History of Mining in Latin America. From the Colonial Era to the Present. Albuquerque: University of New Mexico Press.

Buchanan, Karen. 2013. "Contested Discourses, Knowledge, and Socioenvironmental Conflict in Ecuador." Environmental Science \& Policy 30: 19-25.

Bulmer-Thomas, Victor. 2003. The Economic History of Latin America since Independence. Cambridge: Cambridge University Press.

Burawoy, Michael, 1998. Burawoy, Michael. "The Extended Case Method." Sociological Theory 16, no. 1: 4-33.

-, ed. 2000. Global Ethnography: Forces, Connections, and Imaginations in a Postmodern World. University of California Press.

Bureau of the American Republics. 1892a. Handbook of Ecuador. Vol. 64. Washington: Bureau of the American Republics.

-. Mines and Mining Laws of Latin America. 1892b. Vol. 40. Washington: Bureau of the American Republics.

Burton, Antoinette M. 2003. Dwelling in the Archive: Women Writing House, Home, and History in Late Colonial India. New York: Oxford University Press. 
Caivallet, Chantal. 1988. "Los mecanismos económicos de una sociedad minera: intercambios y crédito Loja: 1550-1630." Revista ecuatoriana de Historia Económica 2, no. 3: 19-66.

Campbell, John. 1988. "Institutional Analysis and the Role of Ideas in Political Economy." Theory and Society 27: 377-409.

Campbell Jr, Nicholas J. 1956. "Principles of Mineral Ownership in the Civil Law and Common Law Systems." Tulane Law Review: 303-312.

Campodónico, Humberto. 2008. Renta petrolera y minera en países seleccionados de América Latina. Vol. 188. Santiago: CEPAL. División de Desarrollo Social.

Cardoso, Fernando Henrique, and Enzo Faletto. 1971. Dependencia y desarrollo en América Latina. México: Siglo XXI Editores.

Carrión, Alberto. 1948. Exposición de la llustre Municipalidad de Zaruma ante el $H$. Congreso Nacional, el Ejecutivo y el País, acerca de la rebaja del Impuesto a la Producción Minera. Zaruma: Artes Gráficas SENEFELDEB.

Carrión, Andrea, Ana María Goetschel, and Nancy Sánchez. 1997. Breve historia de los servicios básicos en Quito. Edited by Mario Vásconez (coord). Quito: Centro de Investigaciones CIUDAD.

Carrión, Fernando, ed. 2007. La descentralización en el Ecuador: opciones comparadas. Quito: FLACSO.

Castillo, José Bolívar, and Rafael León. 1979. El desarrollo de la región sur el Ecuador. Loja: PREDESUR.

Castree, Noel, and Bruce Braun. 2001. Social Nature. Theory, Practice and Politics. Malden: Blackwell Publishers.

Cervone, Emma. 2010. "Celebrating the Chagras: Mestizaje, Multiculturalism, and the Ecuadorian Nation." The Global South 4, no. 1: 94-118.

Cevallos Romero, Alfonso. 2011. Imágenes Zaruma. Fotografías de Ramón Jijón y León Jiménez. Quito: Consejo Nacional de Cultura.

Chacón, Juan. 2001. Historia de la minería en el austro del Ecuador. Cuenca: Cámara de Minería de Cuenca, Ministerio de Energía y Minas.

Chaparro, Eduardo. 2002. Actualización de la compilación de leyes mineras de catorce países de América Latina y el Caribe. Vol. 43. Santiago de Chile: CEPAL, División de Recursos Naturales e Infraestructura. 
Chaparro, Eduardo, and Georgina Ortiz. 2003. Guía para la gestión de las autoridades locales de pueblos y distritos mineros de América Latina y el Caribe. Santiago de Chile: CEPAL/UNCTAD.

Chaparro, Eduardo, and René Salgado. 2005. Sociedad, mercado y minería. Una aproximación a la responsabilidad social corporativa. Santiago de Chile: CEPAL. División de Recursos Naturales e Infraestructura.

Chiaradia, Massimo, Lluís Fontboté, and Bernardo Beate. 2004. "Cenozoic Continental Arc Magmatism and Associated Mineralization in Ecuador." Mineralium Deposita 39, no. 2: 204-222.

Chicaiza, Gloria, and Ivonne Yanez. 2013. "The mining enclave of the Cordillera del Cóndor." In Ecological Economics from the Ground Up, edited by Hali Healy, Joan Martínez-Alier, Leah Temper, Mariana Walter and JulienFrançois Gerber, 55-88. New York: Routledge.

Chiriboga, Manuel. 1980. Jornaleros y gran propietarios en 135 años de exportación cacaotera (1790-1925). Quito: Consejo Provincial de Pichincha.

Chiriboga, Manuel. 1988. "La reforma agraria ecuatoriana y los cambios en la distribución de la propiedad rural agrícola de 1974-1985." In Transformaciones agrarias en el Ecuador, edited by Pierre Gondard, Juan B. León V., and Paola Sylva Ch. Quito: IPGH-Orstom.

Clark, Kim. 1988. The Redemptive Work. Railway and Nation in Ecuador, 18951930. Washington: Scholarly Resources Inc.

-. 2005a. "Ecuadorian Indians, the Nation, and Class in Historical Perspective: Rethinking a 'New Social Movement'." Anthropologica 47, no. 1: 53-65.

—. 2005b. "Feminismos estéticos y antiestéticos en el Ecuador de principios del siglo xx: Un análisis de género y generaciones." Procesos. Revista ecuatoriana de Historia 22 (2005b): 85-105.

Clark, Timothy, and Liisa North. 2006. "Mining and Oil in Latin America: Lessons from the Past, Issues for the Future." In Community Rights and cçCorporate Responsibility. Canadian Mining and Oil Companies in Latin America, edited by Liisa North, Timothy Clark and Viviana Pastroni, 1-17. Toronto: Between the Lines.

Clarke, Simon. 1992. "The Global Accumulation of Capital and the Periodisation of the Capitalist State Form." Open Marxism 1: 133-179.

Clement, Wallace. 1981. Hardrock Mining. Industrial Relations and Technological Changes at INCO. Toronto: McCelland and Stewart Limited. 
Coatsworth, John H. 2005. "Structures, Endowments, and Institutions in the Economic History of Latin America." Latin American Research Review 40, no. 3: 126-144.

Colby, Wm. E. 1917. "Extralateral Right Shall It Be Abolished." California Law Review 5, no. 4: 303-330.

Comaroff, John, and Jean Comaroff. 1992. Ethnography and the Historical Imagination. Boulder, San Francisco and Oxford: Westview Press.

Cope, Meghan. 2010. "Coding Qualitative Data." In Qualitative Research Methods in Human Geography, edited by lain Hay, 281-294. Oxford: Oxford University Press.

Coraggio, José Luis. 1986. "Sobre la espacialidad y el concepto de región." In La cuestión regional en América Latina, by edited José Luis Coraggio, Alberto Federico Sabate, and Oscar Colman, 67-105. Quito: Ediciones CIUDAD.

Coronel, Valeria. 2011. Revolution in Stages: Subaltern Politics, Nation-state Formation, and the Origins of Social Rights in Ecuador, 1834-1943. PhD diss., New York University.

—. 2013. "Justicia laboral y formación del Estado como contraparte ante el capital transnacional 1927-1938." IIles Imperis 15: 171-193.

Corrigan, Philip, and Derek Sayer. 1985. The Great Arch. English State Formation as a Cultural Revolution. Oxford and New York: Blackwell.

Cortázar, Mariana. 2005. El oro de Portovelo. Quito: Soboc Grafic.

Cortázar, Mariana, and José Lavanda. 2008. Portovelo cuenta su historia. Quito: MC Comunicación y Medios.

Coumans, Catherine. 2010. "Alternative Accountability Mechanisms and Mining: The Problems of Effective Impunity, Human Rights, and Agency." Canadian Journal of Development Studies 30, no. 1-2: 27-48.

Cox, Kevin R. 1998. "Spaces of dependence, Spaces of Engagement and the Politics of Scale, or: Looking for Local Politics." Political Geography (Elwier Science Ltd.) 17, no. I: 1-23.

-. 1990. "Territorial Structures of the State: Some Conceptual Issues." Tijdschrift voor Economische en Sociale Geografie 81, no. 4: 251-266. 
—. 2005. "Local:Global." In Spaces of Geographical Thought: Deconstructing Human Geography's Binaries, edited by Paul Cloke and Ron Johnston, 175-198. London: Sage.

Crampton, Jeremy, and Stuart Elden. 2006. "Space, Politics, Calculation: An Introduction." Social \& Cultural Geography 7, no. 5 (October): 681-685.

Crane, Walter. 1910. Ore Mining Methods. New York: John Wiley \& Sons.

Cueva, Agustín. 1970. "Interpretación sociológica del velasquismo." Revista Mexicana de Sociología, 709-735.

-. 1981. The Process of Political Domination in Ecuador. New Brunswick: Transaction Books.

Dalby, Simon. 1991. "Critical Geopolitics: Discourse, Difference, and Dissent." Environment and Planning D: Society and Space 9, no. 3: 261-283.

David, A. Paul, and Gavin Wright. 1997. "Increasing Returns and the Genesis of American Resource Abundance." Industrial and Corporate Change 6, no. 2: 203-245.

Davidov, Veronica. 2014. "Land, Copper, Flora: Dominant Materialities and the Making of Ecuadorian Resource Environments." Anthropological Quarterly 87, no. 1: 31-58.

D’Amico, Linda. 2012. "Environmentalism and Gender in Intag, Ecuador." In Gender and Sustainability: Lessons from Asia and Latin America, edited by Maria Luz Cruz-Torres and Pamela McElwee, 25-49. Tucson: The University of Arizona Press.

De la Cadena, Marisol. 2005. "Are Mestizos Hybrids? The Conceptual Politics of Andean Identities." Journal of Latin American Studies 37, no. 2: 259-84.

De la Torre, Carlos. 1994. "Velasco Ibarra and 'La Revolucion Gloriosa': The Social Production of a Populist Leader in Ecuador in the 1940s." Journal of Latin American Studies 26, no. 3: 683-711.

DeLanda, Manuel. 2006. A New Philosophy of Society. Assemblage Theory and Social Complexity. London: Continuum. 
Deleuze, Gilles, and Félix Guatari. 1987. A Thousand Plateus. Capitalism and Schizophrenia. Translated by Brian Massumi. Minneapolis and London: University of Minessota Press.

Deler, Jean-Paul. 2007. Ecuador del espacio al Estado nacional. Quito: Universidad Andina Simón Bolívar; IFEA; Corporación Editora Nacional.

Demeritt, David. 2002. "What is the 'Social Construction of Nature'? A Typology and Sympathetic Critique." Progress in Human Geography 26: 767-790.

Derrida, Jacques. 1995. "Archive Fever. A Freudian Impression." Diacritics 25, no. 2: 9-63.

Descalzi, César Ricardo. 1951. Portovelo. Episodios de un campamento minero. Quito: Casa de la Cultura Ecuatoriana.

DeVault, Marjorie, and Liza McCoy. 2006. "Institutional Ethnography: Using Interviews to Investigate Ruling Relations." In Institutional Ethnography as Practice, edited by Dorothy Smith, 15-44. Lanham: Rowman \& Littlefield Publishers.

Deverell, John.1975. Falconbridge: Portrait of a Canadian Mining Multinational. Toronto: James Lorimer \& Co.

DiFilipo, Armando. 2009. "Estructuralismo latinoamericano y teoría económica." Revista CEPAL (CEPAL) 98: 181-202.

Dinius, Olivier J., and Angela Vergara. 2011. Company Towns in the Americas. Landscape, Power, and Working-class Communities. Athens: University of Georgia Press.

Dirlik, Arif. 2001. "Globalism and the Politics of Place." In Globalisation and the Asia-Pacific. Contested Territories, edited by Peter Dicken, Philip F. Kelly, Lily Kong, Kris Olds, and Henry Wai-chung Yeung, 36-54. London: Routledge.

Dooley-Feldman, Eric. 2007. Los esfuerzos de desarrollo sostenible en Pucará, Ecuador. Vol. 164. ISP Collection.

Dougherty, Michael L. 2011. "The Global Gold Mining Industry, Junior Firms, and Civil Society Resistance in Guatemala." Bulletin of Latin American Research: 1-16.

Downey, Liam, Eric Bonds, and Katherine Clark. 2010. "Natural Resource Extraction, Armed Violence, and Environmental Degradation." Organization \& Environment 23, no. 4: 417-445. 
Drake, Paul. 2012. "Difusión histórica, desarrollo y durabilidad de las instituciones democráticas en América Latina en los siglos XIX y XX." Revista Uruguaya de Ciencia Política 21: 7-30.

Driver, Felix. 1991. "Political Geography and State Formation: Disputed Territory." Progress in Human Geography 15: 268-280.

Dunn, Kevin. 2010. "Interviewing." In Qualitative Research Methods in Human Geography, edited by lain Hay, 101-138. Oxford: Oxford University Press.

Echave, José. 2009. "Minería y conflictos sociales en el Peru." In Minería y Territorio en Perú. Conflictos, resistencias y propuestas en tiempos de globalización, edited by José Echave, Raphael Hoetmer, and Mario Palacios, 105-130. Lima: Programa Democracia y Transformación Global.

ECLAC. 1950. The Economic Development of Latin America and its Principal Problems. Lake Success: United Nations Deptartment of Economic Affairs.

Egas, José María. 1975. Ecuador y el Gobierno de la Junta Militar. Buenos Aires: Tierra Nueva.

Eichengreen, Barry, and Marc Flandreau.1997. The Gold Standard in Theory and History. London: Routledge.

Eichengreen, Barry, and lan W. McLean. 1994. "The Supply of Gold under the Pre-1914 Gold Standard." Economic History Review XLVII, no. 2: 288309.

Elden, Stuart. 2004. Understanding Henri Lefebvre. Theory and the Possible. London: Continuum.

Epps, William Thayer. 2009. Maintaining the Empire: Diplomacy and Education in U.S.-Ecuadorian Relations, 1933-1963. PhD. diss., University of Texas.

Escobar, Arturo. 2001. "Culture Sits in Places: Reflections on Globalism and Subaltern Strategies of Localization." Political Geography (Elsevier) 20: 139-174.

Espinosa, Reinaldo. 1990. Vamos a la tierra. Zaruma: Casa de la Cultura Ecuatoriana, Núcleo de El Oro.

Espinosa, Santiago. 1986a. Diagnóstico ambiental de la ciudad de Portovelo. Quito: PRODEMINCA.

—. 1986b. Diagnóstico ambiental de la ciudad de Zaruma. Quito: PRODEMINCA. 
Fauroux, Emmanuel. 1983. "Poder regional e instituciones regionales en la provincia de Loja desde principios del siglo XX: ejes de una investigación." Cultura V, no. 15: 235-253.

—. 1984. "Loja: Esquisse d'une histoire des forms de contrôle d'un espace régional ." Institut Français d'Etudes Andines XIII, no. 3-4: 77-100.

Ferguson, James, and Akhil Gupta. 2002. "Spatializing States: Towards an Ethnography of Neoliberal Governmentality." American Ethnologist 29, no. 4: 981-1002 .

Fernández, Sonia. 2006. "La escuela activa y la cuestión social en el Ecuador: dos propuestas de reforma educativa, 1930-1940." ." Procesos. Revista ecuatoriana de Historia 23: 77-96.

Flores, Antonio. 1890. La conversión del la deuda anglo-ecuatoriana. Quito: Imprenta del Gobierno.

Foucault, Michel. 1980. "The Confession of the Flesh." In Power/Knowledge: Selected Interviews and Other Writings, 1972-1977, edited by Collin Gordon, 194-228. New York: Pantheon.

—. 1984. "Nietzsche, Genealogy, History." In The Foucault Reader: An Introduction to Foucault's Thought, edited by Paul Rabinow, 77-100. London: Penguin.

—. 2000. "The Subject and Power." In Power, edited by James Faubion, translated by Robert Hurley, 326-346. New York: The New York Press.

—. 2003. Society Must be Defended. New York: Picador.

—. 2007. Security, Territory, Population. New York: Palgrave Macmillan.

—. 2010. "The Meshes of Power." In Space, Knowledge and Power. Foucault and Geography, edited by Jeremy Crampton and Stuart Elden, 153-162. Farnham: Ashgate.

Fox, Tom, Halina Ward, and Bruce Howard. 2002. The Public Sector Roles in Strenghtening Corporate Social Responsibility: A Baseline Study. New York: IIED-The World Bank.

Fairclough, Norman. 1992. Discourse and Social Change. Cambridge: Polity Press.

-. 2003. Analysing discourse. Textual analysis for social research. London and New York: Routledge. 
-. 2006. Language and globalization. Abingdon and New York: Routledge.

Furtado, Celso. 1976. Economic Development of Latin America. Historical background and Contemporary Problems. Cambridge: Cambridge University Press.

Galeano, Eduardo. 1997. Open veins of Latin America. Five Centuries of the Pillage of a Continent, Translated by Cedric Belfrage. New York: Monthly Review Press.

Garcés Feliú, Eugenio, and Angela Vergara. 2011. "El Salvador. A Modern Company Town in the Chilean Andes." In Company Towns in the Americas. Landscape, Power, and Working-class Communities, by Olivier J. Dinius and Angela Vergara, 178-197. Athens: University of Georgia Press.

Gamarra, José. 2006. Pobreza, corrupción y participación política: una revisión para el caso colombiano. Vol. 70. Bogotá: Banco de la República. Documentos de Trabajo sobre Economía Regional.

Gargarella, Roberto. 2010. The Legal Foundations of Inequality. Constitutionalism in the Americas, 1776-1860. Cambridge: Cambridge University Press.

Gee, James Paul. 2007. An Introduction to Discourse Analysis. Theory and method. New York: Routledge.

Gibson-Graham, Julie Kathy. 1997. "Postmodern Becomings: From Space of Form to the Space of Potentiality." In Space and Social Theory. Interpreting Modernity and Postmodernity, edited by Georges Benko and Strohmayor Ulf, 306-323. Oxford: Blackwell Publishers.

Gier, Jaclyn, and Laurie Mercier. 2006. Mining Women. Gender in the Development of a Global Industry, 1670 to 2005. New York: Palgrave Macmillan.

Gille, Zsuzsa, and Seán ÓRiain. 2002. "Global Ethnography." Annual Review of Sociology 28: 271-295.

Gondard, Pierre. 2005. "Ensayo en torno a las regiones de Ecuador Herencias y reestructuraciones territoriales." Ecuador Debate 66 (Diciembre: 45-60.

Gondard, Pierre, and Hubert Mazurek. 2001. "30 años de reforma agraria y colonización en el Ecuador: 1964-1994: dinámicas espaciales." Estudios de Geografía (CGE-CEN-IRD-PUCE) 10: 15-40. 
Goodwin, Mark, and Joe Painter. 1996. "Local Governance, the Crises of Fordism and the Changing Geographies of Regulation." Transactions of the Institute of British Geographers 21, no. 4: 635-648.

Goonewardena, Kanishka, Stefan Kipfer, Richard Milgrom, and Christian Schmid. 2008. Space, Difference, Everyday Life: Reading Henri Lefebvre. London: Routledge.

Goossens, Pierre. 1967. Ecuador. U.N. Mining Project. Operation $N^{\circ} 4$ Concluding Report. Quito.

Goossens, Pierre. 1972. "Metallogeny in Ecuadorian Andes." Economic Geology 67: 458-468.

Gottman, Jean. 2008. "The Evolution of the Concept of Territory." In Politics. Critical Essays in Human Geography, edited by John Agnew and Virginie Mamadouh, 93-111. Ashgate.

Gracy, Karen. 2004. "Documenting Communities of Practice: Making the Case for Archival Ethnography." Archival Science 4: 335-365.

Grugel, Jean, and Pía Riggirozzi. 2012. "Post Neoliberalism in Latin America: Rebuilding and Reclaiming the State after Crisis." Development and Change 43, no. 1: 1-21.

Guerra, Samuel. 1987. Nambija. Los lejanos senderos del oro. Quito: Banco Central del Ecuador.

Guerra, Sergio, and Germán Rodas. 2011. Forjadores del pensamiento crítico latinoamericano. Quito: Ediciones La Tierra.

Guerrero, Andrés. 1980. Los oligarcas del cacao. Quito: El Conejo.

-. 2010. Administración de poblaciones, ventriloquía y transescritura. Quito: FLACSO-IEP.

Guzmán, Alejandro. 1982. Andrés Bello codificador: Historia de la fijación y codificación del derecho civil en Chile. Santiago: Ediciones de la Universidad de Chile.

—. 2000. Historia de la codificación civil en Iberoamérica. Santiago.

Haber, Stephen H. 1997. How Latin America Fell Behind: Essays on the Economic Histories of Brazil and Mexico, 1800-1914. Stanford: Stanford Unviversity Press. 
Hansen, Hans Krause, and Tony Porter. 2012. "What Do Numbers Do in Transnational Governance?" International Political Sociology 6: 409-426.

Hardoy, Jorge E. 1976. "Sistemas sociopolíticos y urbanización. Una selección de ejemplos históricos y contemporáneos." In Las ciudades de América Latina y sus áreas de influencia a través de la historia, edited by Jorge $\mathrm{E}$. Hardoy and Richard P. Schaedel, 79-112. Buenos Aires: Ediciones SIAP.

Haring, Robert H. 1938. A Description of Operations of the South American Development Company, Portovelo, Ecuador, SA. PhD diss., Lehigh University.

Harmon, John P.1932. Ventilation at the Portovelo Mines. Rolla: School of Mines and Metallurgy of the University of Missouri.

Harris, Cole. 2001. "Archival Fieldwork." Geographical Review 91, no. 1/2: 328334 .

Hart, Gillian. 2001. "Denaturalizing Dispossession: Critical Ethnography in the Age of Resurgent Imperialism." In Creative Destruction: Area Knowledge and the New Geographies of Empire. New York: CUNY.

—. 2004. "Geography and Development: Critical Ethnographies." Progress in Human Geography 28, no. 1: 91-100.

- 2009. "Ethnography." In The Dictionary of Human Geography, edited by Derek Gregory, Ron Johnston, Geraldine Pratt, Michael Watts, Sarah Whatmore, 217-219. Malden: Wiley-Blackwell.

Harvey, Charles, and Jon Press. 1989. "Overseas Investment and the Professional Advance of British Metal Mining Engineers, 1851-1914." Economic History Review: 64-86.

—. 1990."Issues in the History of Mining and Metallurgy." Business History 32, no. 3: 1-14.

Harvey, David. 1974. "Population, Resources and the Ideology of Science." Economic Geography 50, no. 3: 256-277.

—. 1981. "The spatial fix-Hegel, von Thunen, and Marx." Antipode 13: 1-12.

-. 1985. The urbanization of capital. Studies in the history and theory of capitalist urbanization. Oxford: Blackwell.

—. 1987. "Flexible Accumulation Through Urbanization: Reflections on the 'PostModernism' in the American City." Antipode 19, no. 3 (December): 260286. 
—. 1988. "Valor de uso, valor de cambio y teoría de la utilización del suelo urbano." In Antología de Sociología Urbana, edited by Mario Bassols, Roberto Donoso, Alejandra Massolo and Alejandro Méndez, 698-737. México DF: UNAM.

—. 1989a. "From Managerialism to Entrepreneurialism: The Transformation in Urban Governance in Late Capitalism." Geografiska Annaler. Series B, Human Geography 71, no. 1: 3-17.

-. 1989b. The Condition of Postmodernity: An enquiry into the origins of cultural change. Oxford, England; New York, NY, USA: Blackwell.

—. 1990a. Los límites del capitalismo y la teoría marxista. México: Fondo de Cultura Económica.

—. 1990b. "Between Space and Time: Reflections on the Geographical Imagination." Annals of the Association of American Geographers 80, no. 3 (September 1990b): 418-434.

—. 1996. Justice, Nature and the Geography of Difference. Blackwell Publishers.

-. 2001. Spaces of Capital: Towards a Critical Geography. New York: Routledge.

—. 2003. The New Imperialism. Oxford: Oxford University Press.

-. 2005. Spaces of Neoliberalization: Towards a Theory of Uneven Geographical Development. Edited by University of Heidelberg. Stuttgart: Franz Steiner Verlag.

—. 2006. The limits to capital. London \& New York: Verso, 2006.

-. 2014. Seventeen Contradictions and The End of Capitalism. London: Profile Books.

Haslam, Paul. 2004. The corporate social responsibility system in Latin America and the Caribbean. Ottawa: FOCAL.

Hayter, Roger. 2000. "Single Industry Resource Towns." In A Companion to Economic Geography, edited by Eric Sheppard and Trevor J. Barnes, 291-307. Oxford: Blackwell Publishers.

Henderson, Peter V.N. 2008. Gabriel García Moreno and Conservative State Formation in the Andes. Austin: University of Texas Press. 
Herod, Andrew. 2011. "Social Engineering through Spatial Engineering. Company Towns and the Geographical Imagination." In Company towns in the Americas: landscape, power and working-class communities, edited by Oliver Dinius and Angela Vergara, 21-44. Athens: University of Georgia Press.

Herrera, Gerardo. 1994. "El ocaso de la minería del proyecto Portovelo." Minería Ecuatoriana (CODIGEM), Abril: 29-31.

Hirsch, Fred. 1968. "Influences on Gold Production." Staff Papers - International Monetary Fund 15, no. 3: 405-490.

Hoggart, Keith, Loretta Lees, and Anna Davies. 2002. Researching Human Geography. London: Arnold.

Honey, Rex. 1977. "Form, Process and the Political Organization of Space." The Professional Geographer 29: 14-20.

Hovis, Logan, and Jeremy Mouat. 1996. "Miners, Engineers, and the Transformation of Work in the Western Mining Industry, 1880-1930." Technology and Culture 37, no. 3: 429-456 .

Humphreys, David. 2010. Minerals: Industry History and Fault Lines of Conflict. POLINARES Consortium. Working Paper \#4.

Hurtado, Osvaldo. 1980. Political Power in Ecuador. Translated by Nick D. Mills. Albuquerque: University of New Mexico Press.

Huxley, Margo. 2010. "Geographies of Governmentalities." In Space, Knowledge and Power. Foucault and Geography, edited by Jeremy Crampton and Stuart Elden, 185-204. Farnham: Ashgate.

Jäger, Johannes. 2003. "Urban Land Rent Theory: A Regulationist Perspective." International Journal of Urban and Regional Research 27, no. 2: 233-249.

Jaksic, Iván. 2001. Andrés Bello: la pasión por el orden. Caracas: Universidad Católica Andrés Bello.

Joseph, Gilbert M., and Daniel Nugent. 1994. Everyday Forms of State Formation. Revolution and the Negotiation of Rule in Modern Mexico. Durham and London: Duke University Press.

Ibarra, Hernán. 1992. Indios y cholos en la formación de la clase trabajadora ecuatoriana. Quito: El Conejo.

Innis, Harold A. 1995. Staples, Markets, and Cultural Change. Selected Essays. Edited by Daniel Drache. Montreal: McGill-Queen's University Press. 
Isenberg, Andrew C. 2010. Mining California: An Ecological History. Macmillan.

Jaramillo Alvarado, Pío. 1955. Historia de Loja y su provincia. Quito: Casa de la Cultura Ecuatoriana.

Jenson, Jane. 1991. "Thinking (a Feminist) History: The Regulation Approach as Theatre." Cahiers de recherche sociologique 17: 185-197.

Jessop, Bob. 1996. "The Regulation Approach." The Journal of Political Philosophy 5, no. 3: 287-326.

—. 1997. "Capitalism and Its Future: Remarks on Regulation, Government and Governance." Review of International Political Economy 4, no. 3: 561581.

-. 2002. The Future of the Capitalist State. Cambridge: Polity Press.

—. 2007. "From Micro-powers to Governmentality: Foucault's Work on Statehood, State Formation, Statecraft, and State Power." Political Geography 26: 34-40.

-. 2008. State Power. A Strategic-Relational Approach. Cambridge: Polity Press.

Jessop, Bob, and Ngai-Ling Sum. 2006. Beyond the Regulation Approach. Putting Capitalist Economies in their Place. Cheltenham and Northampton: Edward Elgar.

Johnston, R.J., David B. Knight, and Eleonore Kofman. 1988. Nationalism, Selfdetermination and Political Geography. London: Croom Helm and Routledge.

Jordheim, Helge. 2012. "Against Periodization: Koselleck's Theory of Multiple Temporalities." History and Theory 51, no. 2: 151-171.

Kaltwasser, Cristóbal Rovira. 2011. "Toward Post-Neoliberalism in Latin America?" Latin American Research Review 46, no. 2: 225-234.

Keeling, Arn. 2010. "'Born in an Atomic Test Tube': Landscapes of Cyclonic Development at Uranium City, Saskatchewan." The Canadian Geographer 54, no. 2: $228-252$.

Keil, Roger, and Rianne Mahon. 2009. Leviathan Undone? Towards a Political Economy of Scale. Vancouver: UBC Press.

Kellner, Hans. 1989. Language and Historical Representation. Madison: University of Wisconsin Press. 
Kellogg, Alice Lovell. 1933ca. Ecuador 1916-1928.

Kingman, Eduardo. 2002. "Historia social y mentalidades. Los higienistas, el ornato de la ciudad y las clasificaciones sociales." Iconos 15: 104-113.

Kipfer, Stefan, Parastou Saberi, and Thorben Wieditz. 2013. "Henri Lefebvre: Debates and Controversies." Progress in Human Geography 37, no. 1: 115-134.

Kirsch, Stuart. 2010. "Sustainable Mining." Dialectical Anthropology 34, no. 1: 8793.

Koselleck, Reinhart. 2002. The Practice of Conceptual History: Timing History, Spacing Concepts. Stanford: Stanford University Press.

Krause Hansen, Hans, and Tony Porter. 2012 "What Do Numbers Do in Transnational Governance?" International Political Sociology 6, no. 4 (December): 409-426.

Kuecker, Glen David. 2007. "Fighting for the Forests: Grassroots Resistance to Mining in Northern Ecuador." Latin American Perspectives 34, no. 2: 94107.

Kuyek, Joan, and Catherine Coumans. 2003. No Rock Unturned: Revitalizing the Economies of Mining Dependent Communities. Ottawa: MiningWatch Canada.

Lane, Kris. 2004. "Unlucky Strike: Gold and Labor in Zaruma, Ecuador, 16991820." Colonial Latin American Review 13, no. 1: 65-84.

Larrea, Carlos. 1987, El banano en el Ecuador: Transnacionales, Modernización y Subdesarrollo. Quito: FLACSO.

-. 2005. Hacia una istoria Ecológica del Ecuador: Propuestas para el debate. Quito: Universidad Andina Simón Bolivar; Corporación Editora Nacional; EcoCiencia.

Latour, Bruno. 1986. "The Power of Association." In Power, Action and Belief. A New Sociology of Knowledge?, edited by John Law, 264-280. London: Routledge \& Kegan Paul.

- 2010. The Making of Law. An Ethnography of the Conseil d'Etat. Malden: Polity Press.

Le Bilion, Philippe. 2007. "Geographies of War: Perspectives on 'Resource Wars'." Geography Compass 1, no. 2: 163-182. 
Lefebvre, Henri. 1976. De L'Etat. Paris: Union Générale d'Editions.

-. 1991. The Production of Space. Translated by Donal Nicholson-Smith. Malden: Blackwell Publishing, 1991.

-. 2009. State, Space, World: Selected Essays. Translated by Gerald Moore, Neil Brenner, and Stuart Elden. Minneapolis: University of Minnesota Press.

Leiva, Fernando Ignacio. 2008. Latin American Neostructuralism: The Contradictions of Post-Neoliberal Development. Minneapolis: University of Minessota.

León Mera, Juan. 1932. La dictadura y la restauración en la República del Ecuador: Ensayo de historia crítica. Quito: Editorial Ecuatoriana.

Levi-Faur, Jacint Jordana and David. 2005. "The Diffusion of Regulatory Capitalism in Latin America: Sectoral and National Channels in the Making of a New order." Annals of the American Academy of Political and Social Science 598, no. 1: 102-124.

Li, Tania. 2007. The Will to Improve: Governmentality, Development, and the Practice of Politics. Durham: Duke University Press.

Lipietz, Alain. 1987. Mirages and Miracles. The Crises of Global Fordism. London: Verso.

—. 2002. "Regulationist Political Ecology or Environmental Economics?" In Régulation Theory: The State of the Art, edited by Robert Boyer and Yves Saillard, 223-228. London: Routledge.

Loayza, Glenda Cecilia. 2005. Desarrollo de una metodología para la ordenación minero-ambiental en el sector de Zaruma-Portovelo. Master's thesis, Escuela Politécnica de Guayaquil.

Long, Norman, and Bryan R. Roberts. 1984. Miners, Peasants, and Entrepreneurs: Regional Development in the Central Highlands of Peru. Cambridge: Cambridge University Press.

López, Mauricio. 2012. Entre la identidad y la ruptura territorial: la construcción socio-histórica y socio-económica en Íntag. Quito: FLACSO: Maestría en Desarrollo Local y Territorial.

López Saa, A. 1937. Estudio de las condiciones biológicas, económicas y sociales del Campamento Minero de Portovelo. Quito: Imp. Inst. Nac. Prev. 
Love, Joseph LeRoy. 2005. "The Rise and Decline of Economic Structuralism in Latin America: New Dimensions." Latin American Research Review 40, no. 3: 100-125.

Lovitz, Sara Beth. 2006. Scales of Responsible Gold Mining: Overcoming Barriers to Cleaner Artisanal Mining in Southern Ecuador. Vermont: The University of Vermont.

Lucas, Rex. [1971] 2008. Minetown, Milltown, Railtown. Life in Canadian Communities of Single Industry. Oxford: Oxford University Press.

Lynch, Martin. 2002. Mining in World Hstory. London: Reaktion Books.

MacLeod, Gordon, and Mark Goodwin. 1999. "Reconstructing an Urban and Regional Political Economy: On the State, Politics, Scale, and Explanation." Political Geography 18, no. 6: 697-730.

Madero, Mauro. 1934. La provincia de El Oro en 1934. n.p.: n.p.

Mahon, Rianne, and Stephen McBride. 2009. "Standardizing and Disseminating Knowledge: The Role of the OECD in Global Governance." European Political Science Review: 83-101.

Maiguashca, Juan. 1989. "Las clases subalternas en los años treinta." Revista Ecuatoriana de Historia Económica (Banco Central del Ecuador) III, no. 6: 165-189.

—. 1991. "Los sectores subalternos en los años $30 \mathrm{y}$ el aparecimiento del velasquismo." In Las crisis en el Ecuador: Ios treinta y ochenta, by Rosemary Thorp and et.al., 79-94. Quito: Corporación Editora Nacional.

—. 1992. "La cuestión regional en la historia ecuatoriana (1830-1972)." In Nueva Historia del Ecuador, edited by Enrique Ayala Mora, 175-226. Quito: Corporación Editora Nacional.

—. 1994. "El proceso de integración nacional en el Ecuador: El rol del poder central, 1830-1895." In Historia y región en el Ecuador 1830-1930, edited by Juan Maiguashca, 355-415. Quito: Corporación Editora Nacional, FLACSO, CERLAC.

Marcosson, Isaac F. 1949. Metal Magic: The Story of the American Smelting and Refining Company. New York: Farrar, Strauss and Company.

Marston, Sallie A. 2000. "The Social Construction of Scale." Progress in Human Geography 24, no. 2: 219-242. 
Martinez-Alier, Joan. 2001. "Mining Conflicts, Environmental Justice, and Valuation." Journal of Hazardous Materials 86, no. 1: 153-170.

Marx, Karl. [1867] 1982. Capital. A Critique of Political Economy. Translated by Ben Fowkes. Vol. 1. London: Penguin Books.

Massey, Doreen. 1991. "The Political Place of Locality Studies." Environment and Planning A 23: 267-281.

—. 1992. "Politics and Space/Time." New Left Review: 65.

-. 1995. Spatial Divisions of Labor. Social Structures and the Geography of Production. 2nd ed. New York: Routledge.

—. 2004. "Geographies of Responsibility." Geografiska Annaler 86 B, no. 1: 5-18.

—. 2005. For Space. London: SAGE Publications.

Mavroudeas, Stavros. 1999. "Regulation Theory: The Road from Creative Marxism to Postmodern Disintegration." Science \& Society: 310-337.

Merrifield, Andy. 2006. Henri Lefebvre: A Critical Introduction. New York: Routledge.

Meseguer, Covadonga, and Fabrizio Gilardi. 2009. "What Is New in the Study of Policy Diffusion?" Review of International Political Economy 16, no. 3: 527-543.

Mignolo, Walter. 2012. Local Histories/Global Designs. Coloniality, Subaltern Knowledges, and Border Thinking. Princeton: Princeton University Press.

Milk, Richard. 1997. Movimiento Obrero Ecuatoriano: El desafío de la integración. Quito: Ediciones Abya-Yala, PUCE, IIE.

Miño, Wilson. 2008. Breve historia bancaria del Ecuador. Quito: Corporación Editora Nacional.

Moore, Adam. 2008. "Rethinking Scale as a Geographical Category: From Analysis to Practice." Progress in Human Geography 32 (April): 203-225.

Moore, Jennifer, and Dudley George. 2009. "Canadian Mining Firm Financed Violence in Ecuador: Lawsuit." The Tyee 5. 
Moore, Jennifer, and Teresa Velasquez. 2012. "Sovereignty negotiated. Antimining movements, the state and multinational mining companies under Correa's '21st Century Socialism'." In Social Conflict, Economic Development and Extractive Industry. Evidence from South America, edited by Anthony Bebbington, 112-133. New York: Routledge.

Mora, Germán. 2008. "Historia de la explotación minera de los cantones Zaruma y Portovelo." In Historia de la explotación minera de los cantones Zaruma y Portovelo, provincia de El Oro, by Germán Mora and Ramiro Rodríguez, 1-89. Quito: n.publ.

Moran, Theodore. 1992. "Mining Companies, Economic Nationalism, and Third World Development in the 1990s." In Mineral Wealth and Economic Development, edited by J Tilton, 19-38. Washington, D.C.: Resources for the Future.

Moreano, Alejandro. 1976. "Capitalismo y lucha de clases en la primera mitad del siglo XX." In Ecuador pasado y presente, edited by Leonardo Mejía, 137-224. Quito: Instituto de Investigaciones Económicas, Universidad Central del Ecuador.

Moreno, Catalina, and Eduardo Chaparro. 2009. Las leyes generales del ambiente y los códigos de minería en los países andinos. Instrumentos de gestión ambiental y minero ambiental. Vol. 136. Santiago: CEPAL.

Morris, Gordon. 2008. The Mining Law of 1872. Past, Politics, and Prospects. Albuquerque: University of New Mexico Press.

Morse, Kathryn. 2003. The Nature of Gold. An Environmental History of the Klondikie Gold Rush. Seattle: University of Washington Press.

Mosquera, Fernando. 1962. "Las actividades de la Compañía Industrial Minera S. A. "CIMA", de Portovelo, Ecuador, por el año 1961." Anales de la Universidad de Cuenca XVIII, no. 4 (Octubre-Diciembre): 385-410.

Mumford, Georges D. 1900. Propuesta de Georges D. Mumford en representación de la Central South American Company. Quito: Imprenta La Novedad.

Mumford, Lewis. [1934] 2010. Technics and Civilization. Chicago: University of Chicago Press.

Municipio de Zaruma. 2002. Plan de Conservación y Gestión del Centro Histórico de Zaruma, para la Declaratoria de Patrimonio Cultural de la Humanidad. Zaruma: Municipio de Zaruma. 
Munn, Nancy D. 1992. "The Cultural Anthropology of Time: A Critical Essay." Annual Review of Anthropology 21: 93-123.

Murillo, Rodrigo. 2000. Zaruma, historia minera. Identidad en Portovelo. Quito: Ediciones Abya Yala.

—. 2003. Minas, trabajadores y memorias. Machala: Ediciones IMPSSUR.

Neira Rizzo, José. 2014. La ineficacia del COOTAD y de la ley derogada por aquella, en materia de regulación y control del mercado inmobiliario, como instrumento del ordenamiento territorial y urbanístico. Guayaquil: Editorial Edino.

North, Liisa. 2006. "Militares y Estado en Ecuador: ¿construcción militar y desmantelamiento civil?" Iconos (FLACSO): 85-95.

North, Liisa, Timothy David Clark, and Viviana Patroni. 2006. Community Rrights and Corporate Responsibility: Canadian Mining and Oil Companies in Latin America. Toronto: Between the Lines.

Ochs, Kathleen H. 1992. "The Rise of American Mining Engineers: A Case Study of the Colorado School of Mines." Technology and Culture 33, no. 2: 278301.

Ojeda, Lautaro. 2000. La descentralización en el Ecuador. Avatares de un proceso inconcluso. Quito: Abya-Yala.

Osorio, Jaime. 2003. "El neoestructuralismo y el subdesarrollo. Una visión crítica." Nueva Sociedad 183 (Enero-Febrero): 134-150.

Ossa Bulnes, Juan Luis. 1999. Derecho de Minería. Santiago: Editorial Jurídica de Chile.

Otto, James, and John Cordes. 2002. The Regulation of Mineral Enterprises: A Global Perspective on Economics, Law and Policy. Westminster: Rocky Mountain Mineral Law Foundation.

Páez, Alexei. 1996. "El movimiento obrero ecuatoriano en el periodo (19251960)." In Vol. 10, Nueva Historia del Ecuador. Epoca Republicana IV, edited by Enrique Ayala Mora, 123-162. Quito: Corporación Editora Nacional.

Paladines, Agustín. 2005. Los recursos no renovables del Ecuador: Base para la planificación y ordenamiento. Quito: Editorial Universitaria. 
Palomeque, Silvia. 1994. "La Sierra Sur (1825-1900)." In Historia y región en el Ecuador: 1830-1930, edited by Juan Maiguashca, 69-142. Quito: Corporación Editora Nacional, FLACSO, CERLAC.

Paredes, Maritza. 2010. State Formation, Tax Structures and Mineral Abundance, Chile and Peru, 1850-1930s.: CAF Working Papers.

Paredes, Ricardo. 1928. "El movimiento obrero en el Ecuador." La Internacional Sindical Roja 1 (August): 79.

—. [1938] 1970. El imperialismo en el Ecuador. Oro y sangre en Portovelo. Guayaquil: Editorial Claridad.

Pareja Diezcanseco, Alfredo. 1958. Historia del Ecuador. Vol. II. Quito: Casa de la Cultura Ecuatoriana.

Paz y Miño, Juan. 2007. "Constituyentes, constituciones y economía." Boletín THE - Taller de Historia Económica (PUCE. Facultad de Economía) VIII, no. 06 (Junio): 1-22.

Peck, Gunther. 1993. "Manly Gambles: The Politics of Risk on the Comstock Lode, 1860-1880." Journal of Social History 26, no. 4: 701-723.

Peck, Jamie, and Nik Theodore. 2010. "Mobilizing Policy: Models, Methods, and Mutations." Geoforum 41: 169-174.

—. 2012. "Follow the Policy: A Distended Case Approach." Environment and Planning A 44: 21-30.

Peck, Jamie, and Adam Tickell. 2002. "Neoliberalizing Space." Antipode 34, no. 3: $380-404$.

-. 2003. "Searching for a New Institutional Fix: The after-Fordist Crisis and the Global-Local Disorder." In Post-Fordism: A Reader, edited by Ash Amin, 280-315. Blackwell.

Peet, Richard, and Michael Watts. 2004. "Liberating Political Ecology." In Liberation Ecologies. Environment, Development, Social Movements, edited by Richard Peet and Michael Watts. London: Routledge.

Pérez Pimentel, Rodolfo. 1975. "Teodoro Wolf." In Geografía y Geología del Ecudor, by Teodoro Wolf, 13-24. Quito: Casa de la Cultura Ecuatoriana.

Philip, George. 1982. Oil and Politics in Latin America: Nationalist Movements and State Companies. Cambridge University Press. 
Phimister, lan, and Jeremy Mouat. 2003. "Mining, Engineers and Risk Management: British Overseas Investment, 1894-1914." South African Historical Journal 49: 1-26.

Polanyi, Karl. [1944] 2001. The Great Transformation. Boston: Beacon Press.

Poma, Vicente, and Ricardo Paredes R. 2013. Rosa Vivar. Héroe y martir, la mítica sindicalista de Portovelo. Machala: Colección Identidades Orenses №7, Gobierno Provincial Autónomo de El Oro.

Poole, Deborah. 1997. Vision, Race, and Modernity: A Visual Economy of the Andean Image World. Princeton: Princeton University Press.

Portelli, Alessandro. 1991. The Death of Luigi Trastulli and Other Stories: Form and Meaning in Oral History. New York: State University of New York Press.

Pradilla, Emilio. 1997. "Regiones o territorios, totalidad y fragmentos: Reflexiones críticas sobre el estado de la teoría regional y urbana." Revista Eure XXII, no. 68 : $45-55$.

Prebisch, Raúl. 1986. "El desarrollo económico de la América Latina y algunos de sus principales problemas." Desarrollo Económico 26, no. 103: 479502.

PREDESUR. 1980. Plan Regional de Desarrollo del Sur Ecuatoriano 1980-2005. Vol. 9. Loja: PREDESUR.

Prieto, Mercedes. 2004. Liberalismo y temor: Imaginando los sujetos indígenas en el Ecuador postcolonial, 1895-1950. Quito: Editorial Abya Yala.

Quijano, Anibal. 2000. "Coloniality of Power, Eurocentrism, and Latin America." International Sociology 15 (June): 215-232.

—. 2007. "Coloniality and Modernity/Rationality." Cultural studies 21, no. 2 (March/May): 168-178.

Quintero, Rafael, and Erika Silva. 1991. Ecuador: una nación en ciernes. Quito: FLACSO, Abya-Yala.

Radcliffe, Sarah. 2001. "Imagining the State as a Space. Territoriality and the Formation of the State in Ecuador." In States of Imagination. Ethnographic Explorations of the Postcolonial State, edited by Thomas Blom Hansen and Finn Stepputat. Durham: Duke Universiry Press, 2001.

Radcliffe, Sarah, and Sallie Wetwood. 1996. Remaking the Nation. Place, Identity and Politics in Latin America. London: Routledge. 
Rama, Angel. 2012. "The Ordered City." In Foucault and Latin America. Appropriations and deployments of discoursive analysis, edited by Benigno Trigo, 3-16. New York: Routledge.

Ramón, Galo, and Victor Hugo Torres. 2004. El desarrollo local en el Ecuador. Historia, actores y métodos. Quito: Ediciones Abya Yala, COMUNIDEC.

Render, J.M. 2005. Mining and Indigenous Peoples Issues. Virginia: International Council on Mining and Metals.

Robbins, Paul. 2008. "The State in Political Ecology: A Postcard to Political Geography from the Field." In Sage Handbook of Political Geography, edited by Kevin Cox, Murray Low and Jennifer Robinson, 206-217. Sage.

Rodríguez, Gonzalo. 1992a. Apuntes varios sobre la Compañía Inglesa que laboró en Zaruma a fines del siglo XIX. Vol. 7, in Cuatro siglos de peregrinaje histórico. 1560-1992, by Corporación de Amigos de la Genealogía, 217. Colección Medio Milenio.

—. 1992b. "Breve Esbozo de la iglesia matriz, 1800-1930." In Zaruma cuatro siglos de peregrinaje histórico, 1560-1992, 163-181. Quito: Ediciones de la Corporación de Amigos de la Genealogía.

—. 2002. "Proclamación de la provincia de El Oro; Primeras autoridades y situación de Zaruma en 1882." Sociedad de Amigos de la Genealogía 21: 250-259.

Robinson, James A., Ragnar Torvikb, and Thierry Verdierc. 2006. "Political Foundations of the Resource Curse." Journal of Development Economics 79, no. 2 (April): 447-468.

Rockwell, John. 1851. A Compilation of Spanish and Mexican Law in Relation to Mines and Real Estate. New York: John S. Voorhies.

Rodríguez, Linda Alexander. 1985. The Search for Public Policy: Regional Politics and Government Finances in Ecuador, 1830-1940. Berkeley: University of California Press.

Roitman, Karem. 2008. "Hybridity, Mestizaje, and Montubios in Ecuador." QEH Working Paper Series 165 1, no. 19: 1-19.

Rojas, Angel F. [1983] 2010. Curipamba. Loja: Casa de la Cultura Ecuatoriana Benjamín Carrión, Núcleo de Loja. 
Romero, Martha. 1999. La lectura fotográfica en la reflexión y enseñanza de la Historia, en la educación básica Zaruma 1925-1950. Zaruma: Universidad Politécnica Salesiana, Tesis para obtener el Masterado en Docencia con mención en Educomunicación.

-. 2011. "Origen de la provincia de El Oro: Vicisitudes e intereses 1882 - 1884." Paper presented at the 2nd Congress on the Social History of Zaruma, Zaruma: Corporación Sociedad Amigos de la Genealogía y la Casa de la Cultura Ecuatoriana de Zaruma.

Romo, Héctor Guillén. 2007. "De la orden cepalina del desarrollo al neoestructuralismo en América Latina." Comercio Exterior 57, no. 4 (Abril: 295-315.

Rose, Gillian. 2000. "Practising Photography: An Archive, a Study, Some Photographs, and a Researcher." Journal of Historical Geography 26, no. 4: 555-571.

Rose, Nikolas, Pat O'Malley, and Mariana Valverde. 2006. "Governmentality." Annual Review on Law and Social Sciences 2: 83-104.

Rose-Redwood, Reuben. 2006. "Governmentality, Geography, and the Geocoded World." Progress in Human Geography 30, no. 4: 469-486.

Roosevelt, André. 1939. The Miracle of Portovelo. Quito: Editorial Gutenberg.

Rueda, Rocío, and Martha Romero. 2002. "Capítulo II: Aspectos Históricos." In Plan de Conservación y Gestión del Centro Histórico de Zaruma, para la Declaratoria de Patrimonio Cultural de la Humanidad, by Municipio de Zaruma, 41-100. Zaruma: Municipio de Zaruma.

Ruiz, Patricio. 2003. La función de las autoridades en las localidades mineras. Santiago de Chile: CEPAL. División de Recursos Naturales e Infraestructura.

Sáenz de Tejada, F.G. [1892] 1975. "El distrito aurífero de Zaruma." In Geografía y geología del Ecuador, by Teodoro Wolf, 661-700. Quito: Casa de la Cultura Ecuatoriana.

Sacher, William. 2015. "Minería del oro en Ecuador, entre actores nacionales y transnacionales." In La economía del oro: Ensayos sobre la explotación en Sudamérica, 95-138. La Paz: CEDLA.

Sachs, Jeffrey, and Andrew Warner. 1997. Natural Resource Abundance and Economic Growth. Cambridge: Harvard University. 
SADCO. 1929. The South American Development Cy. Su actuación en el Ecuador desde 1896. Quito: El Día.

-. 1938. Memorandum sobre los antecedentes y efectos del Decreto Dictatorial No. 7 de 18 de Febrero de 1938, que desconoce ciertas estipulaciones del contrato vigente entre el Gobierno del Ecuador y la South American Development Company. Quito: El Comercio.

—. 1946. Los problemas de Portovelo. Quito: Gráficas CEDIG.

-. 1948. Bases y razones jurídicas y económicas en que la South American Development Company apoya sus reclamos ante el gobierno de Ecuador. Quito: Editorial Colón.

Sagebien, Julia, Nicole Lindsay, Peter Campbell, Rob Cameron, and Naomi Smith. 2008. "The Corporate Social Responsibility of Canadian Mining Companies in Latin America: A Systems Perspective." Canadian Foreign Policy 14, no. 3: 103-128.

Said, Edward W. 1994. Orientalism. New York: Vintage Books.

Sandoval, Fabián. 2001. Small-scale Mining in Ecuador. Vol. 75. England: IIEDWBCSD.

—. 2002. La pequeña minería en el Ecuador. England: IIED and WBCSD.

Santos, Boaventura de Sousa. 1987. "Law: A Map of Misreading. Toward a Postmodern Conception of Law." Journal of Law and Society 14, no. 3: 279-302.

- 1995. Towards a New Common Sense: Law, Science and Politics in the Paradigmatic Transition. New York and London: Routledge.

Santos, Milton. 1977. "Society and Space: Social Formation as Theory and Method." Antipode 9, no. 1 (February): 3-13.

-. 2000. La naturaleza del espacio. Técnica y tiempo. Razón y emoción. Translated by María Laura Silveira. Barcelona: Editorial Ariel.

Schraps, Florence Reed. n.d. As I Remember. Vacaville, California: mimeo.

Schwartz, Anna J. 1997. "From Obscurity to Notoriety: A Biography of the Exchange Stabilization Fund." Journal of Money, Credit, and Banking: 135-153.

Sassen, Saskia. 2008. "Neither Global nor National: Novel Assemblages of Territory, Authority, and Rights." Ethics \& Global Politics 1, no. 1-2: 61-70. 
- 2010. Territorio, autoridad y derechos. De los ensamblajes medievales a los ensamblajes globales. Buenos Aires: Katz Editores.

Sauer, C.E. 1980ca. Excerpts from the History of Portovelo. Mimeo.

Sayer, Andrew. 1991. "Behind the Locality Debate. Deconstructing Geography's Dualisms." Environment \& Planning A 23, no. 2: 283-308.

Schmitt, Carl. 2006. The Nomos of the Earth. New York: Telos Press Publishing.

Schmitz, Christopher. 1979. World Non-Ferrous Metal Production and Prices, 1700-1976. London: Frank Cass.

—. 1986. "The Rise of Big Business in the World Copper Industry 1870-1930." Economic History Review XXXIX, no. 3: 392-410.

Scott, James. 1998. Seeing Like a State. How Certain Schemes to Improve the Human Condition Have Failed. New Haven: Yale University Press.

-. 2009. The Art of Not Being Governed. An Anarchist History of Upland Southeast Asia. New Haven: Yale University Press.

Sempat, Carlos. 1980. Minería y espacio económico en los Andes, siglos XVI$X X$. Lima: Instituto de Estudios Peruanos.

- 1982. El sistema de la economía colonial. Mercado interno, economía y espacio económico. Lima: Instituto de Estudios Peruanos.

SENPLADES. Plan Nacional para el Buen Vivir. Construyendo un Estado Plurinacional e Intercultural. Quito: Secretaría Nacional de Planificación y Desarrollo, 2009.

Sharpe, L.J. 1970. "Theories and Values of Local Government." Political Studies XVIII, no. 2: 153-174.

Shedden, Leslie. 1983. Mining Photographs and Other Pictures, 1948-1968: A Selection from the Negative Archives of Shedden Studio. Halifax: Press of the Nova Scotia College of Art and Design and the University College of Cape Breton Press.

Shields, Rob. 1999. Lefebvre, Love, and Struggle: Spatial Dialectics. London: Routledge.

Skocpol, Theda. 1977. "Wallerstein's World Capitalist System: A Theoretical and Historical Critique." American Journal of Sociology 82: 1075-1090. 
—. 1985. "Bringing the State Back In: Current Research." In Bringing the State Back In, edited by Peter B. Evans, Dietrich Rueschemeyer and Theda Skocpol, 3-37. Cambridge: Cambridge University Press.

Smith, Bonnie. 1995. "Gender and the Practices of Scientific History: The Seminar and Archival Research in the Nineteenth Century." The American Historical Review 100, no. 4: 1150-1176.

Smith, Carol A. 1997. "The Symbolics of Blood: Mestizaje in the Americas." Identities Global Studies in Culture and Power 3, no. 4: 495-521.

Smith, Dorothy E. 1999. Writing the Social: Critique, Theory, and Investigations. Toronto: University of Toronto Press.

-. 2001. "Texts and the Ontology of Organizations and Institutions." Studies in Cultures, Organizations and Societies 7, no. 2: 159-198.

Smith, Duane A. 1987. Mining America: The Industry and the Environment,18001980. Lawrence: University of Kansas Press.

Smith, Grant Horace. 1998. The History of the Comstock Lode, 1850-1997. Vol. 24. Reno: University of Nevada Press.

Smith, Neil. 1987."The Dangers of the Empirical Turn: Some Comments on the CURS Initiative." Antipode 19, no. 1 (1987): 59-68.

-. 2008. Uneven Development. Nature, Capital, and the Production of Space. 3rd Edition. Athens: University of Georgia Press.

Soja, Edward. 1989. Postmodern Geographies. The Reassertion of Space in Critical Theory. London: Verso.

Solbrig, Otto. 2006. "Economic Growth and Environmental Change." In The Cambridge Economic History of Latin America. Volume II. The Long Twentieth Century, edited by Victor Bulmer-Thomas, John H. Coastworth and Roberto Cortés Conde, 329-376. Cambridge: Cambridge University Press.

Sornarajah, Muthucumaraswamy. 2010. The International Law on Foreign Investment. New York: Cambridge University Press.

Spence, Clark C. 2000. British Investments and the American Mining Frontier, 1860-1901. London: Taylor \& Francis.

Stoler, Ann Laura. 2002. "Colonial Archives and the Arts of Governance." Archival Science 2: 87-109. 
Stoll, W. C. 1962. "Notes on the Mineral Resources of Ecuador." Economic Geology 57, no. 5: 799-808.

Streeck, Wolfgang. 2011. "Taking Capitalism Seriously: Toward an Institutionalist Approach to Contemporary Political Economy." Socio-Economic Review 9, no. 1 (January): 137-167.

Striffler, Steve. 2002. In the Shadows of State and Capital. The United Fruit Company, Popular Struggle, and Agrarian Restructuring in Ecuador 19001995. Durham: Duke University Press.

Sunkel, Osvaldo. 1972. "Big Business and "Dependencia": A Latin American View." Foreign Affairs 50, no. 3: 517-531.

Svampa, Marisela. 2010. Minería transnacional, narrativas del desarrollo y resistencias sociales. Buenos Aires: Biblos.

Swyngedouw, Erik. 1996. "Reconstructing Citizenship, the Re-scaling of the State and the New Authoritarianism: Closing the Belgian Mines." Urban Studies 33, no. 8: 1499-1521.

-. 2000. "Authoritarian Governance, Power, and the Politics of Rescaling." Environment and Planning D: Society and Space 18: 63-76.

—. 2004. "Globalisation or 'Glocalisation'? Networks, Territories and Rescaling." Cambridge Review of International Affairs 17, no. 1 (April): 25-48.

Tarras-Wahlberg, N. H. 2002. "Environmental Management of Small-scale and Artisanal Mining: The Portovelo-Zaruma Gold Mining Area, Southern Ecuador." Journal of Environmental Management 65: 165-179.

Taylor, Alan M. 2006. "Foreign Capital Flows." In The Cambridge Economic History of Latin America. Volume II. The Long Twentieth Century, edited by Victor Bulmer-Thomas, John H. Coastworth and Roberto Cortés Conde, 57-100. Cambridge University Press.

Thorp, Rosemary. 1998. Progress, Poverty and Exclusion: An Economic History of Latin America in the 20th Century. Washington D.C.: Inter-American Development Bank - Johns Hopkins University Press.

Tickell, Adam, and Jamie A. Peck. 1992. "Accumulation, Regulation and the Geographies of Post-Fordism: Missing Links in Regulationist Research." Progress in Human Geography 16, no. 2: 190-218.

Topalov, Christian. 1988. "La formación de los precios del suelo en la ciudad capitalista: Introducción al problema de la renta." In Antología de Sociología Urbana, 647-667. México: Universidad Autónoma de México. 
Touraine, Alain. 1978. Las sociedades dependientes. Mexico: Siglo XXI.

Tulchin, Joseph S., and Andrew Selee. 2004. Decentralization and Democratic Governance in Latin America. Washington, D.C.: Woodrow Wilson Center Report on the Americas.

Tweedy, John, and Beret Strong, directors. 2004. Streams of Gold. Produced by Landloked Films.

UNDP. 1969. Survey of Metallic and Non Metallic Minerals. Vol. 8. Quito: Dirección General de Geología y Minas.

Under Rich Earth. 2008. Documentary film. Directed by Malcolm Rogge.

Unos Imparciales. 1903. Otro ferrocarril. Estudio de la propuesta presentada al Congreso por el Sr. P.J.E.E. Chambost, para la construcción de un Ferrocarril del Pacífico al distrito minero de Zaruma. Quito: Tip. de la Escuela de Artes y Oficios.

Unwin, Tim. 2000. "A Waste of Space? Towards a Critique of the Social Production of Space...." Transactions of the Institute of British Geographers 25, no. 1: 11-29.

Utreras, Manuel, Gonzalo Domínguez, and Rafael Alvarado. 1933. Informe de la comisión legislativa encargada de inspeccionar las minas de Zaruma y Ancón. Quito: Imprenta Nacional.

Vallejo, Maria Cristina. 2010. "Biophysical Structure of the Ecuadorian Economy, Foreign Trade, and Policy Implications." Ecological Economics 70, no. 2: 159-169.

Varela, María Mercedes. 2011. Las relaciones entre Estado, comunidades locales y empresa trasnacionales en la dinámica de los conflictos socio ambientales en América Latina; Caso de Íntag en el Ecuador. Quito: PUCE, Facultad de Ciencias Humanas, Escuela de Sociología.

Vásquez, Lola, and Napoleón Saltos. 2007. Ecuador: Su realidad. Quito: Fundación José Peralta.

Van Dijk, Teun A. 1996. "Discourse, Power and Access." In Texts and Practices: Readings in Critical Discourse Analysis, edited by Carmen Rosa CaldasCoulthard and Malcolm Coulthard, 84-104. London and New York: Psychology Press. 
Van Thournout, F., J. Salemink, G. Valenzuela, M. Merlyn, A. Boven, and Philippe Muchez. 1996. "Portovelo: A Volcanic-hosted Epithermal Veinsystem in Ecuador, South America." Mineralium Deposita 31, no. 4: 269276.

Velasco, Fernando. 1981. Ecuador: Subdesarrollo y dependencia. Quito: Editorial El Conejo.

Veltmeyer, Henry. 2013. "The Political Eeconomy of Natural Resource Extraction: A New Model or Extractive Imperialism?" Canadian Journal of Development Studies 34, no. 1: 79-95.

Vergara Blanco, Alejandro. 1992. Principios y sistema del Derecho minero. Estudio histórico-dogmático. Editorial Jurídica de Chile, Universidad de Atacama.

—. 2006. "El problema de la naturaleza jurídica de la riqueza mineral." Revista chilena de Derecho 33, no. 2: 215-244.

Vergara, Angela. 2005. "The Recognition of Silicosis: Labor Unions and Physicians in the Chilean Copper Industry, 1930s-1960s." Bulletin of the History of Medicine 79, no. 4: 723-748.

Vikentyev, llya, Richard Banda, Anatoliy Tsepin, Vsevolod Prokofiev, and Olga Vikentyeva. 2005. "Mineralogy and Formation Conditions of PortoveloZaruma Gold-sulphide Vein Deposit, Ecuador." Geochemistry, mineralogy and petrology 43: 148-154.

Viteri, Alberto, Alfonso Ortiz, Enrique Romero, Gonzalo Darquea, Gonzalo Estupiñán, Guido Díaz, and Juan Gangotena. 1974. Estudio urbano de Zaruma. Quito: Universidad Central del Ecuador.

Waitt, Gordon. 2010."Doing Foucauldian Discourse Analysis - Revealing Social Realities." In Qualitative Research Methods in Human Geography, edited by lain Hay, 217-240. Oxford: Oxford University Press.

Wallerstein, Immanuel. 2004. World-systems Analysis: An Introduction. Durham: Duke University Press.

Walmesley, Oswald. 1894. Guide to the Mining Laws of the World. London: Eyre \& Spottiswoode and Sweet \& Maxwell, accessed June, 2015, from http://archive.org/stream/guidetominingla00walmgoog\#page/n4/mode/2up

Waszkis, Helmut. 1993. Mining in the Americas: Stories and History. Cambridge: Woodhead Publishing. 
Watkins, Mel. 1967. "A Staples Theory of Economic Growth." In Approaches to Canadian Economic History, edited by Easterbrook and Watkins, 49-73. Toronto: Carleton Library, McClelland and Stewart.

Watts, Michael. 2003. "Development and Governmentality." Singapore Journal of Tropical Geography: 6-34.

Whitehead, Mark, Rhys Jones, and Martin Jones. 2007. The Nature of the State: Excavating the Political Ecologies of the Modern State. Oxford and New York: Oxford University Press.

Widerberg, Karin. 2004. "Institutional Ethnography - Towards a Productive Sociology - An Interview with Dorothy E. Smith." Sosiologisk Tidskrift 2, no. 2 .

Williams, Ann Rector. n.d. Pleasant Reminiscences for Your Old Age. Mimeo.

Williams, Derek. 2003. "Popular Liberalism and Indian Servitude: The Making and Unmaking of Ecuador's Antilandlord State, 1845-1868." Hispanic American Historical Review 83, no. 4 (November): 697-733.

Williams, John P. 2005. Legal Reform in Mining: Past, Present and Future. Vol. 21, in International and Comparative Mineral Law and Policy: Trends and Prospects, by edited Elizabeth Bastida, Thomas W. Wälde, and Janeth Warden-Fernández, 37-72. The Hage: Kluwer Law International.

Wolf, Teodoro. 1879. Viajes científicos por la República del Ecuador. I. Relación de un viaje geognóstico por la provincia de Loja. Guayaquil: Imprenta del Comercio, 1879.

-. [1892] 1975. Geografia y geología del Ecuador. Quito: Casa de la Cultura Ecuatoriana.

Ycaza, Patricio. 1991. Historia del movimiento obrero ecuatoriana: De la influencia de la táctica del frente popular a las luchas del FUT. Segunda parte. Quito: CEDIME, CIUDAD.

—. 2007. Historia del Movimiento Obrero Ecuatoriano: De su génesis al Frente Popular. Quito: Ediciones Tierra.

Yin, Robert. 2003. Case Study Research: Design and Methods. Thousand Oaks: Sage.

Zeitlyn, David. 2012. "Anthropology in and of the Archives: Possible Futures and Contingent Pasts. Archives as Anthropological Surrogates." Annual Review of Anthropology 41: 461-480. 
Zimmerer, Karl. 2006. "Cultural Ecology: At the Interface with Political Ecology the New Geographies of Environmental Conservation and Globalization." Progress in Human Geography 30, no. 1: 63-78. 


\section{Appendices}




\section{Appendix A.}

\section{Ethics scripts}

(Translated into Spanish during the interviews)

Thank-you for agreeing to meet with me to discuss the evolving challenges of local resource governance in Zaruma and Portovelo.

I am a PhD student in the Department of Geography and Environmental Studies at Carleton University in Ottawa, Canada, under the supervision of Jill Wigle and Derek Smith. For this research, I am conducting interviews with people familiar with the role of municipal governments in mining enclaves either on a professional basis (e.g. government official) or on a personal basis (e.g. community resident). I was referred to you by (website or contact name, if applicable and agreed to be identified).

This research project has cleared the ethics research process at Carleton University so I would like to go over some of the procedures. The interview will take about one hour and I will ask questions related with the needs, struggles, and challenges in providing public services in mining towns. Please remember that at any time may refuse to answer any question that you are not comfortable with, and you may stop the interview at any time. You can ask for the transcripts of the interview to review. You can also decide to withdraw from the research project by contacting me within the next three months. (Here is my business card so that you can contact me.) Should you decide to withdraw, the information you have provided will be destroyed.

The primary data gathered in this process will be securely stored and accessible only to me for my thesis. The names of the participants will not be disclosed. After the research is complete, I will write my thesis and might share this research through the publication of articles or through presentations but your answers will remain anonymous and confidential. The data retrieved during the fieldwork may also be used in future projects of a similar nature. If you want I can send you references to publications based on my research as they appear.

Do you have any question about the research or the interview?

$\square$ Yes $\square$ No

Do you agree to participate in this research?

$\square$ Yes $\square$ No

Do you agree that I take notes during the interview?

$\square$ Yes $\square$ No

Do you agree to be recorded?

$\square$ Yes $\square$ No 
Would you like to review the transcript of the interview? (I can send you the transcript by email or by mail. Mailed transcripts will have self-addressed stamped envelope. Please return it within a month after receiving it.)

$\square$ Yes $\square$ No

Observations: (Include any requirement expressed by the participant.)

I (as researcher) promise to respect the context of the knowledge and opinions you contribute to this project, and the terms of this consent form.

Signature of the researcher 


\section{Appendix B.}

\section{Interview guidelines}

(Translated into Spanish during the interviews)

\section{For Public Officials:}

General questions:

- What is your position and area of responsibility?

- How long have you been working in the (local, provincial, national) government?

Specific Questions:

- What was the participation of the municipality during the installation of the mining company?

- Did the roles and responsibilities of the municipal government change to match the requirements of the corporate sector?

- How has the municipal government negotiated with the corporate sector in providing services for the local population?

- Has the corporate sector required the contribution of the municipal government to ensure local governance?

- Can you identify key norms, events, or practices that have influenced the relation between the municipality and the mining sector?

- Has the municipal government raised demands that challenge the operation of the mining company? (If yes, please explain.)

Closing questions:

- Is there anything important that you think I have not asked?

- Is there anything you would like to ask me?

- Could you recommend another contact for my research interviews? Please be aware that your identity could be revealed through these recommendations. So, I will only use your name with your permission when approaching persons you recommend. [If yes] May I use your name when approaching them for an interview? 


\section{For representatives of the private sector:}

General questions:

- What is your position and area of responsibility?

- How many years has the corporation been working in the area of (town)? Specific Questions:

- Was there any contact between the private sector and the municipal government during the installation of the mine?

- Is there any interaction with the municipal government for providing services within the mining camp?

- Does the mining company provide public services in a wider area other than that of the mining camp?

- Has the interaction of the mining company with the municipal government changed over time? If so, how? Why?

- Has the corporate sector required the contribution of the municipal government to ensure the governance of the local population?

- Has the municipal government raised demands that challenge the operation of the mine?

- Can you identify key norms, events, or practices that have determined the relation between the municipality and the mining sector?

- Is there any specific internal policy related with corporate social responsibility? (If yes, may I have access to it?)

Closing questions:

- Is there anything important that you think I have not asked?

- Is there anything you would like to ask me?

- Could you recommend another contact for my research interviews? Please be aware that your identity could be revealed through these recommendations. So, I will only use your name with your permission when approaching the persons. [If yes] May I use your name when approaching the these persons for an interview?

\section{For residents or community leaders:}

General questions:

- Can you tell me the history of the mining camp? 
Specific Questions:

- What was the role of the municipality within the camp?

- Did the private sector ask for the presence of the municipality? When? How?

- Was there any particular event that changed the relations between the company and the municipality?

- Do you think that municipal governments helped develop a local identity or a sense of community that challenged the operation of the mining industries? Can you explain?

Closing questions:

- Is there anything important that you think I have not asked?

- Is there anything you will like to ask me?

- Could you recommend another contact for my research interviews? Please be aware that your identity could be revealed through these recommendations. So, I will only use your name with your permission when approaching these persons. [If yes] May I use your name when approaching these persons for an interview?

For representatives of academia, NGOs, chroniclers:

General questions:

- What is your position and area of responsibility?

- How many years have you worked in the area of (town)?

- Can you tell me about your engagement with (the mining sector, the communities, the local government)?

Specific questions:

- How have mining companies negotiated with the state to ensure the governance at the local level?

- Do you think that municipal governments have helped in developing a local identity or a sense of community that challenge the operation of the mining industries? Can you explain?

- What other economic sectors might have significantly influenced the politics of the municipal governments in mining enclaves? 


\section{Closing questions:}

- Is there anything important that you think I have not asked?

- Is there anything you will like to ask me?

- Could you recommend another contact for my research interviews? Please be aware that your identity could be revealed through these recommendations. So, I will only use your name with your permission when approaching these persons. [If yes] May I use your name when approaching these persons for an interview? 


\section{Appendix C.}

\section{Consent form}

I

choose to participate in a study about the restructuring of local resource governance in the mining district of Zaruma and Portovelo, from 1896 to 1980 . The study aims to understand the socio-spatial relations and local politics that enabled the transformation of the mining enclave of Portovelo, established by the South American Development Company in 1896 and its further conversion towards a municipal township in 1980. The researcher is Andrea Carrión, doctoral candidate from the Department of Geography and Environmental Studies, under the supervision of Professors Jill Wigle and Derek Smith.

The participant has the right to end his or her participation in the study up to one month after the interview. Participants who withdraw will have all of their information destroyed. The participant also has the right to request that specific documentation, answers, or incidents be removed from the study and to ask questions about their involvement at any time.

The researcher will photograph or record historical materials kept within personal or family archives, such as old pictures, letters, company reports, and any other document upon agreement of the interviewee. The information may be quoted and used in the future to continue studying local resource governance in Ecuador, to report to local participants, or to prepare conference presentations, publications, or teaching materials. All material will be cited as pertaining to:

Participants signing this form will not remain anonymous during the project, although he or she has the right to request that certain information be anonymous. During the research, only the researcher and the supervisors will have access to the information.

During the investigation, all the information will be stored digitally on the personal computer of the researcher and backed-up in an external hard drive kept in the researcher's office. The historical documentation will not be publicly archived or disseminated. 
The participant has the right to review the information pertaining to him or herself upon request. The findings of the project will be sent to the participant upon the completion of the project. This project was reviewed by the Carleton University Research Ethics Board, which provided clearance to carry out the research. Should you have questions or concerns related to your involvement, please contact:

Professor Andy Adler, Chair

Research Ethics Board

Carleton University

1325 Dunton Tower

1125 Colonel By Drive

Ottawa, ON K1S 5B6

Tel.: $613-520-2517$

Researcher contact information:

Andrea Carrión

Ph.D. Candidate

Department of Geography and Environmental Studies, Carleton University

Email: Andrea.Carrion@cmail.carleton.ca

Tel.:

Supervisors' contact information:

Dr. Jill Wigle or Dr. Derek Smith

Email: Jill.Wigle@carleton.ca; DerekA.Smith@carleton.ca

Department of Geography and Environmental Studies, Carleton University

1125 Colonel By Drive, Ottawa, ON K1S 5B6

Tel.: $613-520-2600 \times 8131$

Signature of participant Date

Signature of researcher Date

Please retain a copy of this form for your records 


\section{Appendix D.}

\section{Presidents of Ecuador 1830-1980}

\begin{tabular}{|c|c|c|c|}
\hline \# & Name & Possession Date & $\begin{array}{l}\text { Time in office } \\
\text { (years, months, days) }\end{array}$ \\
\hline 1 & Juan José Flores & September 22, 1830 & $3 y 11 m$ 19d \\
\hline 2 & Vicente Rocafuerte & August 08, 1835 & 3y $5 \mathrm{~m} 27 \mathrm{~d}$ \\
\hline 3 & Juan José Flores & February 1, 1839 & $3 y 11 m 15 d$ \\
\hline 4 & Juan José Flores & April 1, 1843 & $1 \mathrm{y} 11 \mathrm{~m} 5 \mathrm{~d}$ \\
\hline 5 & José Joaquín de Olmedo & March 7, 1845 & Oy $9 \mathrm{~m} 1 \mathrm{~d}$ \\
\hline 6 & Vicente Ramón Roca & December 8, 1845 & $3 y 10 m 7 d$ \\
\hline 7 & Manuel de Ascásubi & October 15, 1849 & Oy $7 \mathrm{~m} \mathrm{22d}$ \\
\hline 8 & Diego Noboa & February 20, 1850 & $0 y 6 m, 16 d$ \\
\hline 9 & José María Urbina & July 24, 1851 & $4 y 1 m 9 d$ \\
\hline 10 & Francisco Robles & October 16, 1856 & $2 y 6 m 13 d$ \\
\hline 11 & Gobierno de la crisis & August 31, 1859 & $1 y 5 m 15 d$ \\
\hline 12 & Gabriel García Moreno & January 17, 1861 & $4 y 6 m 13 d$ \\
\hline 13 & Jerónimo Carrión & September 7, 1865 & $2 y 1 m 28 d$ \\
\hline 14 & Pedro José Arteta & November 7, 1867 & $0 y 2 m 13 d$ \\
\hline 15 & Javier Espinosa & January 20, 1868 & 1y $11 \mathrm{~m} 27 \mathrm{~d}$ \\
\hline 16 & Gabriel García Moreno & January 19, 1869 & Oy $4 \mathrm{~m} \mathrm{Od}$ \\
\hline 17 & Manuel Ascásubi & May 19, 1869 & Oy $2 \mathrm{~m} \mathrm{19d}$ \\
\hline 18 & Gabriel García Moreno & August 10, 1869 & $5 y 11 \mathrm{~m} \mathrm{24d}$ \\
\hline 19 & Francisco Xavier León & August 6, 1875 & oy $1 \mathrm{~m} 9 \mathrm{~d}$ \\
\hline 20 & José Javier Eguiguren & September 15, 1875 & Oy $2 \mathrm{~m} 23 \mathrm{~d}$ \\
\hline 21 & Antonio Borrero & December 9, 1875 & Oy $8 m 27 d$ \\
\hline 22 & Ignacio de Veitemilla & September 9, 1876 & $6 y 4 m 4 d$ \\
\hline 23 & Gobierno de Restauración & January 11, 1883 & 0y $9 \mathrm{~m} \mathrm{4d}$ \\
\hline 24 & José Plácido Caamaño & October 15, 1883 & 4y $8 \mathrm{~m} \mathrm{15d}$ \\
\hline 25 & Pedro José Cevallos & July 1, 1888 & Oy $1 \mathrm{~m} \mathrm{16d}$ \\
\hline 26 & Antonio Flores Jijón & August 17, 1888 & 3y $10 m$ 13d \\
\hline 27 & Luis Cordero Crespo & July 1, 1892 & 3y $10 \mathrm{~m} \mathrm{13d}$ \\
\hline 28 & Vicente Lucio Salazar & April 16, 1895 & Oy $1 \mathrm{~m} \mathrm{18d}$ \\
\hline 29 & Eloy Alfaro & June 5, 1895 & $6 y 2 m 22 d$ \\
\hline 30 & Leonidas Plaza & September 1, 1901 & 3y $11 \mathrm{~m} \mathrm{30d}$ \\
\hline 31 & Lizardo García & September 1, 1905 & $0 y 4 m 14 d$ \\
\hline 32 & Eloy Alfaro & January 16, 1906 & $5 y 6 m 25 d$ \\
\hline
\end{tabular}


33 Carlos Freile Zaldumbide

34 Emilio Estrada

35 Carlos Freile Zaldumbide

36 Francisco Andrade Marín

37 Leonidas Plaza

38 Alfredo Baquerizo

39 José Luis Tamayo

40 Gonzalo Córdova

Revolución Juliana

41 (First Provisional Government)

Revolución Juliana

42 (Second Provisional Government)

43 Isidro Ayora

44 Luis Larrea Alba

45 Alfredo Baquerizo Moreno

46 Carlos Freile Larrea

47 Humberto Albornoz

48 Alberto Guerrero Martínez

49 Juan de Dios Martínez

50 Abelardo Montalvo

51 José María Velasco Ibarra

52 Antonio Pons

53 Benigno Flores

54 Federico Páez

55 Alberto Enríquez Gallo

56 Manuel María Borrero

57 Aurelio Mosquera Narváez

58 Carlos Alberto Arroyo del Río

59 Andrés Córdova

60 Julio Enrique Moreno

61 Carlos Alberto Arroyo del Río

62 José María Velasco Ibarra

63 Carlos Mancheno

64 Mariano Suárez Veintimilla

65 Carlos Julio Arosemena Tola

66 Galo Plaza Lasso

67 José María Velasco Ibarra

68 Camilo Ponce Enríquez

69 José María Velasco Ibarra

70 Carlos Julio Arosemena Monroy

71 Junta Militar

72 Telmo Vargas
August 11, 1911

September 1, 1911

December 22, 1911

March 6, 1912

September 1, 1912

September 1, 1916

September 1, 1920

September 1, 1924

July 10, 1925

January 10, 1926

April 1, 1926

August 24, 1931

October 15, 1931

August 28, 1932

August 30, 1932

September 2, 1932

December 5, 1932

October 20, 1933

September 1, 1934

August 21, 1935

September 26, 1935

September 26, 1935

October 23, 1937

August 10, 1938

December 2, 1938

November 18, 1939

December 11, 1939

August 10, 1940

September 1, 1940 June 1, 1944

August 23, 1947

September 2, 1947

September 15, 1947

September 1, 1948

September 1, 1952

September 1, 1956

September 1, 1960

November 7, 1961 July 11, 1963

March 29, 1966 0y 0m 19d

0y $3 \mathrm{~m} \mathrm{20d}$

Oy $2 \mathrm{~m} 12 \mathrm{~d}$

Oy $5 \mathrm{~m} \mathrm{22d}$

3y $11 \mathrm{~m} \mathrm{30d}$

3y $11 \mathrm{~m} \mathrm{30d}$

3y $11 \mathrm{~m} \mathrm{30d}$

3y $10 \mathrm{~m} 8 d$

Oy $5 \mathrm{~m} 27 \mathrm{~d}$

Oy $2 \mathrm{~m} \mathrm{20d}$

5y $5 \mathrm{~m} 24 \mathrm{~d}$

Oy $1 \mathrm{~m} \mathrm{20d}$

Oy $10 \mathrm{~m} \mathrm{12d}$

Oy $0 \mathrm{~m} 2 \mathrm{~d}$

Oy $0 \mathrm{~m} \mathrm{2d}$

Oy $3 \mathrm{~m} \mathrm{2d}$

Oy $10 \mathrm{~m} 12 \mathrm{~d}$

Oy $10 \mathrm{~m} \mathrm{12d}$

Oy $11 \mathrm{~m} \mathrm{20d}$

Oy $1 \mathrm{~m} \mathrm{4d}$

Oy $0 \mathrm{~m} \mathrm{1d}$

2y 0m 26d

Oy $9 \mathrm{~m} \mathrm{15d}$

Oy $3 \mathrm{~m} 21 \mathrm{~d}$

oy $11 \mathrm{~m} \mathrm{13d}$

Oy 0m 24d

Oy 0m 20d

0y 0m 21d

3y $8 \mathrm{~m} \mathrm{27d}$

3y $2 \mathrm{~m} \mathrm{22d}$

Oy 0m 9d

Oy 0m 13d

Oy $11 \mathrm{~m} 16 \mathrm{~d}$

3y $11 \mathrm{~m} \mathrm{1d}$

3y $11 \mathrm{~m} \mathrm{30d}$

3y $11 \mathrm{~m} \mathrm{30d}$

1y $2 \mathrm{~m} 5 \mathrm{~d}$

1 y $8 \mathrm{~m} \mathrm{4d}$

2y $8 \mathrm{~m} \mathrm{17d}$

Oy $0 \mathrm{~m} \mathrm{1d}$ 
73 Clemente Yerovi

74 Otto Arosemena

75 José María Velasco Ibarra

76 Guillermo Rodríguez Lara

77 Consejo Supremo de Gobierno

78 Jaime Roldós Aguilera

79 Osvaldo Hurtado
March 30, 1966

November 16, 1966

September 1, 1968

February 15, 1972 January 11, 1976 August 10, 1979 May 24, 1981 0y $7 \mathrm{~m} \mathrm{12d}$

1y $10 \mathrm{~m} \mathrm{14d}$ $3 y 5 \mathrm{~m} \mathrm{13d}$ 3y $10 \mathrm{~m} 24 \mathrm{~d}$

$3 y 6 \mathrm{~m} \mathrm{28d}$

$1 \mathrm{y} 9 \mathrm{~m} 14 \mathrm{~d}$

3y $2 \mathrm{~m} \mathrm{13d}$ 